\title{
Taking the Roof off a Modern Building
}

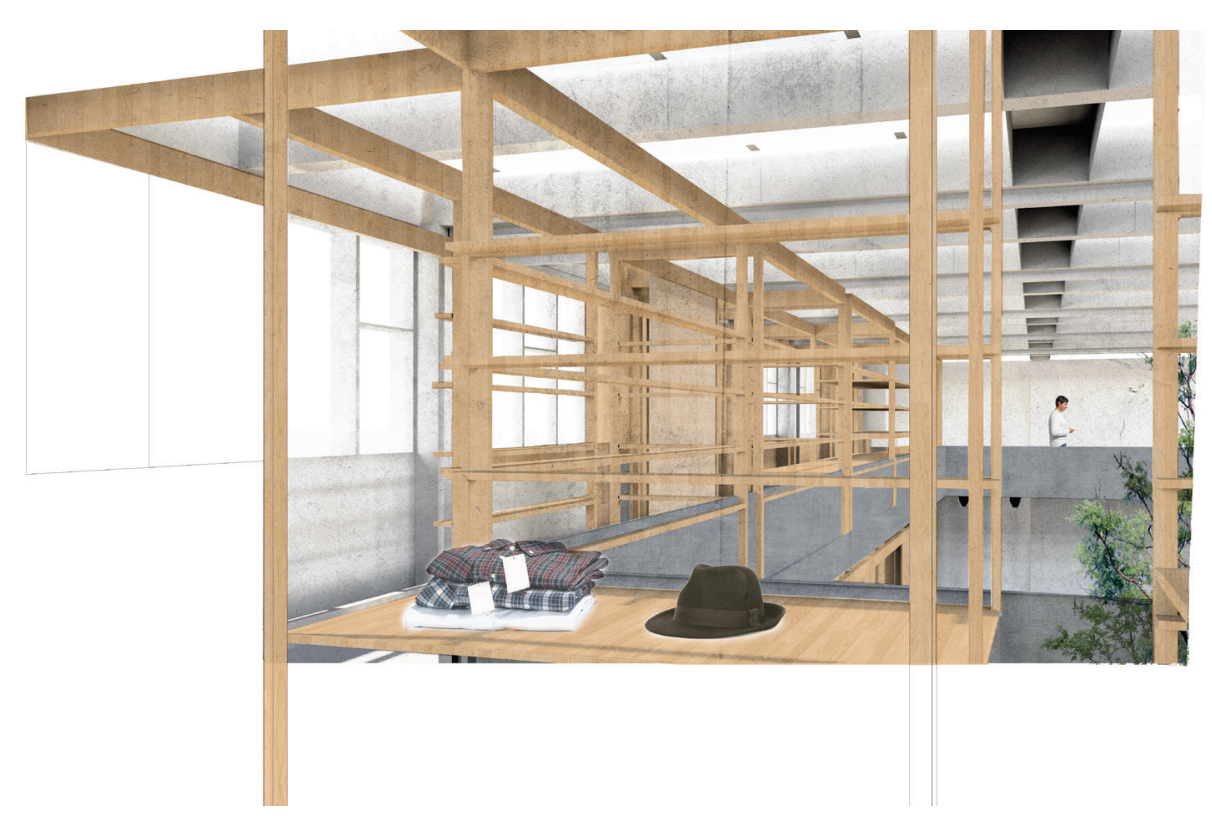

Helen Alice Brunskill 2016 



\title{
$\longrightarrow$ \\ Taking the Roof off a Modern Building
}

\author{
A 120 point thesis submitted to the Victoria University of Wellington \\ in partial fulfilment of the requirements for the degree of \\ Master of Interior Architecture.
}

Helen Alice Brunskill

Victoria University of Wellington

2016

School of Architecture 


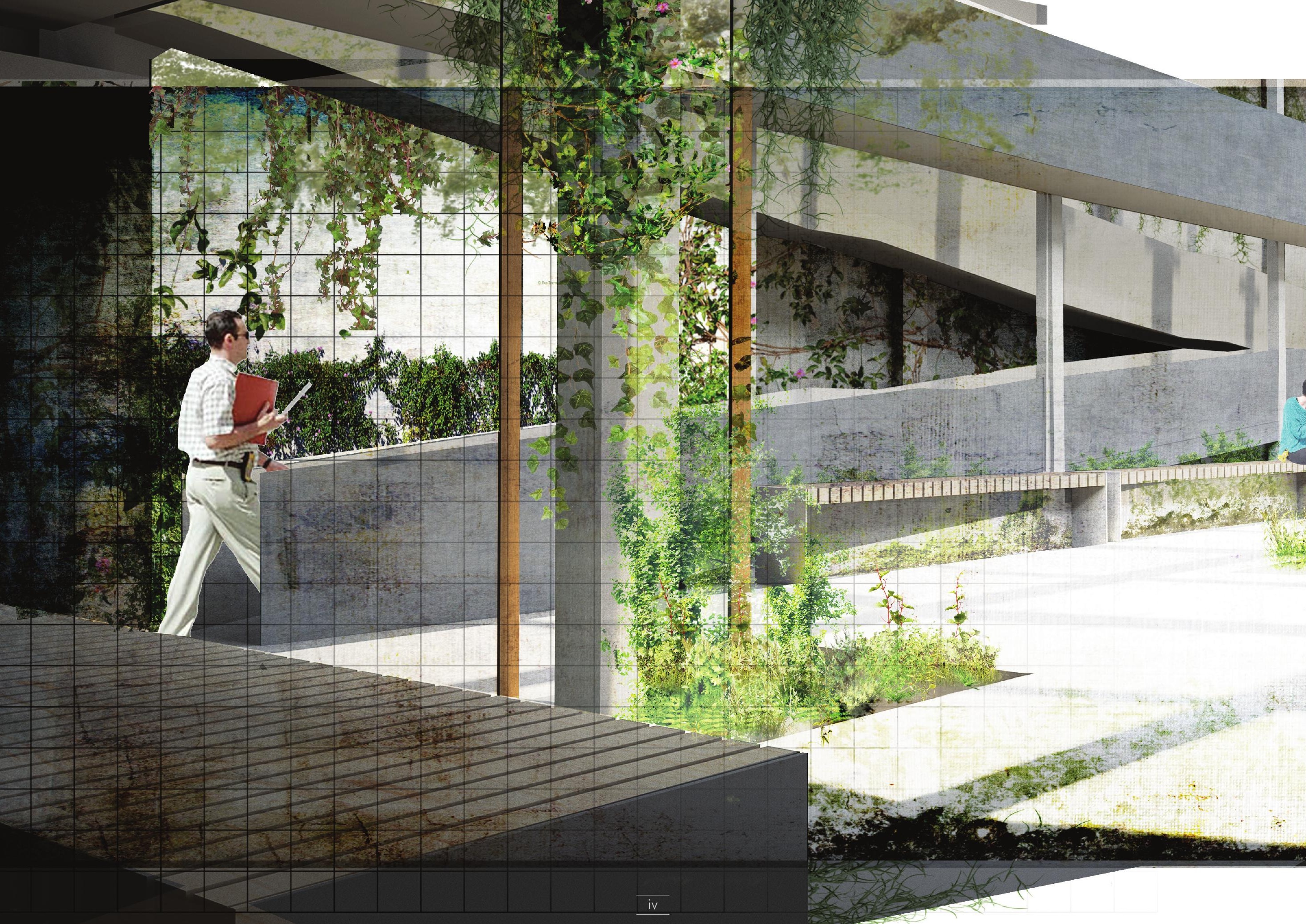



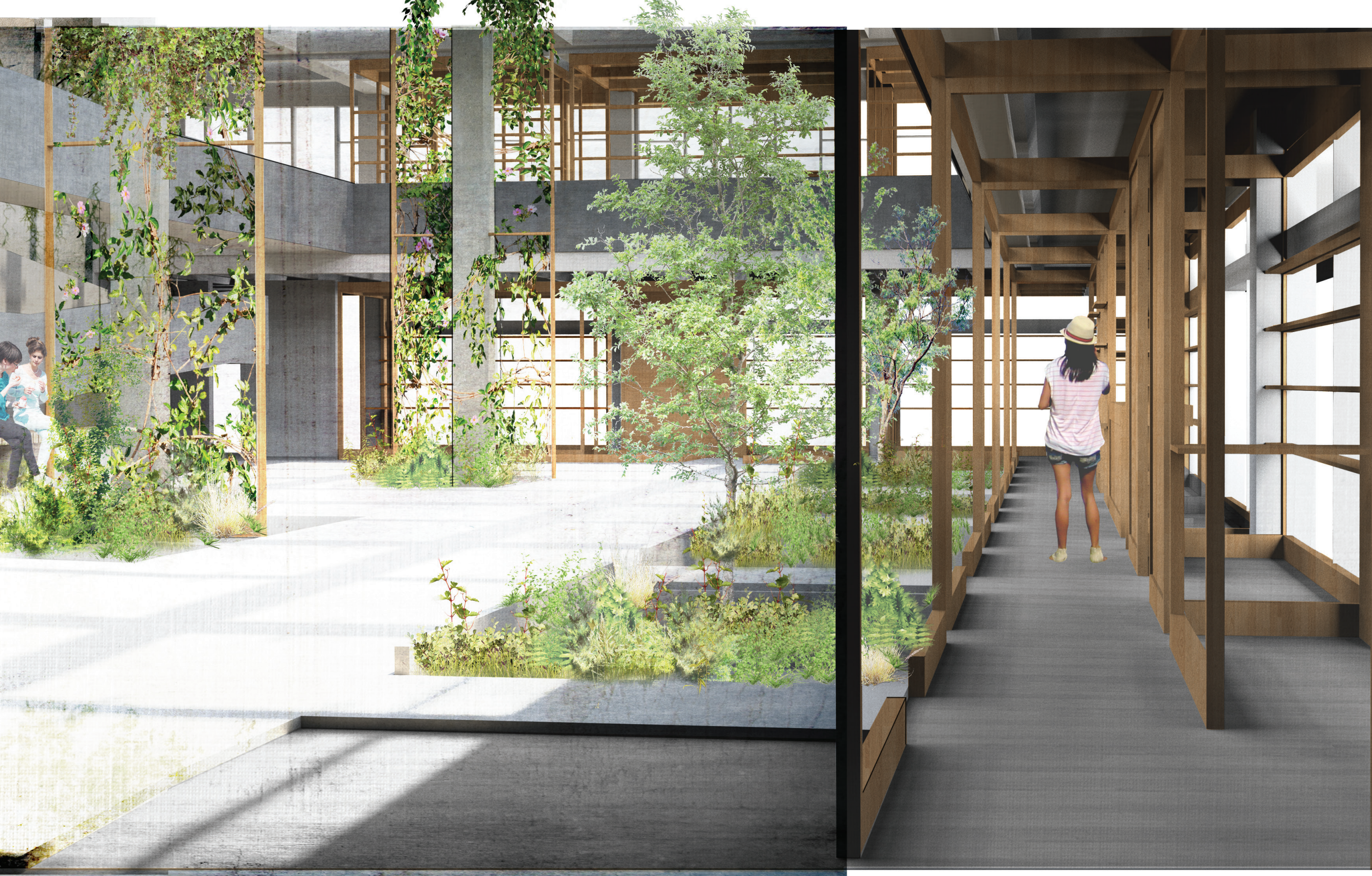

01/ Opening up a provincial modernist building brings new life into the space. The main design elements- the ramp, courtyard and retail frames reactivate this interior. 


\section{Abstract}

Taking the Roof off a Modern Building explores ways to appropriately reactivate modernist architecture, acknowledging the social, economic and contextual constraints of a contemporary provincial New Zealand township. This research is motivated by the lack of use and maintenance of aging Kapiti modern architecture.

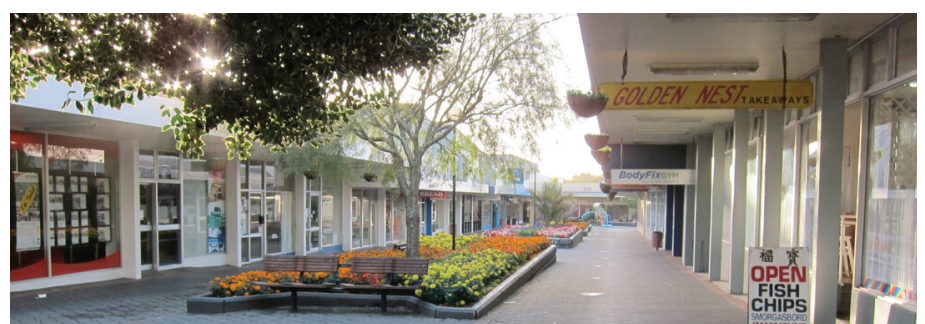

02/ Pedestrian street, Mahara Place Precinct containing a selection of buildings built in the 1970s and 80s. Many stores are quiet, oversized and lacking life.

Like many small towns, Waikanae, in the Kapiti Coast region, has a variety of buildings which are often up for lease (fig 2). Within this catalogue, the modernist buildings stand out as ones that theoretically should be adaptable for changing requirements. The aim of the research is to develop a design solution to preserve the Parker Building, situated in Mahara Place, understanding the potential implications for the wider region (fig 3).

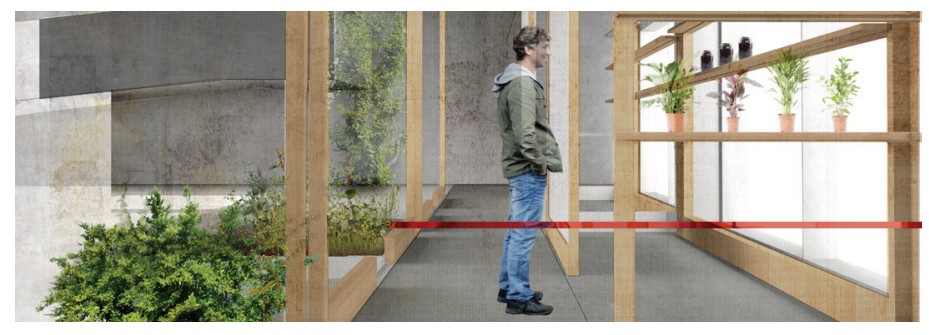

03/ Retail pathways reconnect the interior to the exterior through the use of layered zones. A light adaptable solution to large open Modernist buildings. 


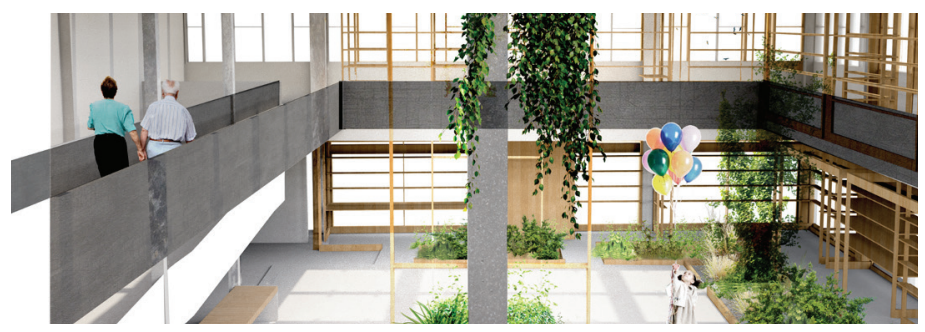

04/ The courtyard acts as a central element to the space, connecting the many small nodes of users with each other, creating a hive of activity. This is reactivation.

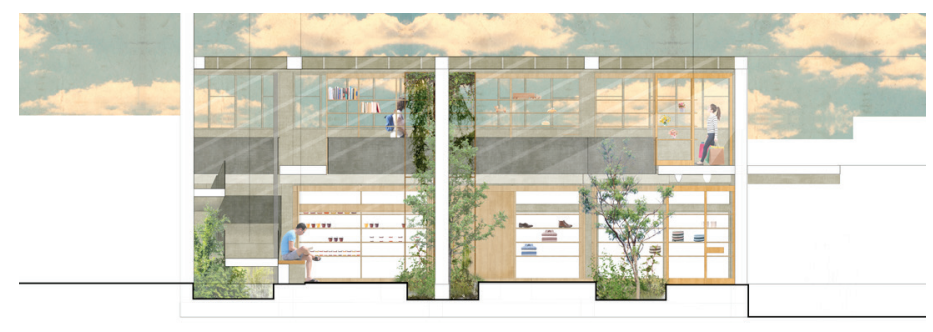

05/ The sympathetic interior fit out allows the building to be used in a contemporary way, preventing possible demolition.
The research is completed through design experiments which pursue reactivation, examining modernism, preservation and programme. The exploration of spatial possibilities focus on how the Mahara Place shopping precinct may function for social and economic needs of the current society, which differs from when it was built, in the 1970s (fig 4). Designing is done through a process of research into physical and social constraints, while iterating design ideas, feeding off each other to develop the outcome.

New Zealand Modernist Architecture is a relevant research topic due to the prominent place of these buildings in our cities and towns, and their association with many great New Zealand architects. While isolating a site within the Kapiti Region, Mahara Place was highlighted as a strip of buildings not used to their fullest potential. Many buildings similar to these are at risk of demolishment, but research is needed to explore how the interior can function appropriately for the users (fig 5 ). 
06/ Axonometric evening view of the proposed solution, with the ETFE cushioned roof removed. The layers through the interior-exterior boundary are made up of people, existing architecture, intervention and planting. This is a distinctly provincial solution to a New Zealand Modernist building. 


\section{Dedicated to Mum and Dad}

for raising me to believe that anything is possible. 


\section{Acknowledgements}

First and foremost, I would like to thank my parents, Robyn and Ewen none of this would have been possible without your support. To Tim Voss, for your encouragement and enthusiasm, and to my extended family and friends, thank you for your love.

Thank you to Sam Kebbell and Martin Bryant, your guidance throughout the year has been invaluable. You have helped me to understand the possibilities of the profession. I want to express my gratitude to the other lecturers and tutors who have taught and influenced me over the past five

years.

To the Kapiti/Horowhenua group, you have all taught me so much about the opportunities of the different scales of architecture within the area.

And to the critics through the year who inspired the research with new ideas-Richard Black, Anthony Burke, Richard George, Morten Gjerde, Eudardo Kainz, Simone Kilbane, Phil Mark,

Tane Meleta and Fleur Palmer. 
The preservation of buildings, structures, or sites in any form is about much more than merely saving their material existence. In contrast to the heritage of earlier periods, architecture and design of more recent vintage represents the ideals and philosophies of the original architects, their clients, and subsequent occupants, many of whom are well-known or even still alive. Capitalising on those visions is far more complex than ever before, but is as much a part of the preservation as the preservation of the physical fabric.

These intentions are the most difficult to capture, the hardest to interpret, and the most complicated to defend for an architecture that is often much more the result of theoretical concepts than the buildings of earlier periods. At the same time, maybe we can also learn something from this past, its optimism, and this interest in improving the quality of life, not just for a few, but for everybody.

Prudon, Preservation of Modern Architecture 


\section{Contents}

Context. Opportunity. Proposal. 


$\begin{array}{lr}\mathrm{OO} / & \\ & \\ \text { Abstract } & v i \\ \text { Dedication } & x i \\ \text { Acknowledgements } & x i i i \\ \text { Contents } & x v i \\ \text { Research Methodology and Design Chronology xvii }\end{array}$

03/ New Zealand Modernist

Modernist Architecture

Built in Furniture

Compacting Programme

Office Built in Furniture

06/ Garden

The Middle

Hortus Conculus

Paddington Reservoir

09/ Conclusion

101

104

\section{1/ Introduction}

Design Overview

04/ Preservation

Modernist Conservation

Materials

Ruins

Programme Elements Design

07/ Solution

10/ References and Figures

132
02/ Waikanae

Mahara Place

Setting the Scene

Initial Design

Parker Building Impression

History

17

18

22

28

05/ Retail

Paraparaumu's Influence of Waikanae Small Box

\section{8/ Discussion}

109

Preservation

Provincial Modernism in New Zealand Programme

$11 /$ Appendix 


\section{Research Methodology}

Downton (2003), states that "designing as a way examined the overall Mahara Place site while completing of researching", facilitates a "process [which] is sketch designs of various buildings. Preservation fundamentally focused on enabling decisions to be experiments introduced theories of preservation and made". This is used throughout the research as a driver. programme issues, resulting in a series of small interior Research through, for and about design, terms coined experiments based on simple reactivation methods. by Frayling (Findeli, 1999), illustrate ways of enquiring The final reactivation solution involved focusing on the into design. Research for and about design are done to conservation of a single building. Each step gathered aide and support the process of designing. This includes new information sources and design ideas, which were contextual, theoretical and precedent related research. used in subsequent sections to further explore the design problem and enhance the solution.

Research through design is completed over three key sections; context based research, preservation experiments These research elements feed off each other to propel the and reactivation solutions. Context based research project forward.

\section{March}
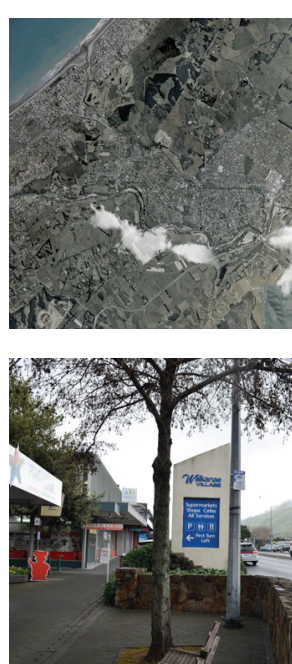

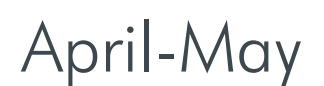

The research began by looking at the Kapiti Coast, identifying possible interior projects and sites within the wider area.

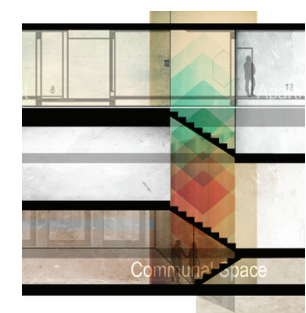
The initial design
looked at how multiple buildings, within the shopping precinct, could be intervened in order to work as a whole and to bring more people to the area.

Mahara Place was selected as an area which is tired but has potential for the interiors of the buildings to better function for Waikanae.

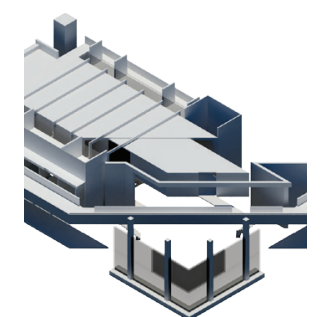

It became clear that the interior refit for a community based a community based positive impact on the whole of Mahara Place.

\section{June}

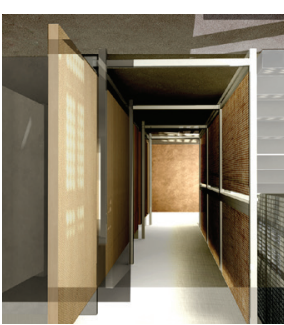

Building upon the previous design research, the aim was to create an intervention that more sympathetic to the exterior structure as well as the interior.

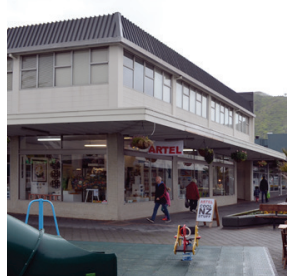

The June Design review promoted further research into provincial modernist buildings, and how design may aide its preservation. 


\section{Design Chronology}

The below images show the order of design research experiments, illustrating how the iterative and informed decisions took place throughout the research period. The first phases focused on finding a scope within the setting of Mahara Place. Leading towards preservation and reactivation, the design narrowed into an interior based solution for a single building.
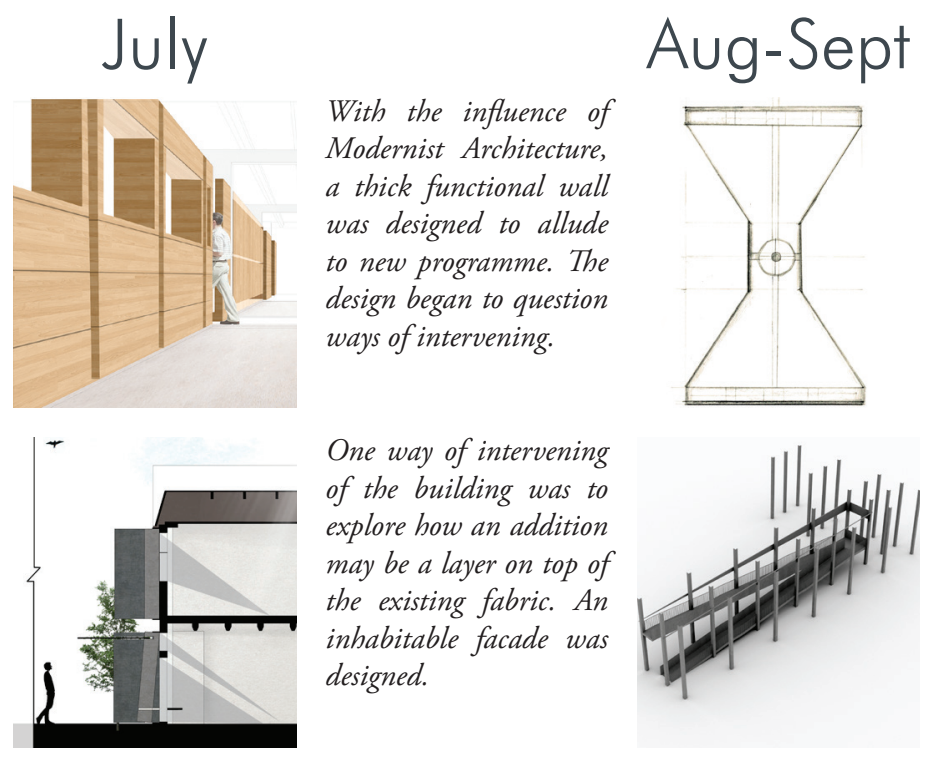

\section{Oct-Nov}

With the influence of Modernist Architecture, a thick functional wall was designed to allude to new programme. The design began to question ways of intervening.

One way of intervenin of the building was to explore how an addition may be a layer on top of the existing fabric. An inhabitable facade was designed. 



\section{Introduction}

01/ A Solution to the Reactivation of Modernist.

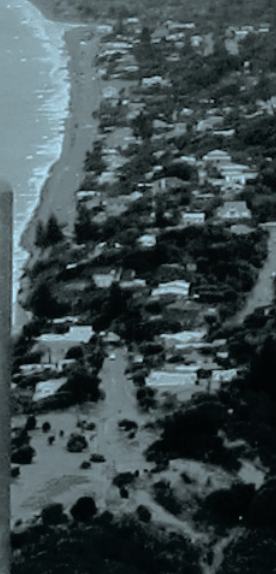

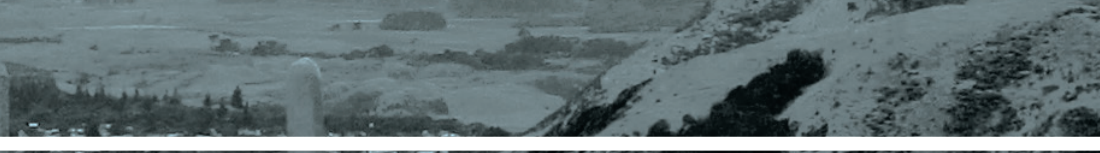
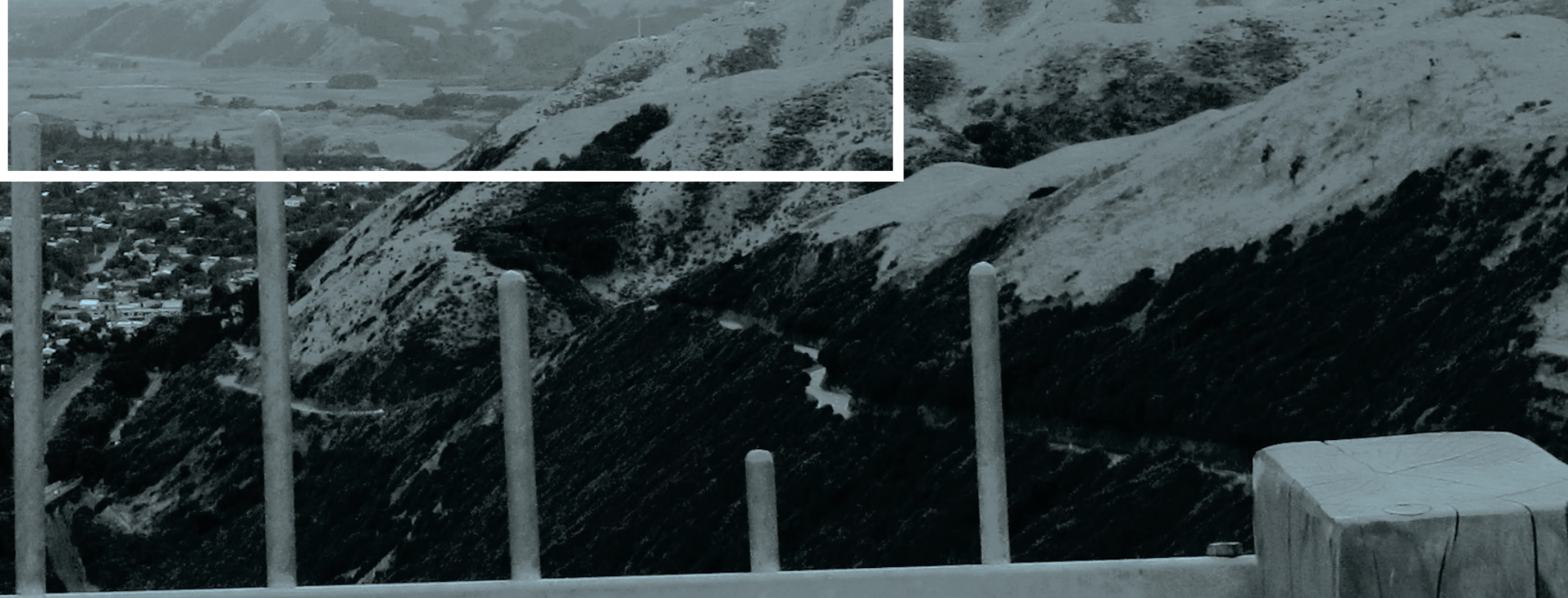


\section{Design Overview}

\section{How can we reuse modernist buildings in the regions?}

A solution for these buildings is retail; big box retail is the Modernist architecture is supposed to be flexible, open tendency within provincial towns. However, this has been plan and able to change use. Clearly there is something shown to be unsuccessful for the community as a whole wrong with the Parker Building, because of its disuse, - drawing people away from town centres, causing main therefore there must be issues with context, adaptability of streets to become empty and the loss of local businesses interior, programme, access, amenity or anti-progamme. (Curran, 2002). The reactivation design for one of these lonely buildings, the Parker Building, Waikanae, is for 'small box retail' to be placed at the perimeter, the middle remains. Using the centre as an isolated garden allows for adaptation in the future.

Waikanae, like other provincial towns, has a range of buildings which are abandoned, for sale or up for lease. These buildings vary in age and style, however modernist examples lead to an apt case study for reactivation of townships.

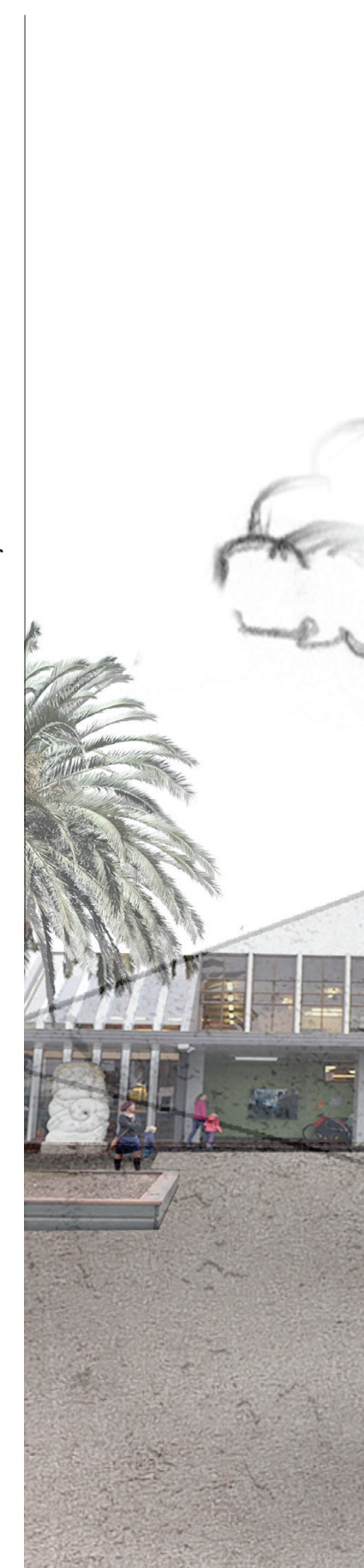


The design is based around reactivating the site through testing and critiquing preservation methods. Programmatically, the solution becomes a combination of small retail stores on the exterior edge and a community courtyard in the centre. This design solution introduces the newly reactivated building, offering an active edge that draws people in. The eight ground floor, timber framed shops are placed at the boundary between the interior and exterior. The interior garden acts as a back drop to this activity, and could be used for relaxing and recreation. Stores placed on the upper floor look into the double height garden space. The exterior shell is preserved as ruins, narrating the history of the building.

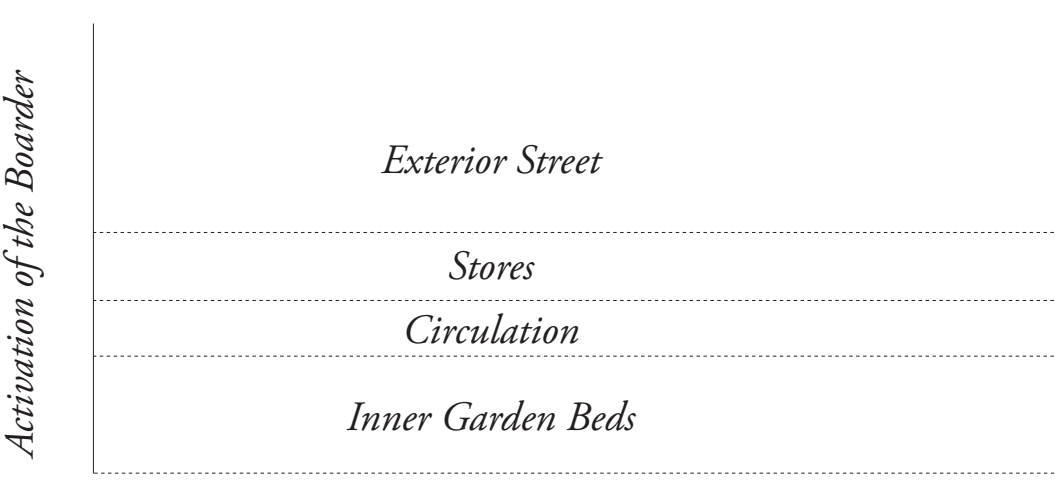

Courtyard and Garden Walls

10/ The plan shows the garden courtyard designed

around the principles of hortus conclusus. The

stores on the exterior follow the same geometry to

activate the facade of the store, creating maximum

connection between the Parker Building and

Mahara Place.

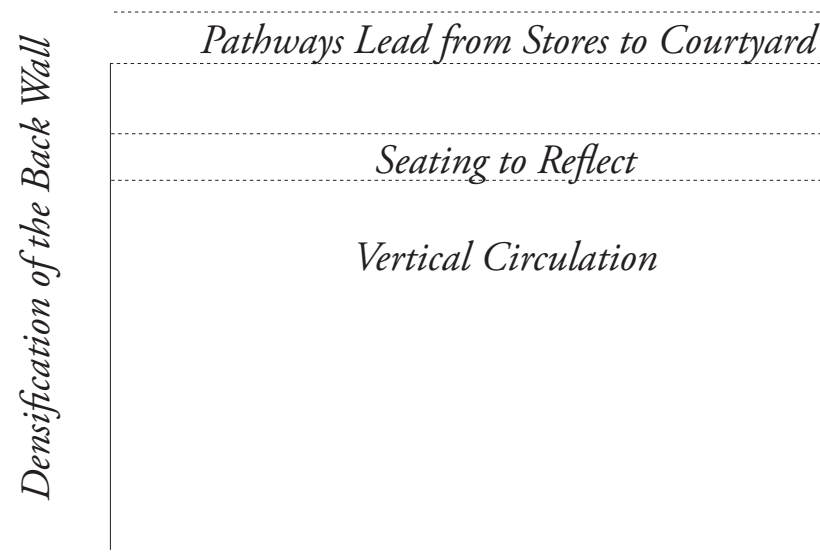




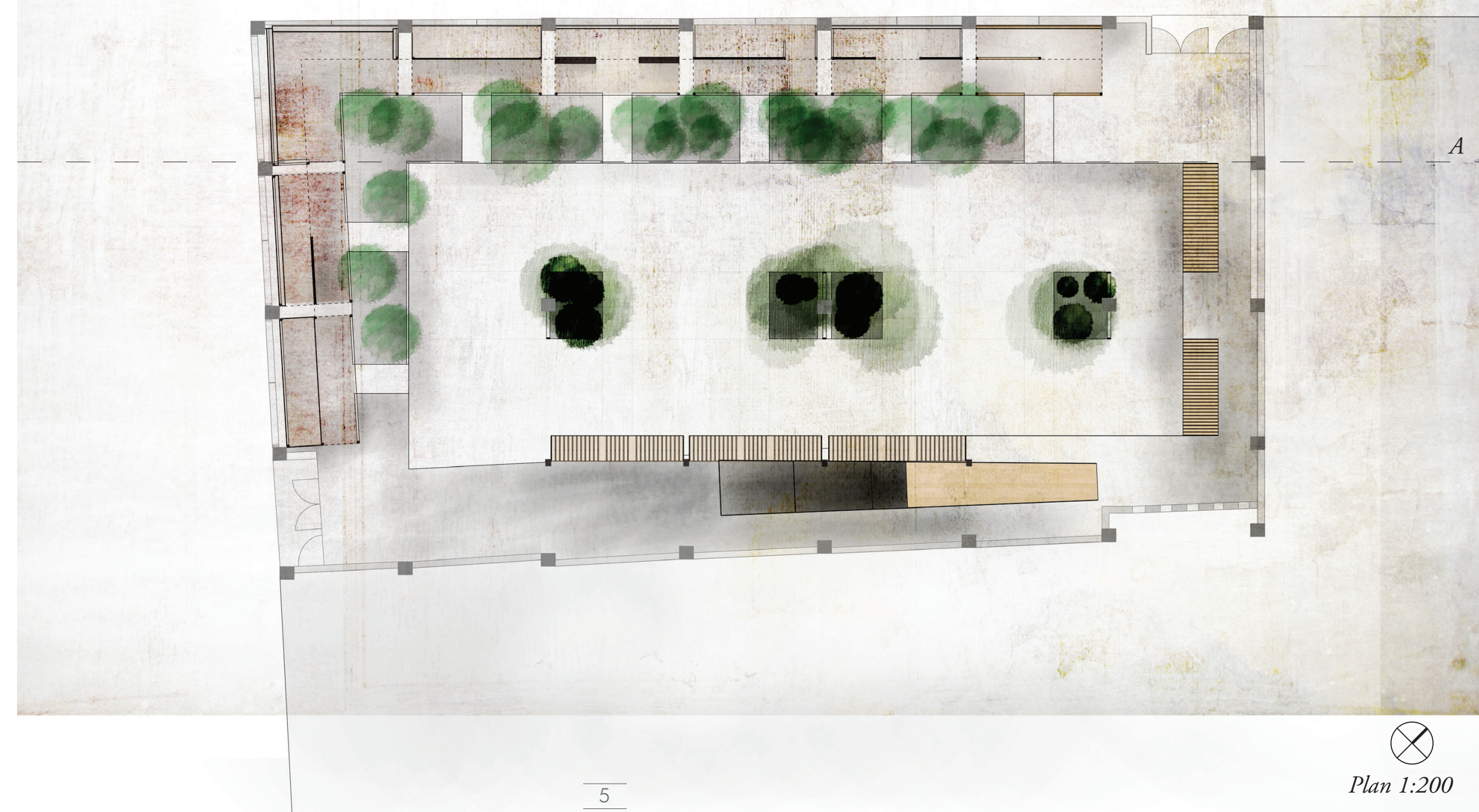




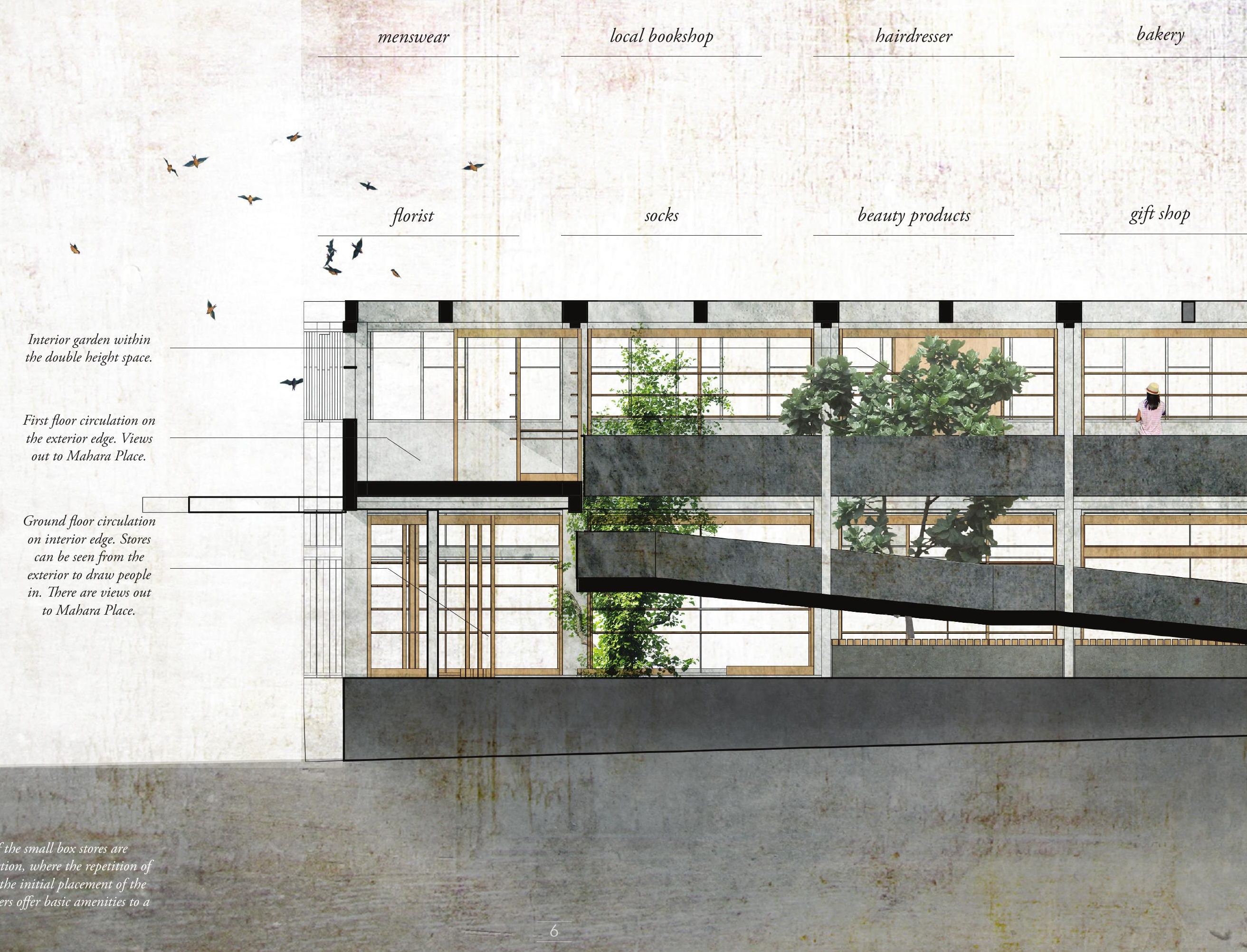

11/ The repetition of the small box stores are highlighted in this section, where the repetition of the structure informs the initial placement of the stores. Proposed retailers offer basic amenities to a provincial setting. 


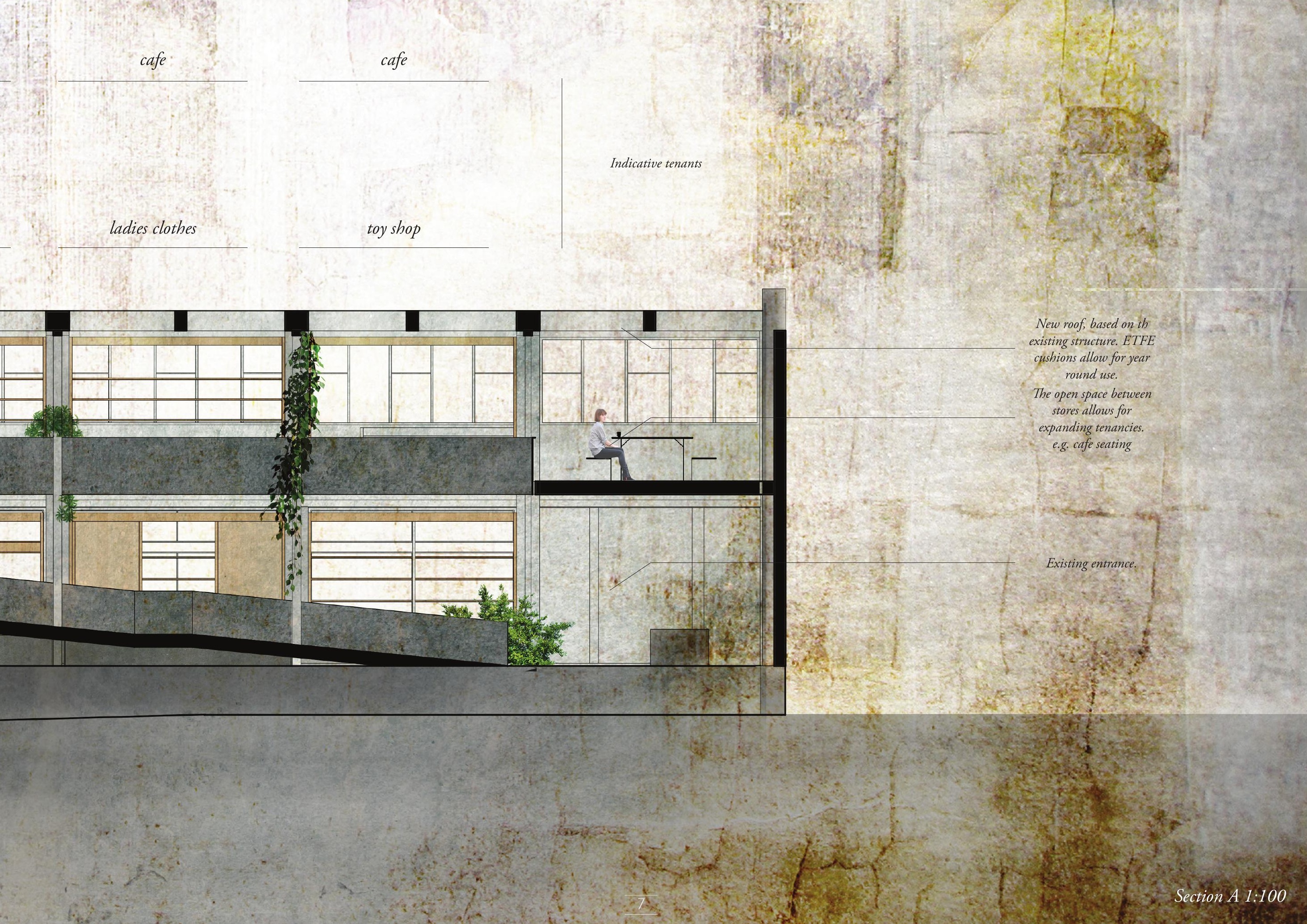


Structure of timber frames in a lighter

version of the gridded structure, with the same proportions.

The solution aims to explore reactivation through a design which encourages more people to use space functionally, responding to the regional context. This is done by reintroducing adaptability into the modernist building through simple but bold design moves.

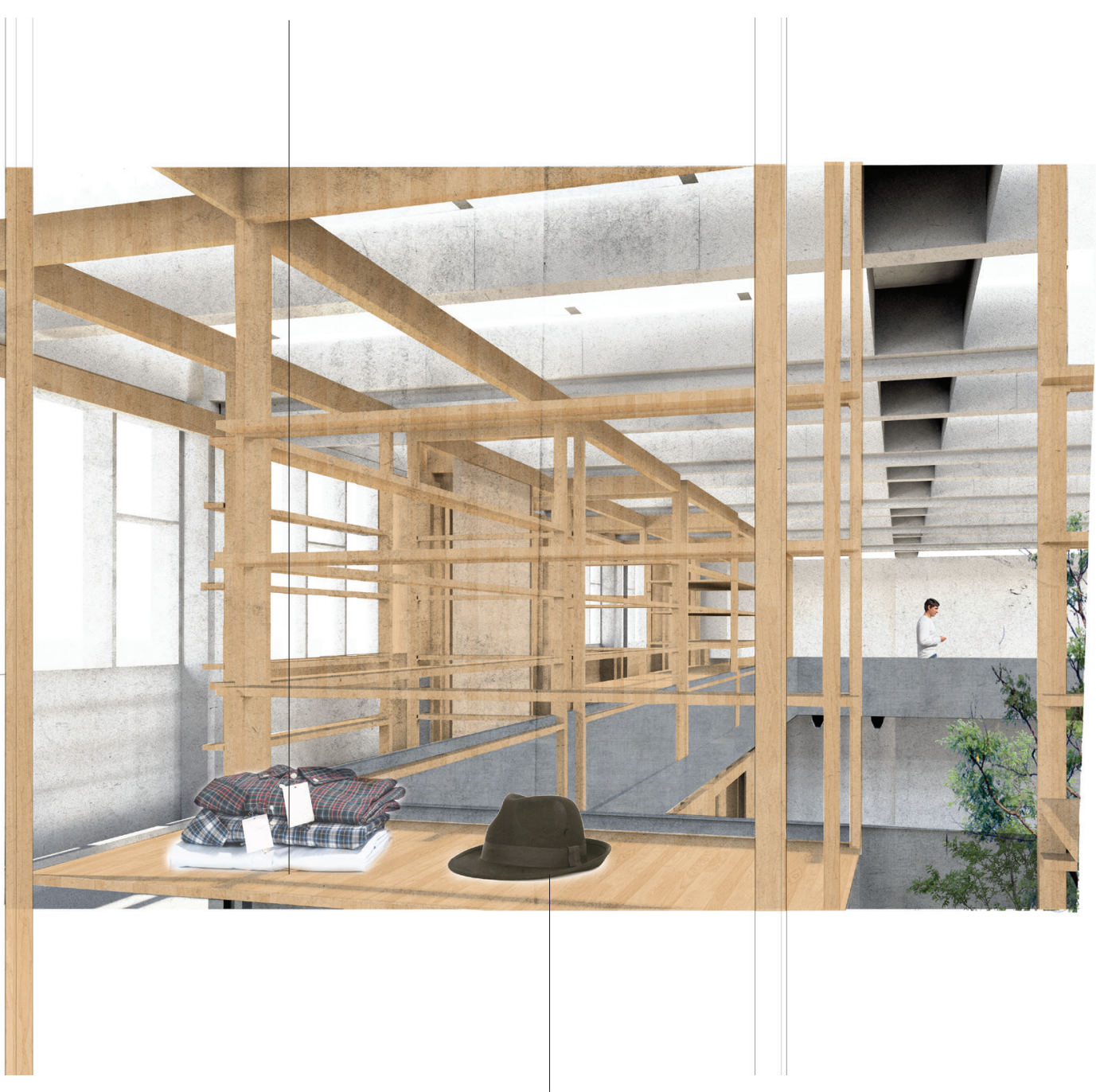

Versatile shelving system.

12/ The small box stores offer flexible retail

options including a variety in size of shelves, desks and partitions. Upper stores have a relationship 


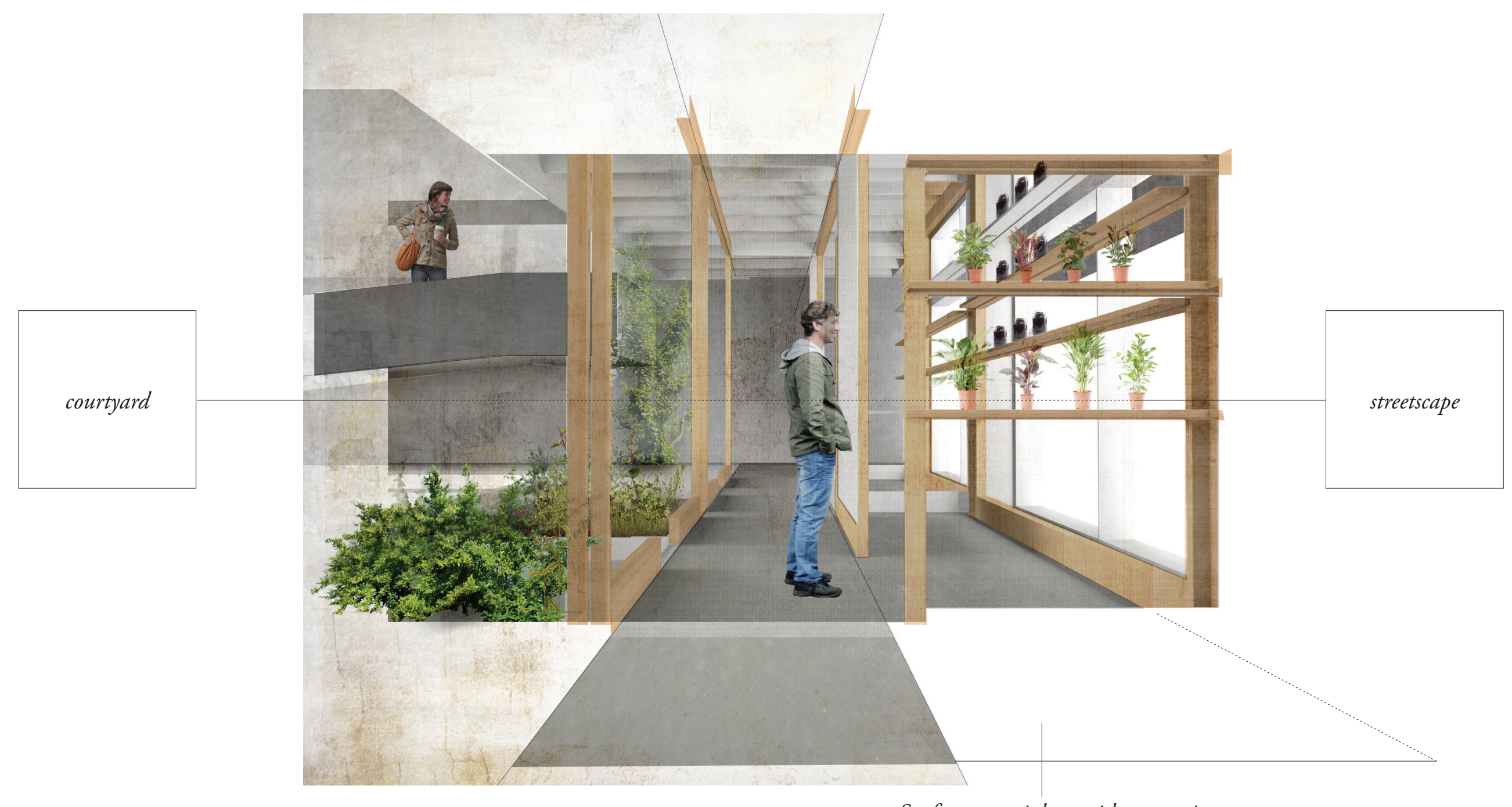

Surface materials provide separation

between spaces. 


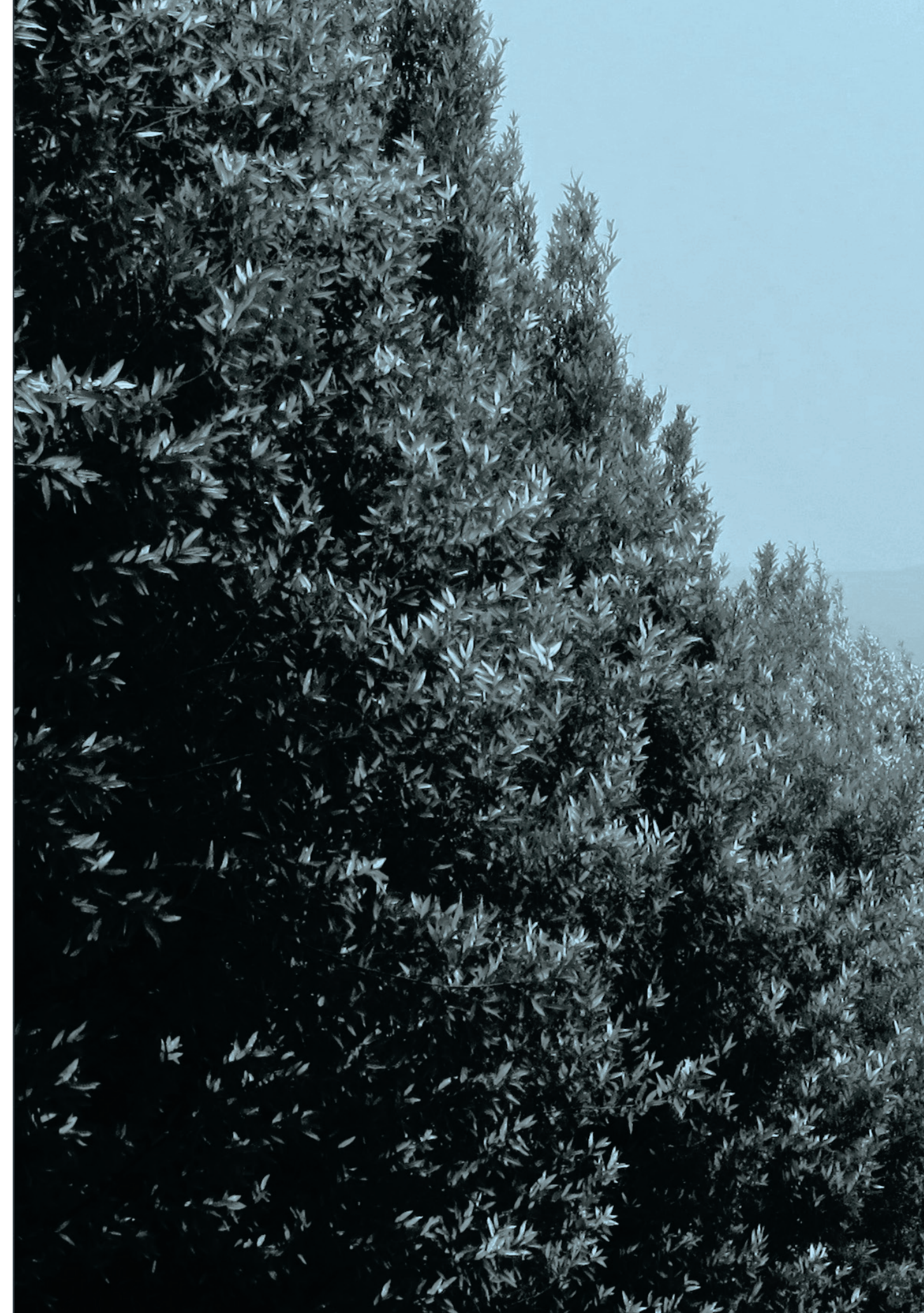




\section{Greater Waikanae}

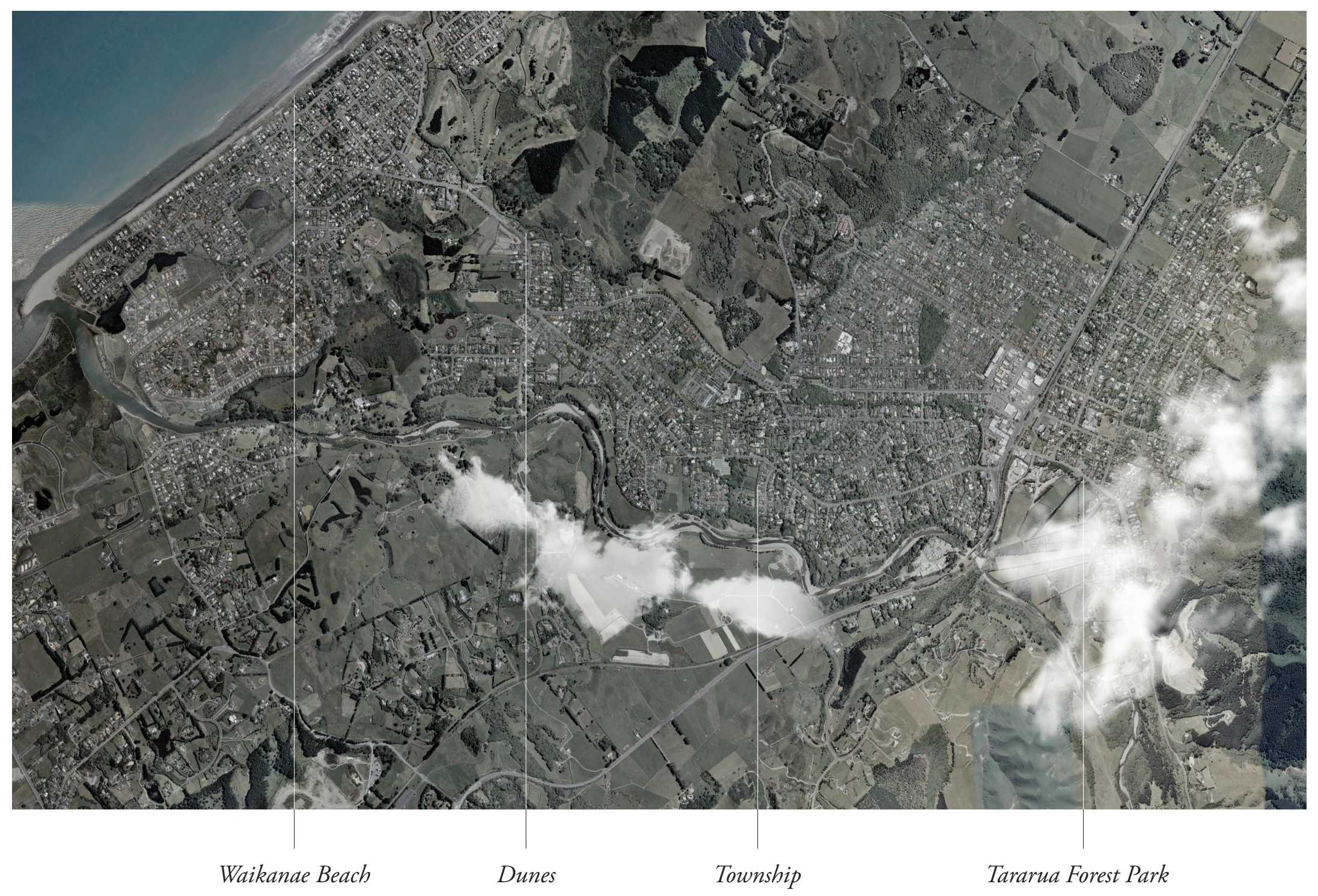

15/ This highlights the placement of the township between the rise of the Tararua Ranges and the parabolic dunes, bordering the beach. 
Waikanae Central

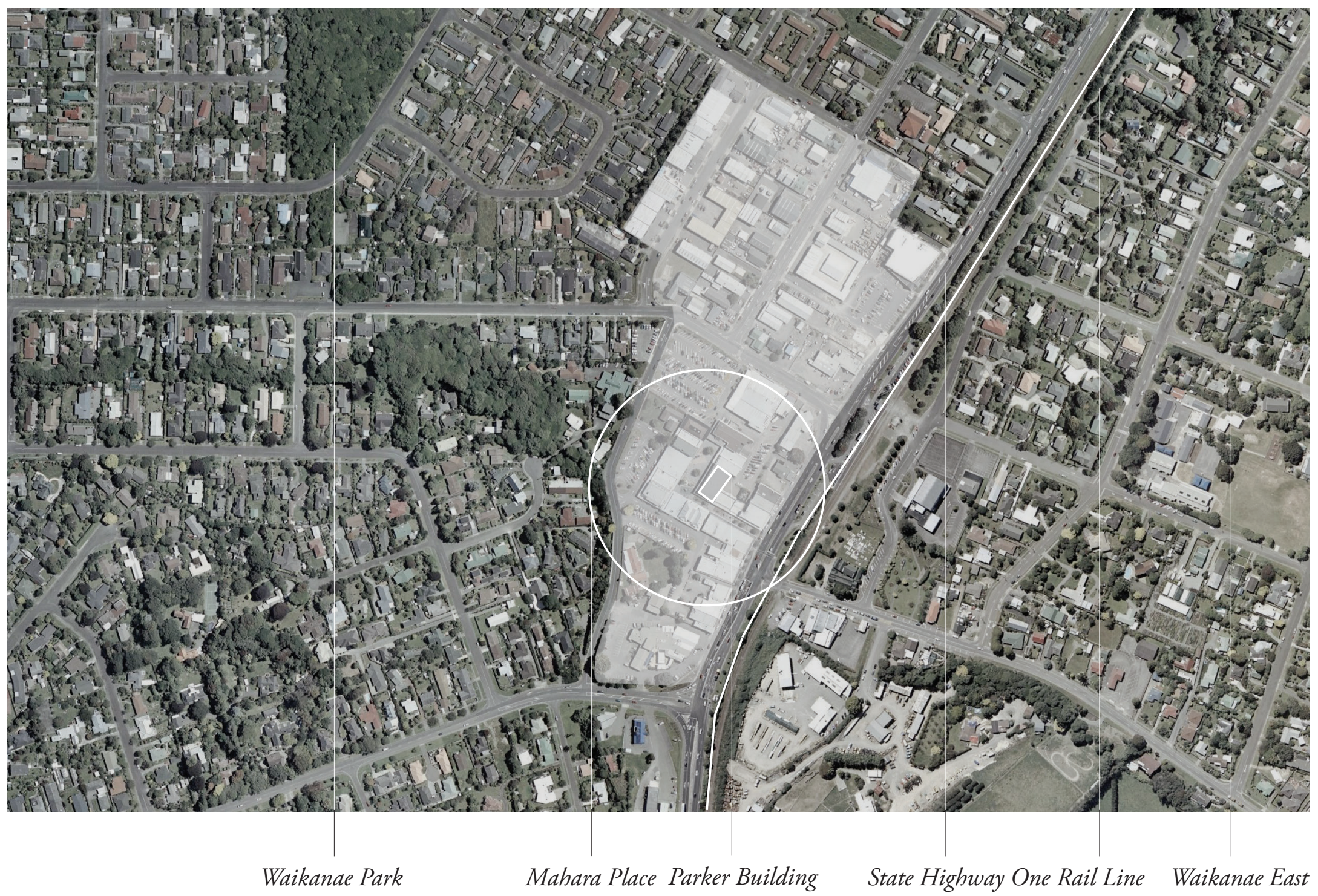


Mahara Place

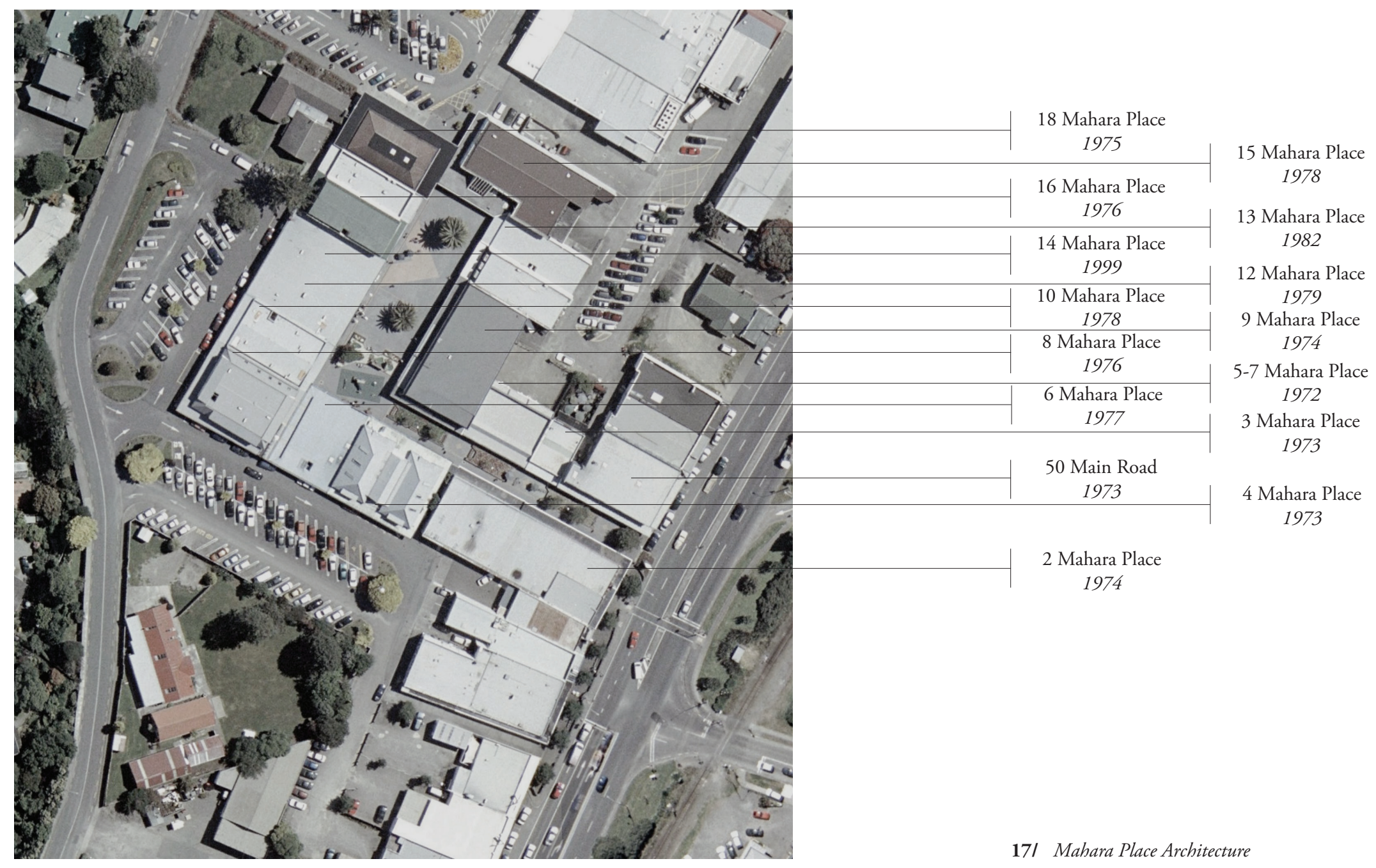


18/ The initial research of Waikanae and Mahara

Place involved understanding the position and

context of the shopping precinct, as well as the

programmatic relationships within the area. Inward

facing facades of the street have a close relationship

to users, highlighted by the movement lines.

The outer facing exterior edge acts primarily as service entries. Key buildings are located at the pedestrian entrances, book ending the precinct with public service programmes.

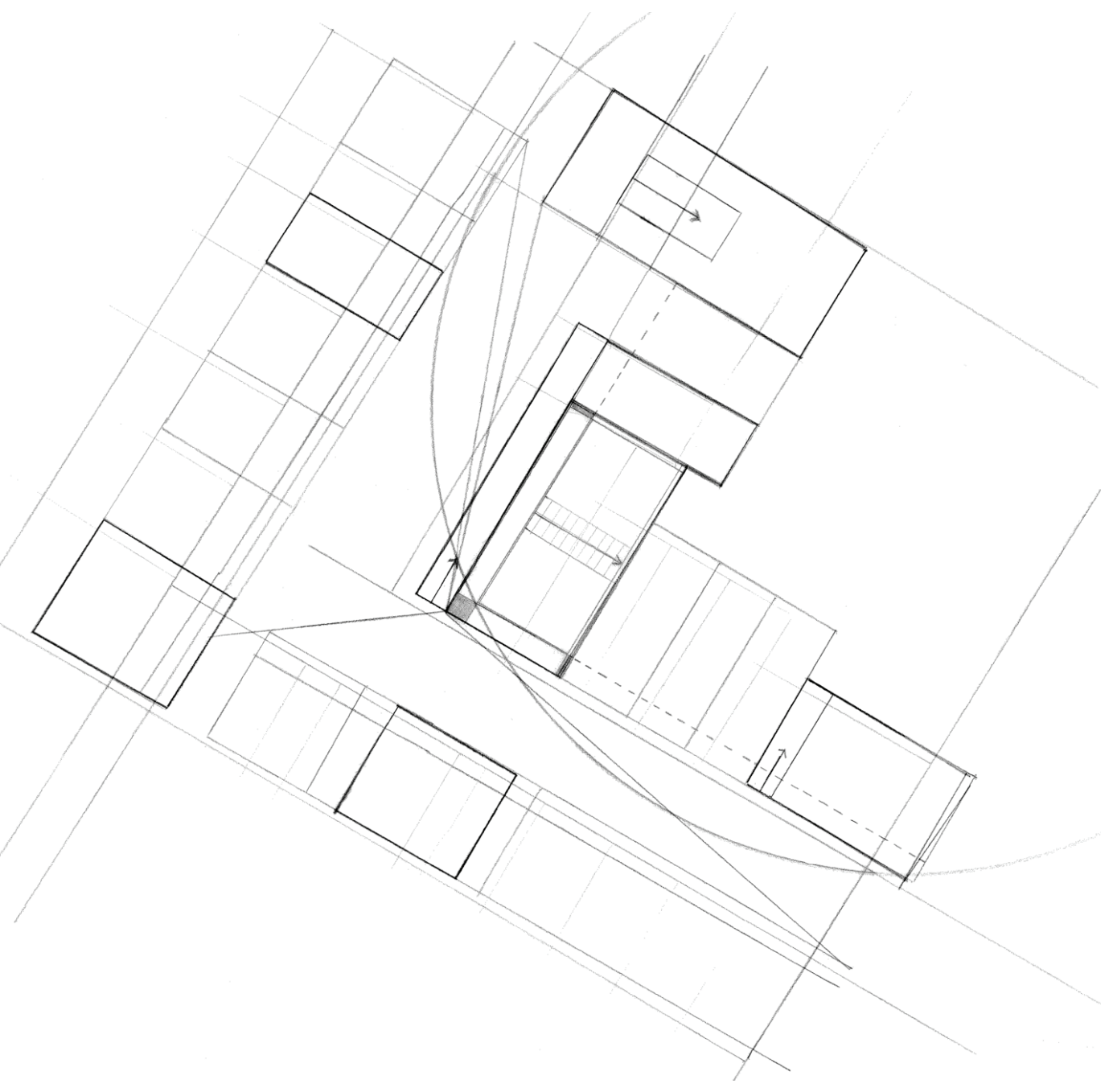




\section{Mahara Place}

Located on the Kapiti Coast, North of Wellington, Waikanae is town of 10,700 people (MacClean, 2015). Mahara Place is in the town's centre, perpendicular to State Highway One. It is a pedestrian shopping street with 14 buildings and 39 tenancies, including: a library, a gallery, bakeries, cafes, real estate agents, banks, a post office, cinemas and other retail stores (fig 17) (Kapiti Coast District Council, 2015).

Waikanae Town centre is larger than average compared to other New Zealand towns with a similar catchment size, highlighting the dependence on State Highway One traffic. These temporary users may depart due to the upcoming MacKays to Peka Peka Expressway, negatively affecting income. The shopping precinct operates as a "local convenience and supermarket" area, rather than a town centre. These larger stores appear to be replacing the "traditional pattern of narrow fronted store fronts lining a shopping street" (Heath, 2011).

\section{Impression}

Mahara Place, 10am Saturday 14 March 2015.

Car park full, a couple of children playing in the playground and a smattering of people wondering around the shop fronts. Many shops are solely occupied by the shop assistant. The car park appeared to be false hope. The community was in the supermarket, adjacent to the mall, rather than residing in the large, light, open-air courtyard.

At face value, the street should be the bustling centre of Waikanae, located at a point of transverse with State Highway One, the Railway Station and the key route to Waikanae Beach. However the garden lined, hanging basket and park bench filled space gave false hope for the atmosphere.

Looking down the street, an eclectic mix of shop fronts were arranged on the axis. Cobwebs hung from overhangs, some desperately required a coat of paint and for lease signs scattered the windows. Many don't give hints to the life contained within. 


\section{Setting the Scene}

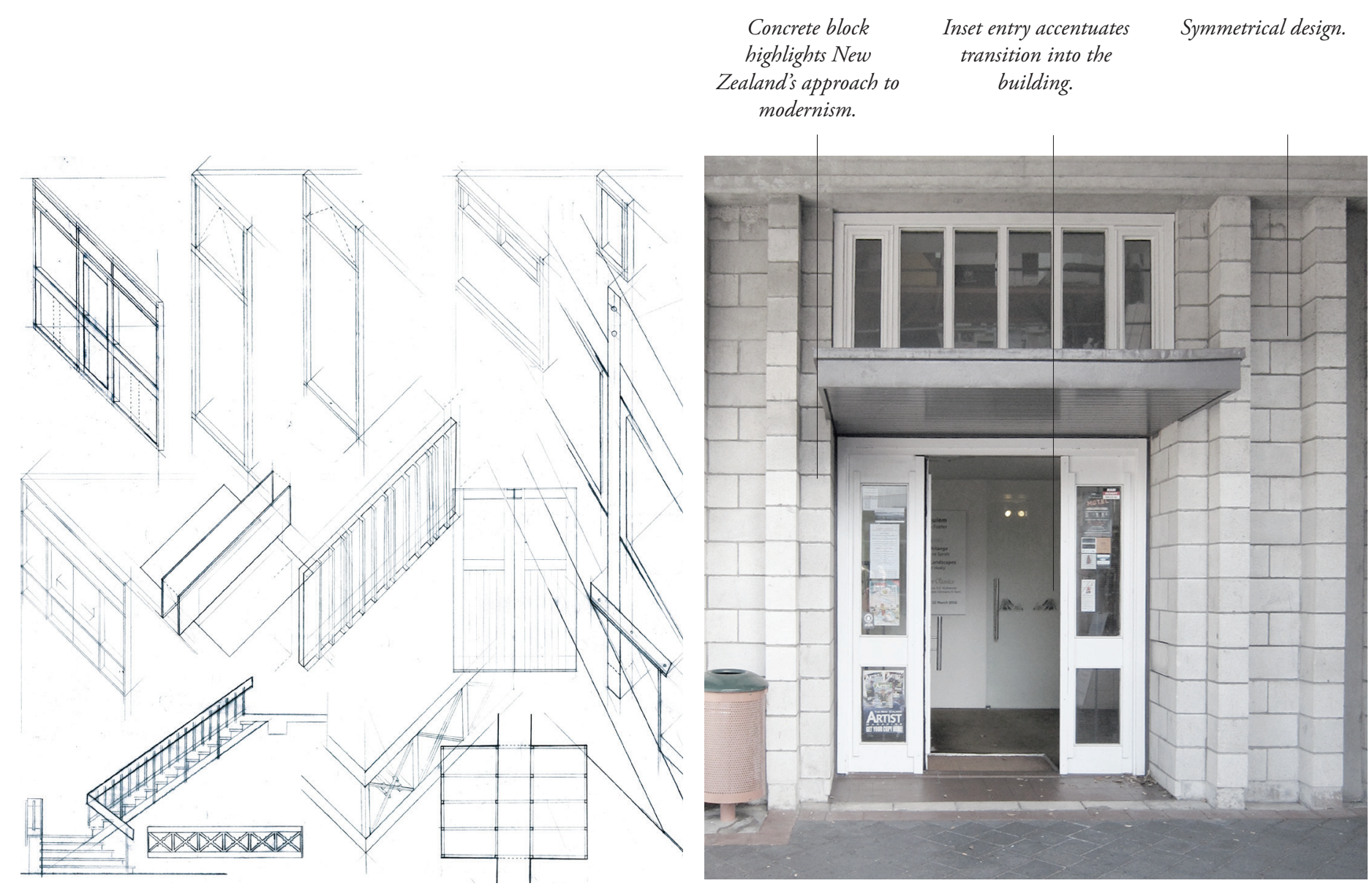

19/ Catalogue of elements within existing Mahara

20/ Mahara Gallery Entry, 18 Mahara Place,

Place buildings. Elements having linear components

1974. Originally the Waikanae Library, designed by Bill Allington. 
Flat roofs, feature of Upper windows allow many modernist designs. for views into Mahara Place.

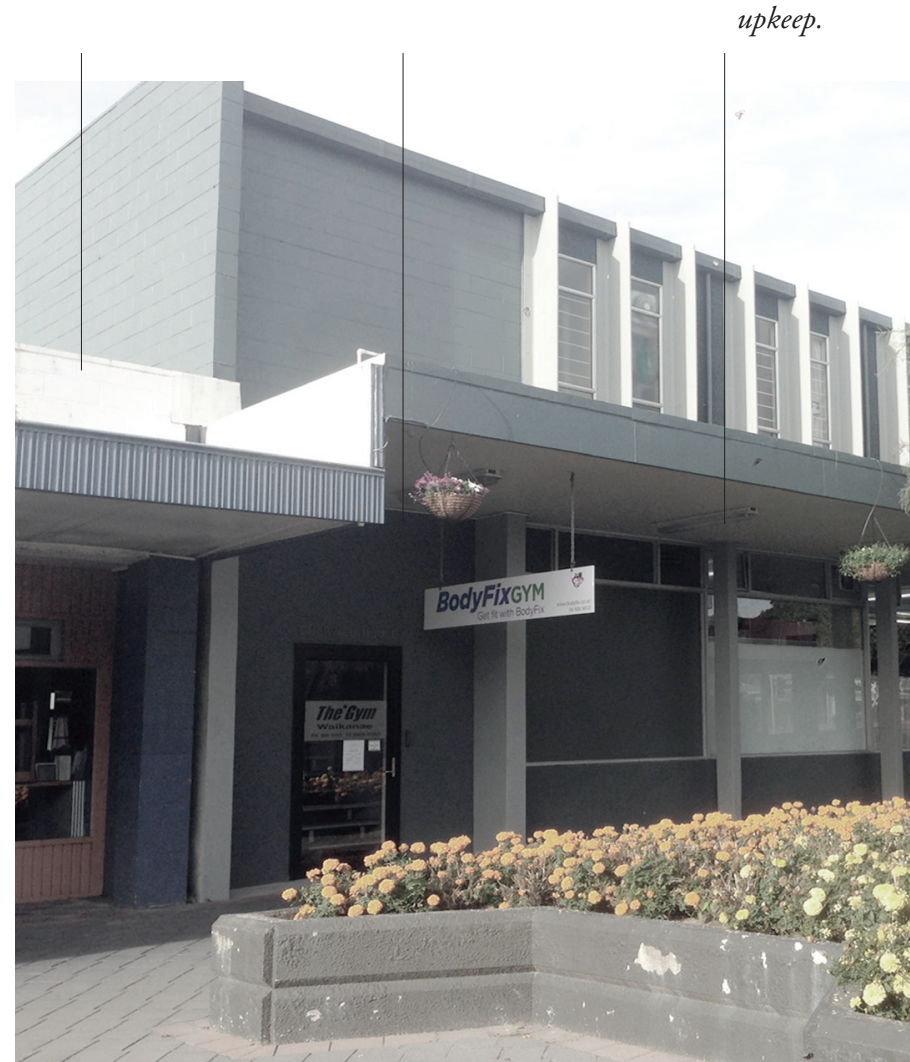

21/ 50 Main Road, 1973

Colourful garden bed

placed in the center

of the street. Showing

$$
\text { upkeep. }
$$
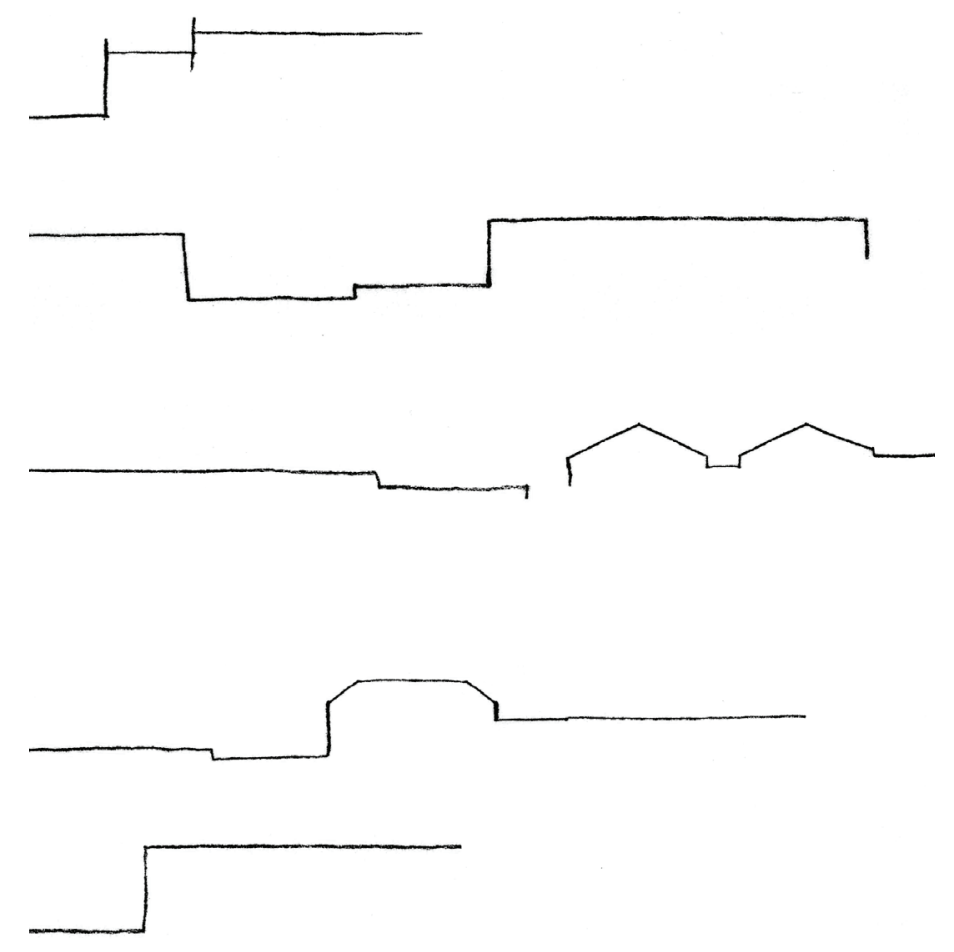

22/ Roof Lines, mostly flat create a simple skyline.

This is contrasted by some pitched roofs. 

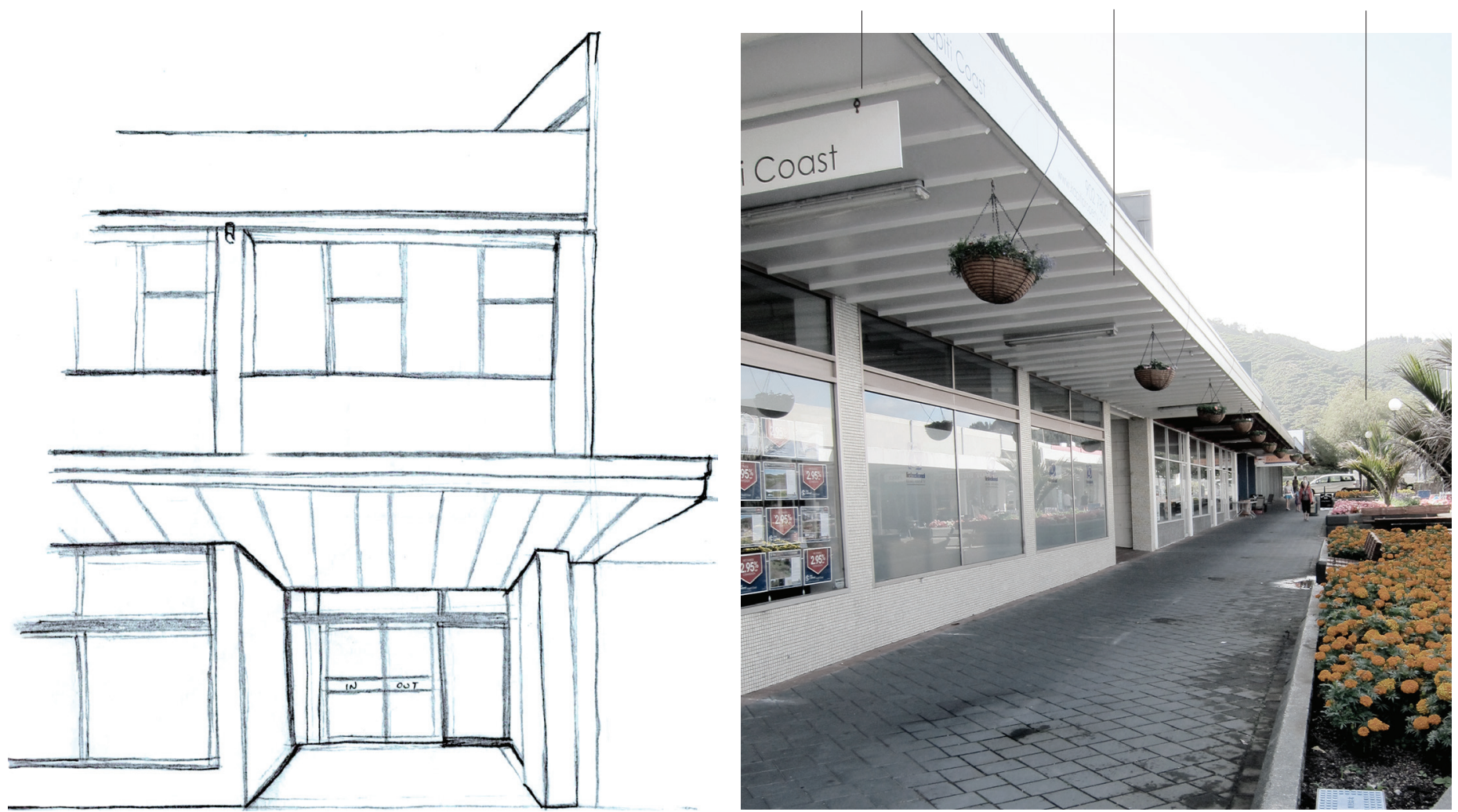

23/ The entrance way to the Parker Building.

24/ Mahara Place street view, Parker Building,

shous the linear elements and basic forms. This

inset way is similar to Mahara Gallery (fig 20).

1974 
Stairs on the corner of the site allow for

alternative route

through the edge of the building.

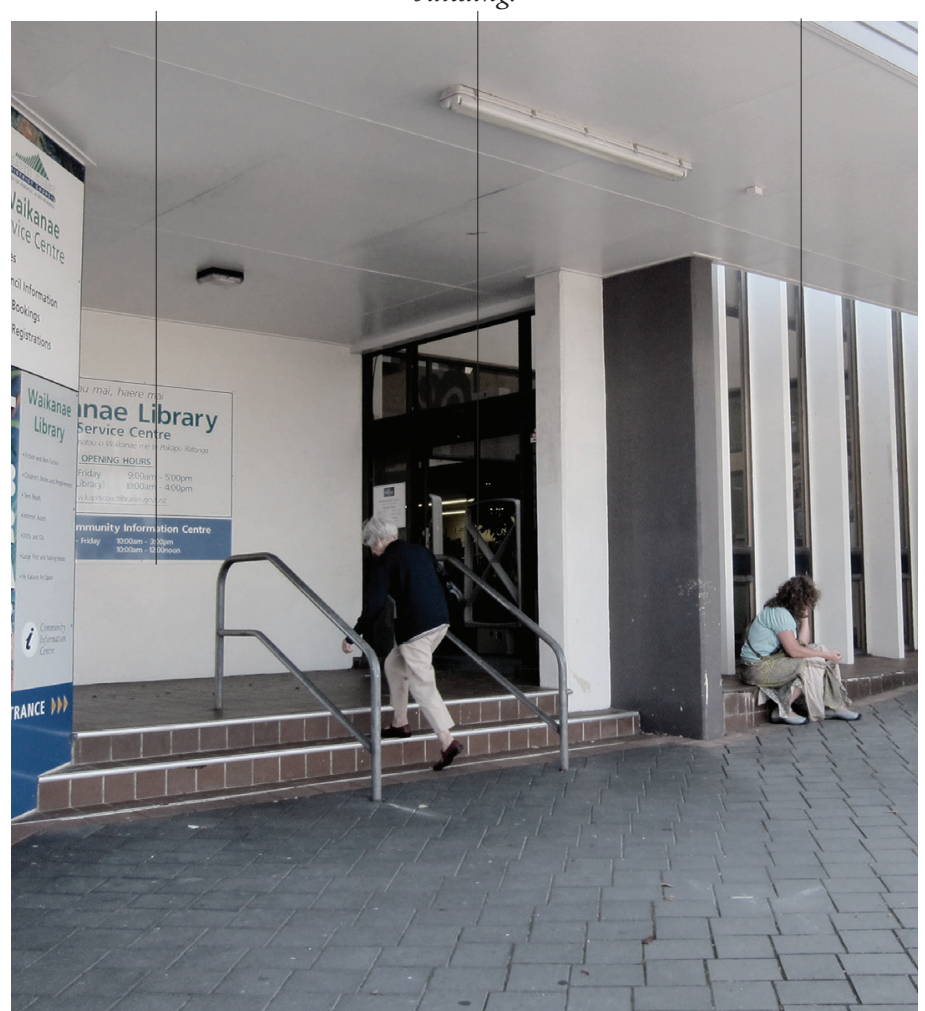

25/ Waikanae Library, 15 Mahara Place, 1978

Fins frame window

openings.

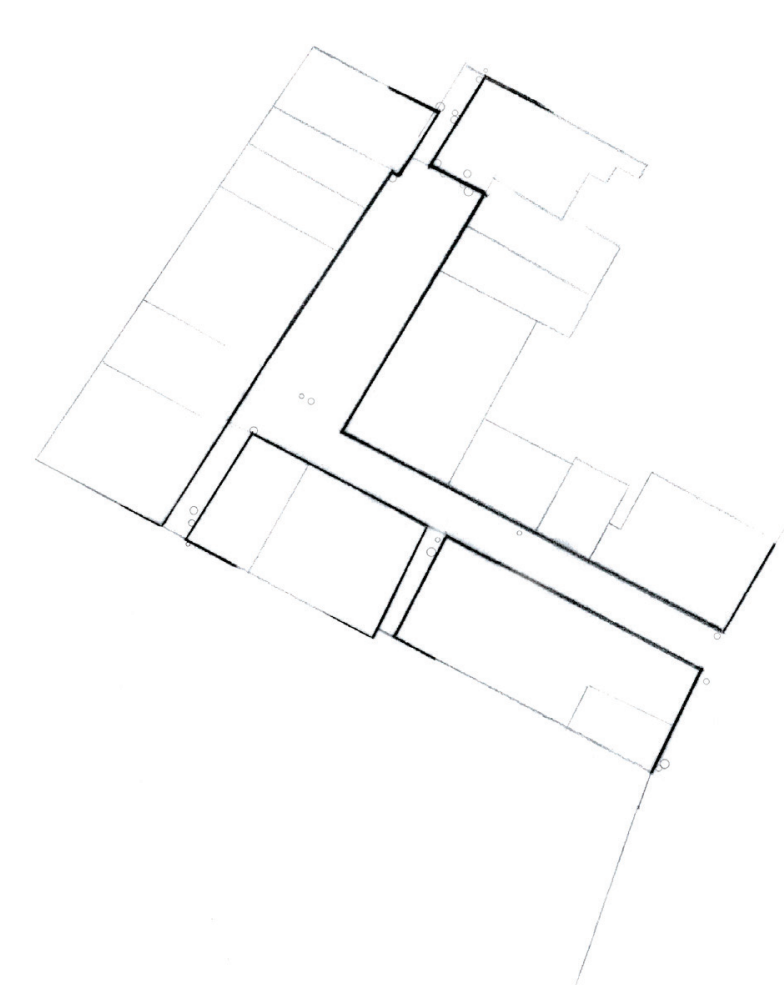

26/ User flows and patterns. Most people observe meet and migrate alongside the inner façade of the buildings. Four access ways show entry points into the area. 


\section{Initial Hunch Designs}

Initial research produced 'hunch' designs that explored ways in which activation could take place. Interventions were influenced by the observed movement within the wider space. 15 Mahara Place, Waikanae Library, and 50 Main Street were chosen for the way they bookend the set of buildings with apparent modernist principles. Figures 27 and 28 are a redesign of the Waikanae Library, retaining the current programme and introducing a cafe. Figures 29 and 30 detail a restaurant which responds to the ideals and needs of a small community.

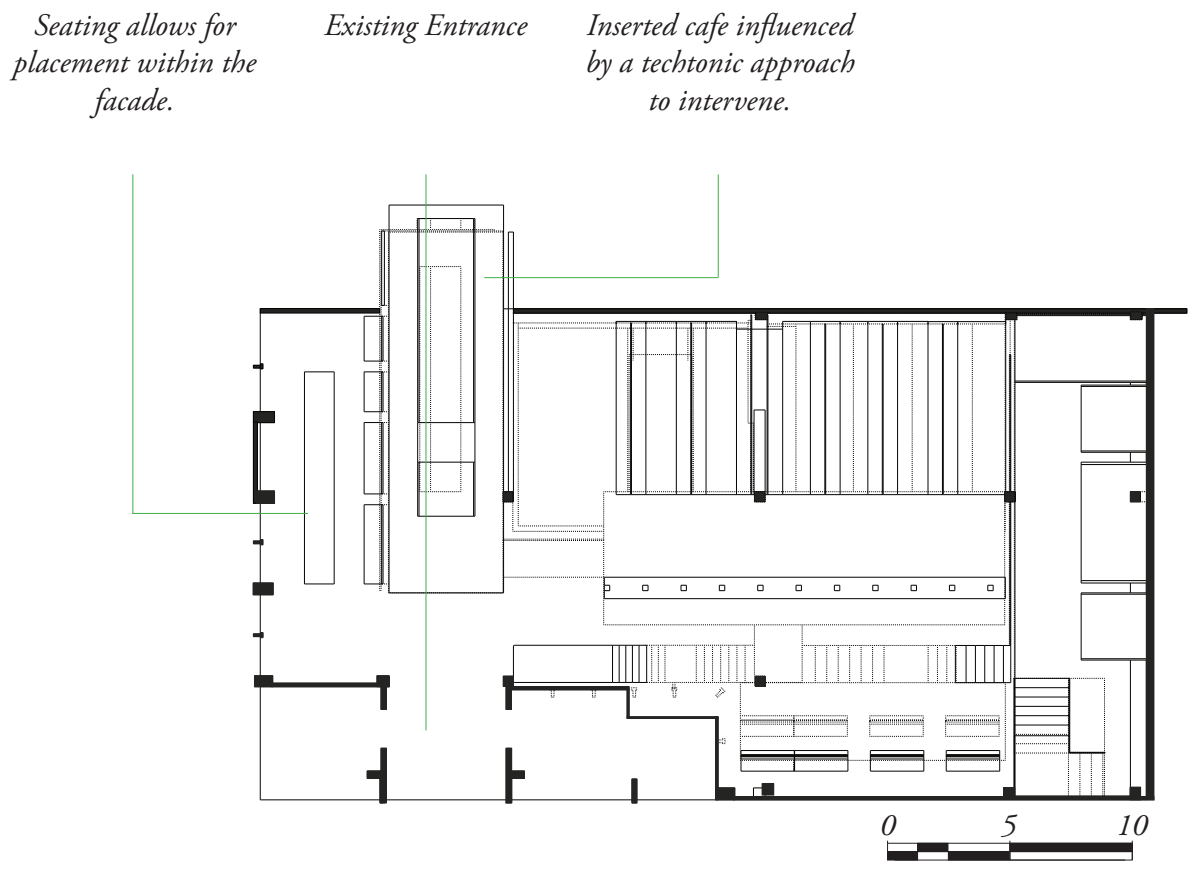

27I Library-Café Plan. The library's redesign retains the current programme while introducing a café, allowing socialising between the users of both programmes. 


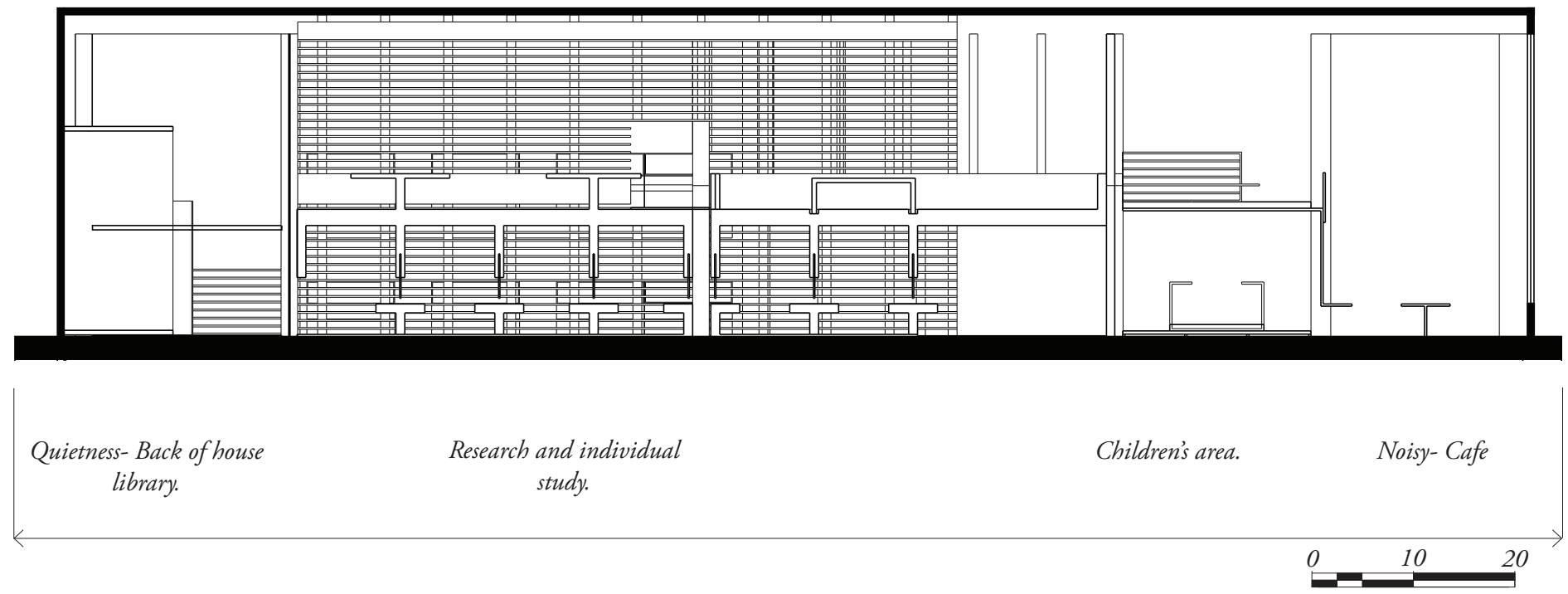

28/ Library-Café Section. The aim was to change the library to suit a community based, technology

driven future, creating places to access information

socially and digitally alongside traditional methods. 


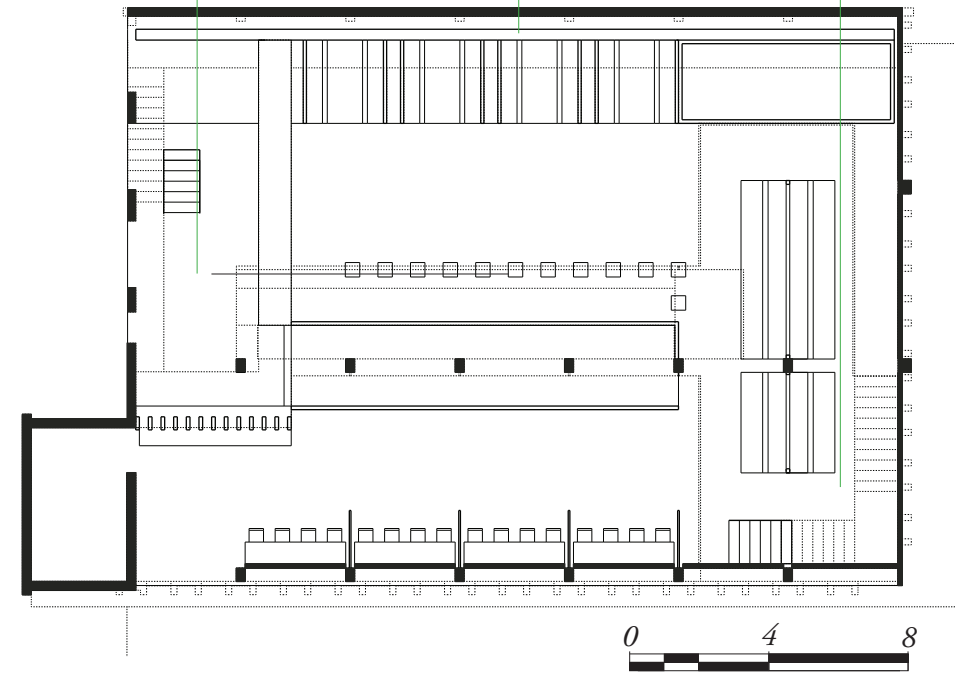

29/ Restaurant Plan. Along with responding to movement and contextual patterns of Mahara Place, this restaurant intervention responds to the ideals and needs of a small community. Seating options are based around communal dining, joining groups of people together. 


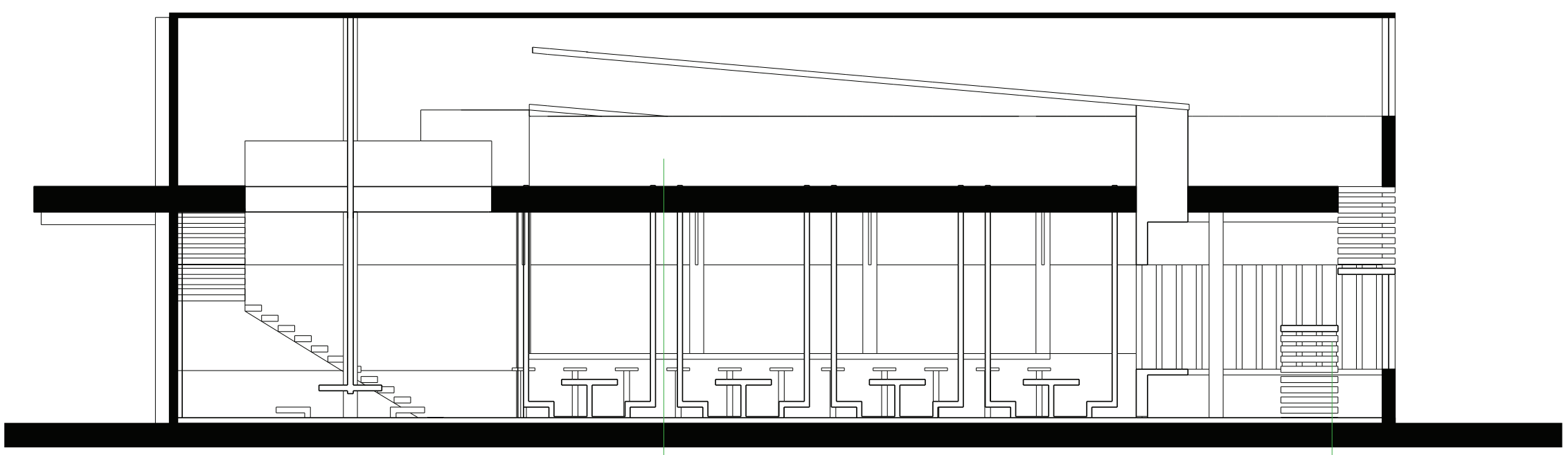

30/ Restaurant Section. The upper floor contrasts

the restaurant's space down stairs, offering

a function area. A new stair case allows for

Two floors arose the issue

of kitchen placement for

connections between general dining and function ease of service.

spaces, bringing vertical circulation to the forefront.

Stairs at edge end of

building allow for

service and served space.

0 


Parker Building Impression
At first sight the Parker Building is clearly the
largest building in Mahara Place. On the corner of
the street, opening out onto the currently empty
courtyard, it is located at a key position. The
modernist building appears to be trademarked with
a large 123 Mart sign, which weakens the authority
of the architecture. The interior of the building
seems daunting, dark and large. The shops seem
oddly placed in a large building.
The upperfloor of the buildingseems unapproachable
due to narrow and unwelcoming staircases, behind
closed glass doors. This upper floor is hidden behind
small windows and curtains from the exterior.
It feels ugly and large, without warmness or delicate
detail
Further Analysis in Appendix A-C.




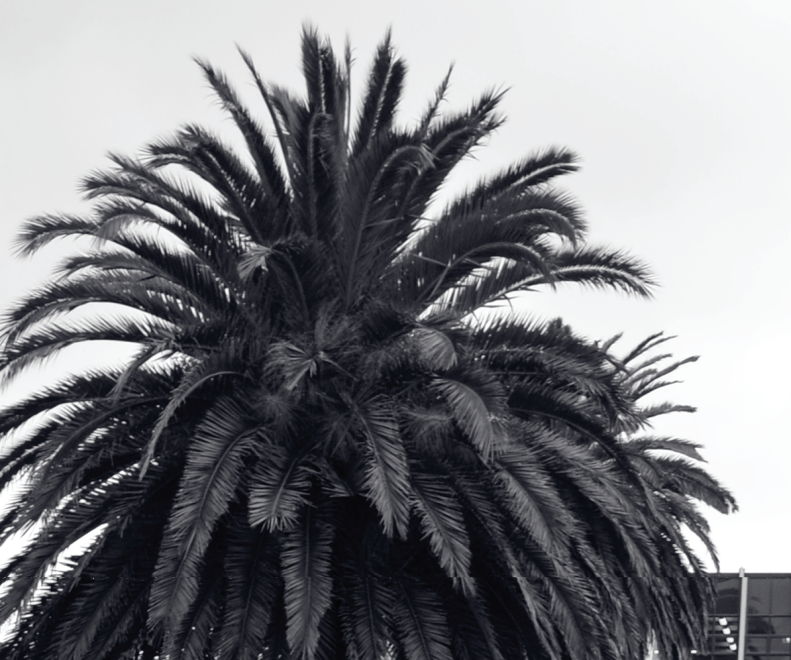

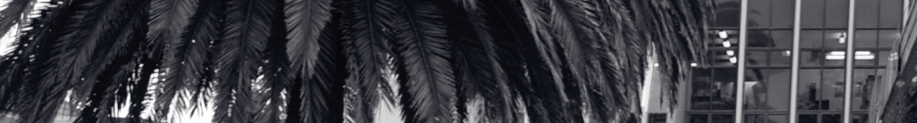

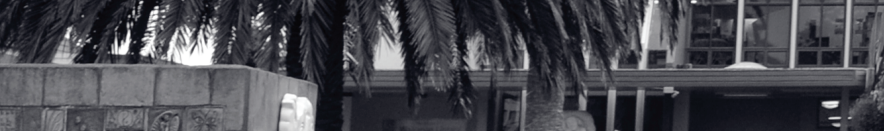

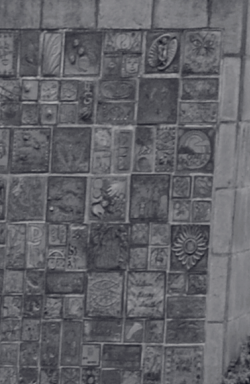
2. 8

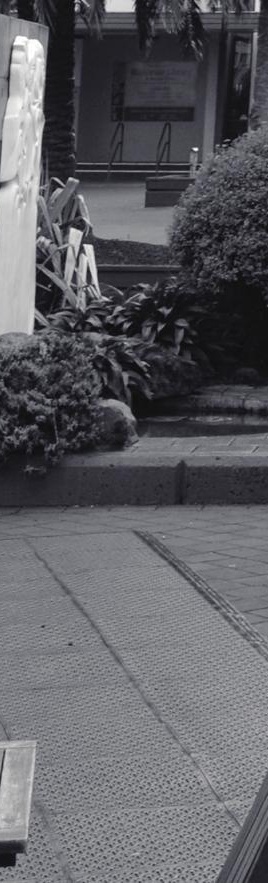
1.) $=$
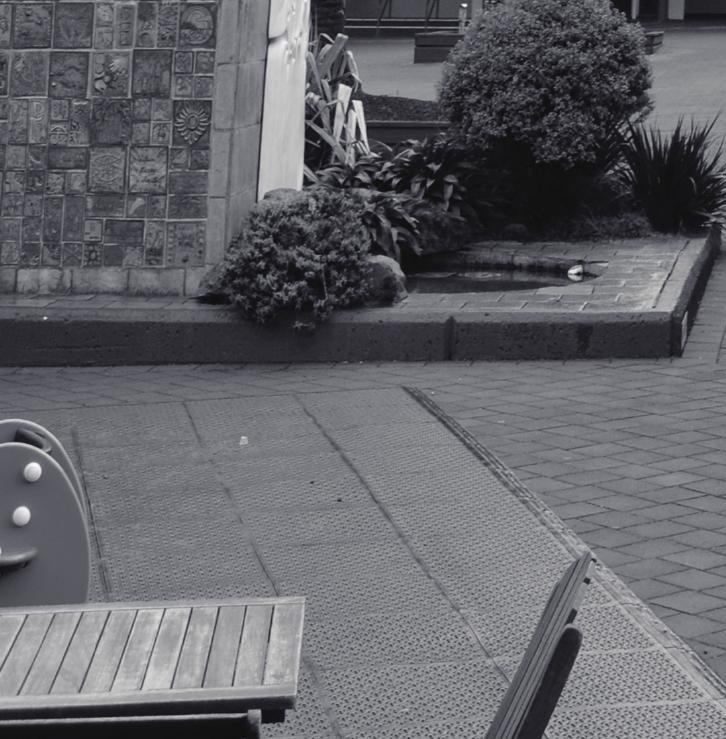
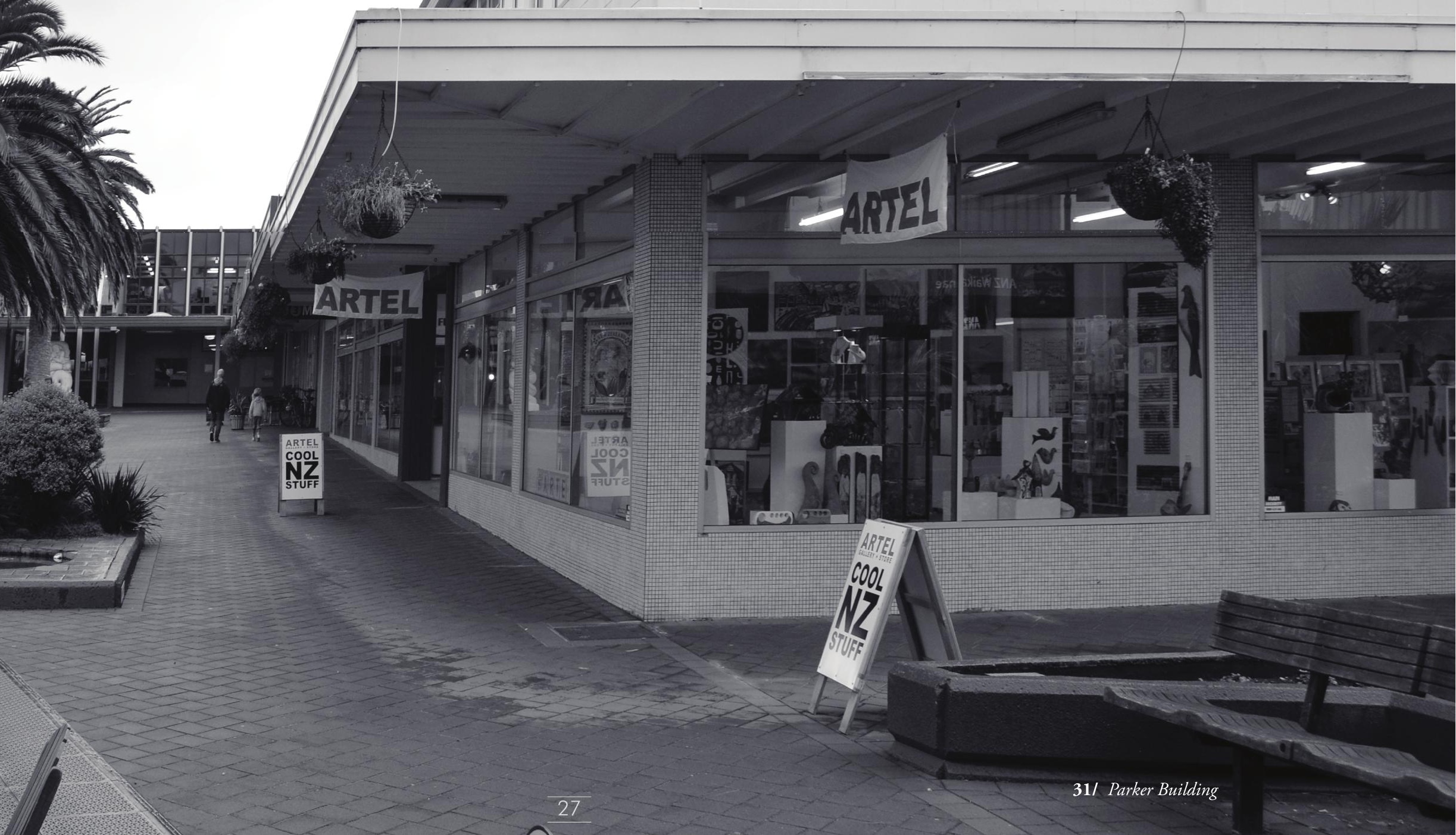


\section{History}

The Parker Building was selected as a case study, due to its normality in the landscape of provincial New Zealand, it is the common rather than the gem. It can be used to test reactivation of provincial modernist buildings. Built in 1974 for Mrs H. L. Parker for $\$ 110,000$, the two storey retail building has had alterations and new fit-outs in 1979 and 1998 respectively. Current tenants are: Artel Gallery and Store, Bright photo Lab, The 123 Mart, Coast Access Radio, Smartswitch Marine Monitoring Systems and Parkinson's New Zealand. A reinforced concrete frame was designed with an open interior (Kapiti Coast District Council, 2015). Three internal columns support the upper structure, with partitions along these dividing the space. All services are located to the rear, with a service hallway linking the shops and offices.

There are some key issues with the building; a high tenant turnover and lack of connection to the street. These shops have large store footprints for the required retail of a small population (Stockwell, 2009), indicated by few customers. Little connection between the ground floor, first floor and the street causes unclear navigation of the building.

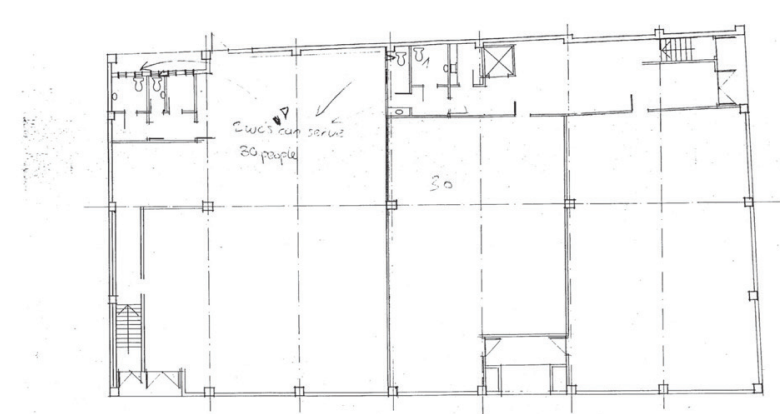

Ground Flooks Rhan nioo

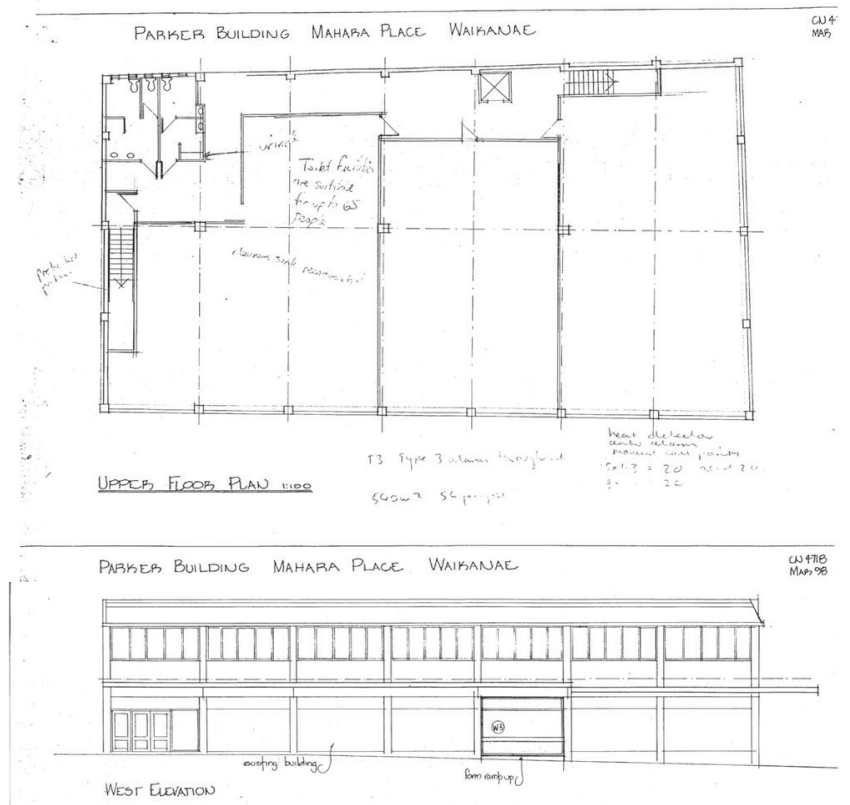

32/ Mahara Place, 1992. Fit out drawings show

division of tenancies with the building. 


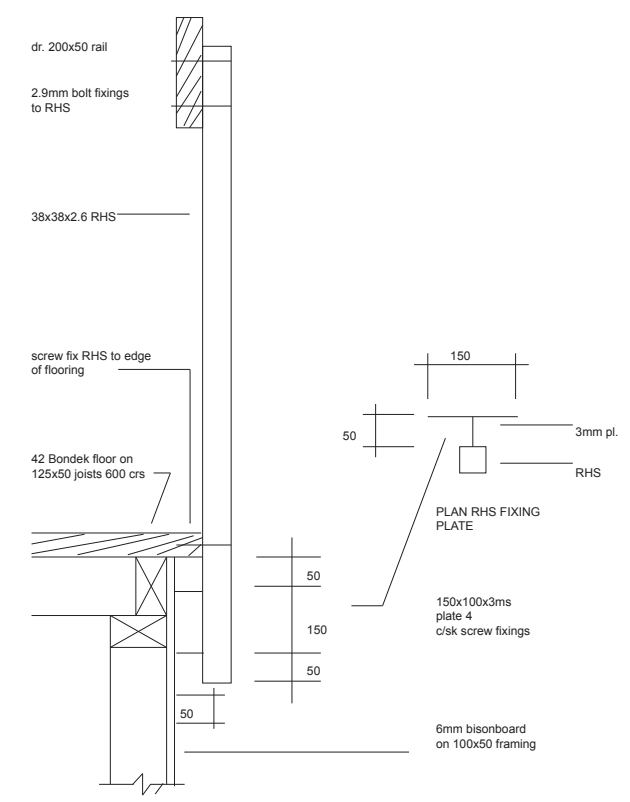

LANDING HANDRAIL

33/ Stair Detail, 1979 Timber handrail with steel fixtures. Rawness of connections. The disengagement of the railing to the landing will allow for shadows.

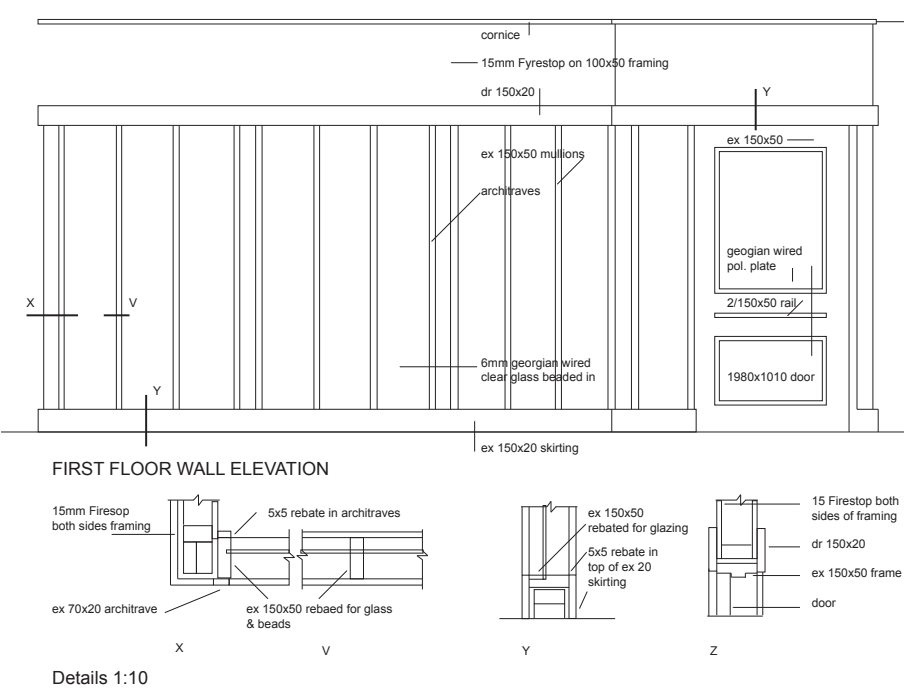

34/ Wall Detail, 1979. Georgian wired glass wall, disjointed by vertical timber beads. The wall allows

for privacy, but lets some light into the rear of the building. 


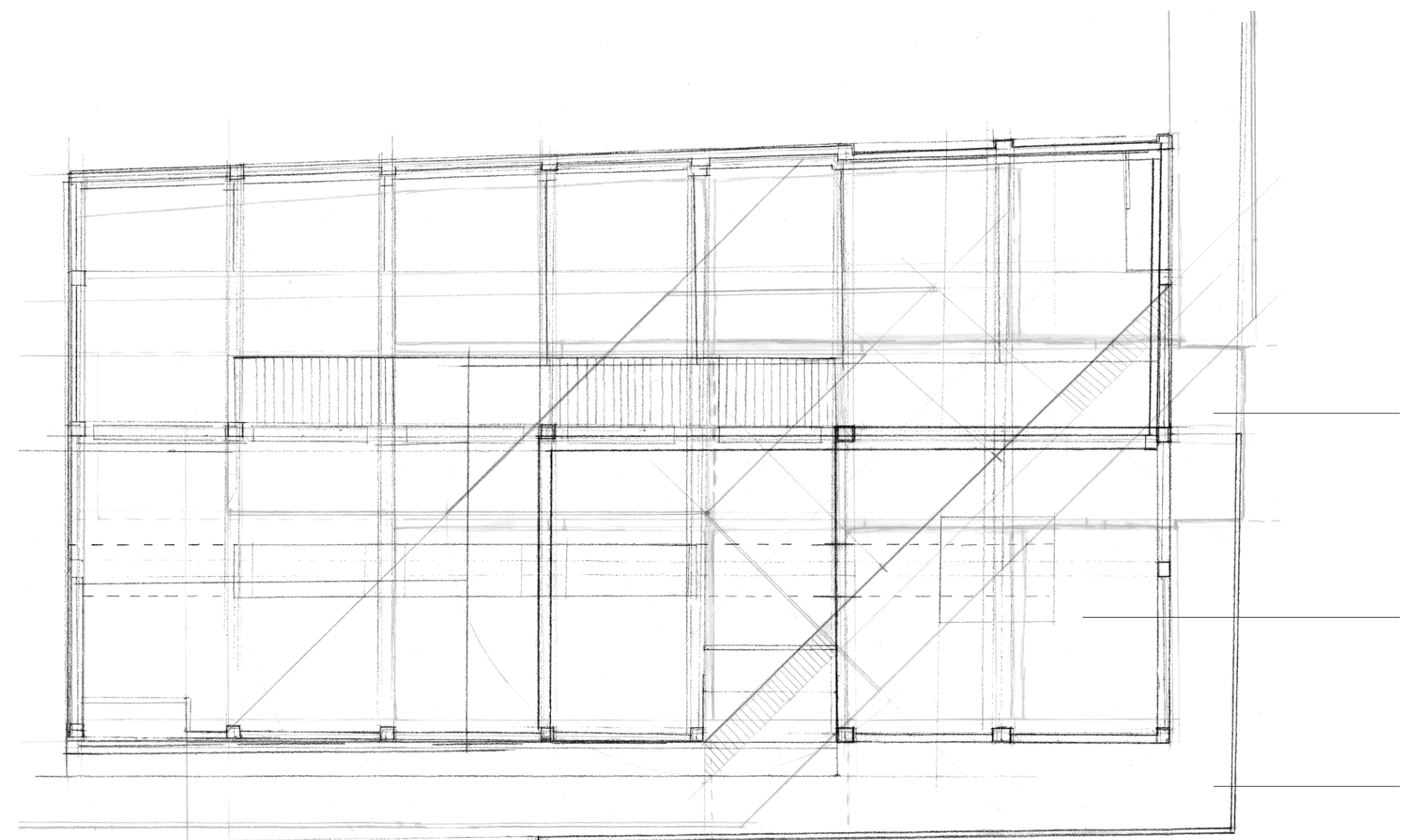

Cut through with possible access to first floor.

Courtyard created within building.

Screen allows for community flyers and advertisements.

35/ 2D drawings show movement across the building-concepts are overlaid to produce this drawing, highlighting issues with the current buildings and its lack of people within. Weather often forces people from the courtyard to under the eaves. The cut through allow people to access and pass through the building. 


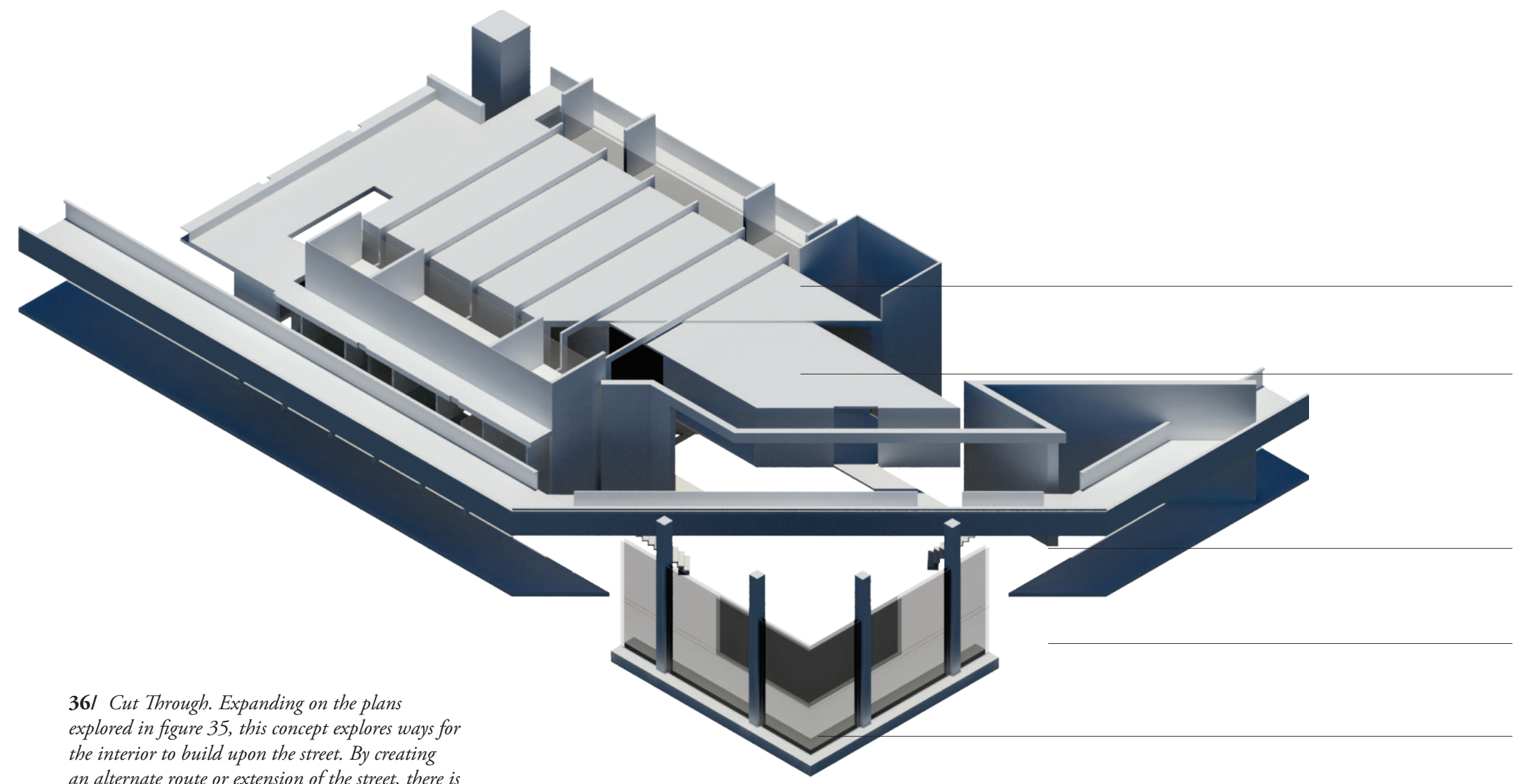

Small public service offices complement the

auditorium.

Central community auditorium.

Exterior hallway attached to facade.

Courtyard.

Notice board.

an increase in accidental inhabitation of the built

form. The programme is a community centre, so

opening the building provides transparency between

residents. It was evident pragmatically to offer

a community space with outdoor interior space.

This intervention is not sympathetic to the existing

structure. 


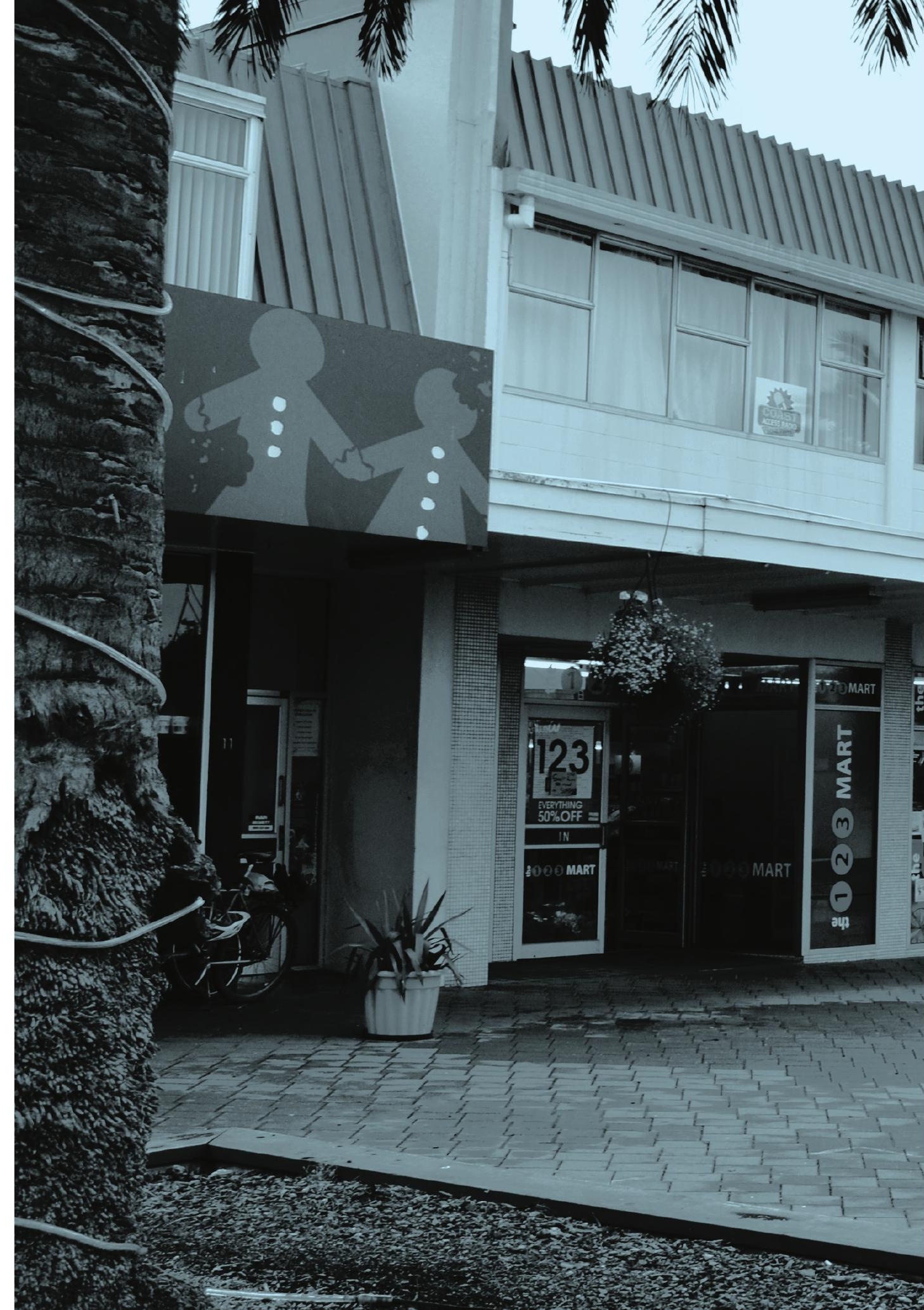




\section{Modernist Architecture}

New Zealand Modernist Buildings, Post World War 2, were primarily small houses and public buildings built by the Ministry of Works (Gatley \& Lima, 2008). The simple utilitarian style meant public buildings could be adaptable and have open structures. The Parker Building, along with other provincial modernist buildings (fig 38-43), conform into these non-decorative and flexible ideals, hence it is appropriate for this research.

38/ Maori Battalion Memorial Hall, Palmerston North, 1964. Designed by John Scott, this could been seen as a contemporary marae, bringing together Maori and Pakeha. This highlights cultural influence on Modernism.

39/ Government Precinct, Nelson, 1973-1974. This pre-stressed concrete building generates the illusion of a floating cube. Angular window openings articulate the simple form.
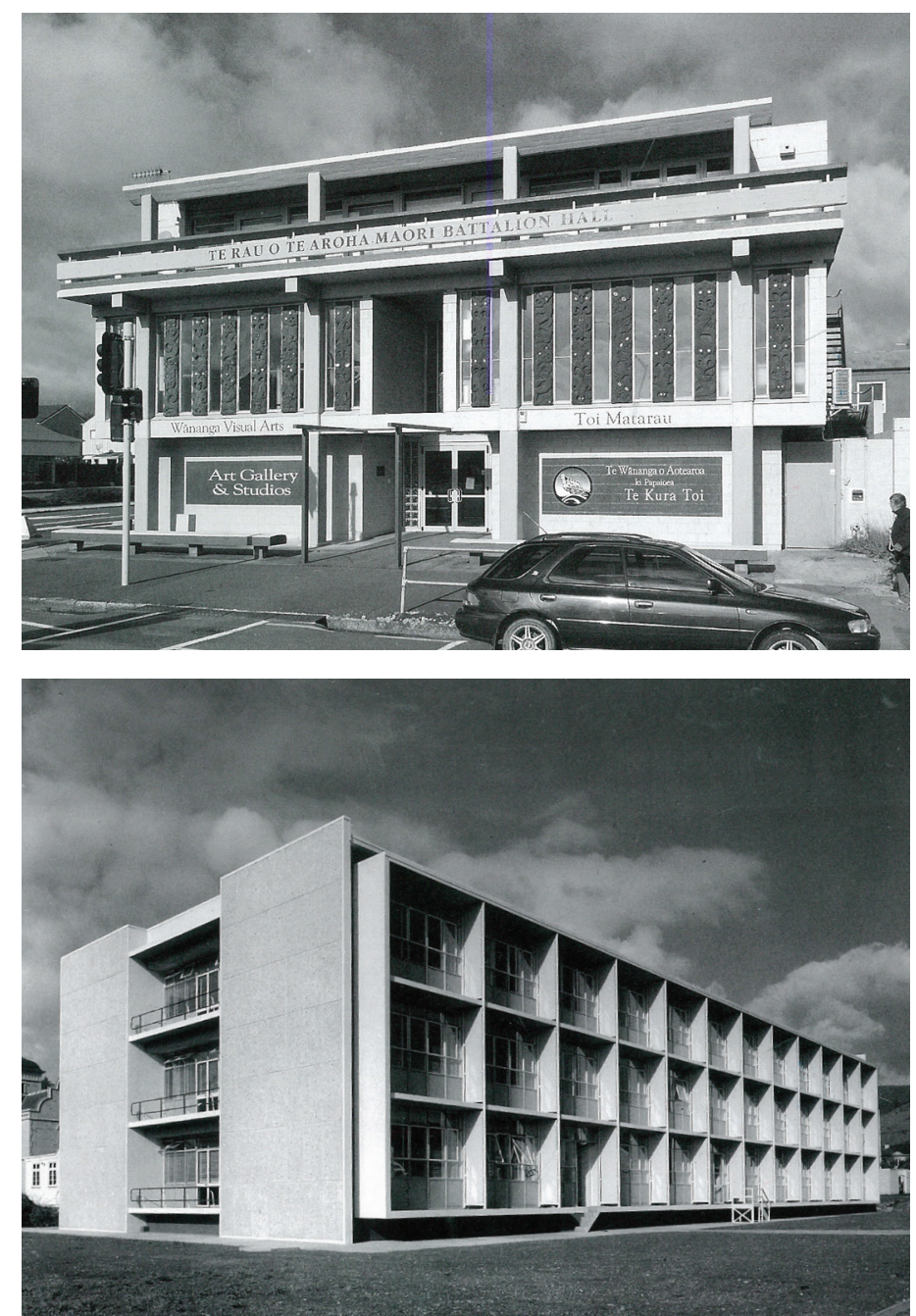

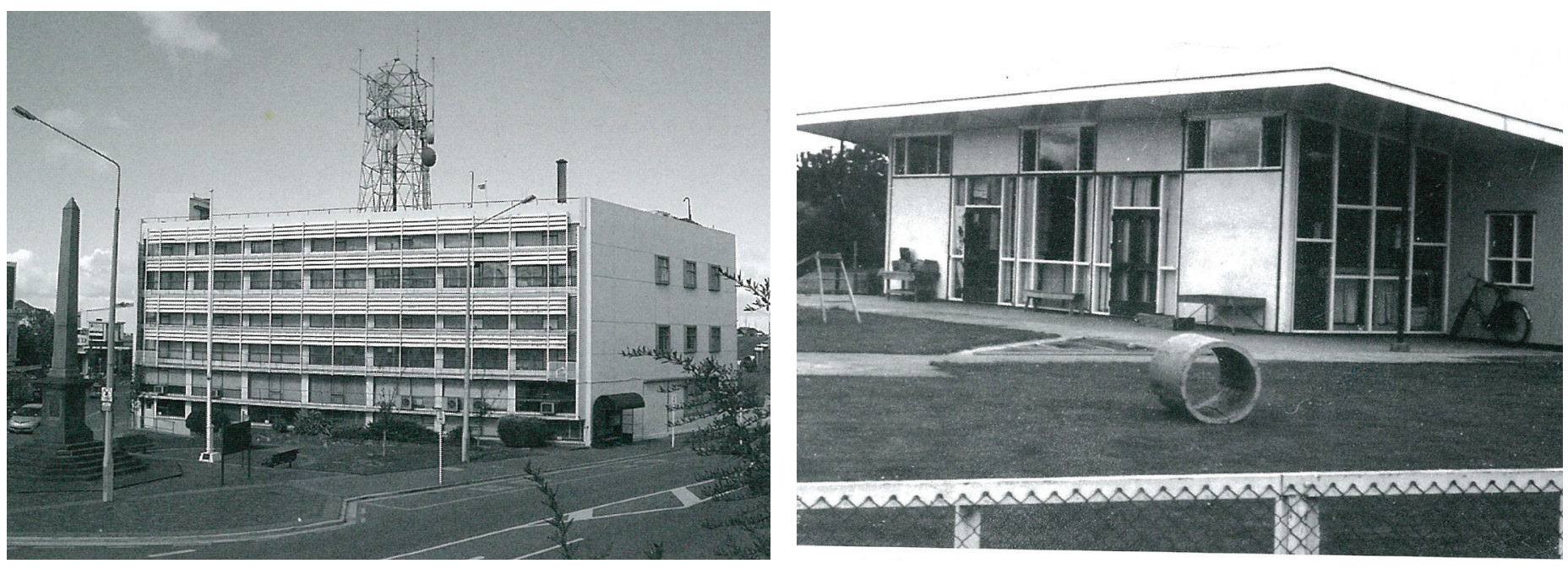

40/ Timaru Telephone Exchange, Timaru, 1957. With a large glass facade the public building becomes open to the township, showing transparency. This open design is offset by solid side elevations.
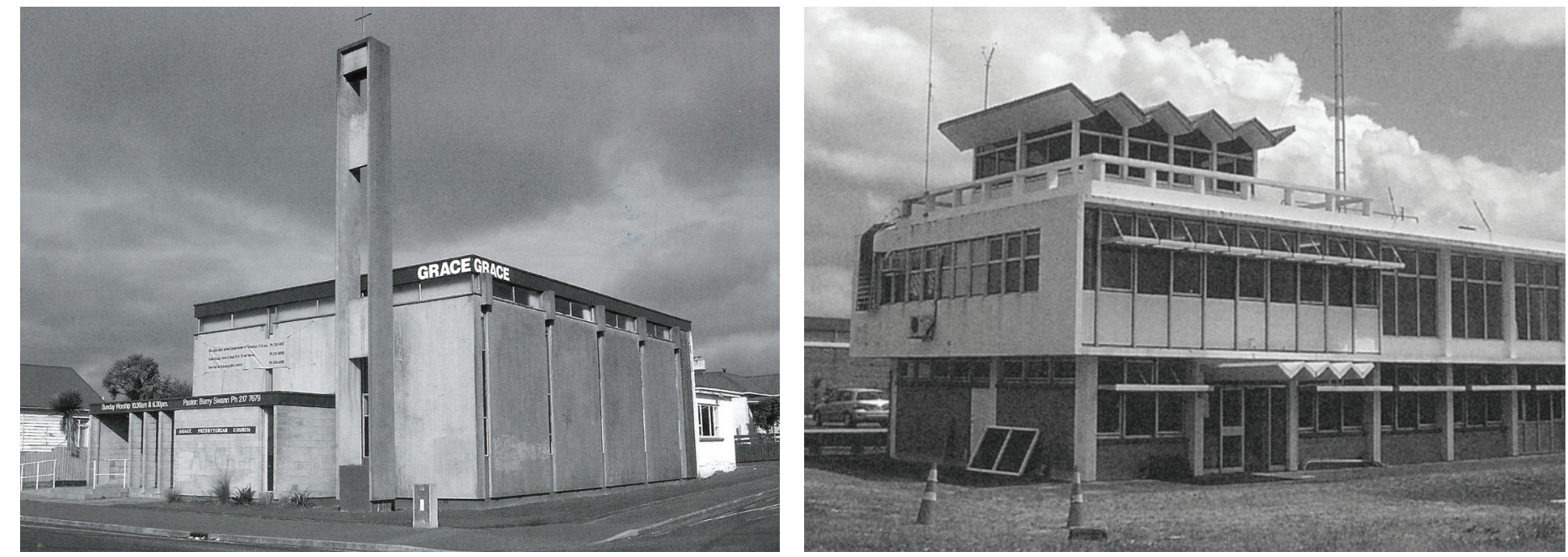

Wever's'- Daniell had infuence over materiality and geometry. The design follows a simple grid with a large overhang to fit with programmatic needs.

42/ Georgetown Baptist Church, Invercargill, 1967. The solid structure is pierced with small openings filled with coloured class. The minimal exterior is offset by a timber and concrete interior, highlighted by coloured light.

43/ Northland Ltd Building, Ruakaka 1962-1973. Influenced by the nautical placement, the modernist architype is reminiscent of a ship. The playful roof offsets the linear forms. 


\section{Built in Furniture}

During the 1940s, modernist architecture was restricted by land, availability of materials and limited funds. The interior of these buildings were designed in fine detail, to perform with maximum function, rebelling from the previous decorative trends. Built in furniture followed this mantra. Storage and ergonomics contrast open space. (Clark, 2000; Hansen, 2013) In 2016, financial constraints are now a widespread issue for many provincial projects (Stockwell, 2009). Through designing a functional piece of temporary interior architecture there is an opportunity to specifically design for function.

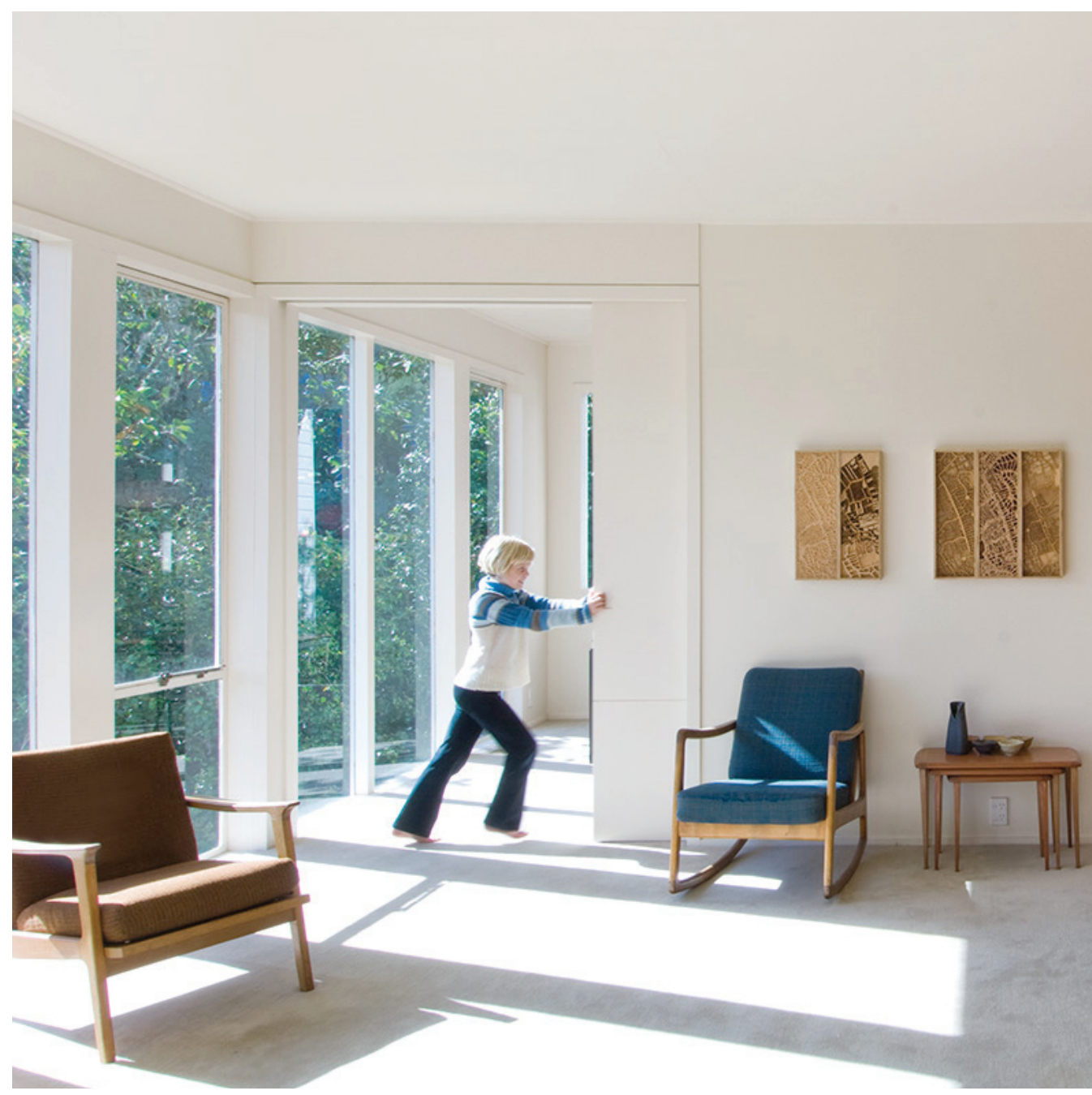

44/ McKenzie House, Cedric Firth. The built in furniture element spreads the entire wall, creating functional space. Storage, shelves', cupboards and drawers, along with a built in sound system offset the open space in the rest of the room. 


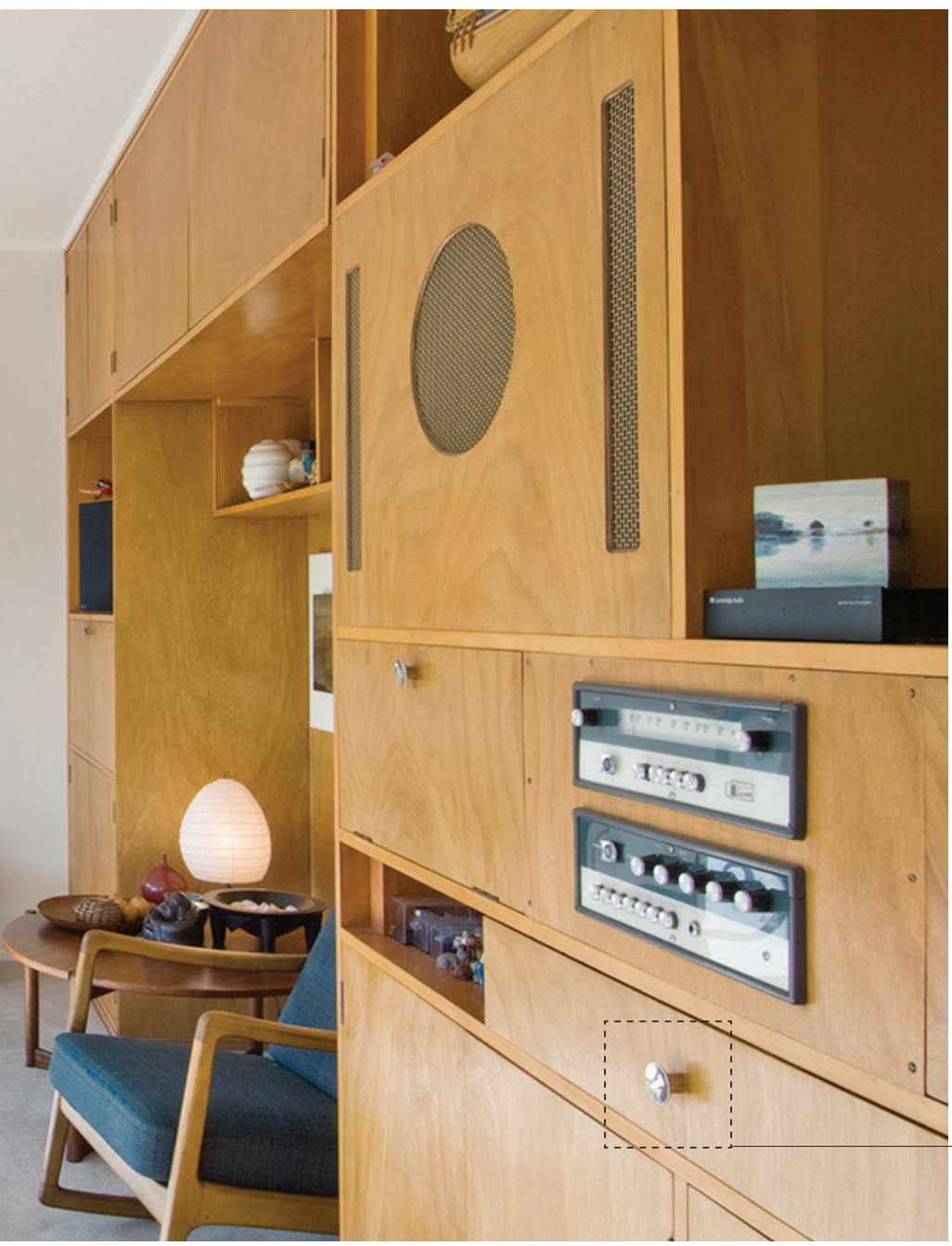

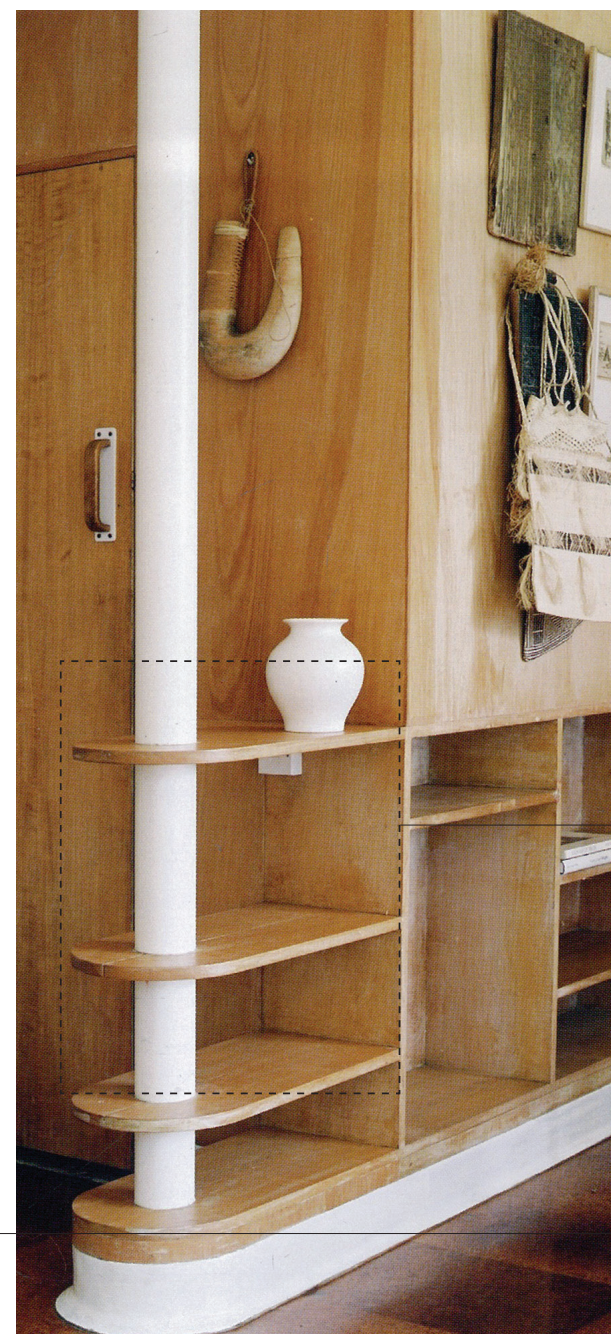

45/ Donner House, Tibor Donner. A section of the wall has been designed with additional function.

Varying sized shelves allow for the need of less stand-alone furniture.

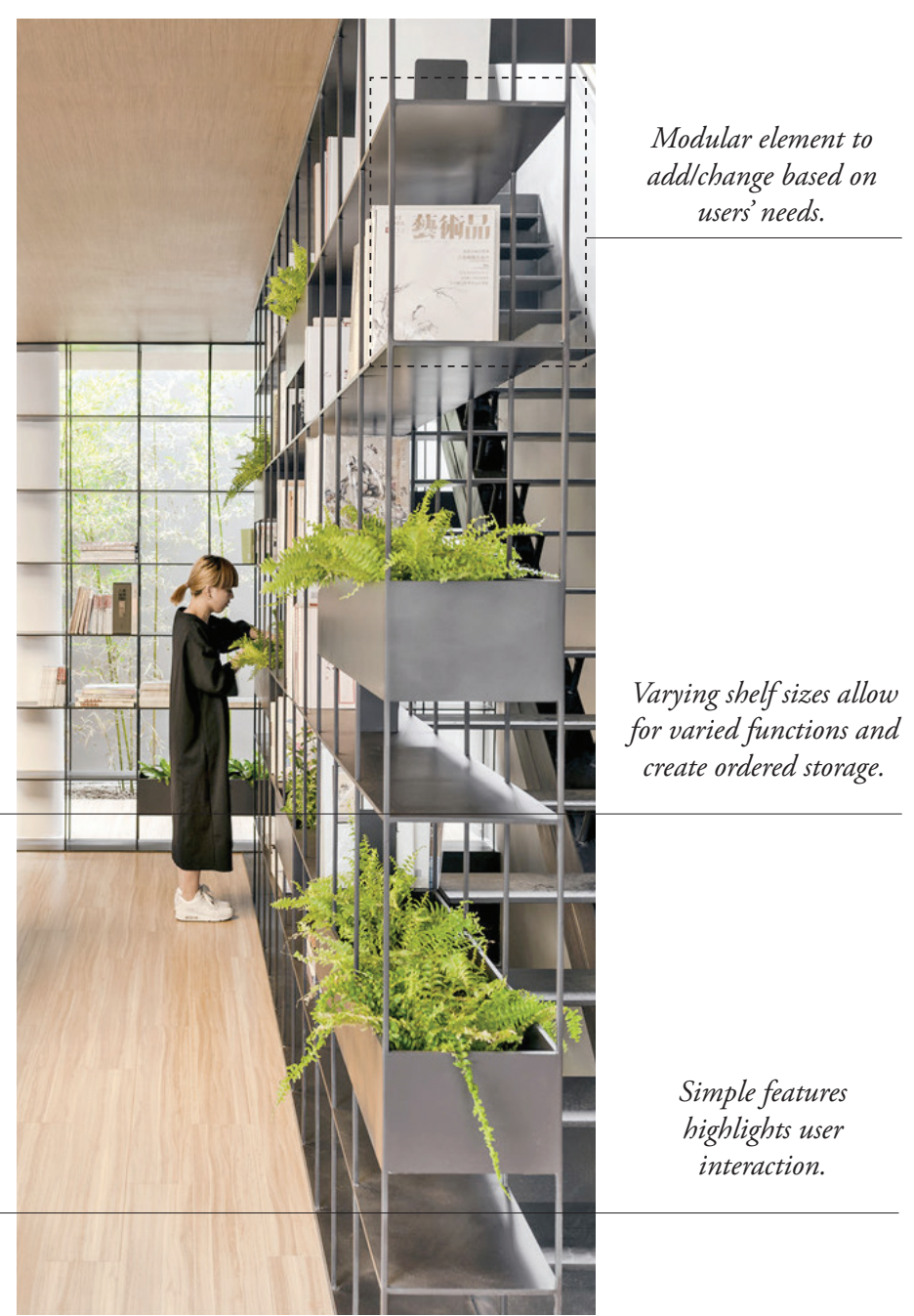

46/ Rong Bao Zhai, Archstudio. Contemporary

built in furniture element offers a solution to circulation and shelving. Hard materials are softened by planting. 


\section{Compacting Programme}

As an experiment, three modular furniture elements were designed to fit into current tenancies using the existing ground floor building layout; a café, kitchen and community meeting space. The space uses modernist principles to concentrate utilities in a single area. Multiple programmes are integrated to achieve a unique environment for the community to foster social interaction, for example, the café with community theatre. Timber frames allow for coherent function across the interventions. The designs question if the solution should be more temporary rather than directly reflecting modernist built in furniture.

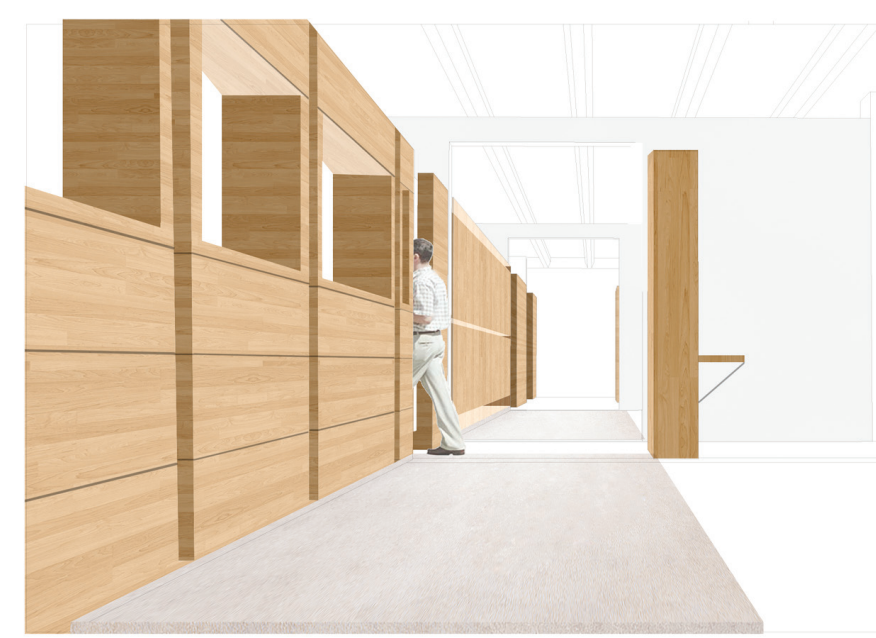

471 Hallway Separation. Hallway space measures

$3 m$, allowing four people to comfortably use the

space. This width allows for slow circulation because

people can linger. 

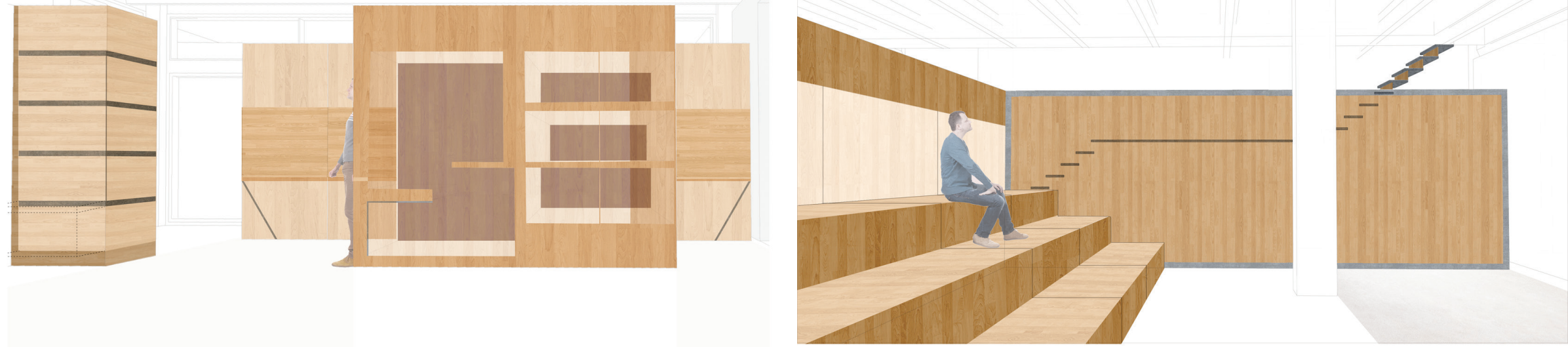

48/ Cafe seating and counter. Café furniture

combines needs of customers, seating, as well as

49/ Community auditorium and meeting space.

Teared seating, which can contract, allows the space

to be used in different ways. Walls around the edge

business needs, counter and cabinetry. The design

offer both storage and visual privacy.

allows for the hallway space to be used as part of the ocialisation. 


\section{Office Built in Furniture}

Compacting Programme was further developed to create first floor interventions. The modular design for a local medical practice and two other offices allow amenities from the area to be located in one building. Maximum storage and function was the aim, while creating private temporary offices.

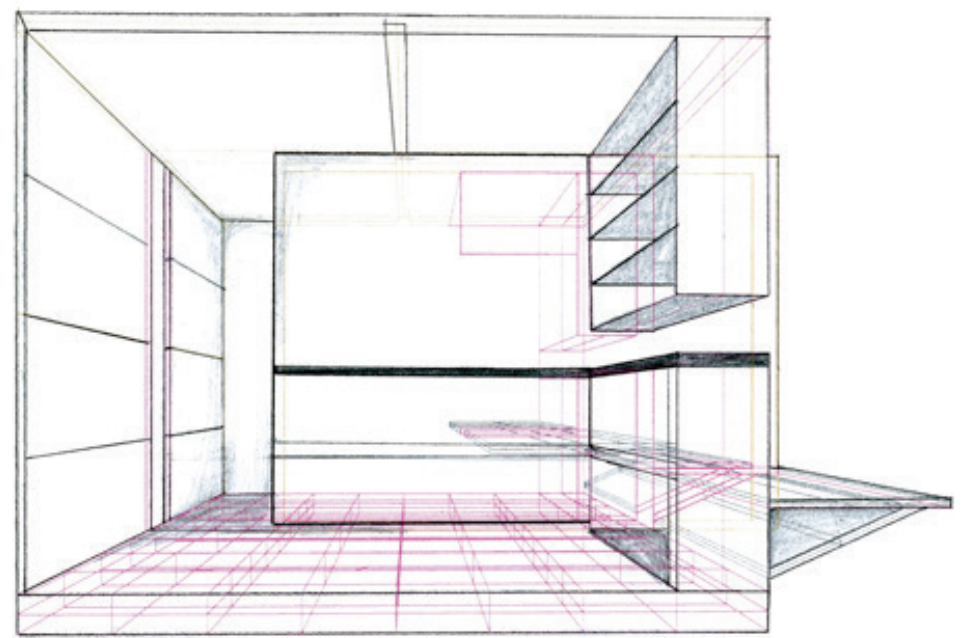

50/ Feeding on from figures 47-49, this built in

furniture offers an inhabitable wall option. The

intervention space is made to be budoet friendly.

using basic timber construction with plywood

sheeting. 


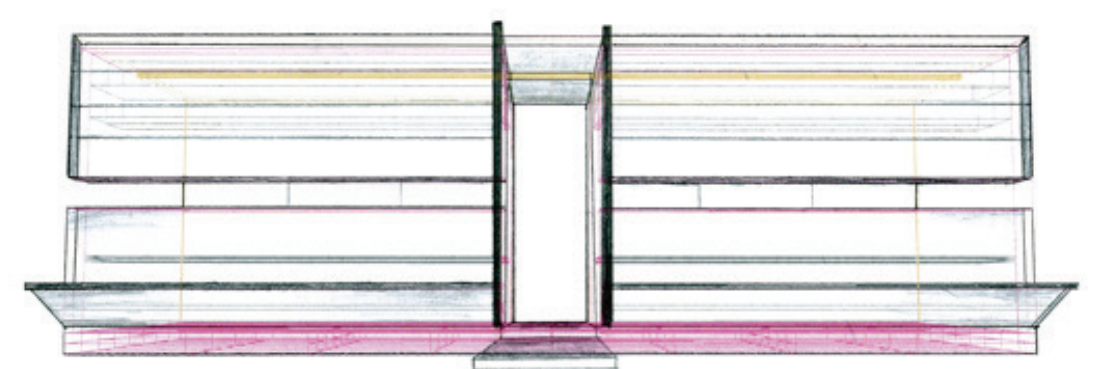

51/ The office elevation combines figures 50 and

52, showing the two wings of office space with a

central entrance hallway. Seating on the front face offers waiting space.

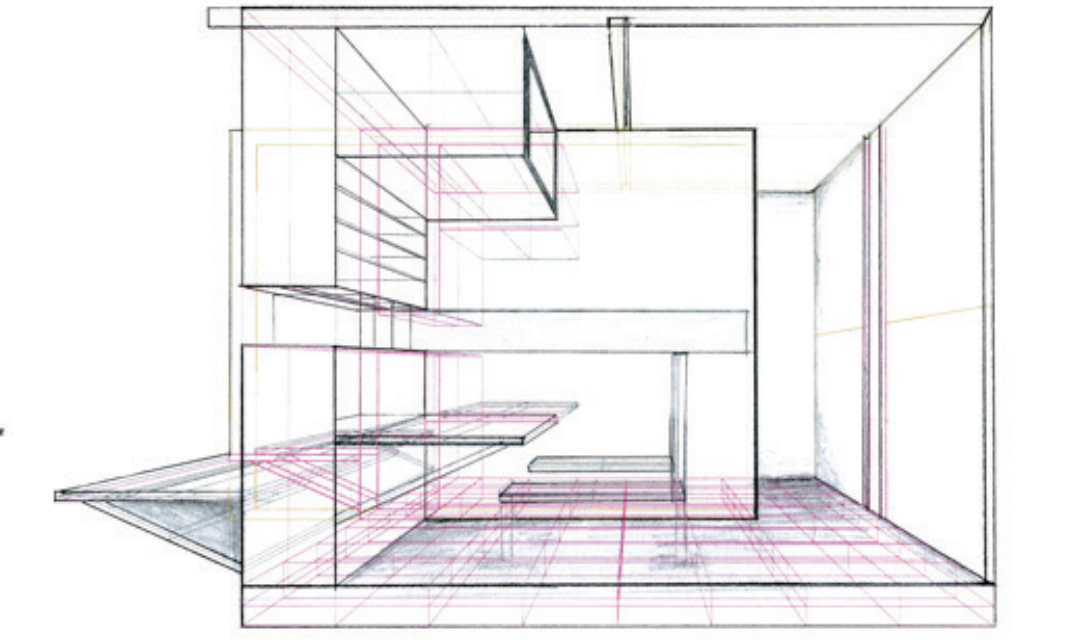

52/ Each office is of open design, where no doors offer complete privacy. However, partitions with

functional storage offer some privacy.

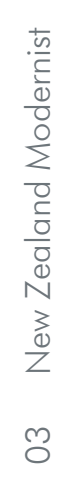



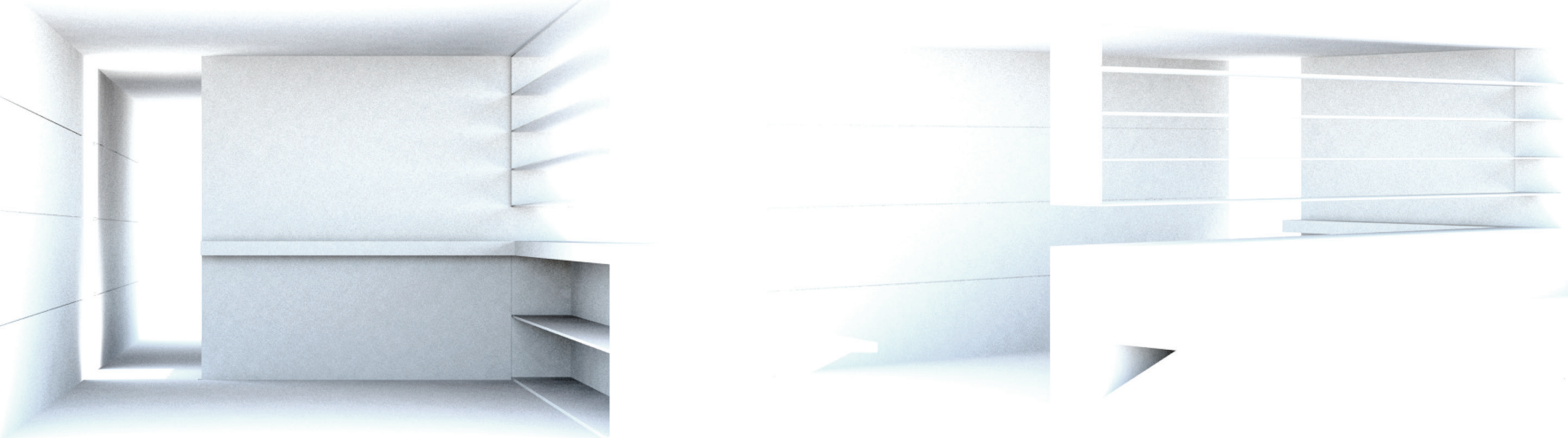

53/ Office space lighting exploration highlights

issues of the design, fig 50-52. The wall and ceiling enclosure created a dark interior. 
54/ Density experiments, figures 47-53 are

combined to offer a design solution for the Parker Building. This raises questions of how the design.

can be influenced by more than modernism.

Contemporary design and preservation techniques

may further the design. 


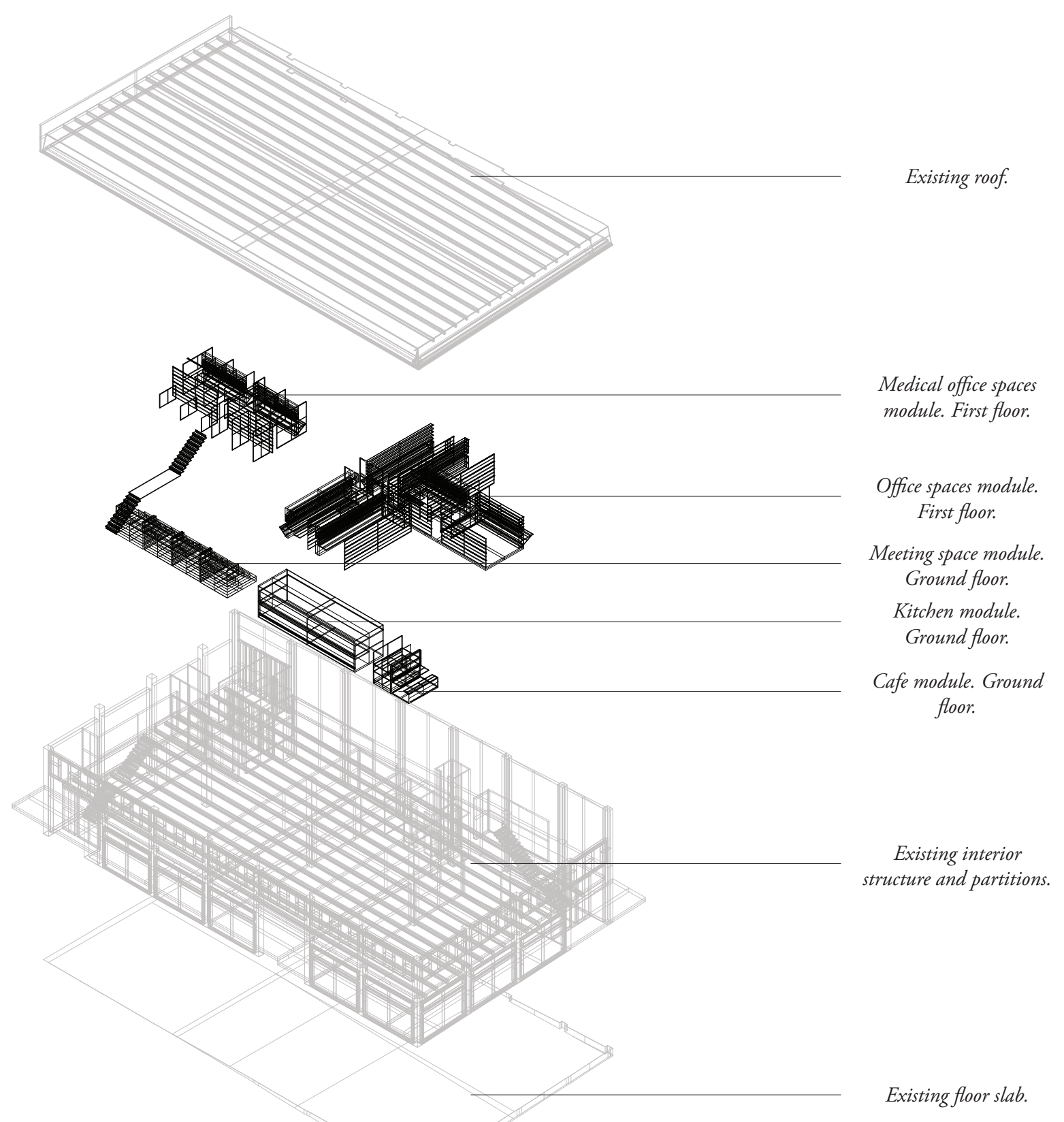




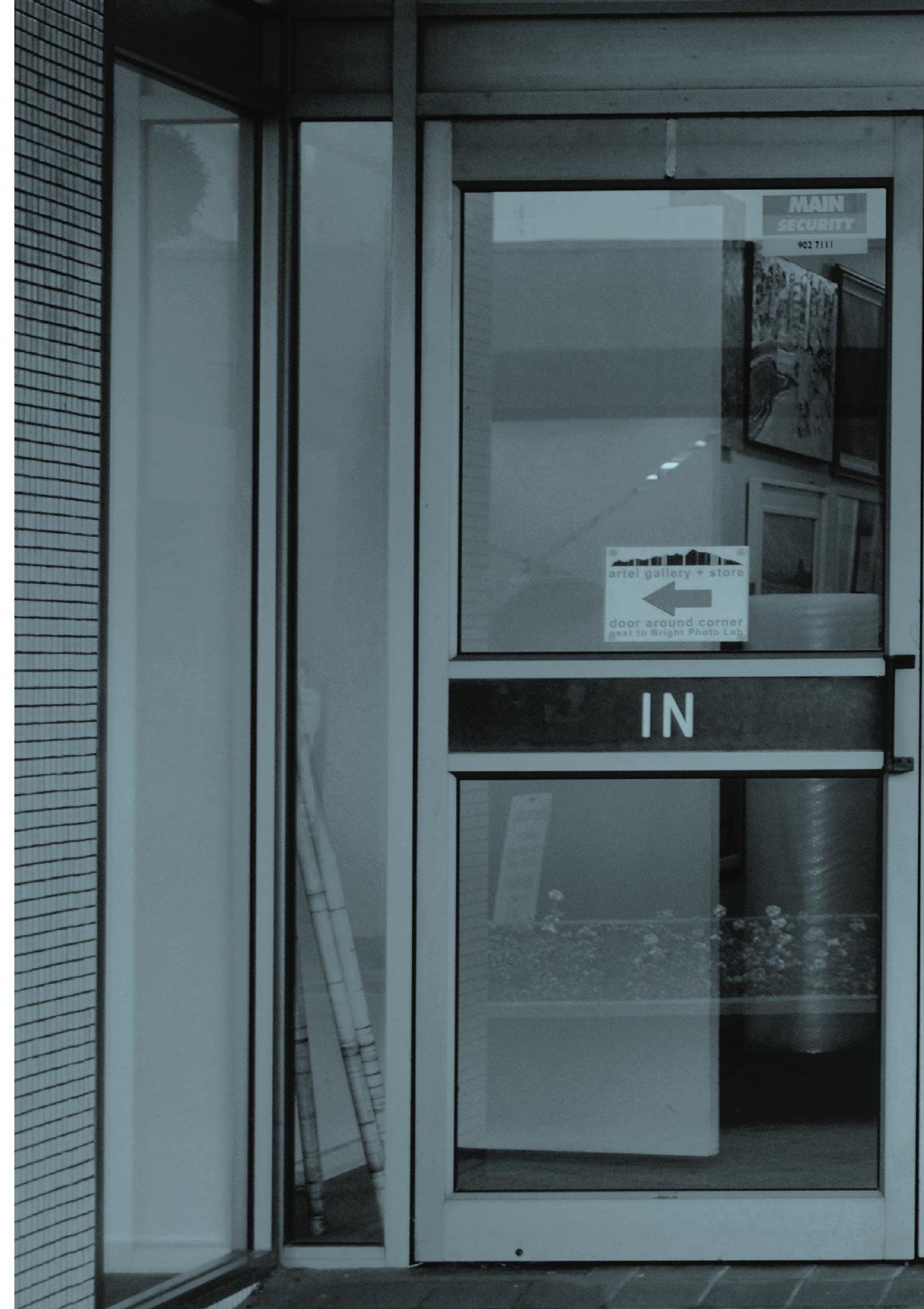




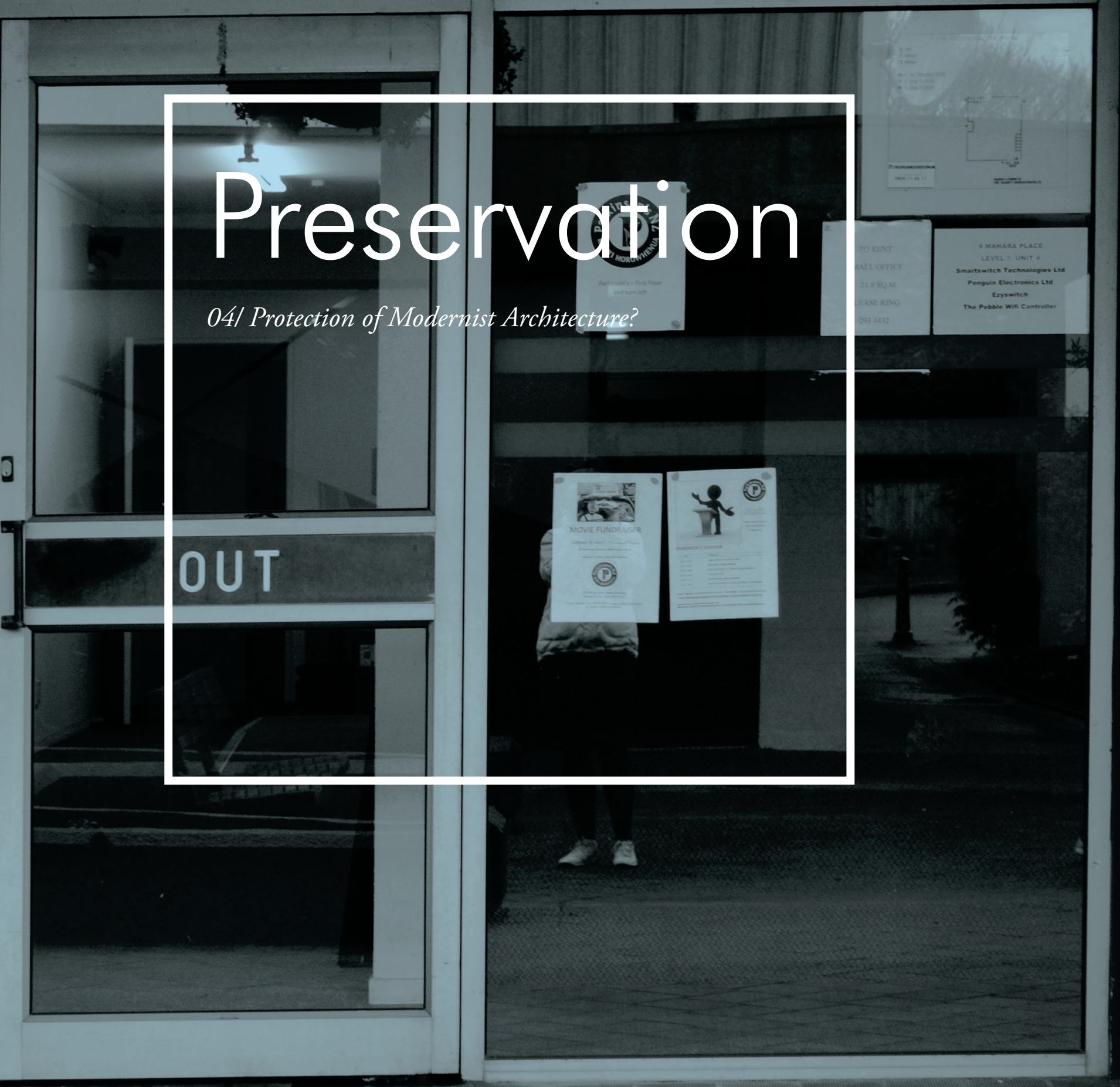

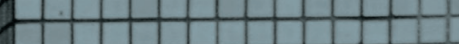
\begin{tabular}{l}
$1+2+2+2$ \\
\hline
\end{tabular}

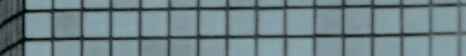
H 200 $1+20+2$ $200+200$ $+2020$ $+200+2$ 200

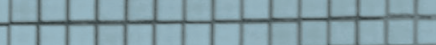
4 - 0000 L

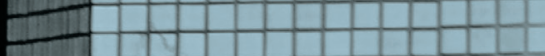

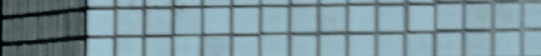

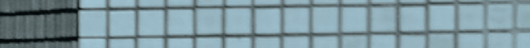
-

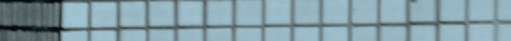
-

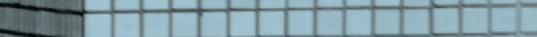
- T

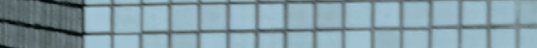
ב-10

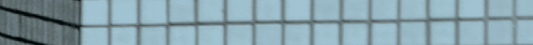

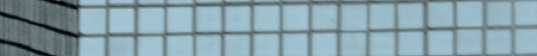

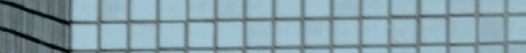

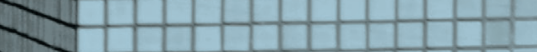

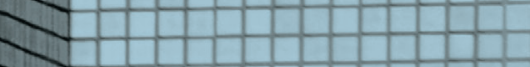
$\begin{array}{lll}2 & -10 & \end{array}$ - 10 H 10 - 10 i 10 2 10 i 1 H 0 M 100 100 $\sqrt{2}+100$ $-1 \mathrm{n}-551$ 


\section{Modernist Conservation}

Modernist buildings and their preservation has been a Modern (2008) raises the following questions: topic of concern since the turn of the century. At this point, many Modernist buildings were over 50 years old and eligible for historic place listings (Vesci, 2005). The preservation of these buildings appears more complex than other examples of historic architecture, because they represent more than an aesthetic and physical materials, but "the ideals and philosophies" of the designer. Modernist architects' creations were about a way of life, simplicity of design elements and languages to embody the social morality and anti-historic ethos (Gatley \& Lima, 2008).

When these buildings need preserving, restoring or renovating does not protect the way of thinking, and respect the initial ideals behind the building. This struggle highlights the need for new and innovative ways to preserve. The use over time and expected life span predicted by the architects were unclear due to new techniques and materials. This questions if repairs, restoration and the turning back of time is the correct solution (Prudon, 2008). Current practice of preserving Modernist Buildings is one of debate. Long Live the

- Should modernist buildings be preserved,

- Or celebrated,

- Or Painted over,

- Or reclad? (Gatley \& Lima, 2008)

"There was, and often still is, the additional problem that many members of the public have difficulty understanding and appreciating the heritage value of the modern, sometimes struggling with the very idea that modern architecture might be considered to have heritage values."

(Gatley \& Lima, 2008) 
DOCOMOMO, Documentation and Conservation However, the thesis research takes a different stance of buildings, sites and neighbourhoods of the Modern on preservation - reactivation rather than restoration. Movement, highlights the need to raise public awareness The aim was to find a design solution which doesn't and recognition of historic value. The significance of a merely reinstate the original appearance, structure and Modernist Building is assessed upon chronology, building aesthetic of the building, which The Venice Charter type, scale, location, architect, architectural design ideas, and DOCOMOMO advocate. Instead it aims to find construction method and material palette ('Docomomo', ways that Modernist Buildings could, again, become n.d.; Gatley \& Lima, 2008). Similarly, The Venice an integral part of our built fabric, functioning in a Charter, adopted by the International Charter for the contemporary way.

Conservation and Restoration of Monuments and Sites,

highlights the "common responsibility to safeguard them Some argue that a building's preservation can be restricted for future generations" (ICOMOS, 1965).

Conservation and preservation guidelines include:

- Not changing layout or decoration of a building

- No new construction, demolition or modification to alter the mass or colour

- All periods of the building must be respected

- Restoration mustn't falsify historic evidence.

(ICOMOS, 1965) due material failure, deferred maintenance, functional and physical obsolesce (Prudon, 2008). Modernist buildings were designed with new construction methods, prefabricated materials and often on constricted budgets, posing the question: was it the architect's intent for the building to last forever? Or due to abandonment is demolition a real solution (Prudon, 2008)?

The method has been to critique, through design, topics and techniques raised in the above theory. These design strategies are: preservation, densities, proximities and layers, activating the edge, circulation and explorations of function. The design aims to create an alternative solution to better address and make use of provincial Modernist Buildings, highlighted throughout the experiments. 
56/ Community Centre CLEC Montreuil / CUT architectures. Located within a community housing development this alteration project rejuvenates the

dilapidated building. The exterior of the 1960's

building has a layer of golden aluminium applied

to the façade. The project shows how small moves

can make maximum change to the appearance of a

building, a face lift.

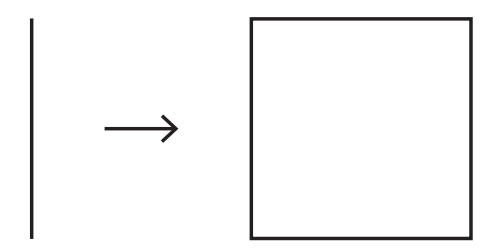

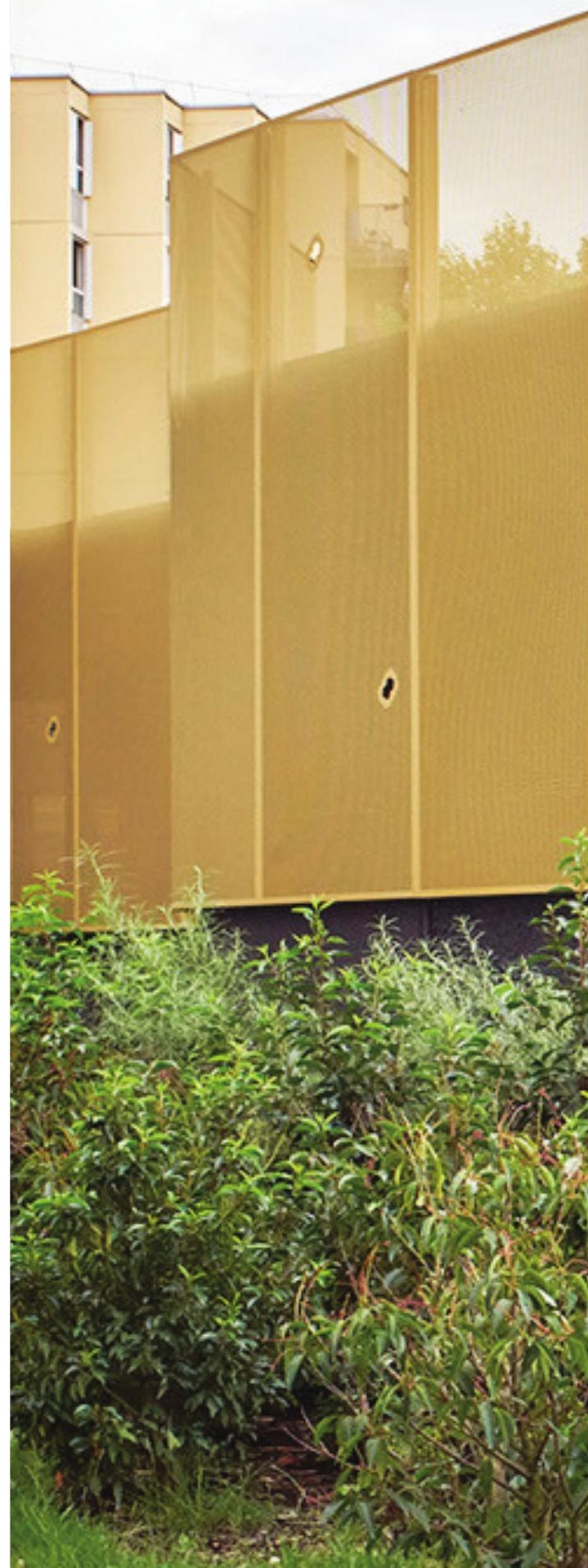




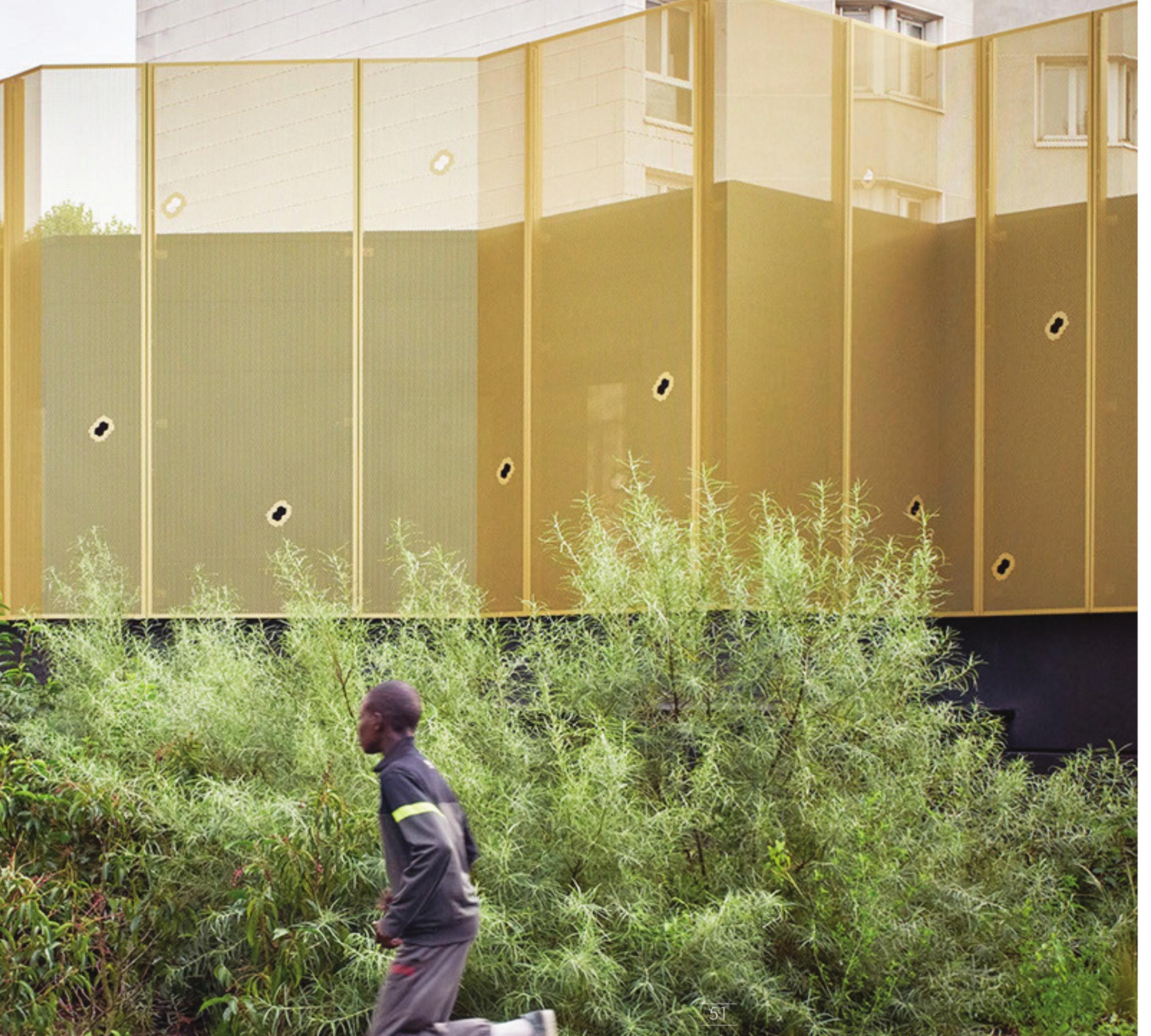


57I Interior Hallway of Layers Diagram. A

of intervention layers. The layers begin to change

the relationships and proximities between different

spaces within the building. The aim is to create

varying levels of transparency between tenants.

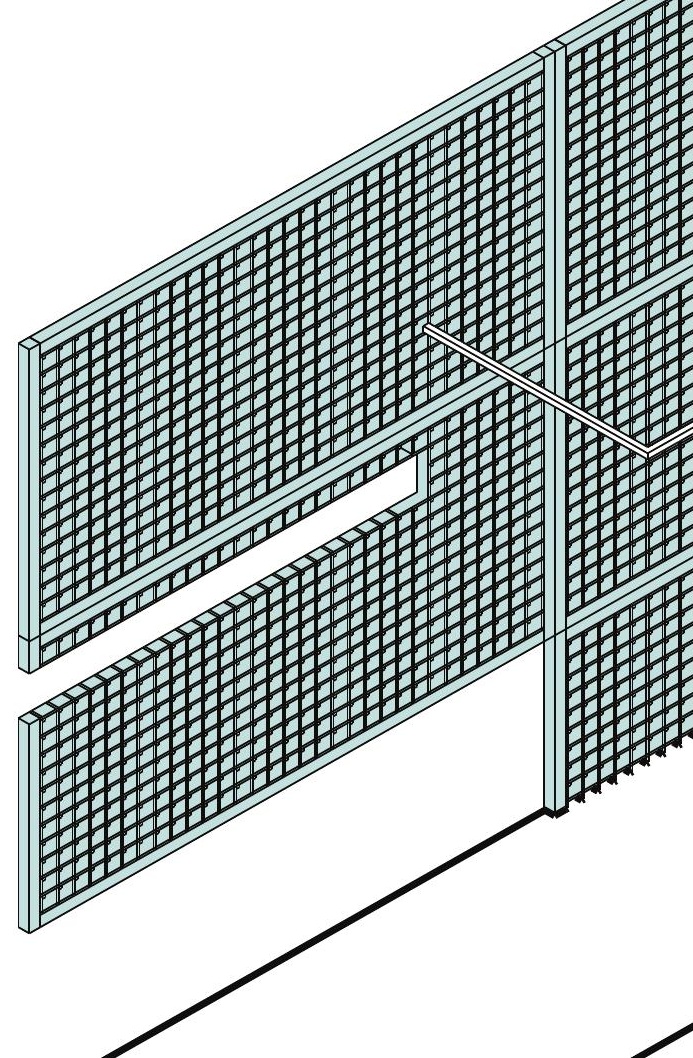




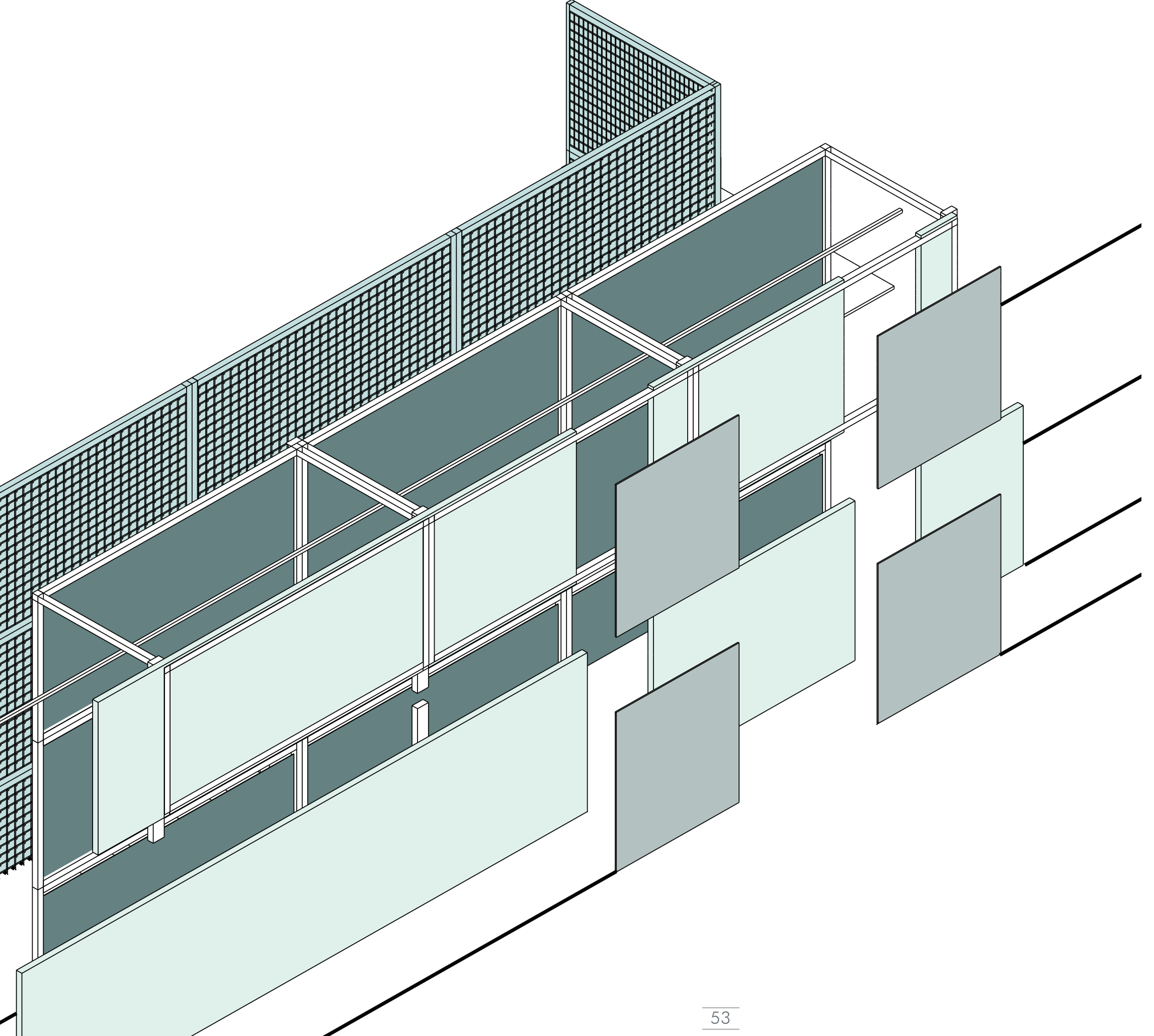


58/ Interior Hallway of Layers. The engagement between the functional interior spaces and the exterior happens through vertical and horizontal

circulation spaces. However, it lacks the delicate and respectful approach that is required with this building

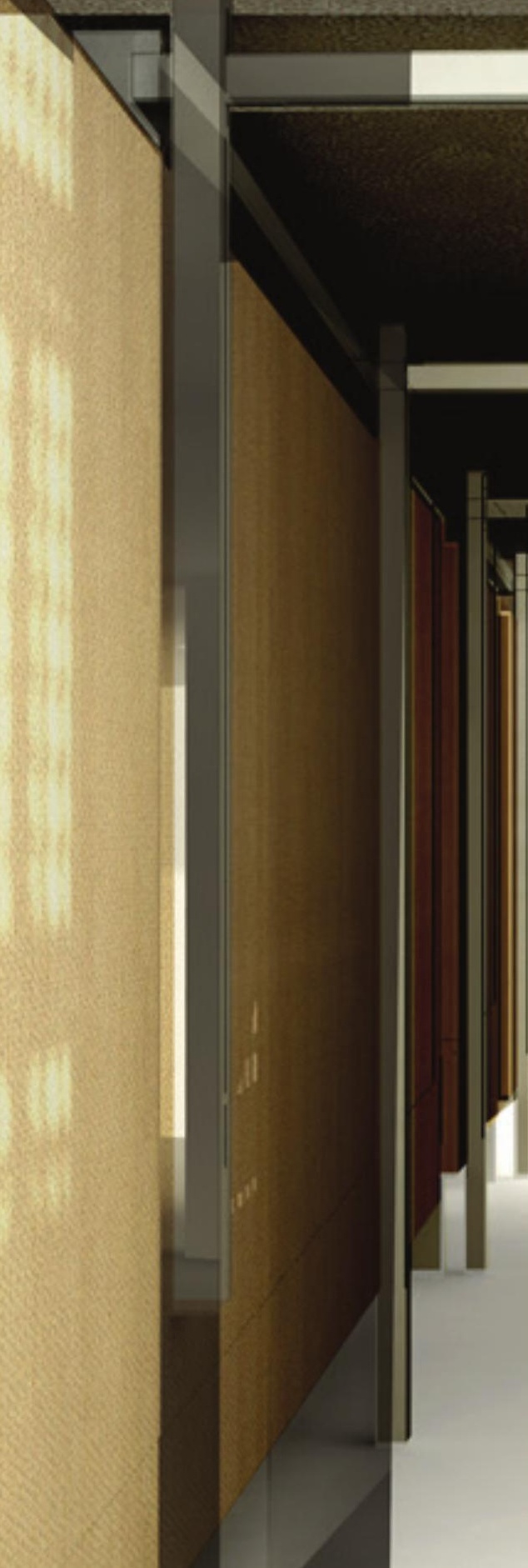



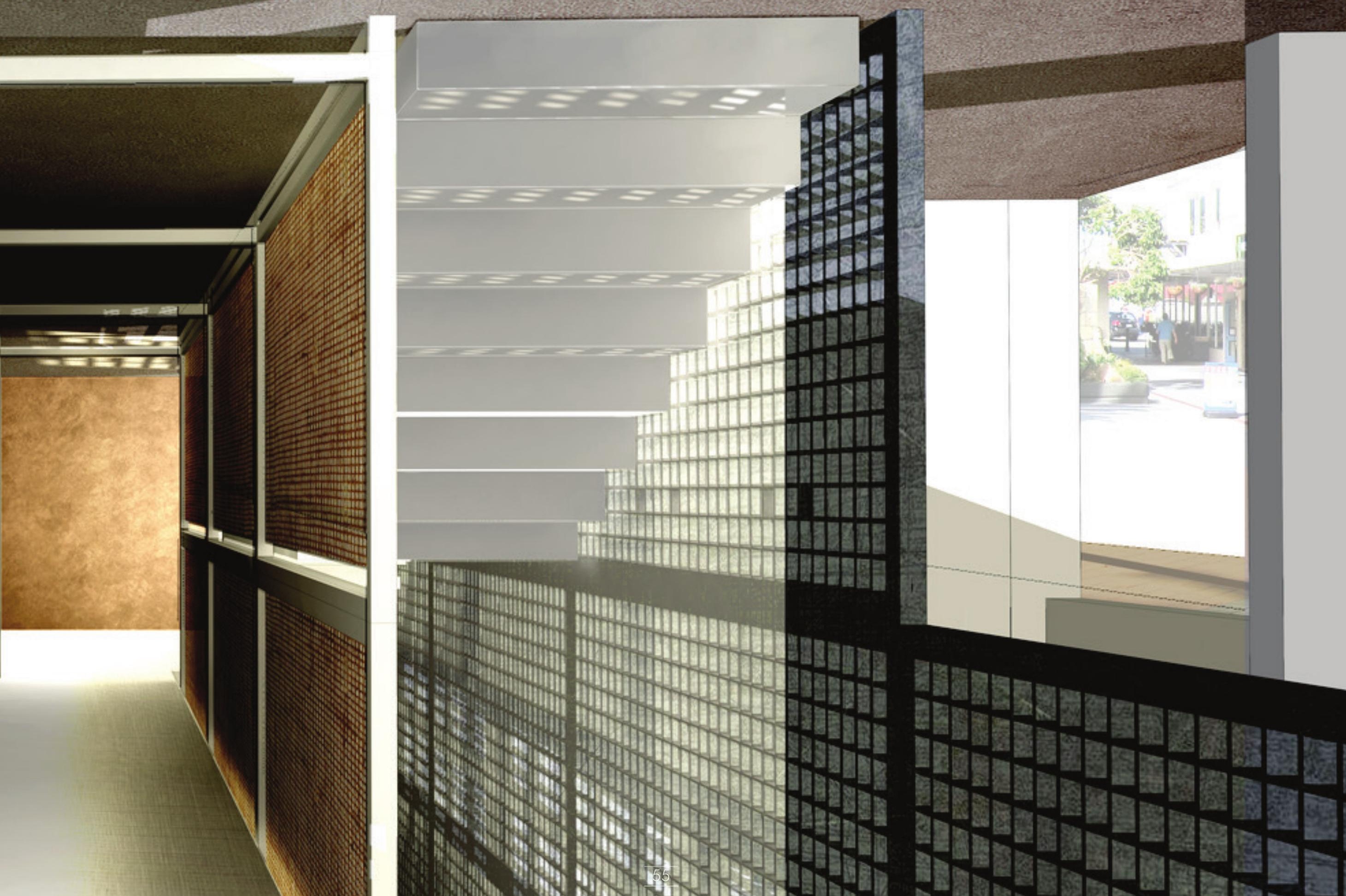


\section{Binary to Blurred}

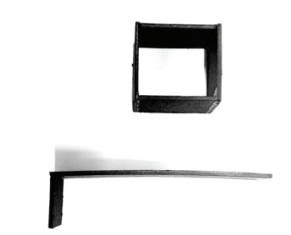

59/ A series of collages informed experiments about

relationships between intervention and existing.

On a scale from binary to blurred, relationships

were explored, with parti models, understanding

how new elements could intervene on an existing

Expanding

Dividing

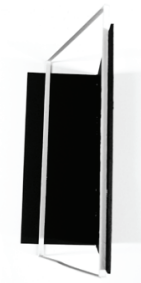

framework. 

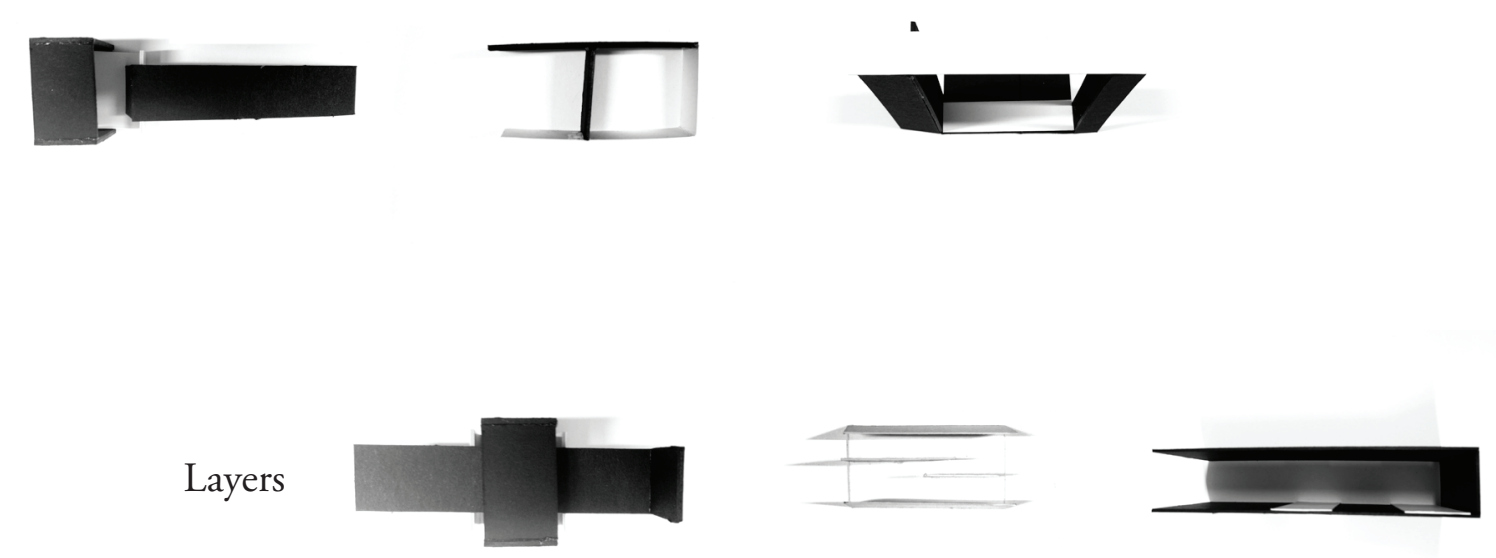

Layers with Depth

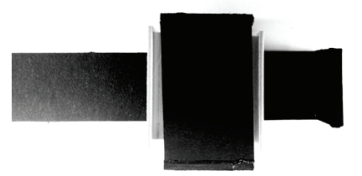

I

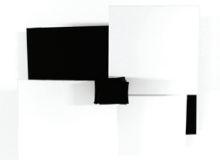

Connecting Layers

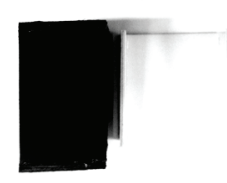

7

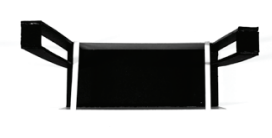

Intertwining Layers
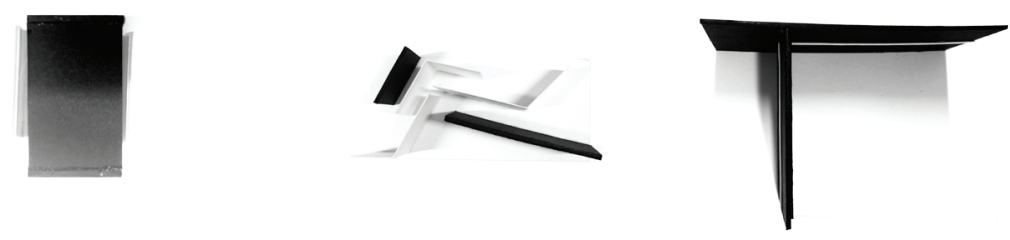
Can people inhabit the façade to create an intermediate threshold between the exterior and interior?
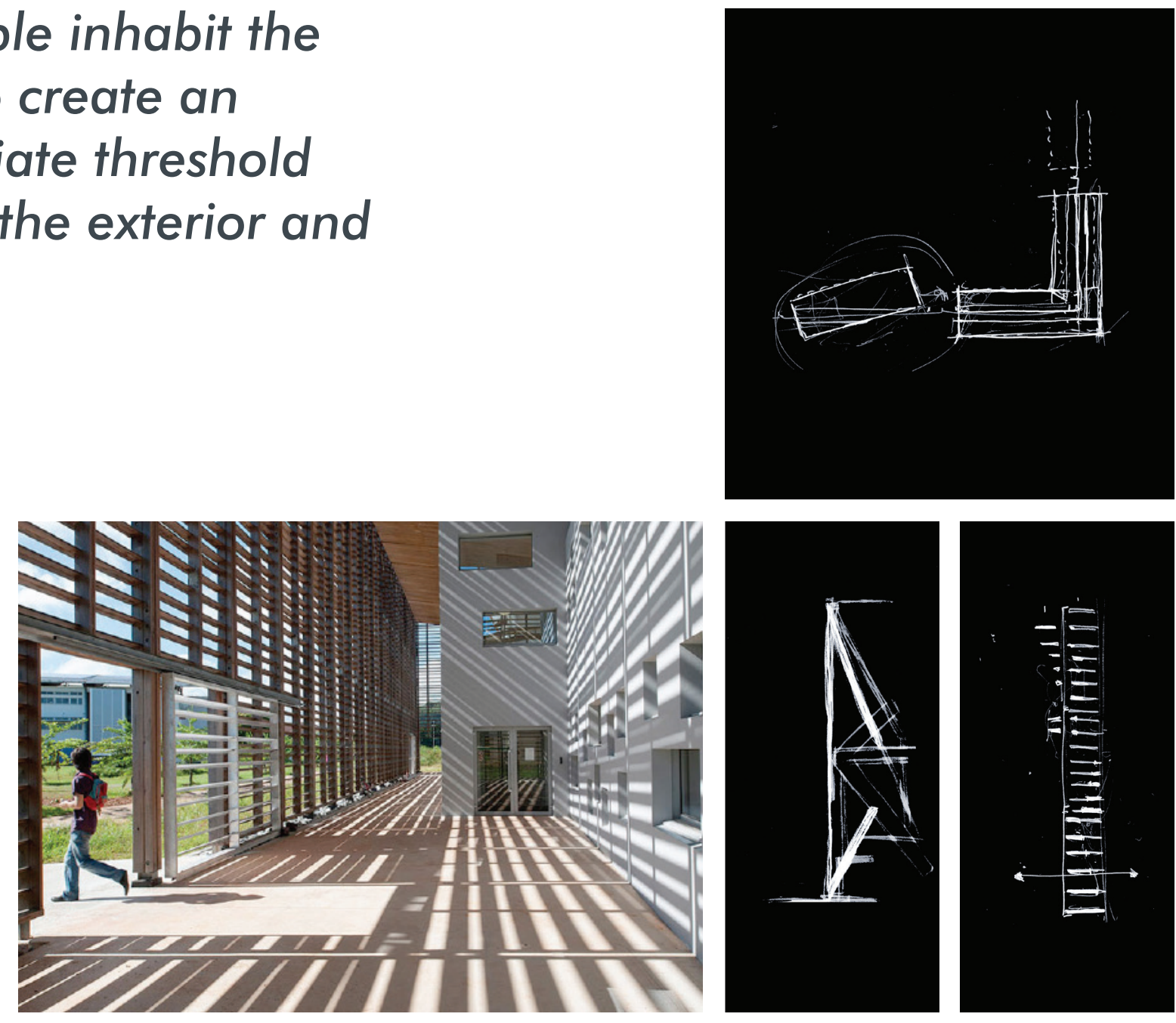

60/ University Library in Cayenne, French

61/ Activating the Edge. Initial facade sketches of Guiana, RH+ Architecture. Architecture is

how the edge could be activated.

enclosed by a timber shell, creating an intermediate

threshold between the interior and exterior. 


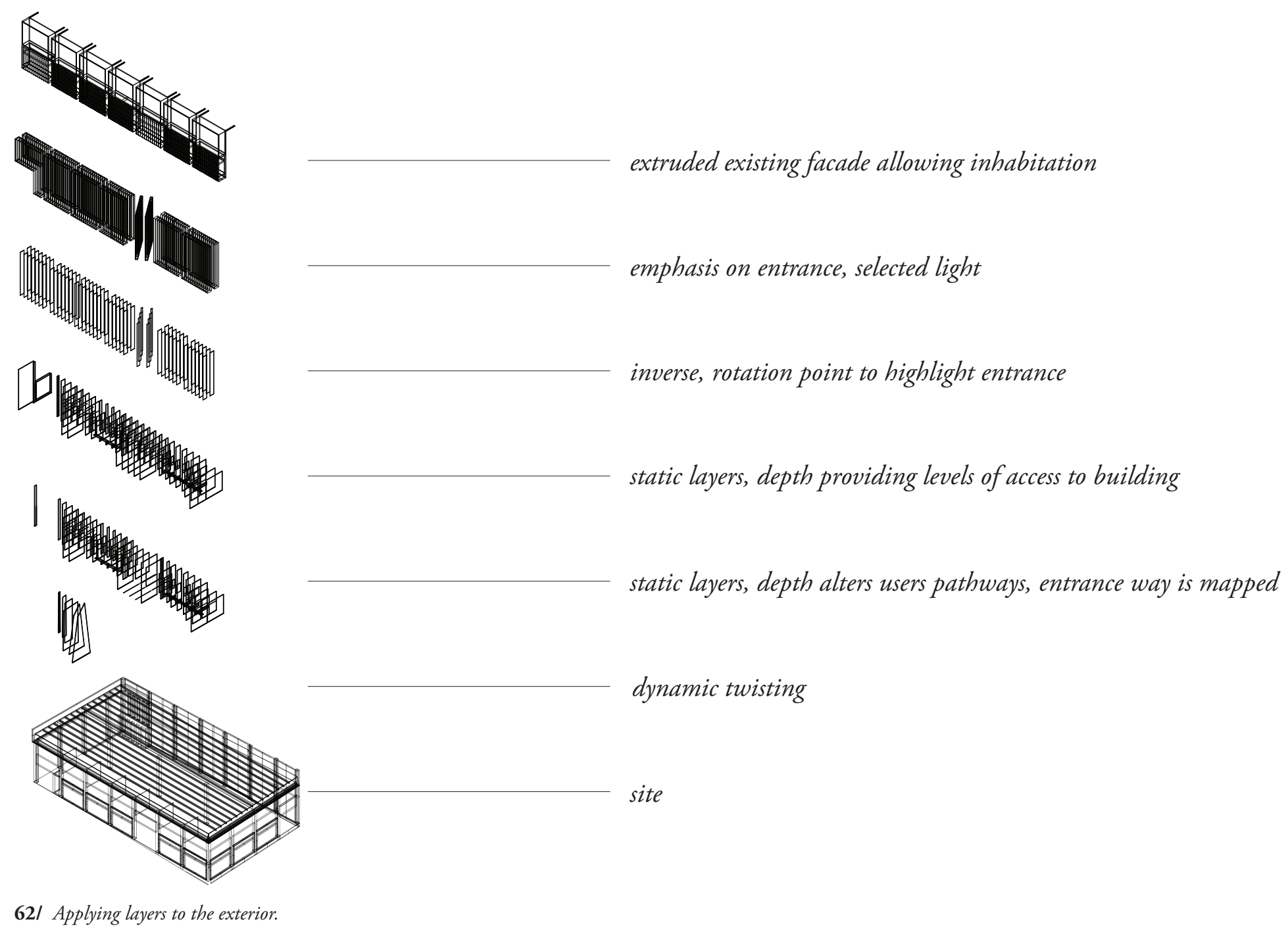


63/ This Façade design activates the face of the

building, giving the external shell interiority. It

also changes atmospheric qualities of the interior.

offering shading from the sun.

$+\quad+$

$x$
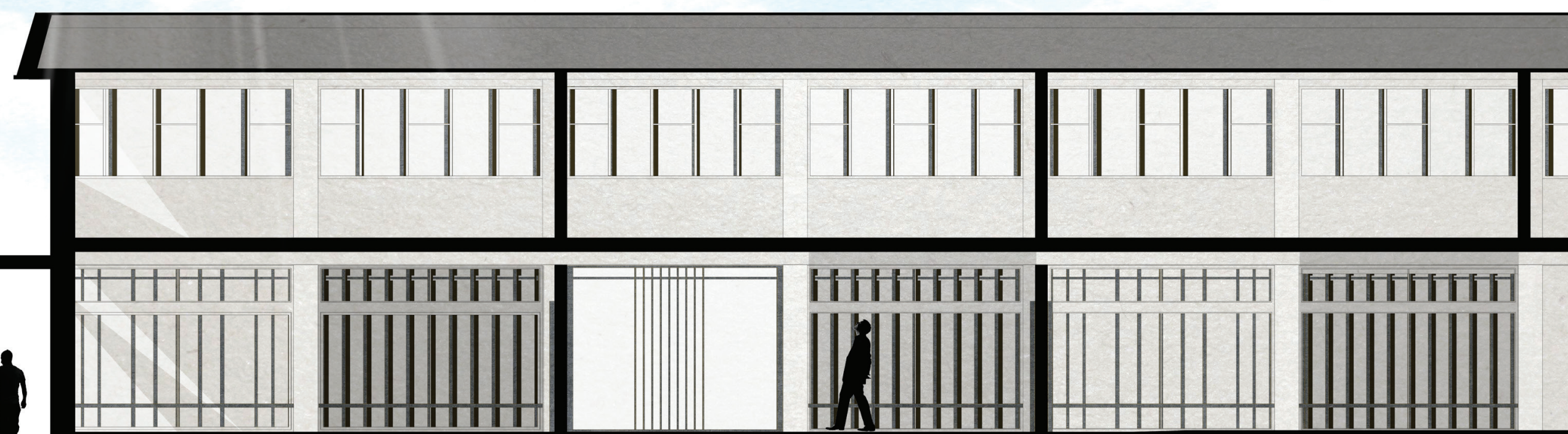


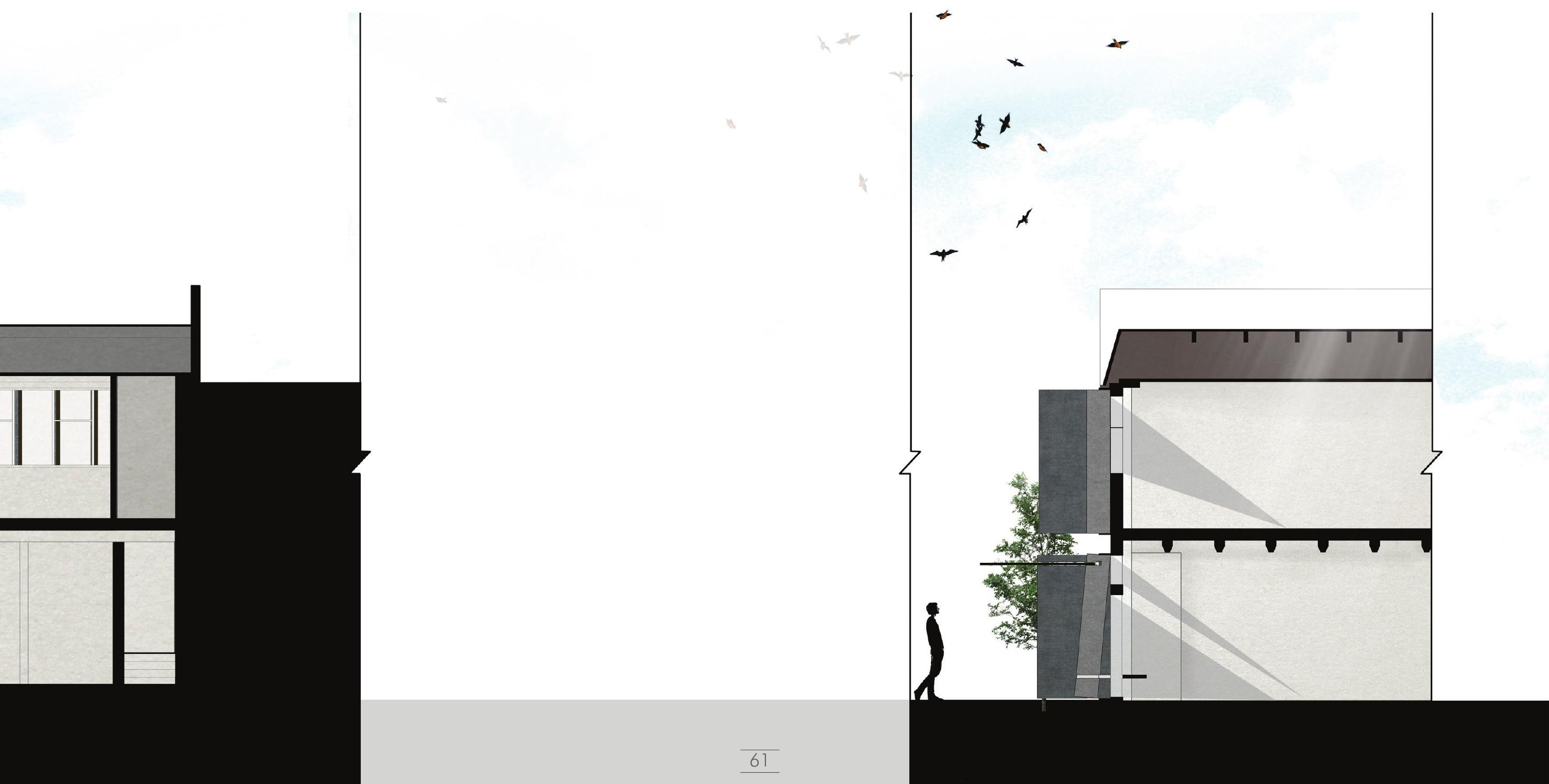


64/ This collage aims to illustrate moments of

activity contrasted with privacy, highlighting

relationships between existing and new

materials. The collage combines the design for the

restaurant, figures 27-23, with possible residential

programming.

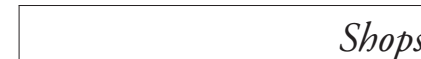

Shops

Apartments
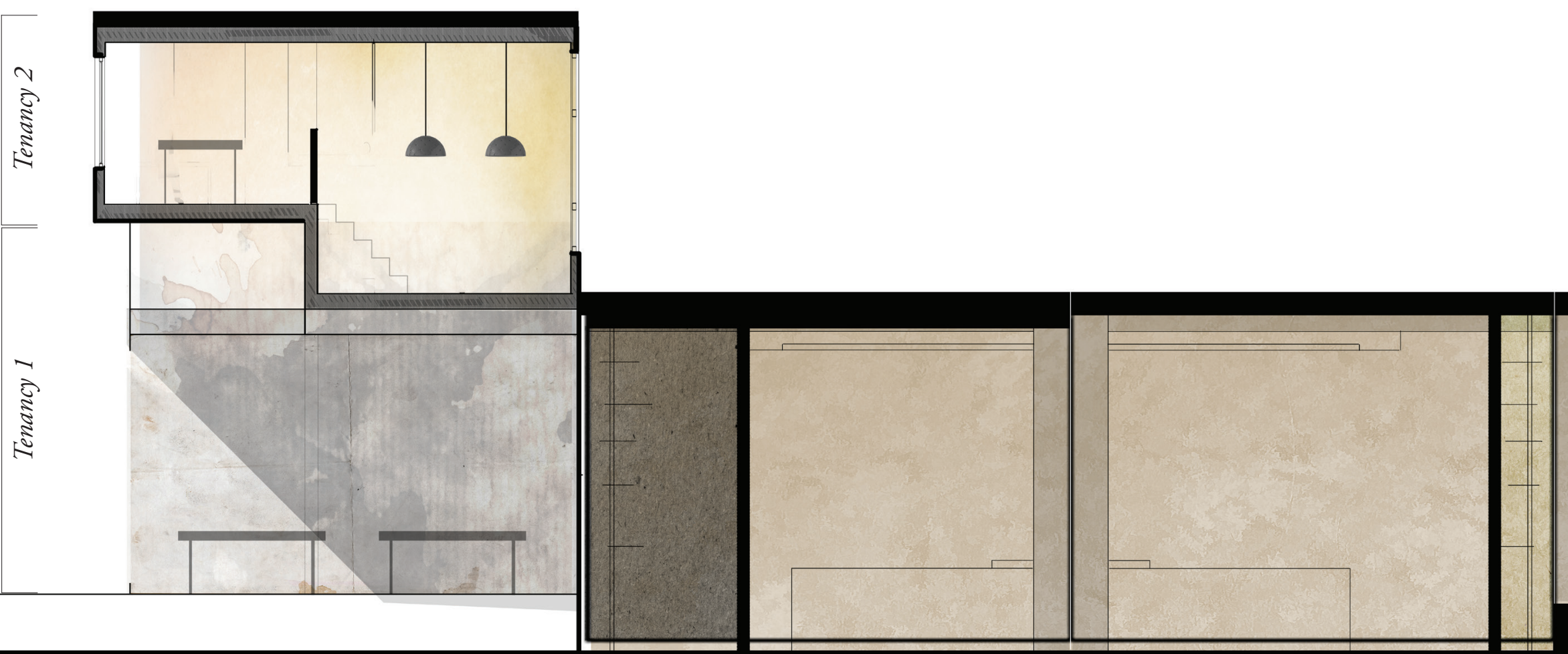


\begin{tabular}{|l|l|l|}
\hline Circulation Social Dining & Private Dining
\end{tabular}

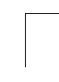

Restaurant

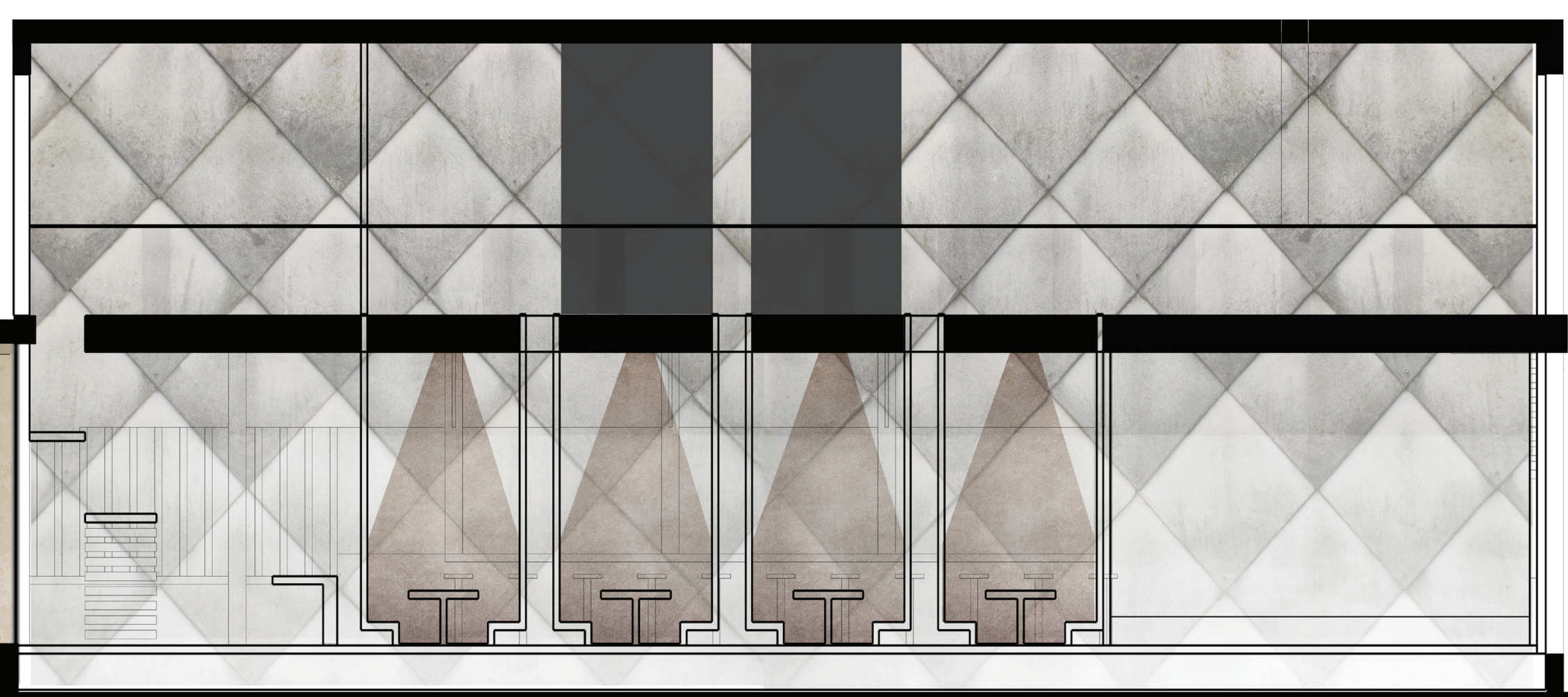




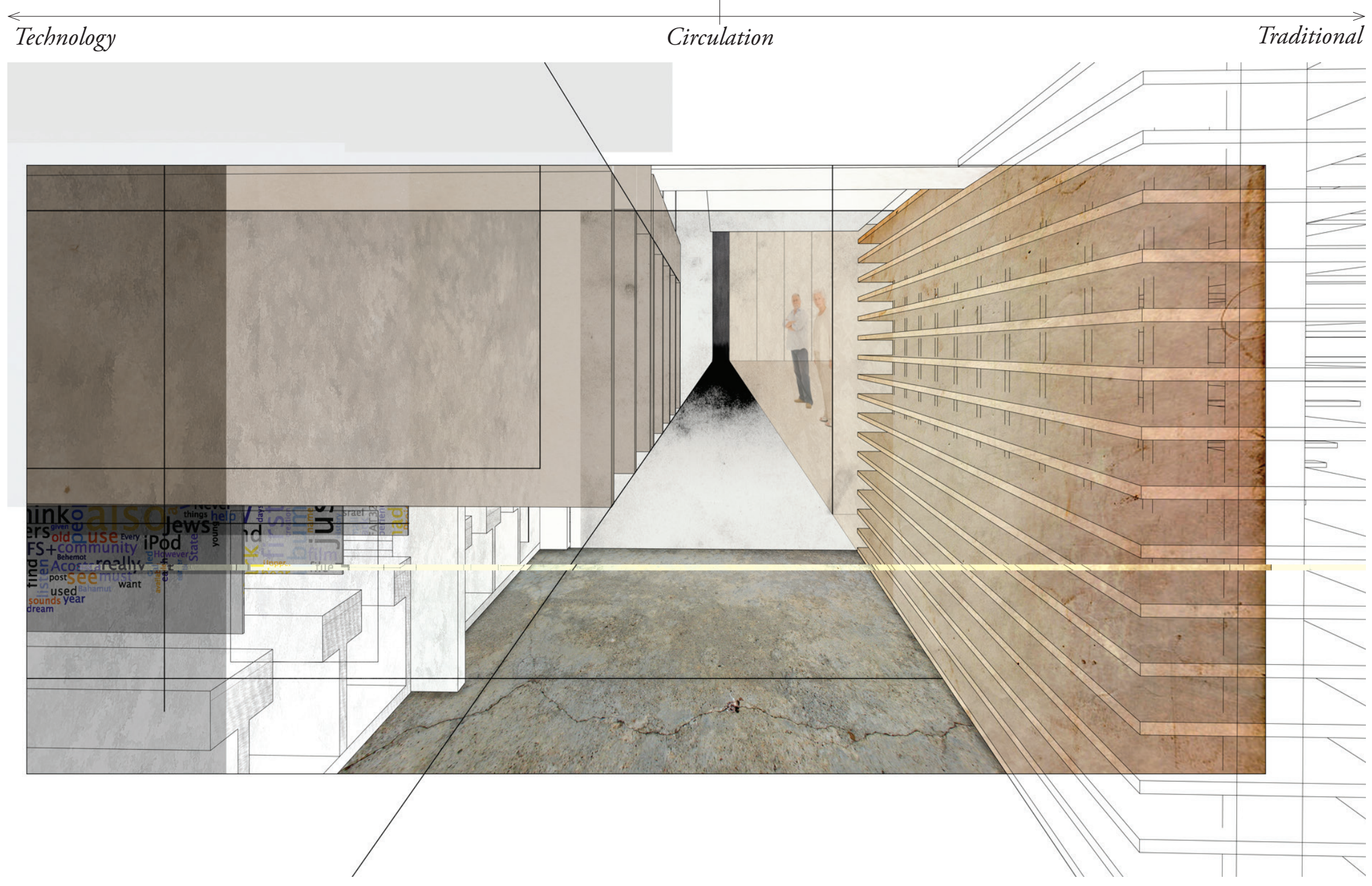

65/ Library atmosphere. Technology zones contrasts

traditional book shelving. 


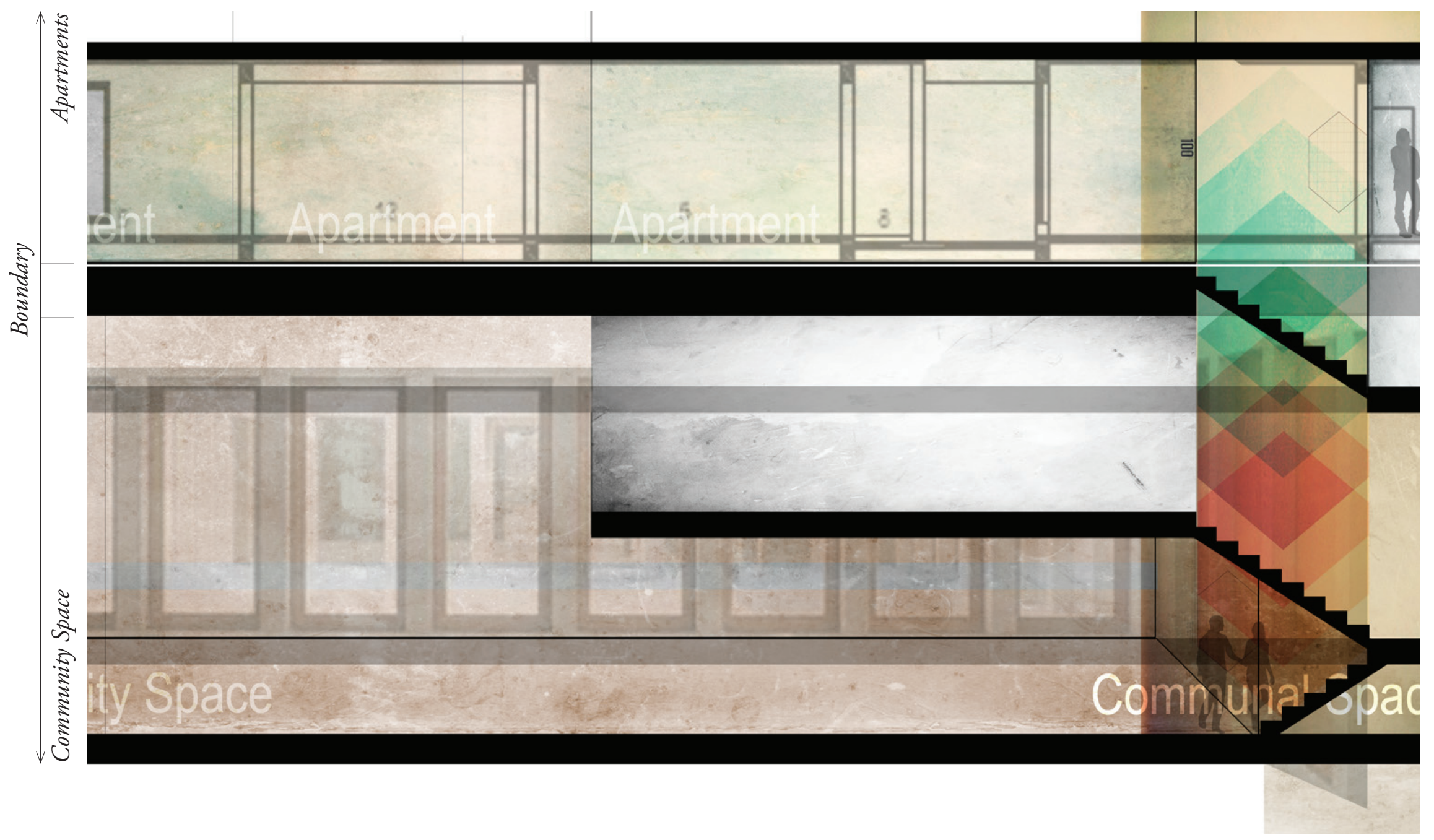

66/ Private and Common. Apartment living is

above community spaces 
67/ Ecology of a Building. This diagram highlights the thinking of the Parker Building as a whole.

When designing for the building, while considering

preservation, the issue of what parts of the building to preservelsave and what could be removed led to a diagram which shows relationships between parts of the building. Through this analysis it became evident that traditionally preserved elements of buildings, for instance, the facade, was also of a more permanent nature. This diagram resulted in designing for the building, rather than for a new programmatic use (fig 83-86). 


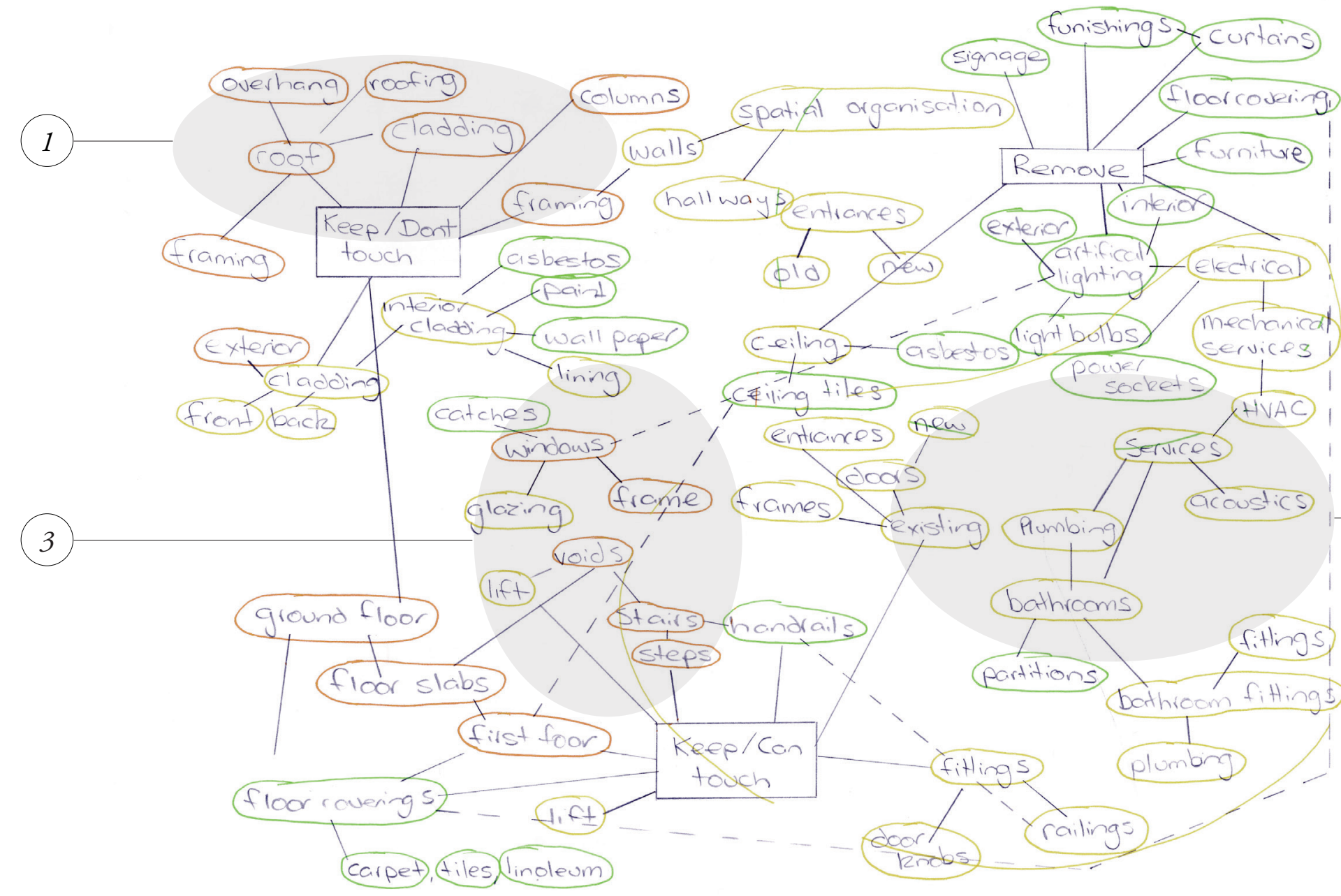

Permanent

Semi Permanent

Temporary 


\section{Existing Materials}

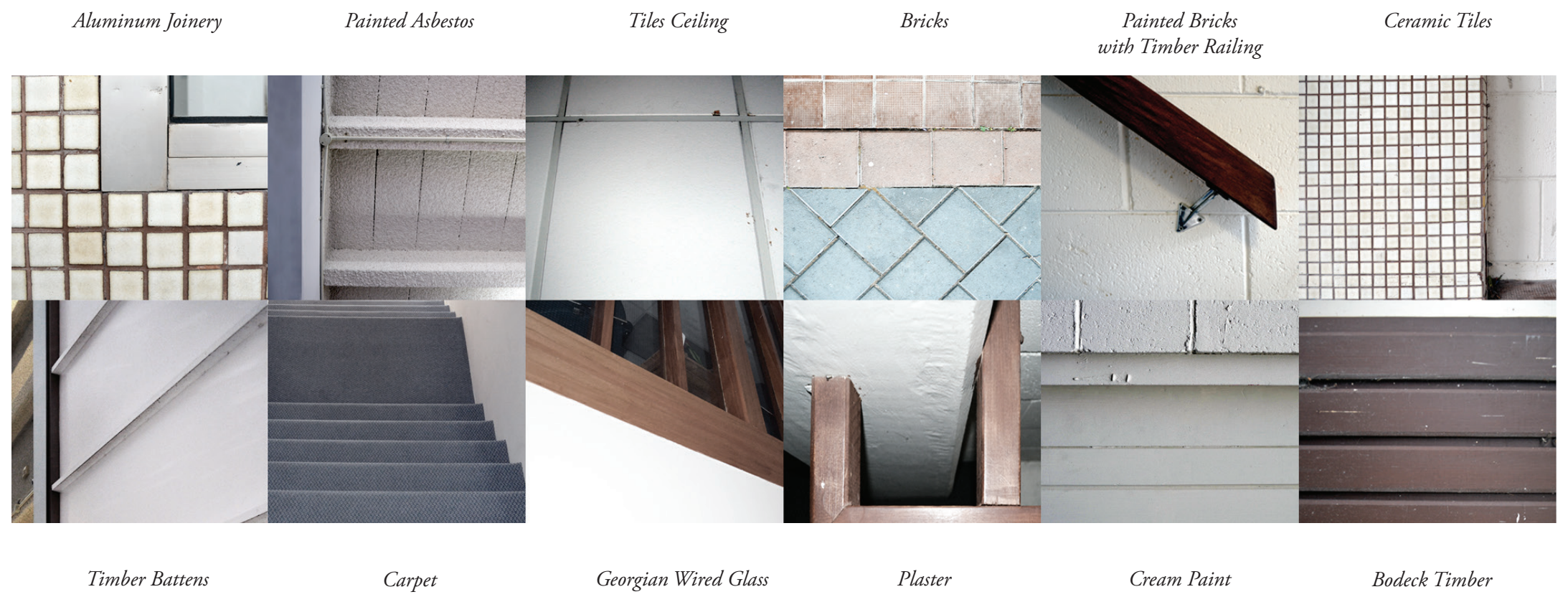

68/ The materials in the exiting building are

durable, simple application and construction methods. 


\section{Proposed Materials}

Steel Sheeting
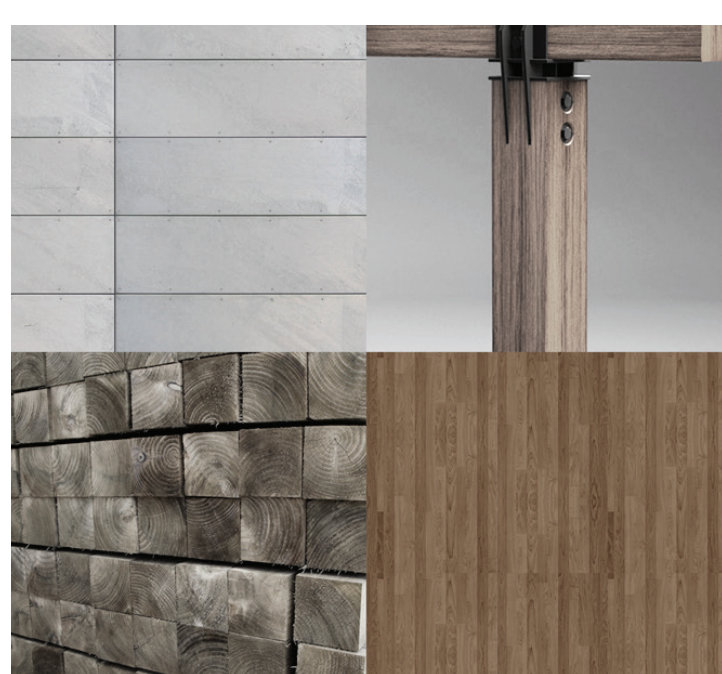

Rough Sawn Timber

Timber Flooring
Corrugated Iron
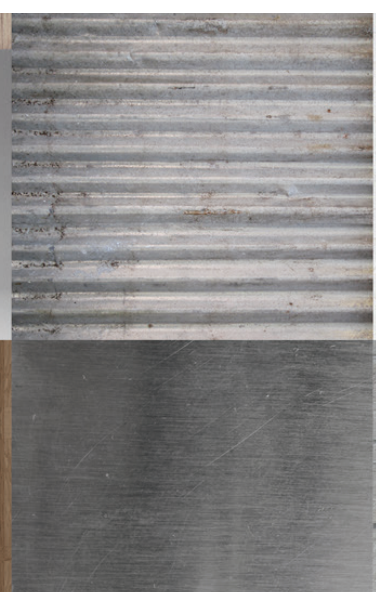

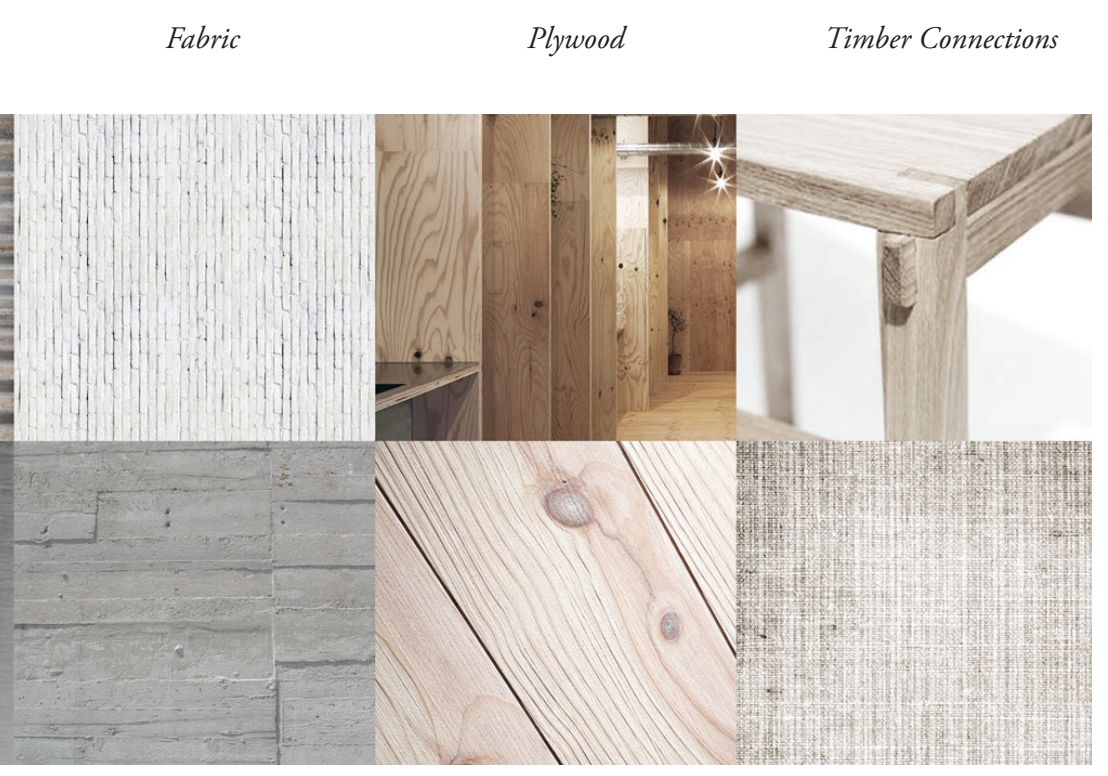

Timber Cast Concrete

Timber Lengths

Material 


\section{Ruins}

The life of a building is not always predicted by the This research has developed a similar mind set of architect, the decay of a building is part of its narrative. preservation to Krag, through the revealing of layers Robert Harbison (1991) discusses how "ruins can be a by removal of current function. However, it differs by way of seeing", highlighting emotions of history and reversing the buildings purpose with the primary goal of the past. Since the 18th century, ruins are more than it once again being a highly functional space (fig 71).

issues of maintenance, they emote ideas of the "beauty of

disorder", giving the user a context within the life span Provincial New Zealand is struggling with a decline in of the built environment they inhabit (Harbison, 1991). population and economy, people are using the amenities within nearby cities (Allan, 2009). The modernist In Mo Michelsen Stockholm Krag's research, buildings are a key part of the history of many of these Transformation of Abandonments: a New Critical places. Based on this the Parker Building has become Practice, abandonment and increasing decay in the increasingly likely to be abandoned, however rather than rural villages of Denmark is described and the design completely demolishing it, the building can be used to solution explored. People are leaving their settlements play homage to its history. By using the existing structure for major cities, which are experiencing a steady growth and keeping the existing materiality, the building can be in population and economy, due to a decline in farming appreciated and celebrated. Aspects of the original fit out and associated industries. Krag proposes an alternative tell stories and events of the past, allowing the memory to the European Union's state funded demolition of the building exist through the new layers.

scheme for neglected houses. Telling of the materiality, immateriality, cultural heritage, building densities and local narratives, allowing the memory of the ruin to remain in the users mind. Similar to projects from artist's Gordon Matta-Clark and Rachel Whiteread (fig 72-73), the buildings focus on architectural solutions to transform full scale abandoned buildings. The buildings are treated as artefacts, in varying stages of controlled ruins (Krag, 2014).

\begin{abstract}
"The local people are carriers of narratives of a place, and they are the connection between the embedded fragments of local identity, which remain in the abandoned building"

(Krag, 2014)
\end{abstract}




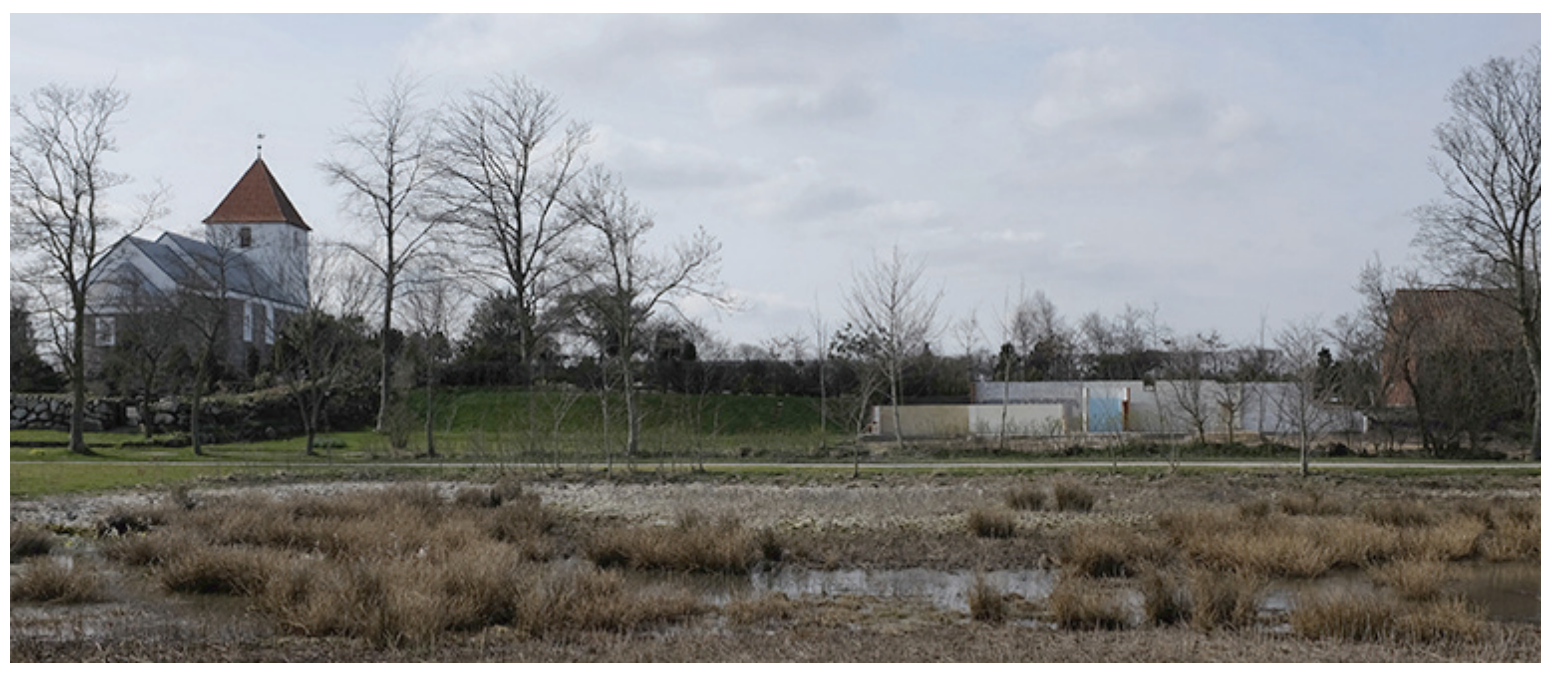

70/ Controlled Ruin 2014, Thisted Municipality Denmark. Ruins show how the designer is crafting the narrative of the building. The building has had programme removed and is in a stage of ruin.

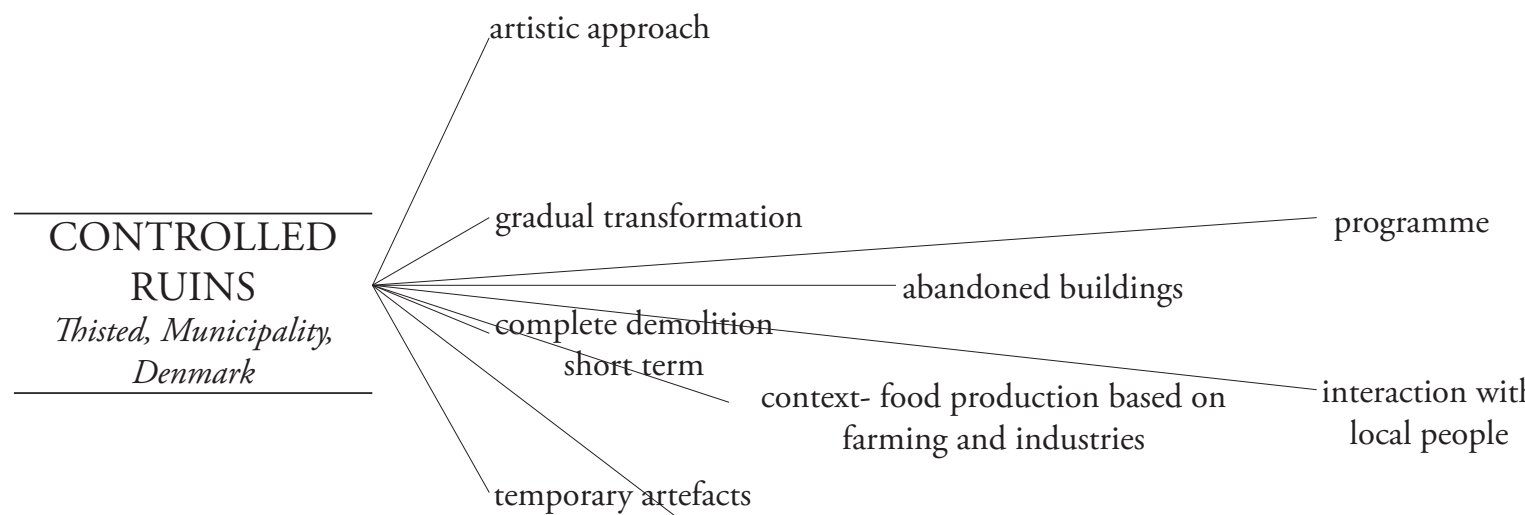

identify and activated values of embedded material and immaterial

THESIS PROJECT

Mahara Place, Waikanae, New Zealand

71/ Level of impact on thesis project. 

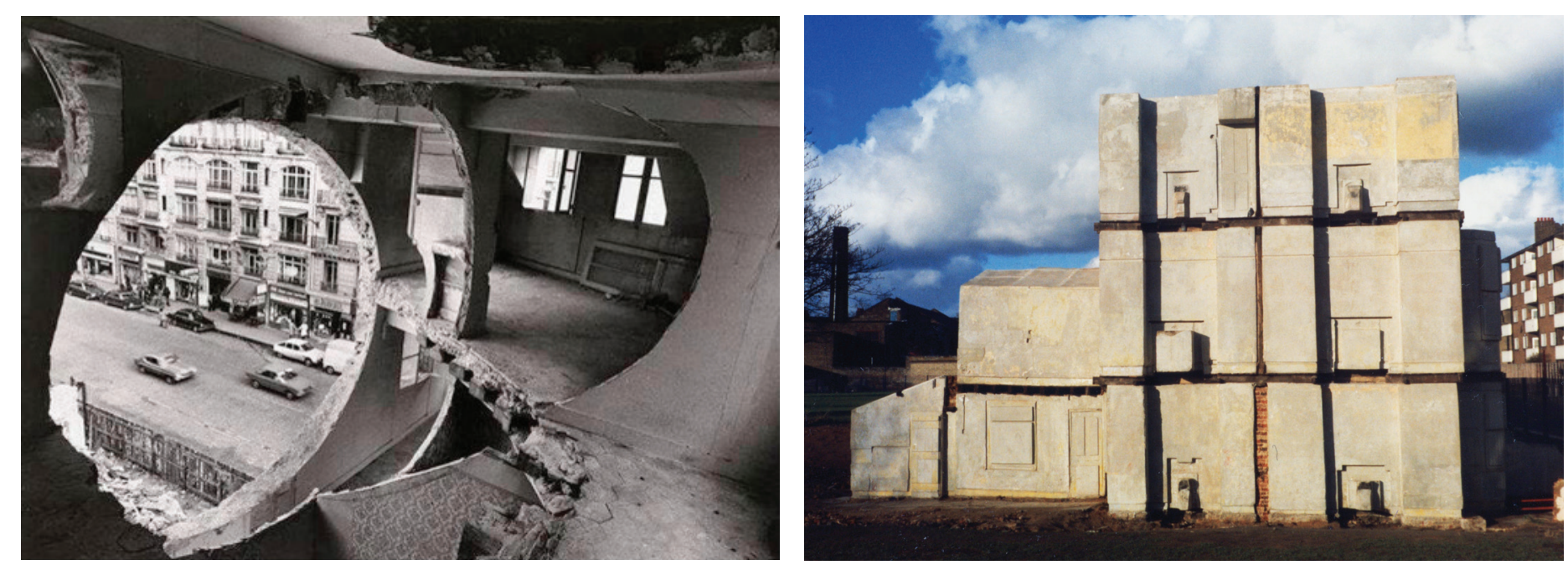

72/ Gordon Matta-Clark. The abandoned

73/ Rachel Whiteread. By casting interior space, building is transformed into a temporary piece of the history of the workings of the building become a piece of architecture art, similar to that of Clark and Krag. 


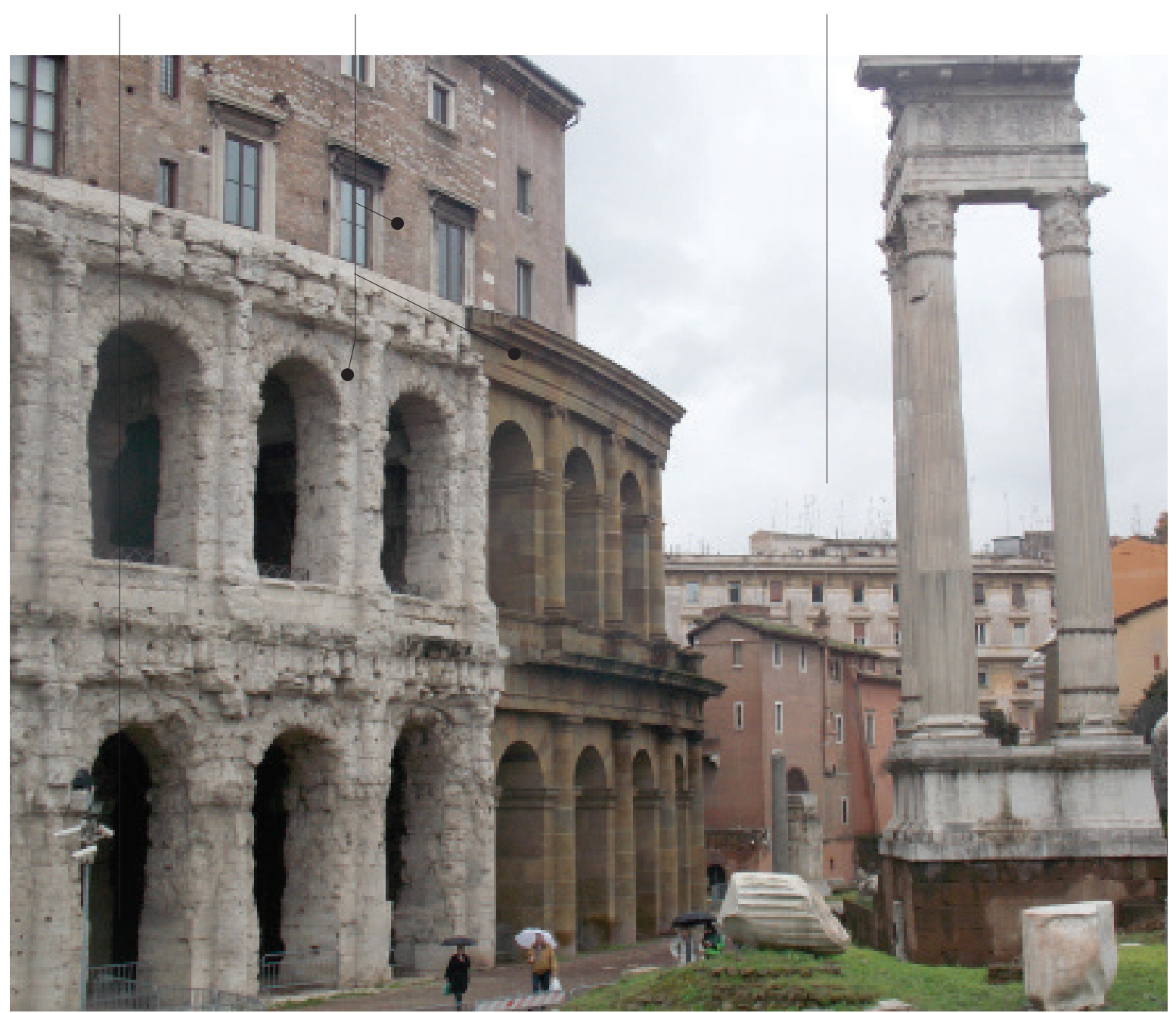

74/ Palimpsest Ruins, Rome. Like many old cities, Rome has countless examples of palimpsest. Architecture which has become superimposed with layers of change. The architecture becomes a patchwork of history, highlighting aids of preservation. This example shows how the Theatre of Marcellus has had additions over time according to programmatic needs. The latest addition involved adding apartments on the upper levels above the theatre. 


\section{Programme Elements Design}

75/ Designing in isolation from programme, a disconnect between levels in the building became apparent. The existing building has two narrow stairs at each end of the building, which push circulation and amenities to the rear. A ramp moves the busyness of users from the rear, where current vertical circulation is, to the front. A

ramped solution explores gradual movement through the building, creating awareness of context and the surrounding users, opening up the building. This ramp breaks through the existing

floors, a bold decision that the space will be based around the current needs of the community.
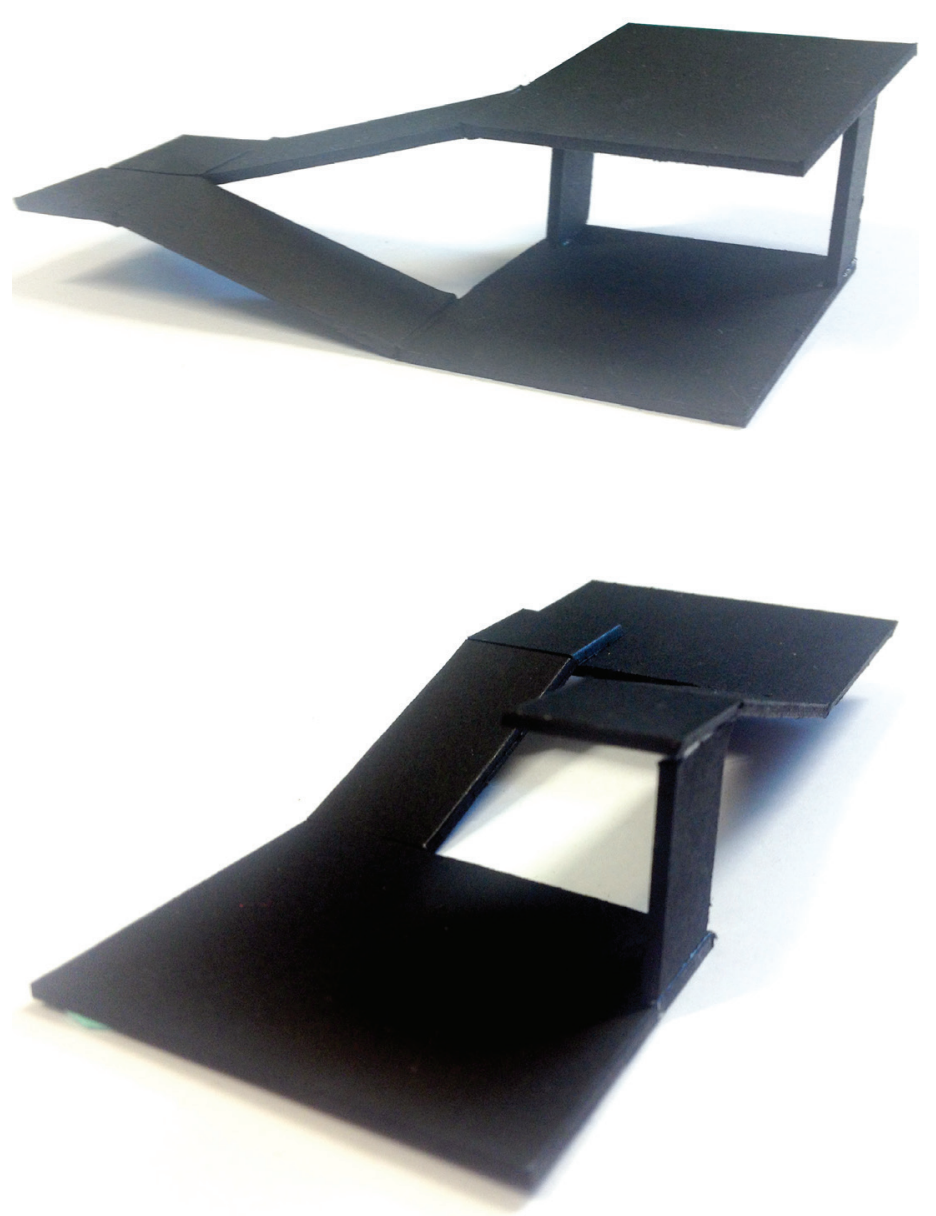


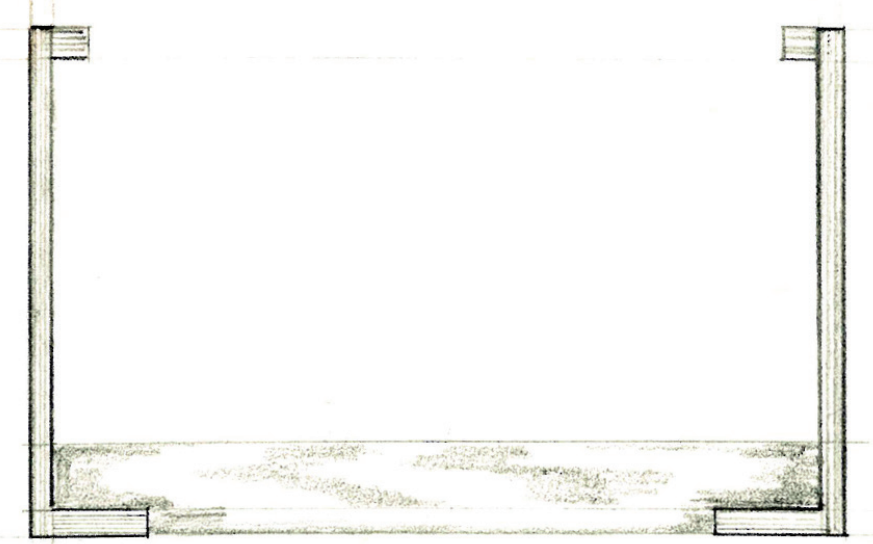

76/ Section of ramp element.

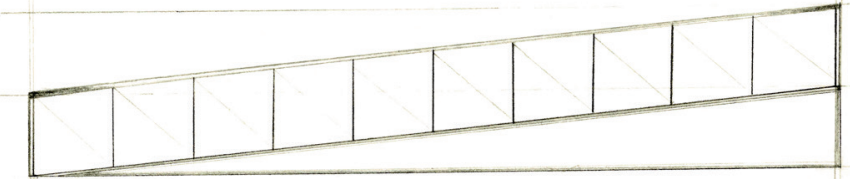

12000

$77 /$ Elevation

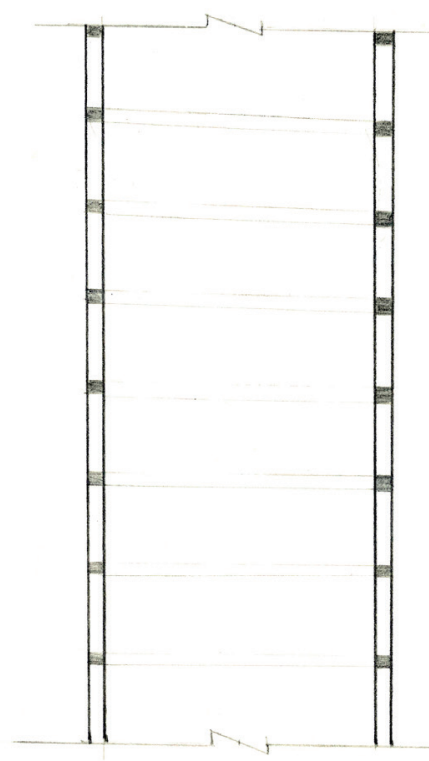

78/ Plan section. 

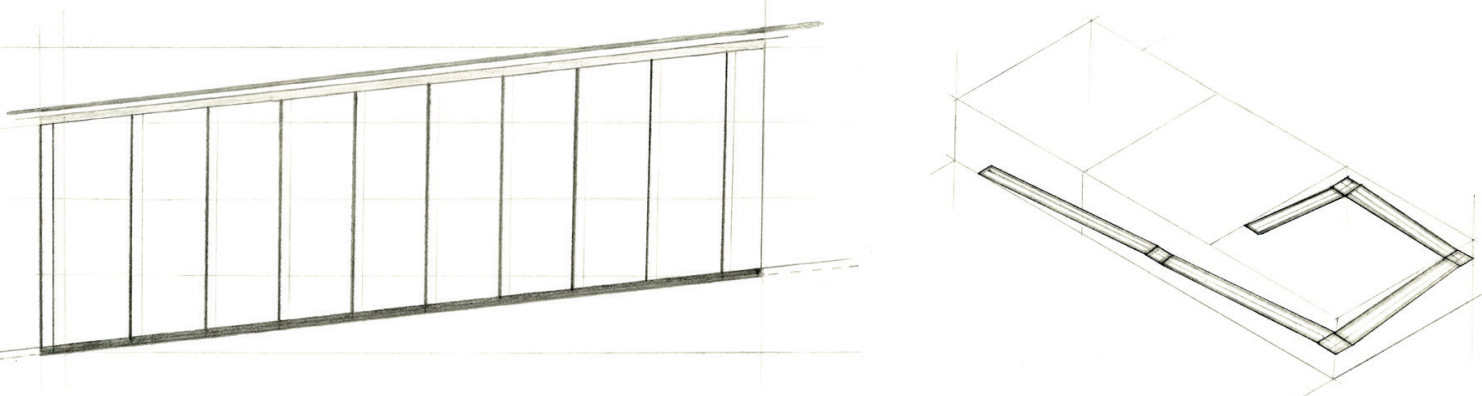

\section{Ramp sketches}

These sketches propose how a ramp may be used for alternative circulation. Allowing the building to be used as a whole and opening up the separated two floors. 
81/ Scale model of ramp 1:20

Repetitive supports influenced by the grid structure of the Parker Building.

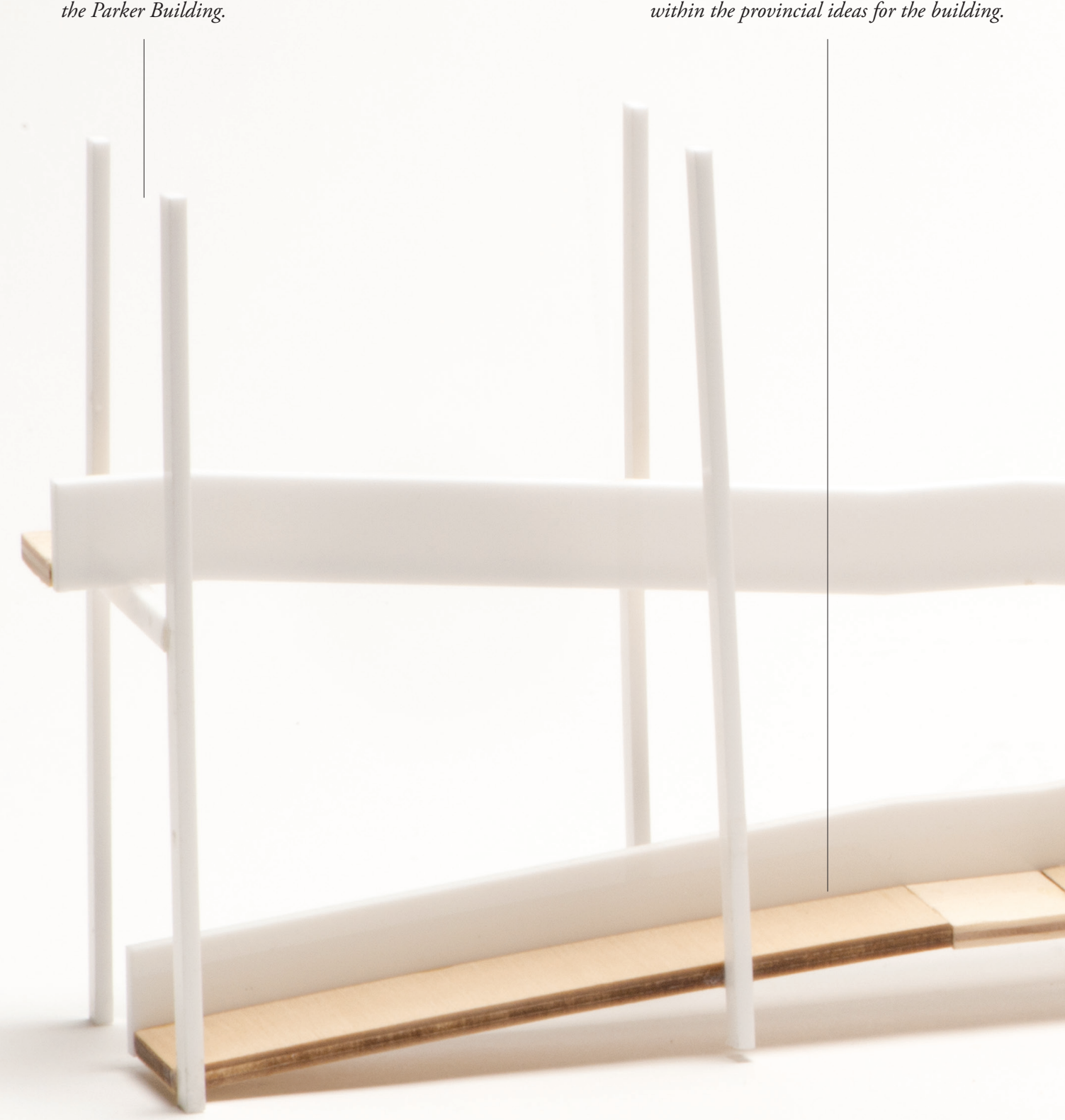



82/ Ramp mode 


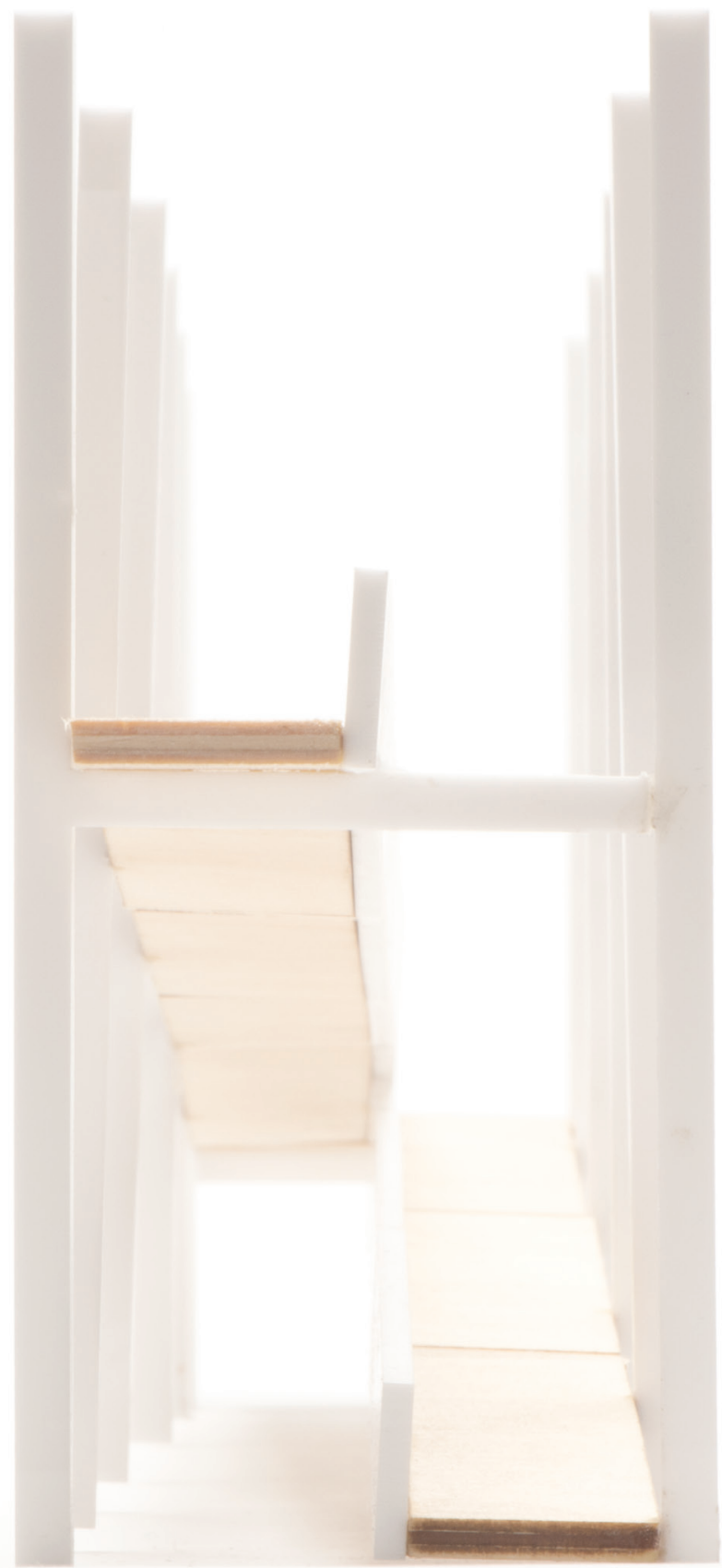


To maintain the memory of the past, a series of small outcomes work to specifically add new layers to the building. The importance of programme was questioned, asking if the building could be designed around rapidly changing needs.

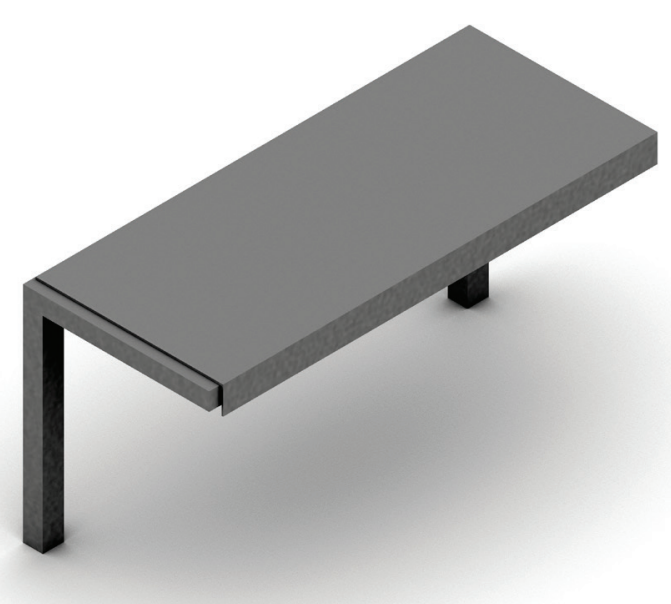

83/ Overhead frame.

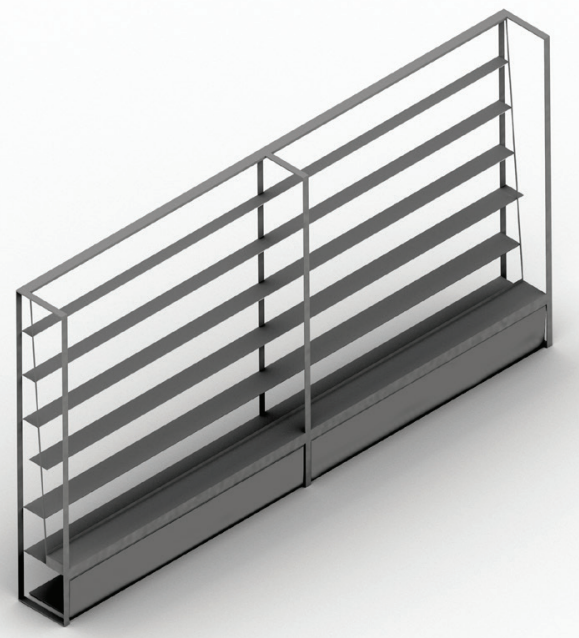

84/ Shelves 


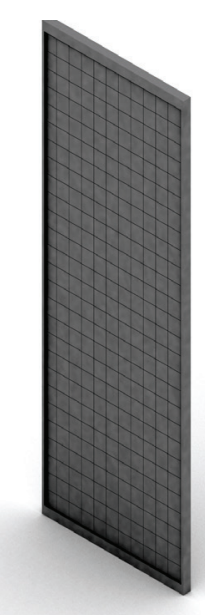

85/ Garden wall.

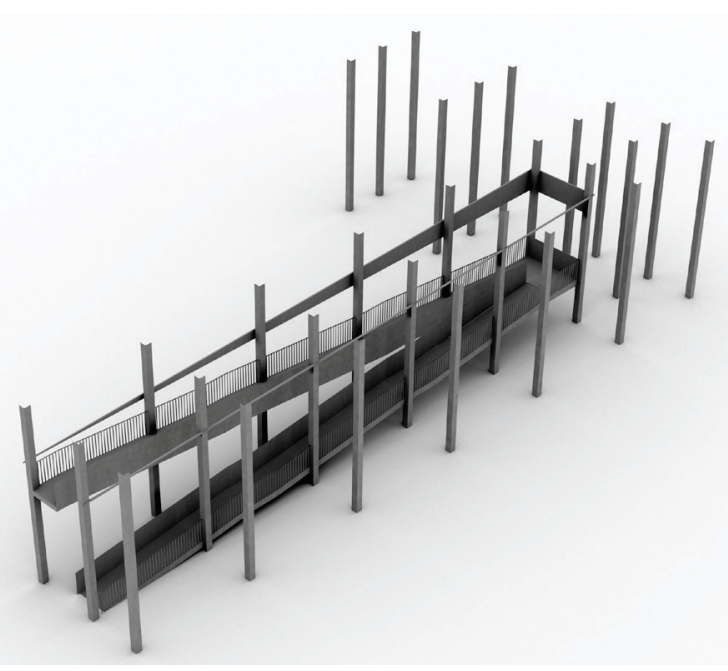

86/ Garden ramp.

The adaptive design response was at odds with the desire for a fixed programme, with design responding to hunches and relationships to the space. The elements show a series of interventions responding to the building's function and form. 


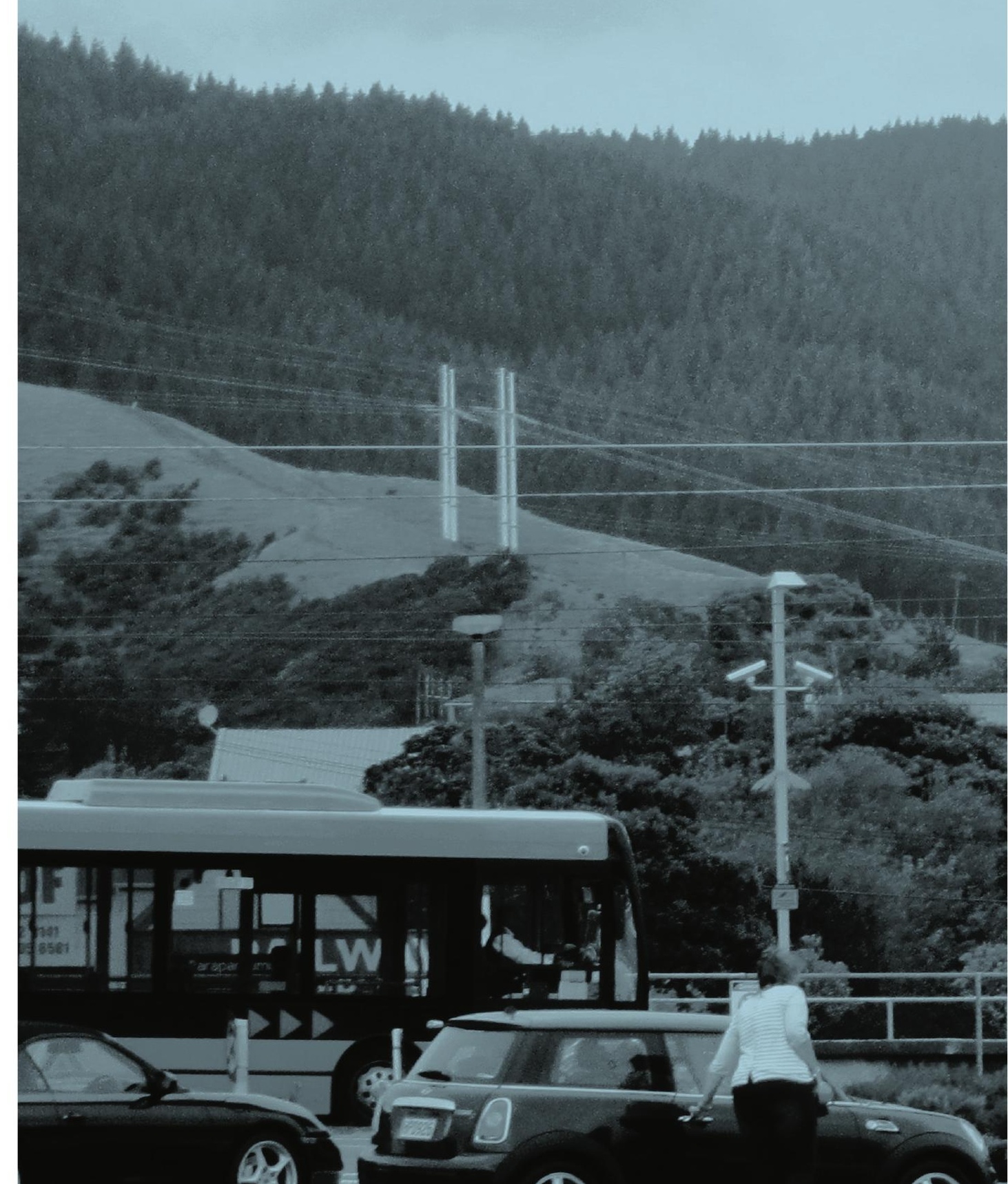




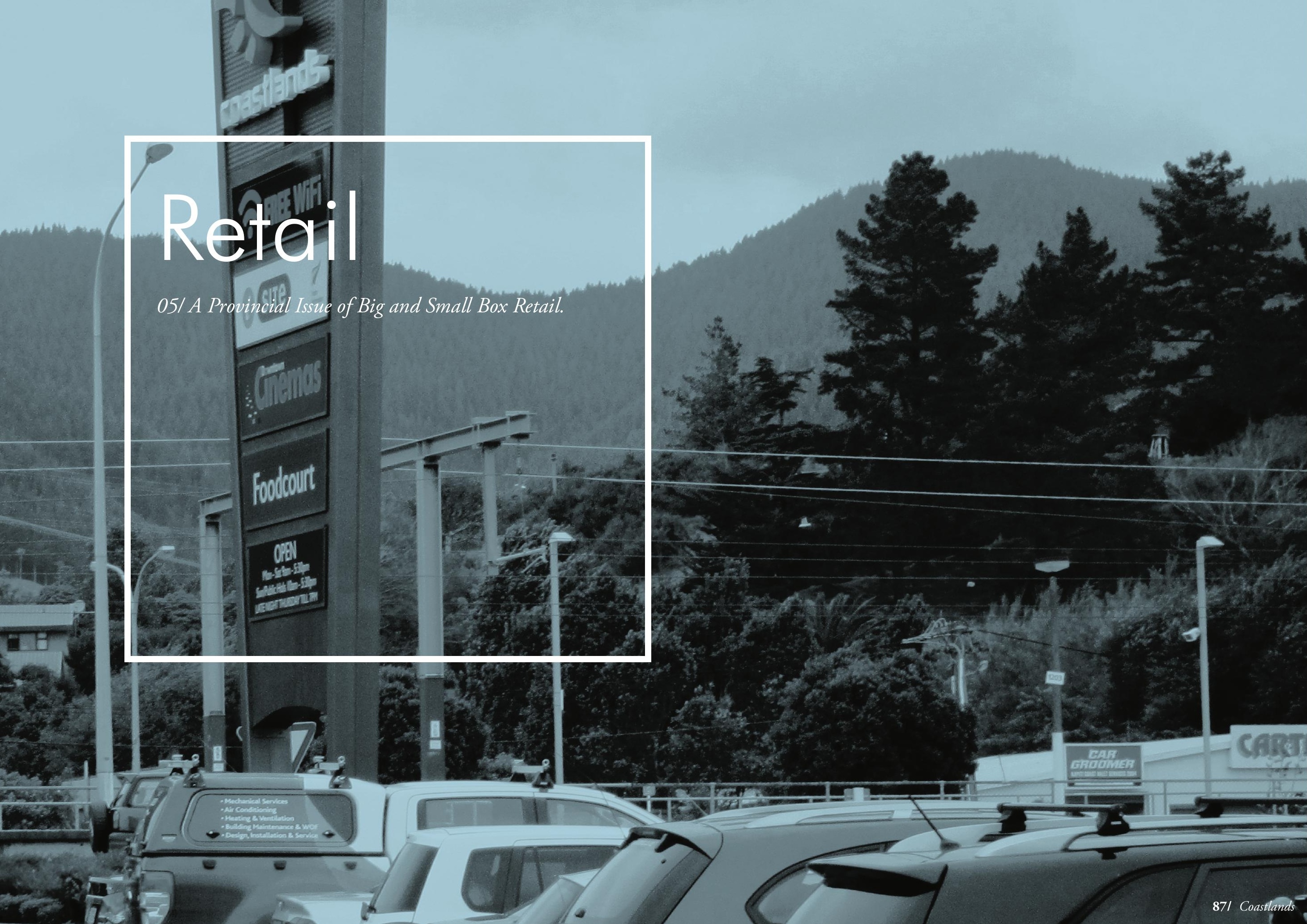




\section{Paraparaumu's Influence on Waikanae}

Over the past 60 years, big box retail has become Small towns in New Zealand have undergone changes in increasingly present in cities and regions within New traditional retail, opting for chain stores or online retail. Zealand. For example, in nearby Paraparaumu big box With this change, in June 2015, Wanganui had 35 empty stores are rapidly engulfing vast amounts of land near shops that were either for sale or lease (Zoio, 2015).

the airport (Blundell, 2013). Not only does this building type support urban sprawl and dependence on cars, it also Decreasing foot traffic in the central cities "increases the "contributes to the decline of urban and neighbourhood empty shop rate" causing a strip mall development and centres as it attracts retail activity out of the central "large retailers replacing town-centre outlets" (Stockwell, business district to the urban fringe," (Curran, 2002) a 2009). Big Box Retail stores remove the buzz within phenomenon happening to Mahara Place. At face value, town centres (Stockwell, 2009), offering explanation for large chain stores create more jobs for the area, offer the recent decline of Mahara Place. Stores are unable to lower prices and more convenient shopping. However, compete with nearby larger stores, especially those in over time they can replace small local businesses as these Paraparaumu, $7 \mathrm{~km}$ south.

cannot remain competitive (Curran, 2002). Major chain stores offer a diverse selection of products and services, suited to the busy lifestyle of many. Small and medium size retail enterprises are unable to purchase bulk products and offer significant discounts (Stockwell, 2009).

There are countless examples of the ill effects of Big Box retail, with Stockwell (2009) commenting that the arrival of "large scale retail outlets such as The Warehouse in rural districts" create "even further pressure on the remaining in SME [Small or Medium Enterprise] retail businesses". In a small town in Iowa, America, $47 \%$ of retail trade was lost within the first 10 years of a WalMart opening (Stockwell, 2009). 


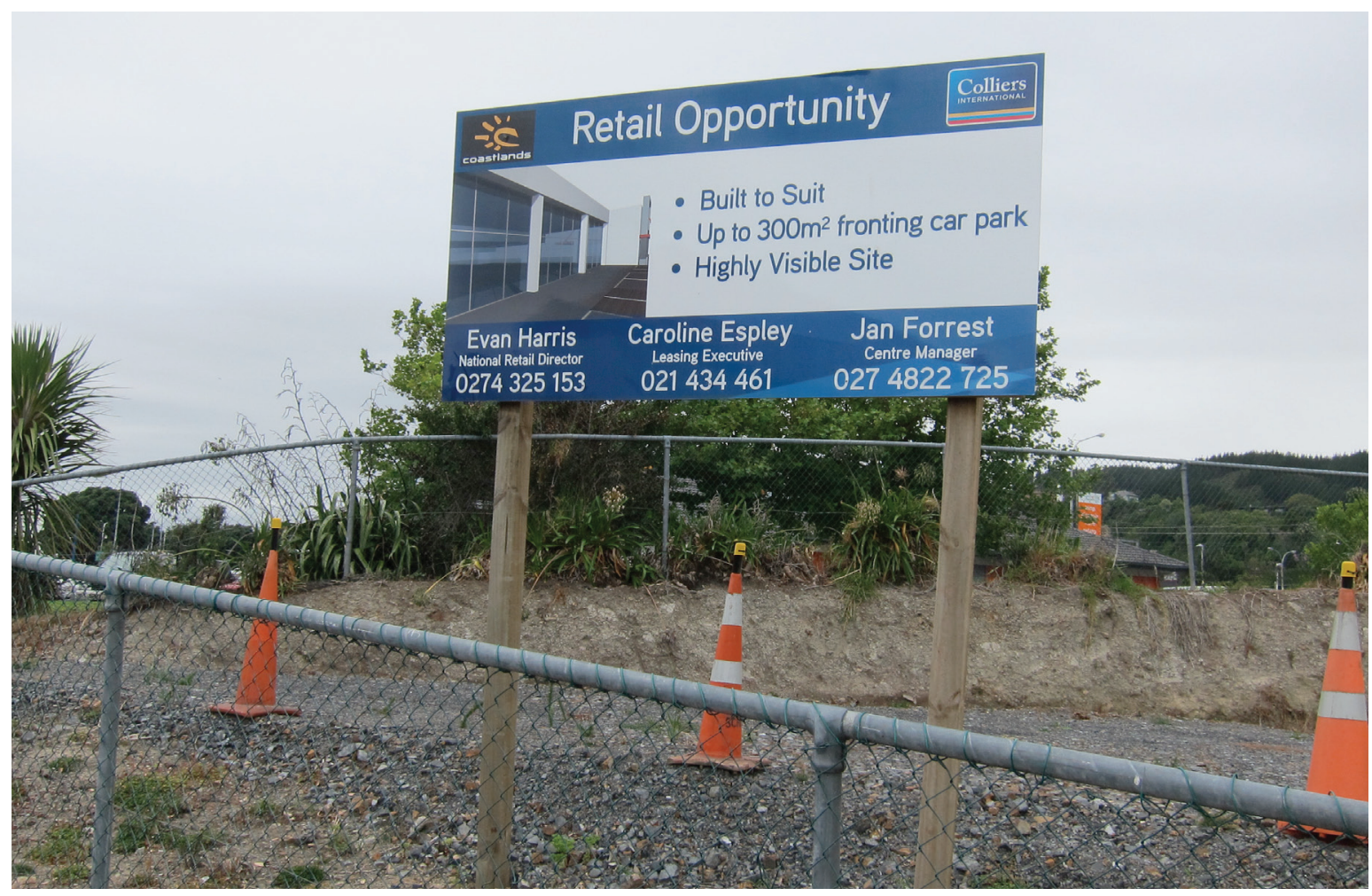

88/ Retail tenancy example, Paraparaumu 2015. 


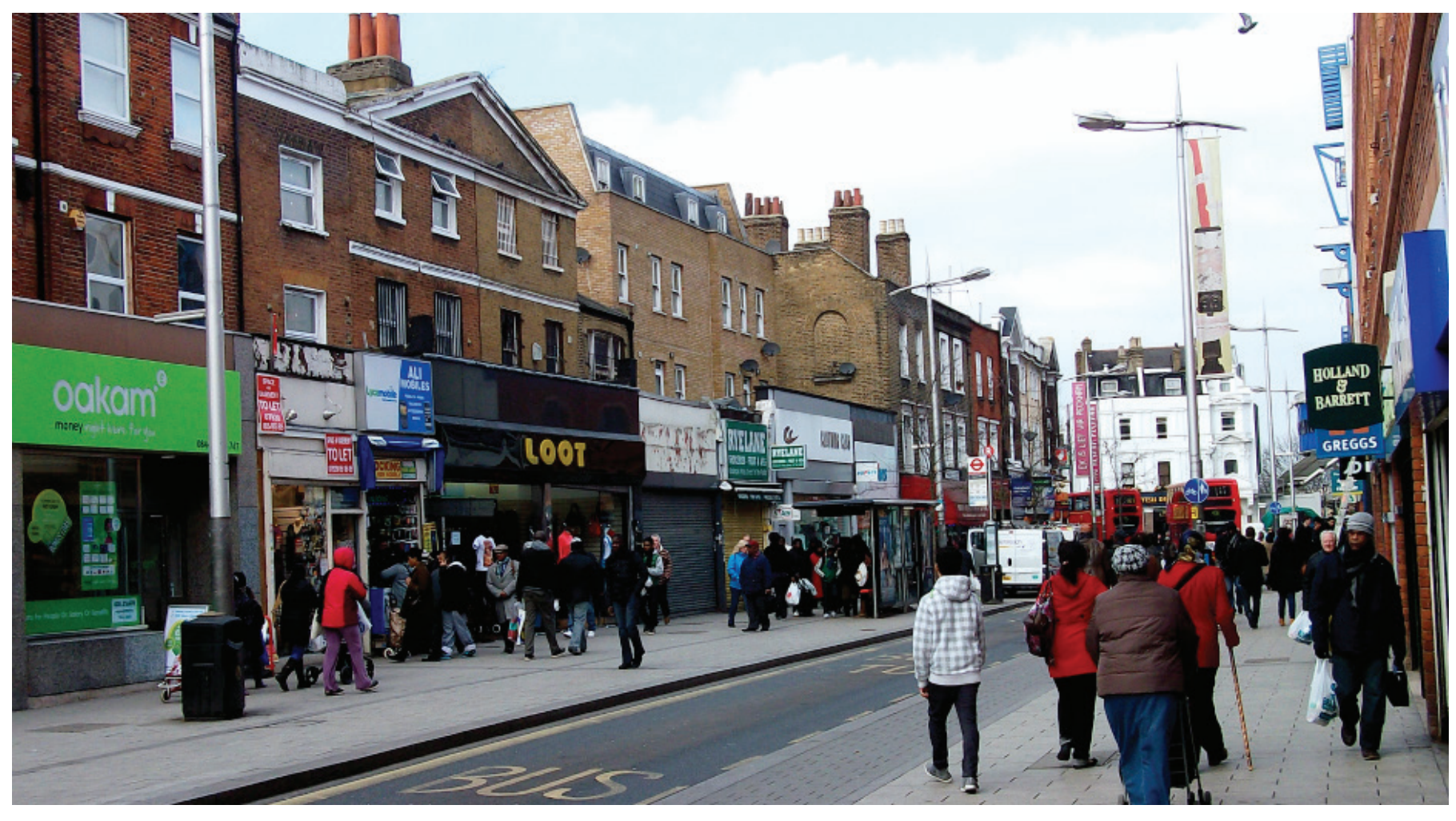

89/ Rye Lane 


\section{Small Box}

Suzanne Hall, writer of Super-Diverse Street: a 'transethnography' across migrant localities, and City, Street and Citizen, explains the economic and cultural advantages created in the dense multi ethnic streets of London.

"Exploring the city at the scale of interiors and individual recalibrations of retail space and rental provides important cues for understanding retail renewals, migrant entrepreneurs and their transformations of the high street".

Rye lane, in Peckham, South London, has 199 retail units densified into one kilometre of street frontage. The initial fabric of the street was mid-1800's suburban villas for the middleclass. With industrialisation, stores were built in the front and back yards, creating a dense mixed fabric (S. M. Hall, 2015).

In Rye Lane one quarter of independent stores have been either sublet or subdivided into smaller spaces. One retailer rents his store for $£ 10,000$ per annum. He sublets a hair salon $£ 80$ per week ( $£ 4160$ per annum) and a $6 \mathrm{~m}^{2}$ Western Union for $£ 9600$ per annum. In the initial years of being in business, the rental income supported his business. $75 \%$ of customers are likely to purchase other products from retailers in the same building, creating a market atmosphere that allows stores to feed off each other (S. M. Hall, 2015).

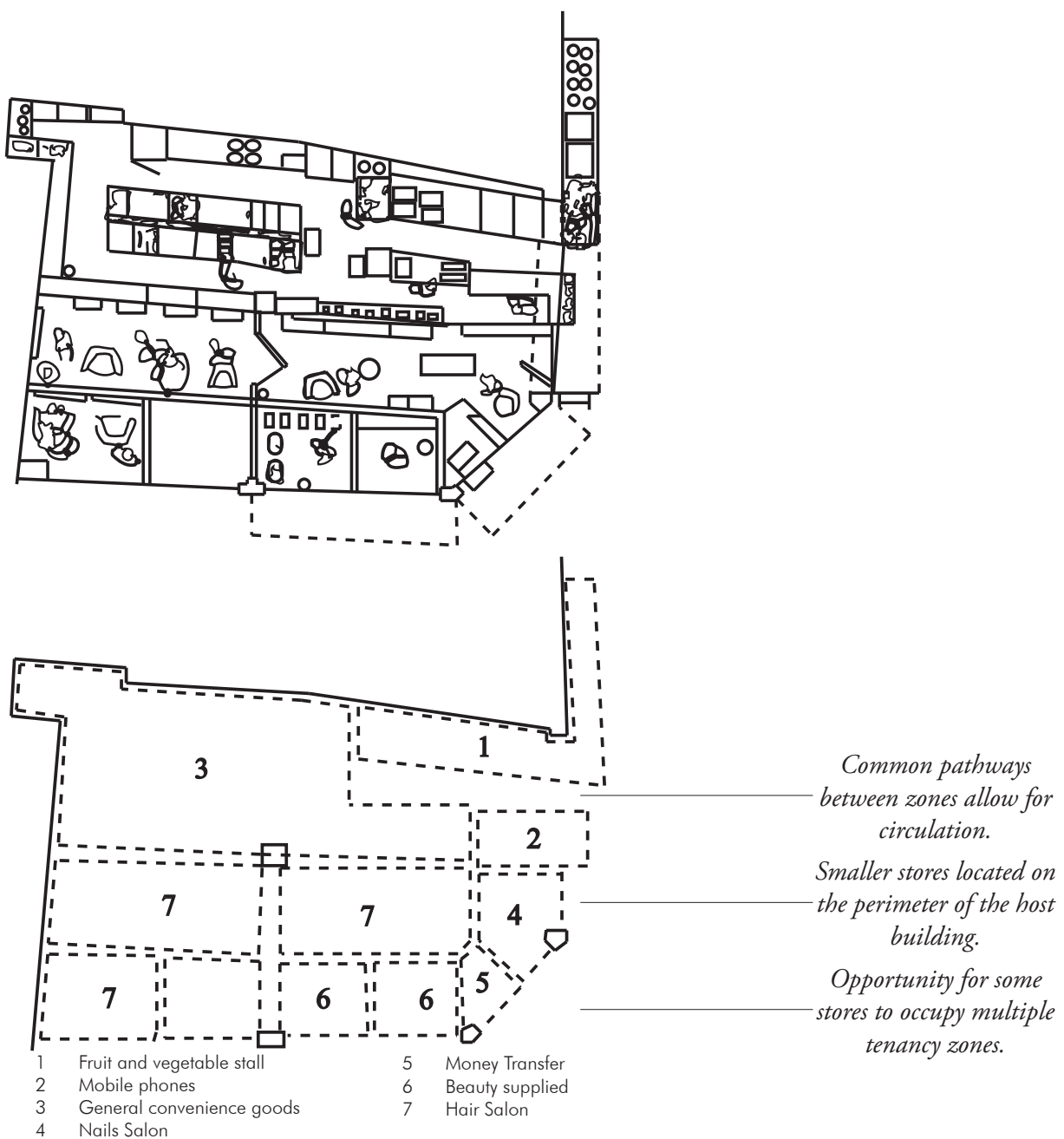

90/ Hybrid Retail Interior, from Rye Lane. The plan diagram illustrates how the seven tenancies fit into small zones within the building. The zones vary in footprint according to space requirements. 
Retail options for small towns could work under the premise of small stores, similar to those in a market. A small box alternative is the following:

- Low cost,

- Low maintenance, and

- High Density.

Retailers could offer small amounts of specialty products or services, with lower overheads and margins.

The patchwork of surfaces and expressions allow for retail diversity. Walworth Road, which is similar to the Kapiti Coast, is undergoing large amounts of regeneration (S. Hall, 2012). Figures 91 and 92 compare the retail diversity of Walworth Road to current Mahara Place. This shows there is opportunity for the retail spaces of Mahara Place to be densified into a smaller area. The diversity within shops promotes a range of programmatic reasons to inhabit. Big box stores highlight that people are more inclined to go to a single location, for convenience. The diversity within shops promotes a range of programmatic reasons to inhabit. Big box stores highlight that people are more inclined to go to a single location, for convenience.
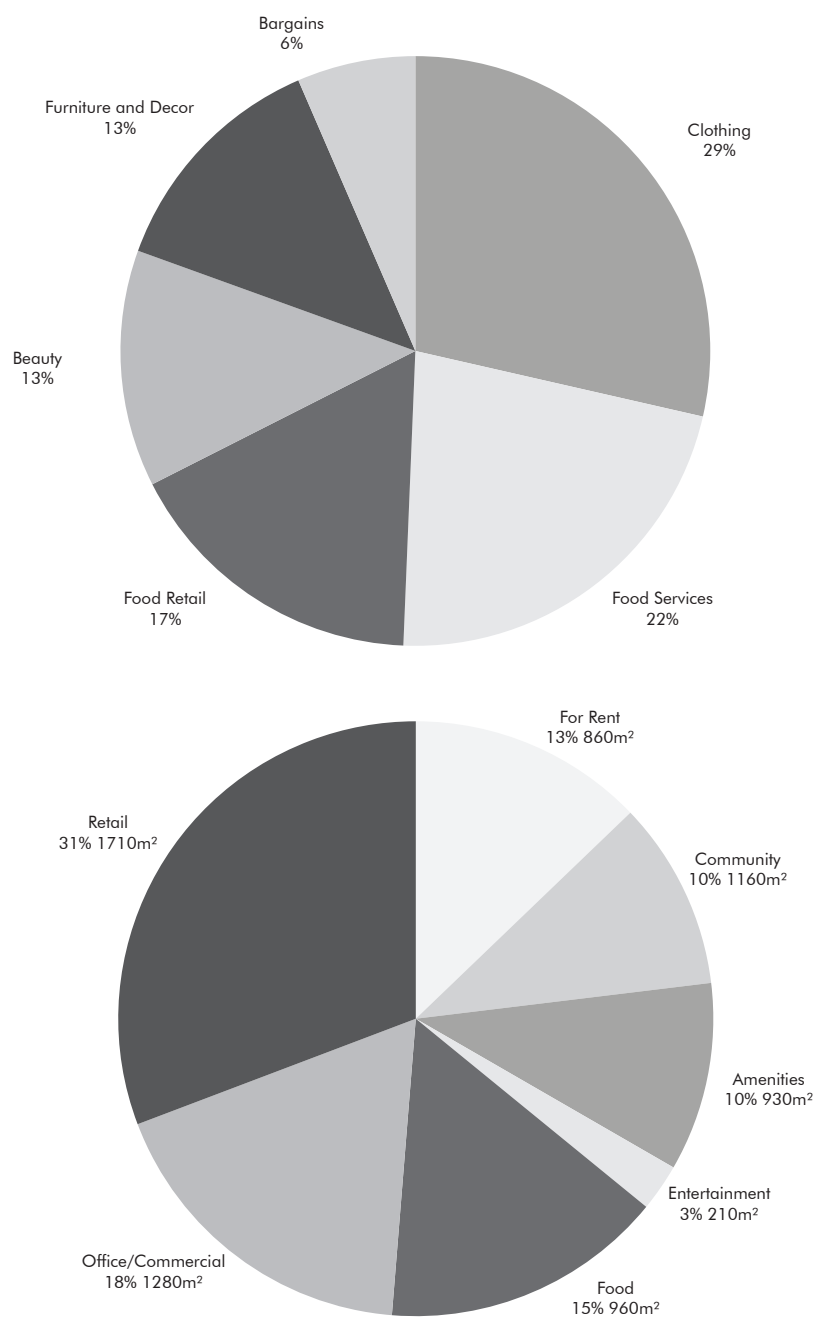

91/ The range of businesses on Walworth Road' vary. The retail activity is primarily food and clothing based, as expected for most main streets. With a lack of offices and commercial activity. Mahara place differs to this case.
92/ Tenancies in Mahara Place. This chart shows the type of current tenancies and the amount of floor space. It shows the retail is the primary programme of Mahara Place followed by Officel Commercial and shops for lease. 
In translating the busy and dense atmosphere of described precedent projects to the Parker Building, it became clear it was important to the small scale retail of Rye Lane. Connections between spaces within the host stores of Rye Lane are often zoned areas rather than fully isolating each tenancy. In the design for the Parker Building each shop was zoned using a grid from the building's structure. By doing so, the windows framed by the structural columns outline each store and allotted a footprint of $5-10 \mathrm{~m}^{2}$, fitting within Hall's study. Each store allows for a circulation area of $1150 \mathrm{~mm}$, enough space for two people to stand side by side (Ernst. Neufert, 1980). 


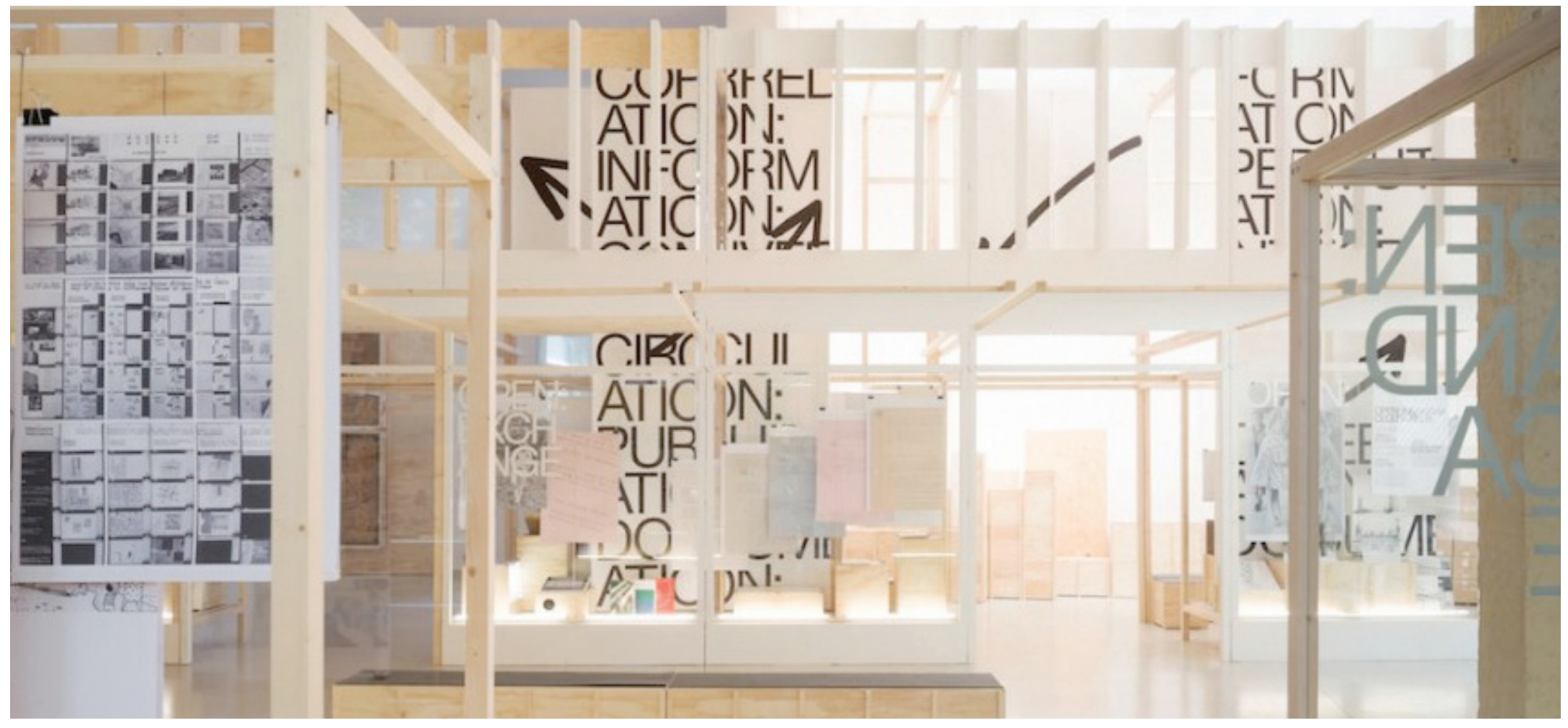

93/ The Open: A Bakema Celebration, was the Dutch Pavilion at the 2014 Venice Biennale. The light weight constructed Pavilion was designed to act as a scale model of his Lijnbaan Shopping area in Rotterdam. My design uses light timber structure to develop a similar effect and view on open

society. Each zone becomes clearly defined, however transparency is created between each space. The

stores allow for organic growth, with stores that can shrink or expand as spatial requirements change. 


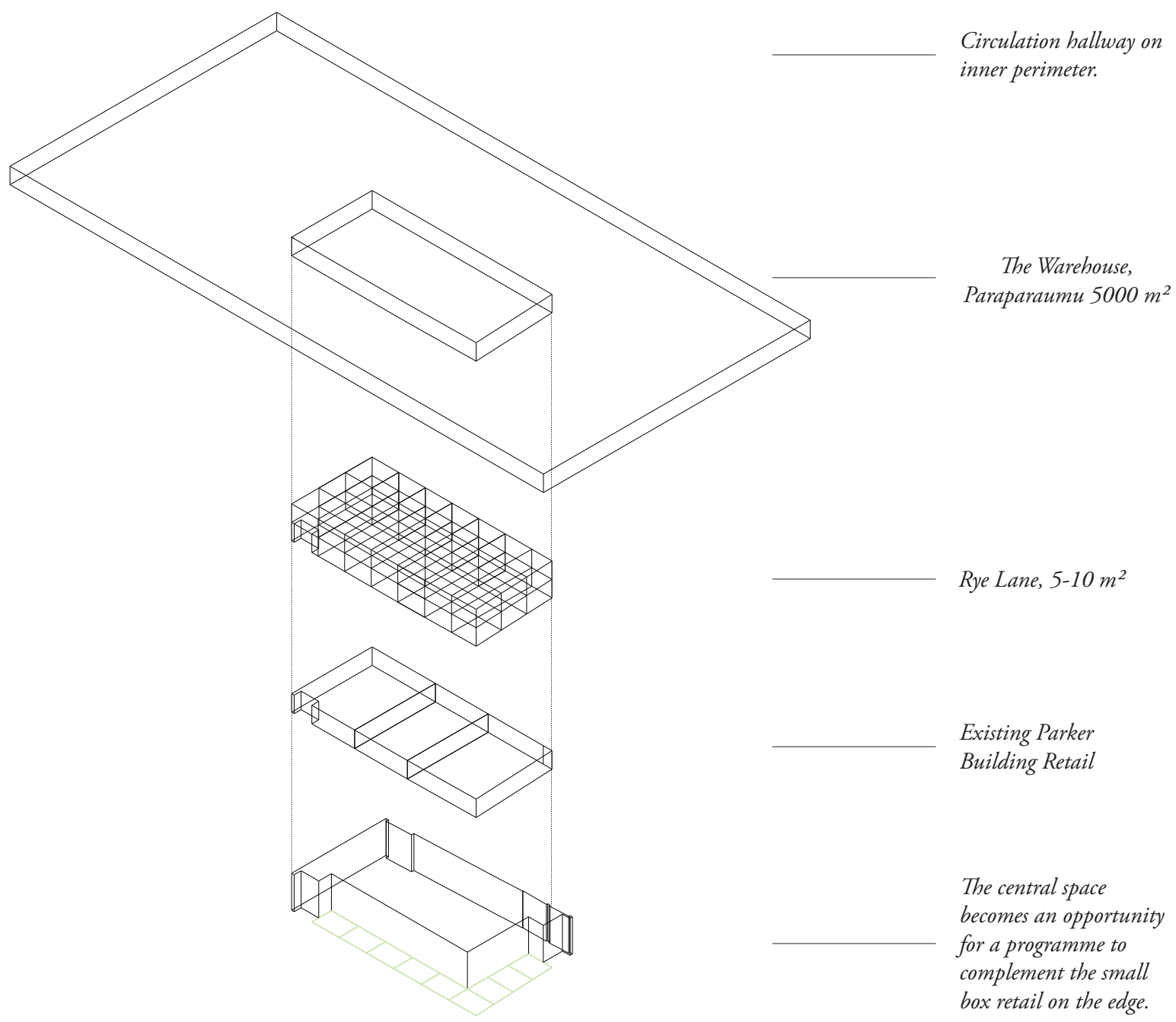

94/ Activating the edge with retail involved using the structural dimensions to form initial footprint sizes. New retail stores are formed by looking at typical tenancies- the existing, Rye Lane and Big Box. The stores are then divided into two floors and finally adding a circulation path. The question of the middle is raised. 
95/ Acoustic Panel. A partition system is a

temporary element to create inhabitation of defined

space. This acoustic partition alters the acoustic

privacy allowing for larger spaces to be divided

temporarily into smaller spaces. The perforated

surface creates connections between the spatial

zones. This intervention is extremely temporar

however it does not respond to programme. 
Using the framing technique the shelves become interchangeable.

Transparency allows views of product from both sides, acting as a viewport. 


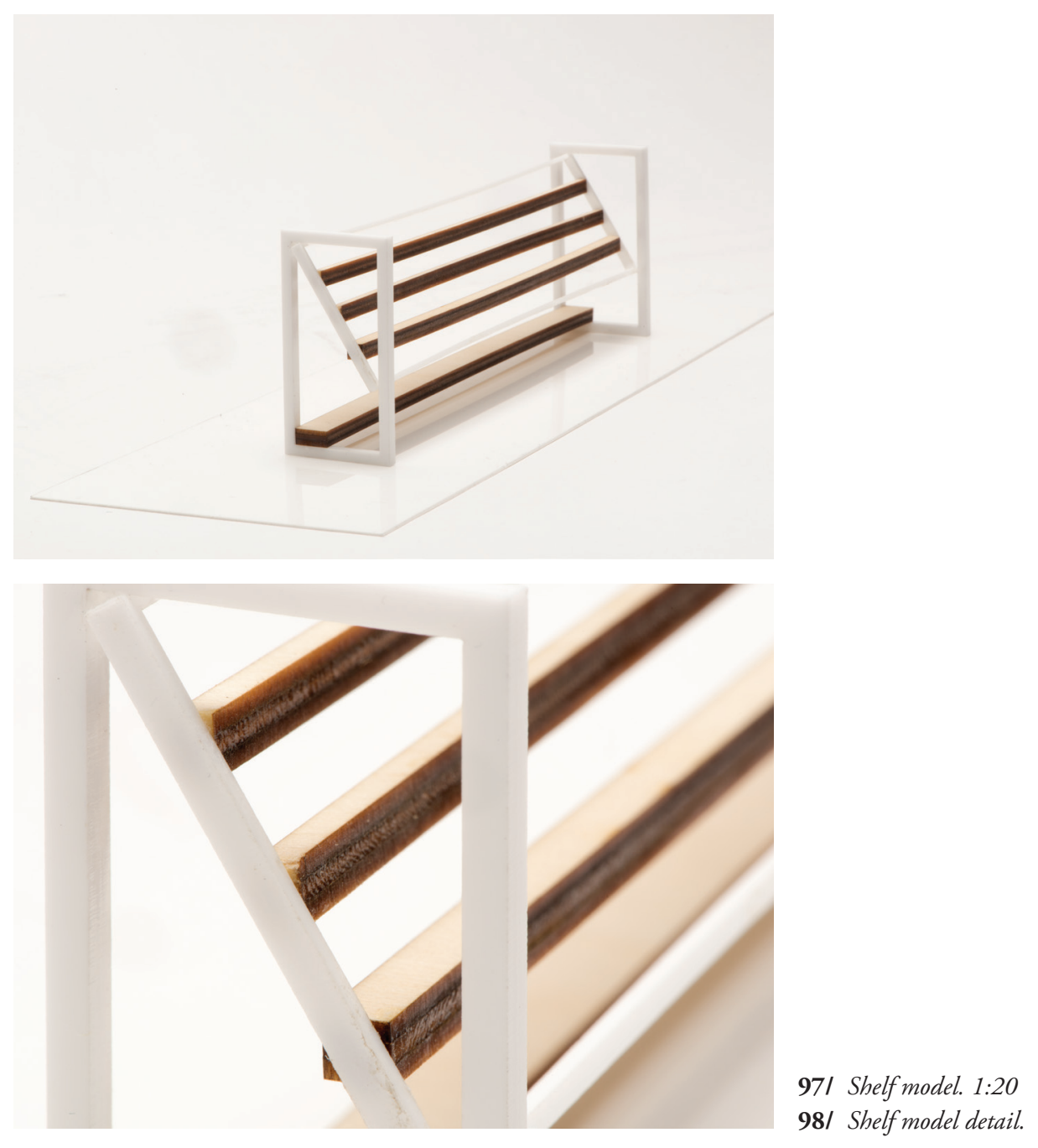




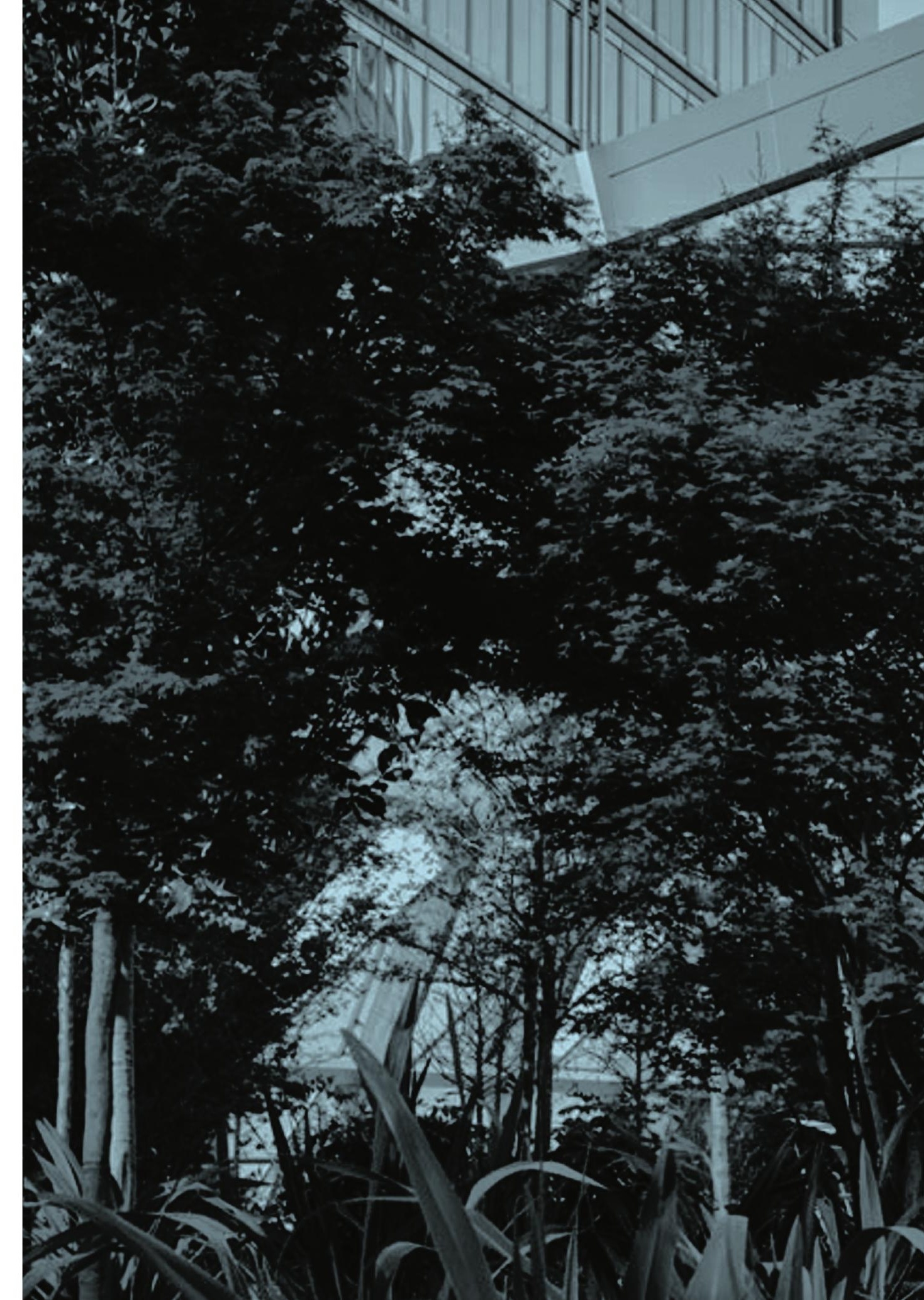




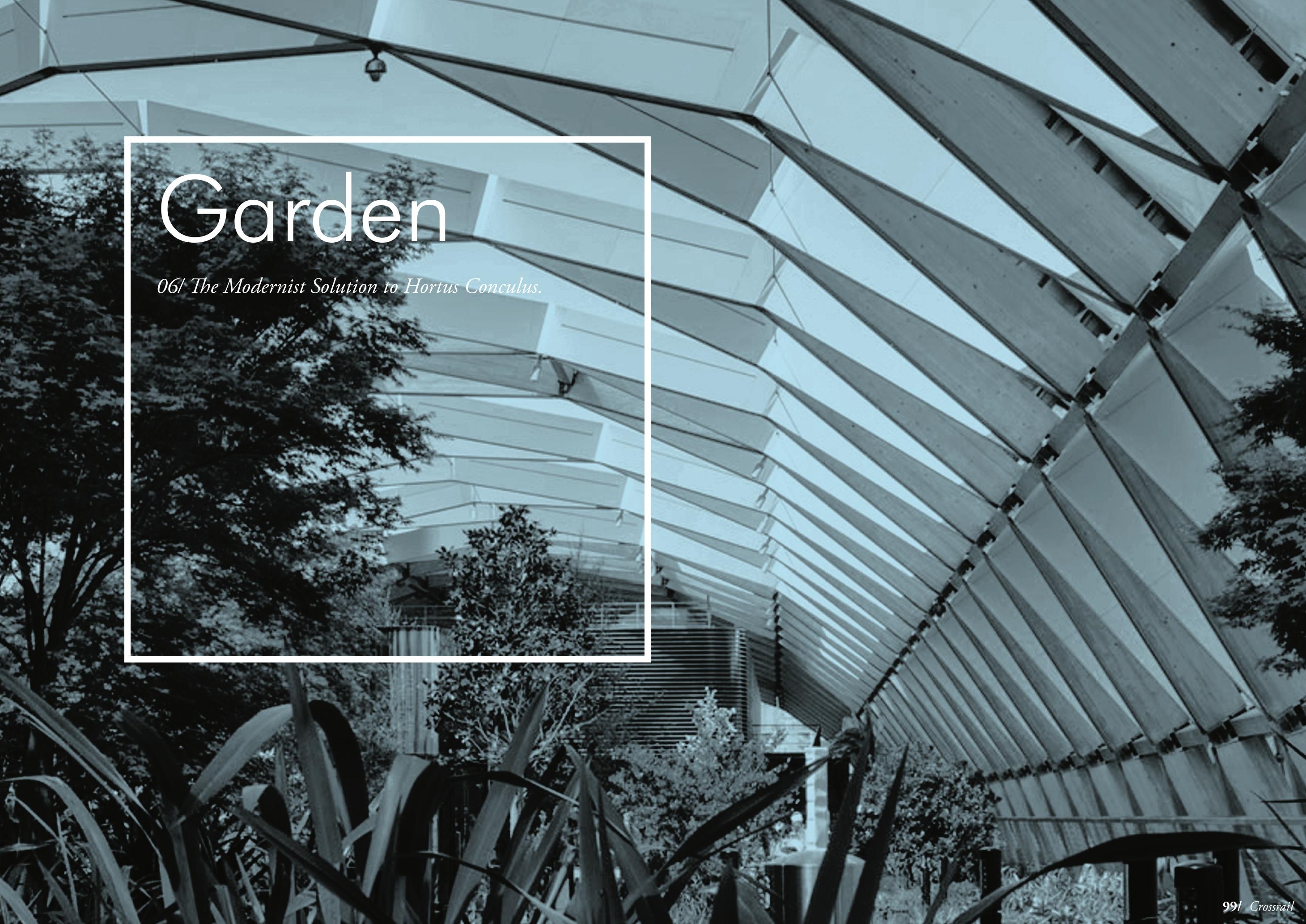




\section{The Middle}

Once the edge became activated a series of programmatic designs were briefly explored, in plan, to see how the large space $450 \mathrm{~m}^{2}$ could be used (fig 100). The garden became a solution that sat well alongside the retail, complementing it with a focus on the community of Waikanae. As a whole, Mahara Place has the ability to become a town centre, a social space for the community. Jan Gehl (2013) states that "modernists turned their backs on the typologies of traditional cities, including the street. Studies of public spaces brought back the street as the most important public space. Jane Jacobs in The Death and Life of Great American Cities defends the street as a social space, not just a space for the transport of people and cars. Similar to traditional planning, common squares can be designed within active parts of the city, they can act as "intimate and urban spaces" (Gehl, 2013). The centre of the building can become a social intimate space, knitted and inserted within the built fabric.

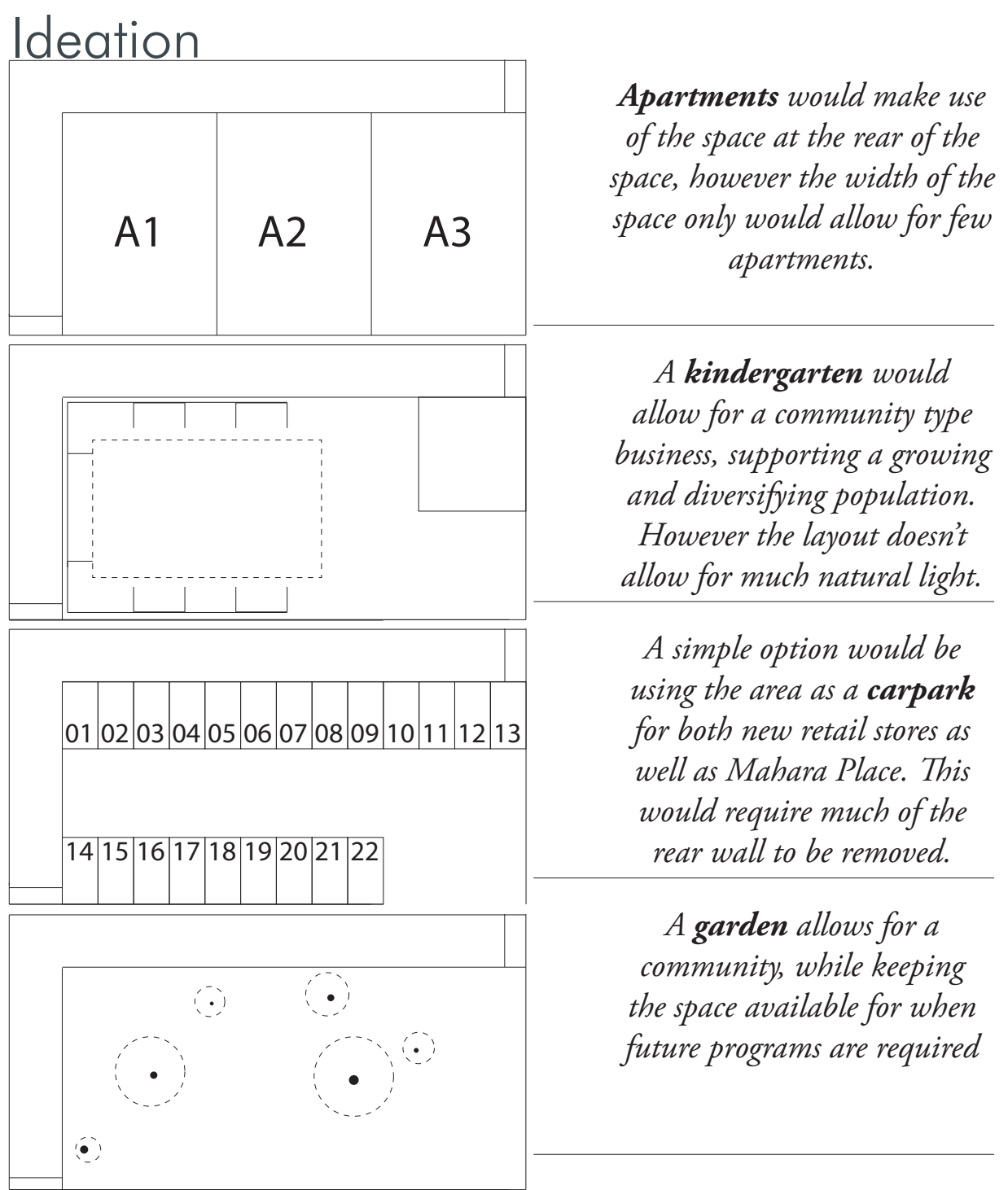

100/ Concept diagrams, indicating to programme for the interior. space only would allow for few apartments.

\section{A kindergarten would} allow for a community type business, supporting a growing and diversifying population.

However the layout doesn't allow for much natural light.

A simple option would be the area as a carpark This would require much of the

A garden allows for a community, while keeping the space available for when future programs are required sace, however the width of the 


\section{Hortus Conclusus}

Aben and Wit (1999) discuss the history of the Hortus Conclusus defined by an open roof garden enclosed by walls or a fence. Classically, four paths divide it into quadrants. Each path leads to either an exit, through the surrounding walls, a contemplation area or a seat. The middle of the garden contains an element representing water. It references the Virgin Mary and infant Jesus, and their enclosed environment of the purity of a virgin birth. Plants were selected under religious meaning and planted in rectangular beds. Recreation occurs in the pathways between the beds (Aben, 1999).

The Enclosed Garden shows how landscape can be organised separately to the natural world. By enclosing the landscape, the natural horizon is shut out and an internal horizon is created. Expansive sky contrasts the containment. The contemporary city can be seen as today's version of the natural environment being shut out (Aben, 1999). The idea of expansive of sky is dealt with in this particular idea of preservation. Removing the existing roof recreates the enclosed garden which has been around since early civilisation. However, due to the New Zealand climate, the garden would not be habitable all year round if there was no roof.

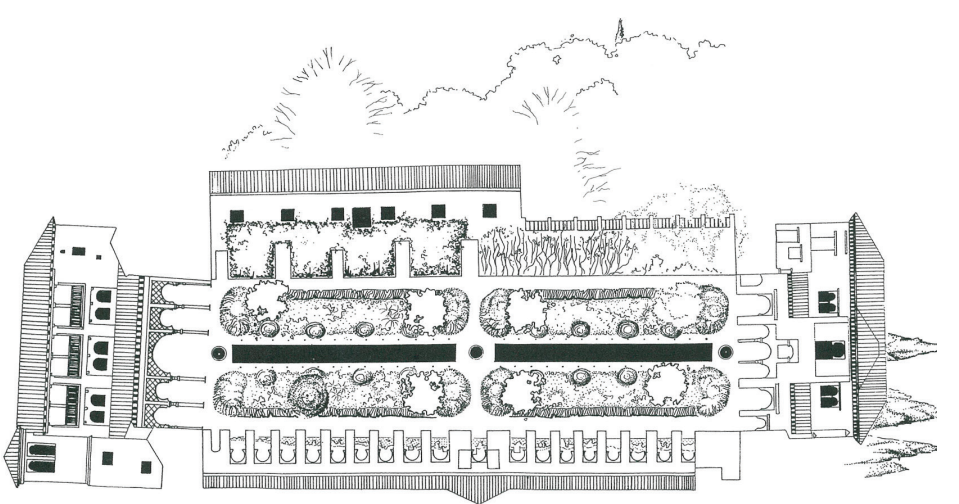

101/ Patio de la Acequia, Granada, 13th century. Exploded box plan. The diagram highlights the

symmetry created within.

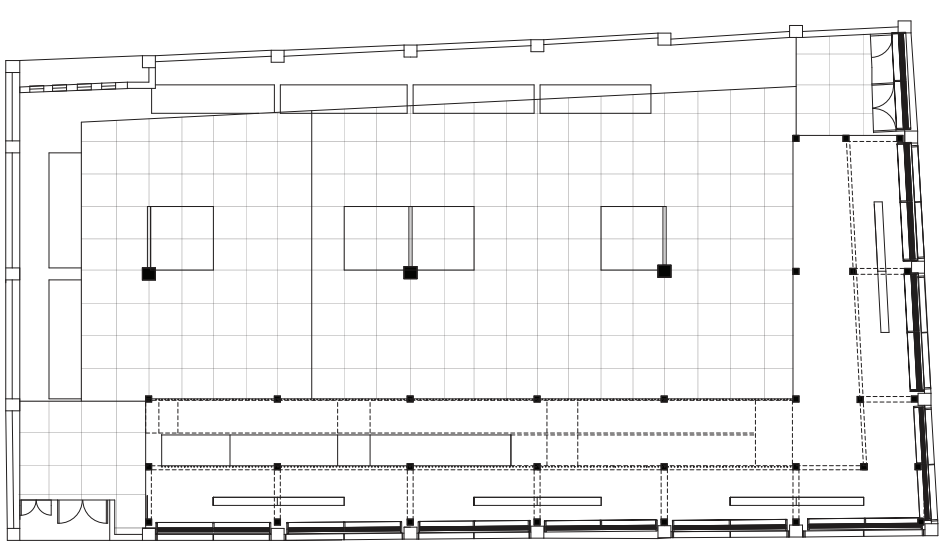

102/ Early plan based on the principles of Hortus Conculus. Seating around exterior with ramp and shops on activated edge. 
Similar to enclosed garden's discussed by Aben, Canary Warf Cross Rail (fig 104) and Atocha Train Station (fig 105) combine communal public spaces with internal gardens. Foster and Partners designed an ETFE roof for Cross Rail in London. These are a "highly insulating material, to [help] create a unique microclimate for the garden below" ("Canary Wharf Crossrail | Foster + Partners', 2015). The planning for climate is reflected upon by Gehl, where squares show people prefer warm space in the sun (Gehl, 2013). The structure for the proposed roofing is designed using the grid pattern identified in the building's structure. The landscape is further enclosed by the stores on the boundary edge. Moments of flux between the landscape and the retail stores is programmed as circulation, a moment of transition between retail and the garden.
"Their rooflessness is a fantastic freedom, to be large, ungainly, irresponsible, and also an acknowledgement of powerful forces which elude any control they exercise."

(Robert. Harbison, 1991)

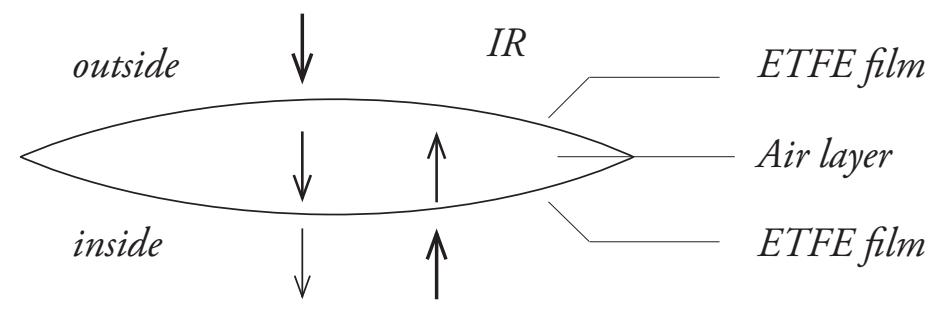

103/ Insulation properties of ETFE. Showing how the material works to insulate the interior of the building. 


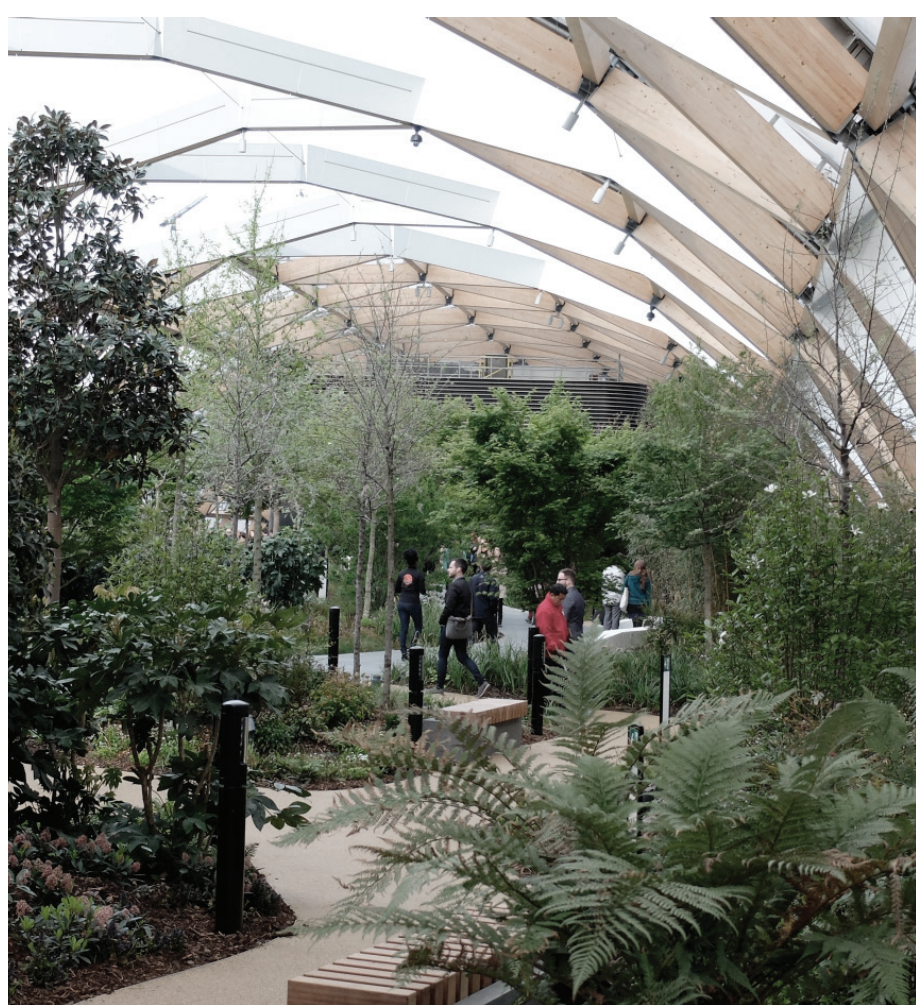

104/ Canary Wharf Crossrail, London.

Foster+Partners. The project shows how this garden,

designed to be micro climate, acts as a gateway or

entry to canary wharf.

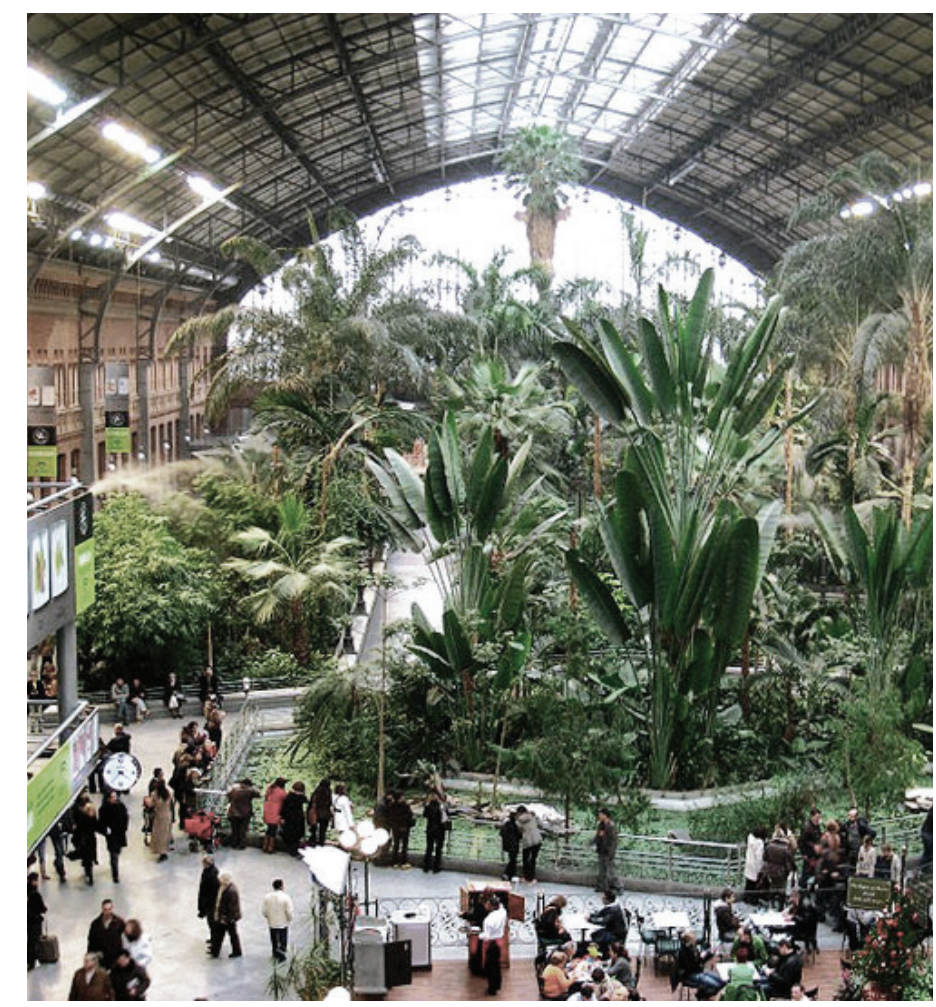

105/ Atocha Train Station, Rafael Moneo. The

covered tropical garden is placed in the centre with

retail stores and amenities surrounding it. 


\section{Paddington Reservoir}

The garden becomes key to how the design fits within Key detail is the wider landscape of both Mahara Place and Waikanae. change of height It is logical for the interior garden to be a flexible space, works for the community in multiple ways; community garden, meeting area, exhibitions and performance space. However by doing this, it may detract from the wider setting. Removing people from the existing street could mean that the remaining Mahara Place would continue to decline in use.

Paddington Reservoir, Sydney, highlights how two types of socially zoned spaces can emerge in an urban setting. The common busy community space happens at street level in Walter Read and John Thompson Reserve, with parallels to the wider Mahara Place precinct. The 'Sunken Garden' is designed in the original reservoir. This space, a tropical garden with reflection ponds, seating and shade, contrasts the rest of the urban space above. Similar to Paddington Reservoir, the garden within the Parker Building raises the problem of entry points to draw people into the solitude. The case study is accessible via a raised boardwalk around the exterior and with stepping stones into the interior. Grand staircases allow change in level from the street. (JMD Design, 2009)
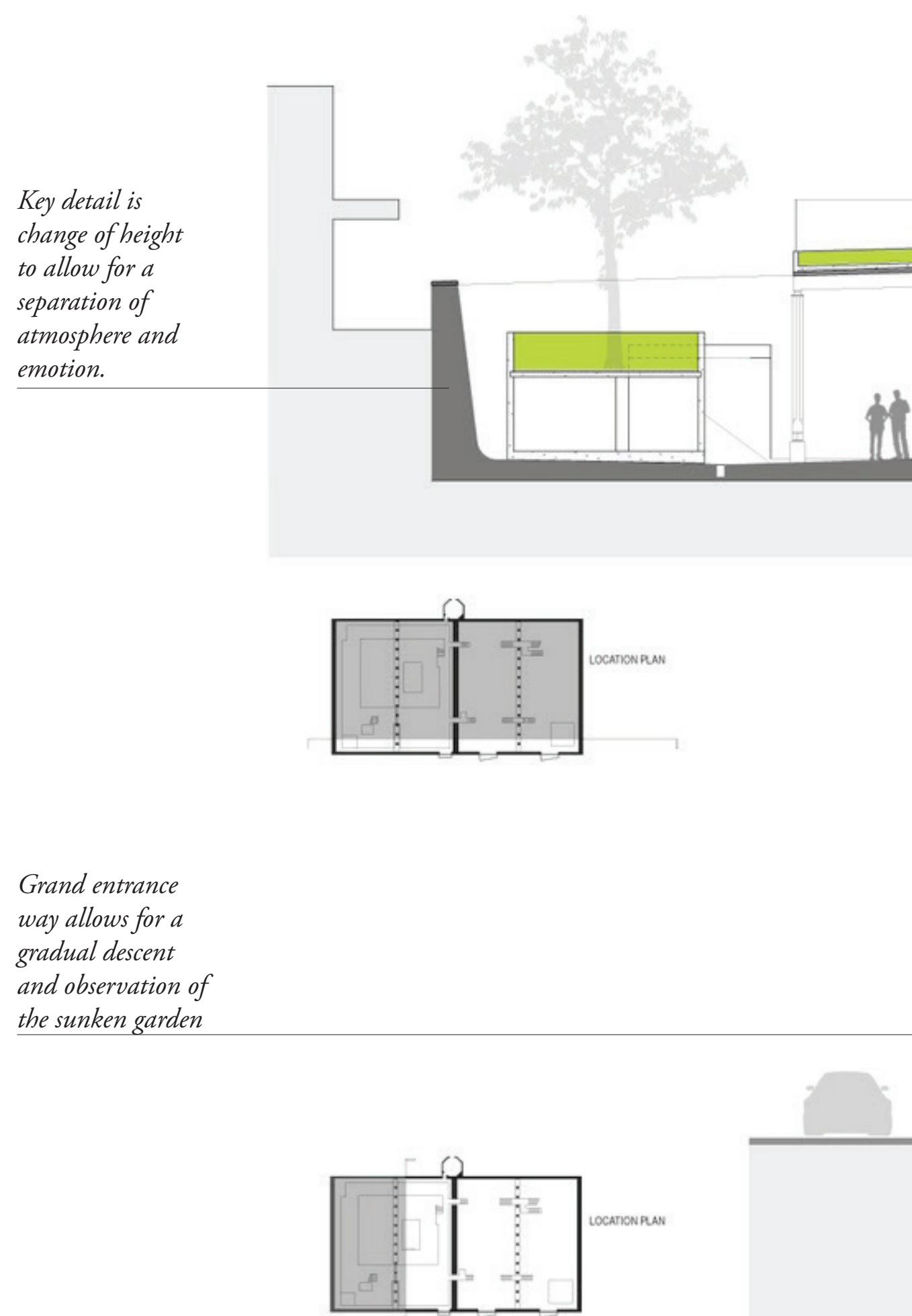


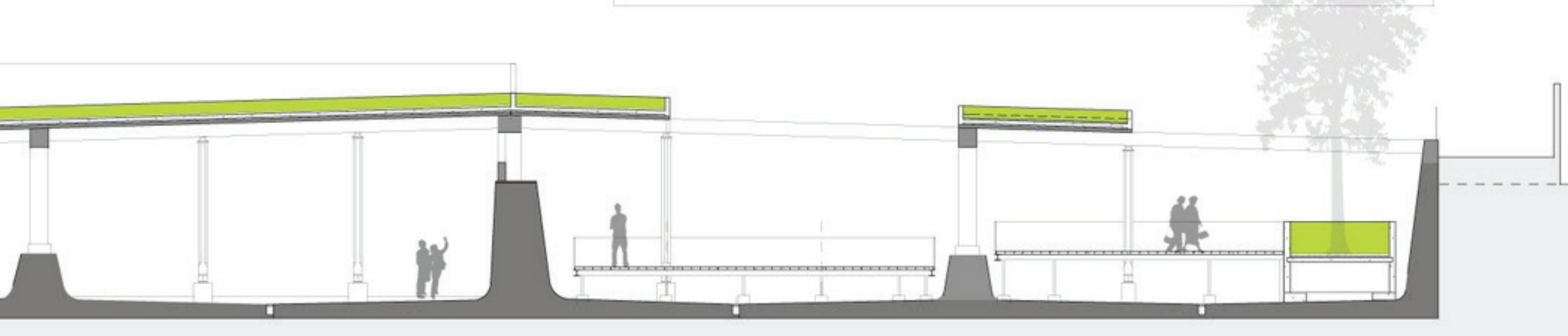

Lower Level

Mid Level

Top Level

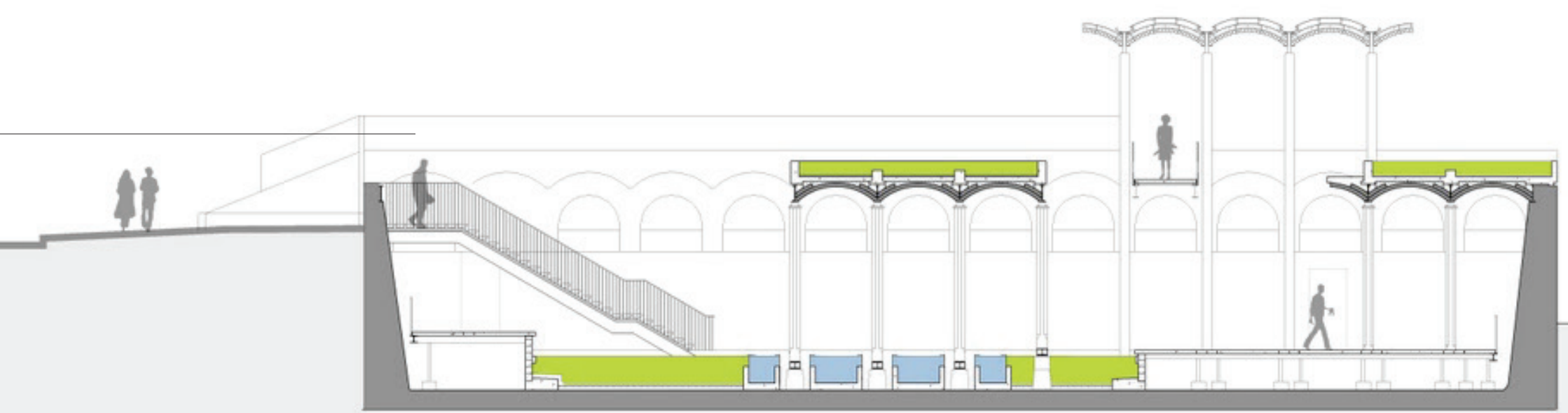

106/ Paddington Reservoir Sections. 


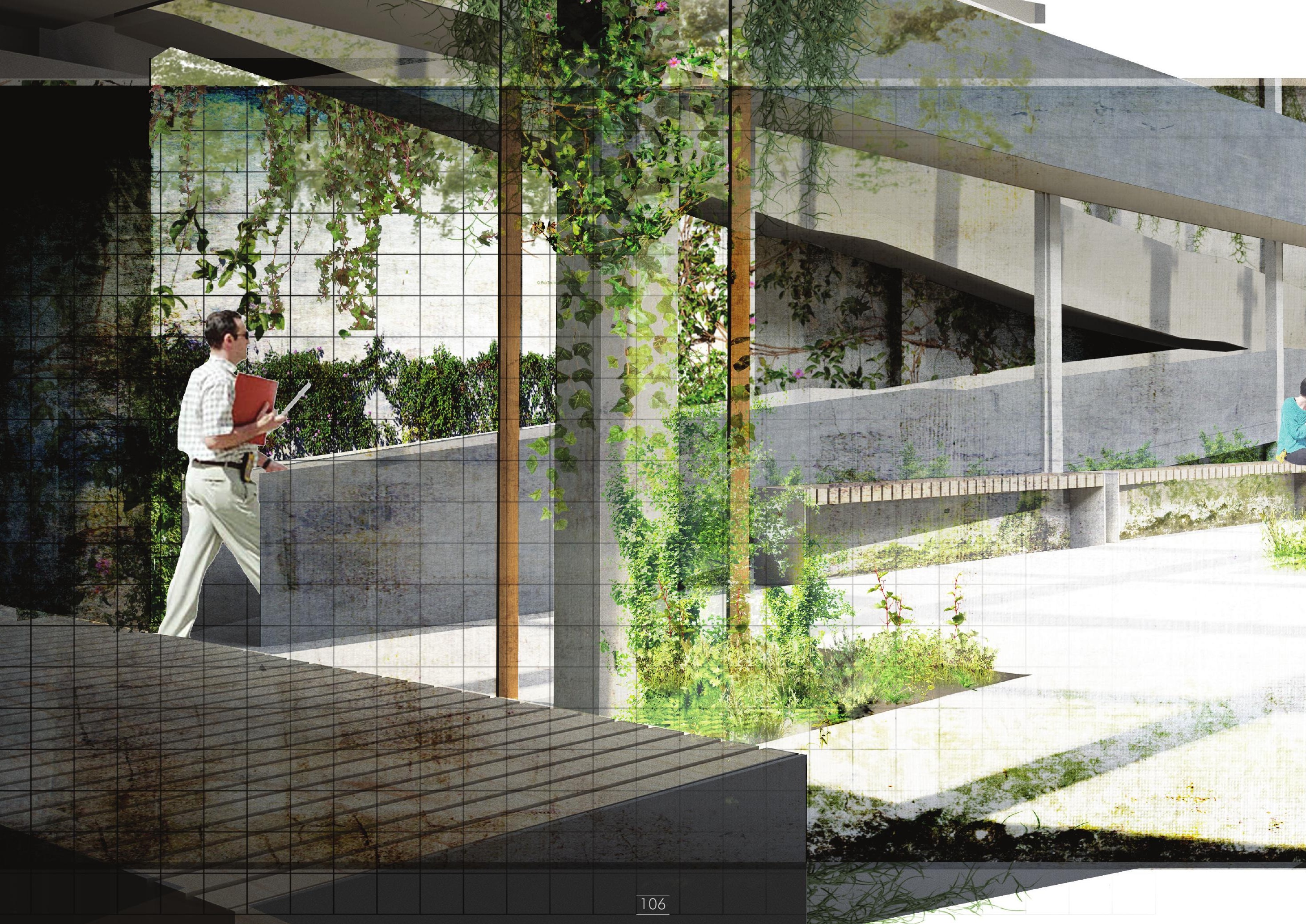




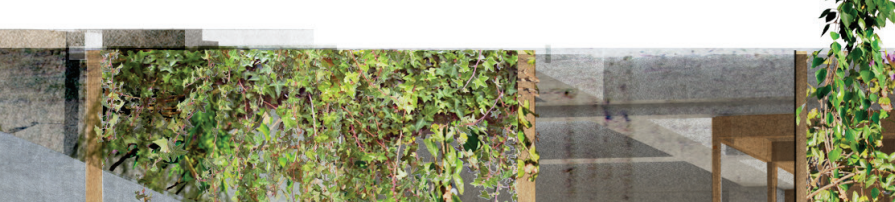

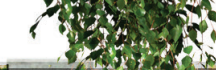

1)

(3)

I.

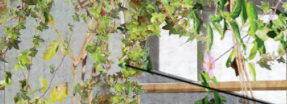

त) तो को

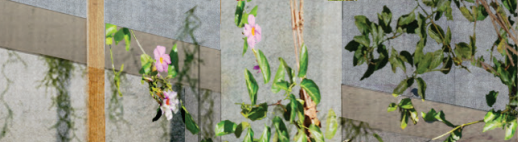

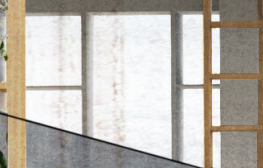

( )

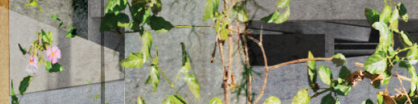

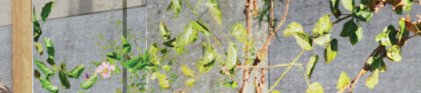

2.

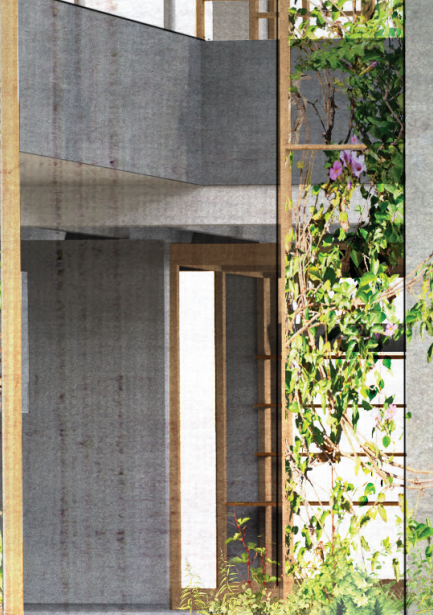

14:

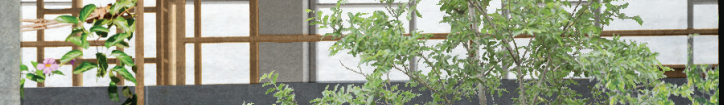

$-x^{2} x^{2}+2 x^{2}=1$

ir an now
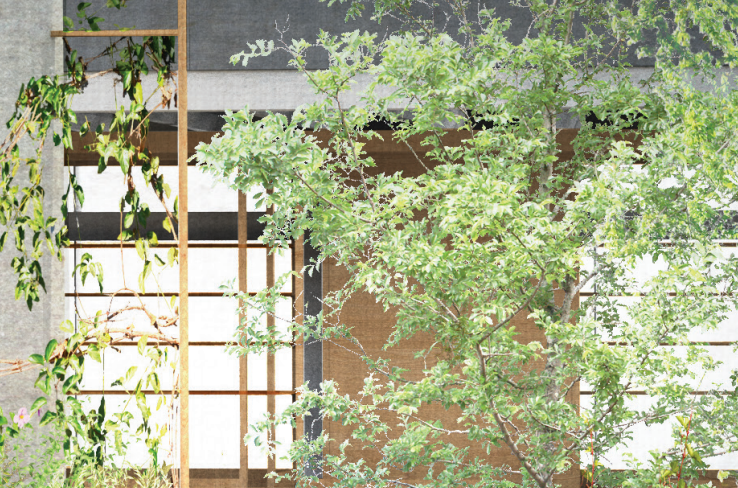

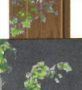

if 3

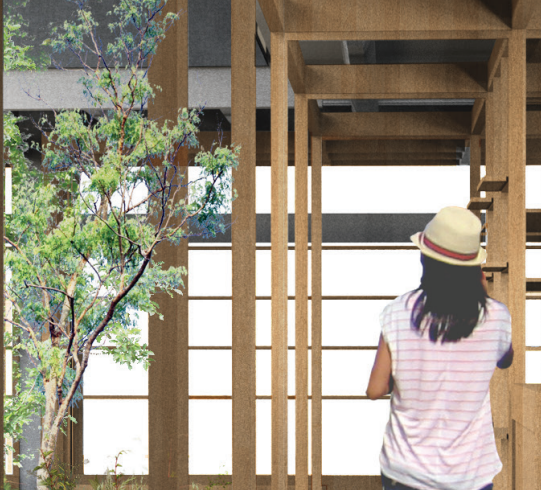

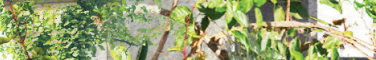

A.m.

ay.t.

(3)
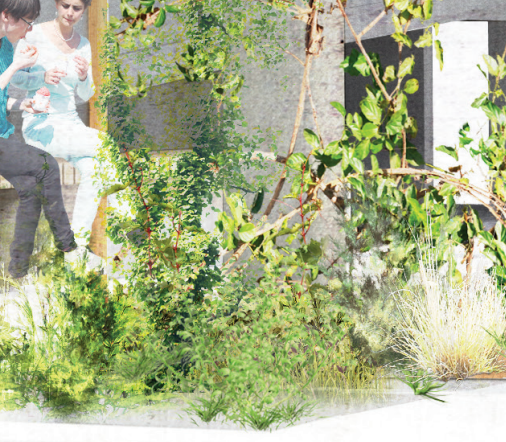

is $=11$

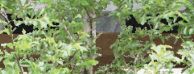

$+x^{2}, 3$

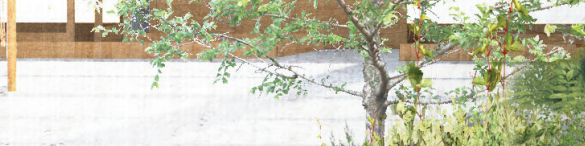

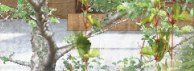
W. at:
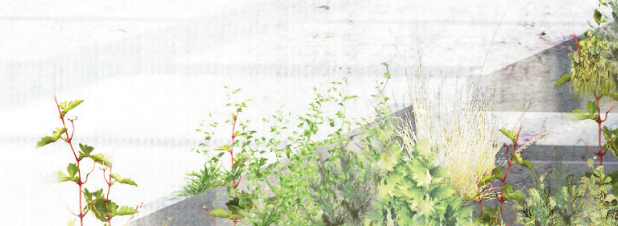

3.t.

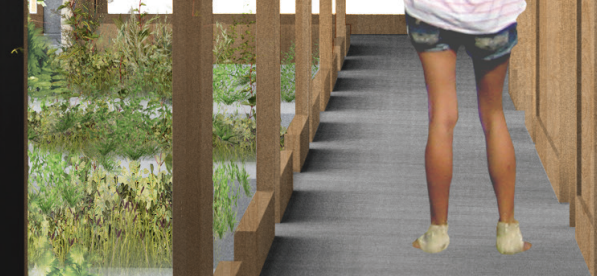

\section{is}

1ㄴ

$x=12$

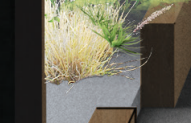

1. $x_{1}$ 



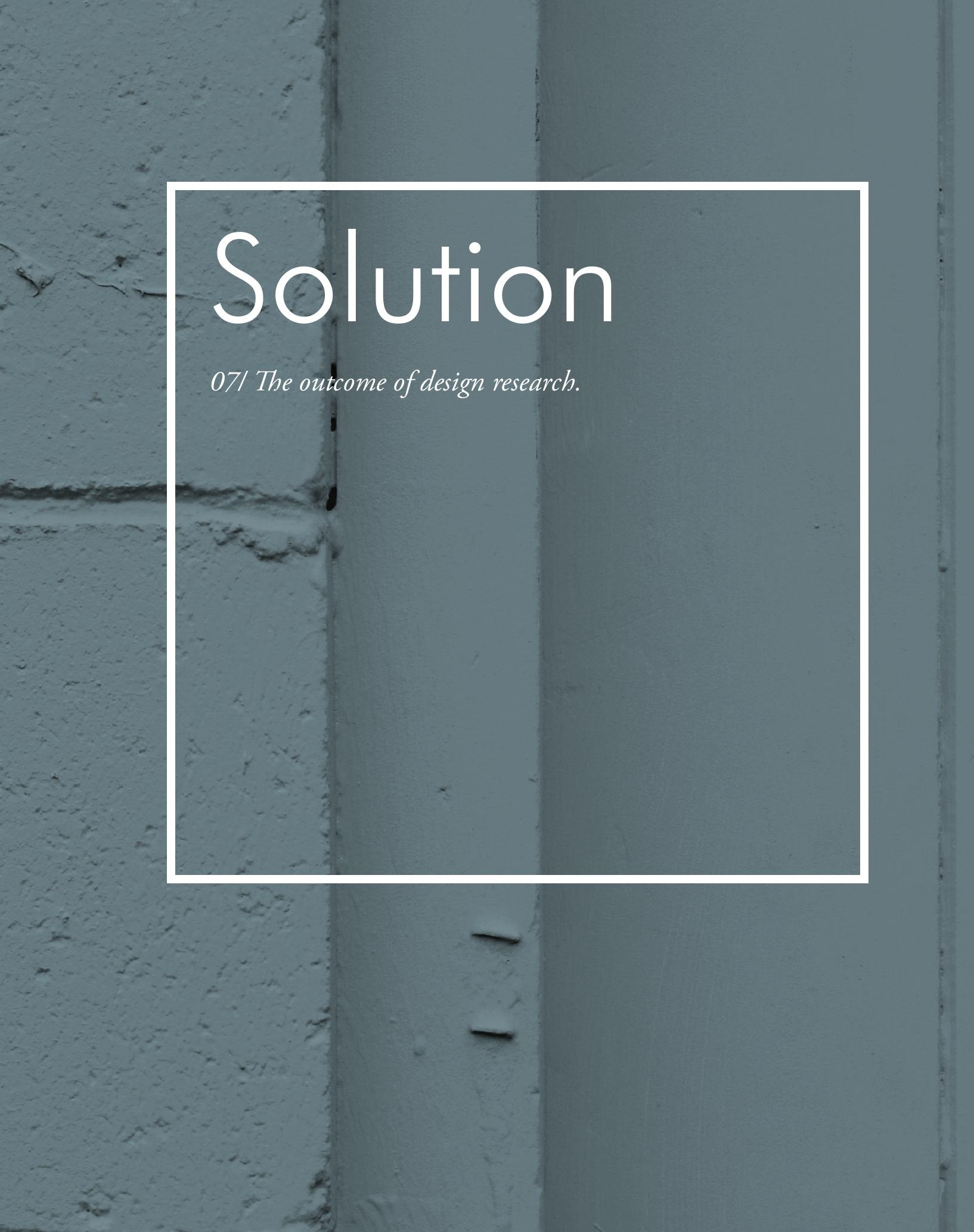

108/ Parker Building 



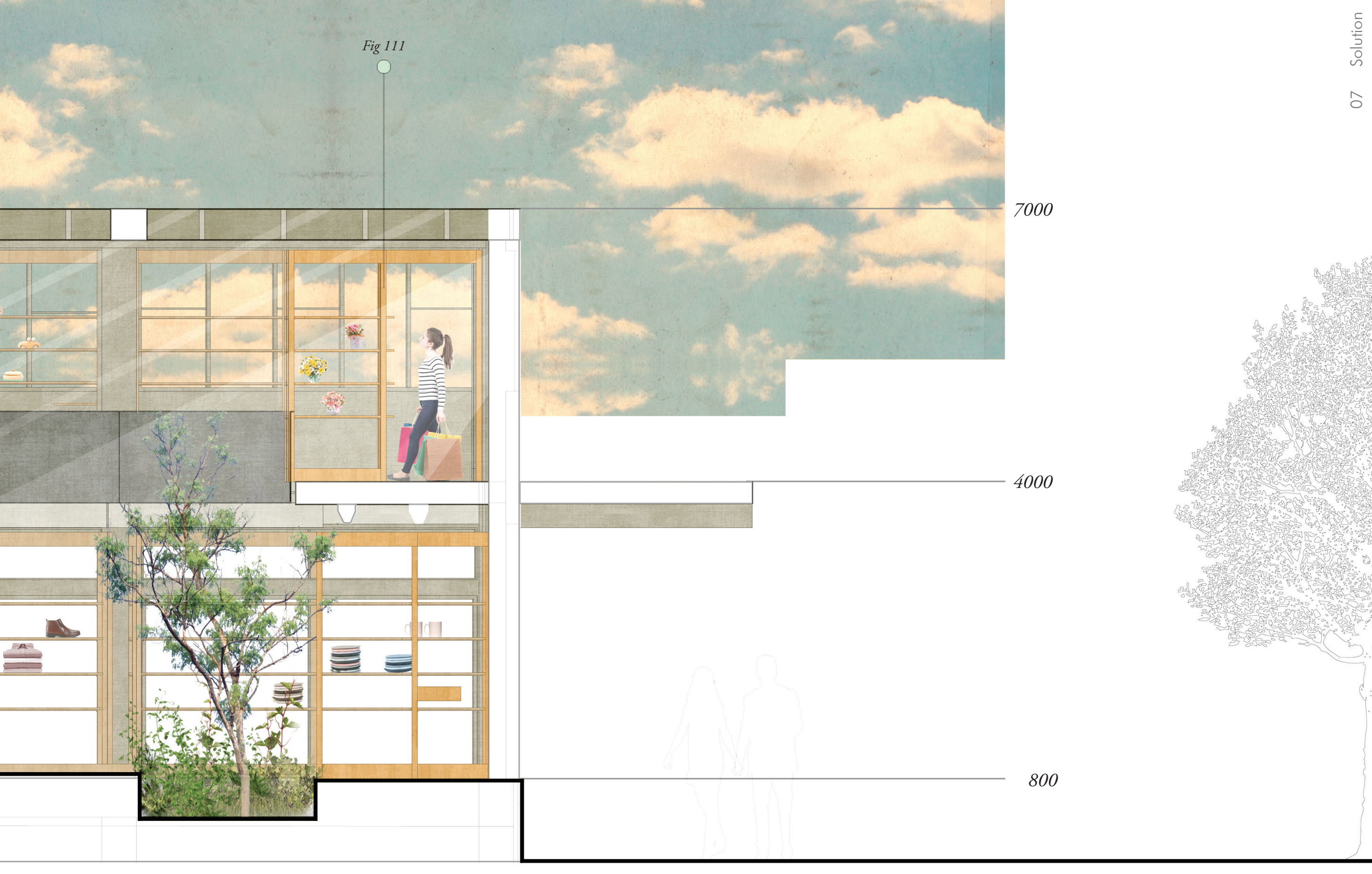




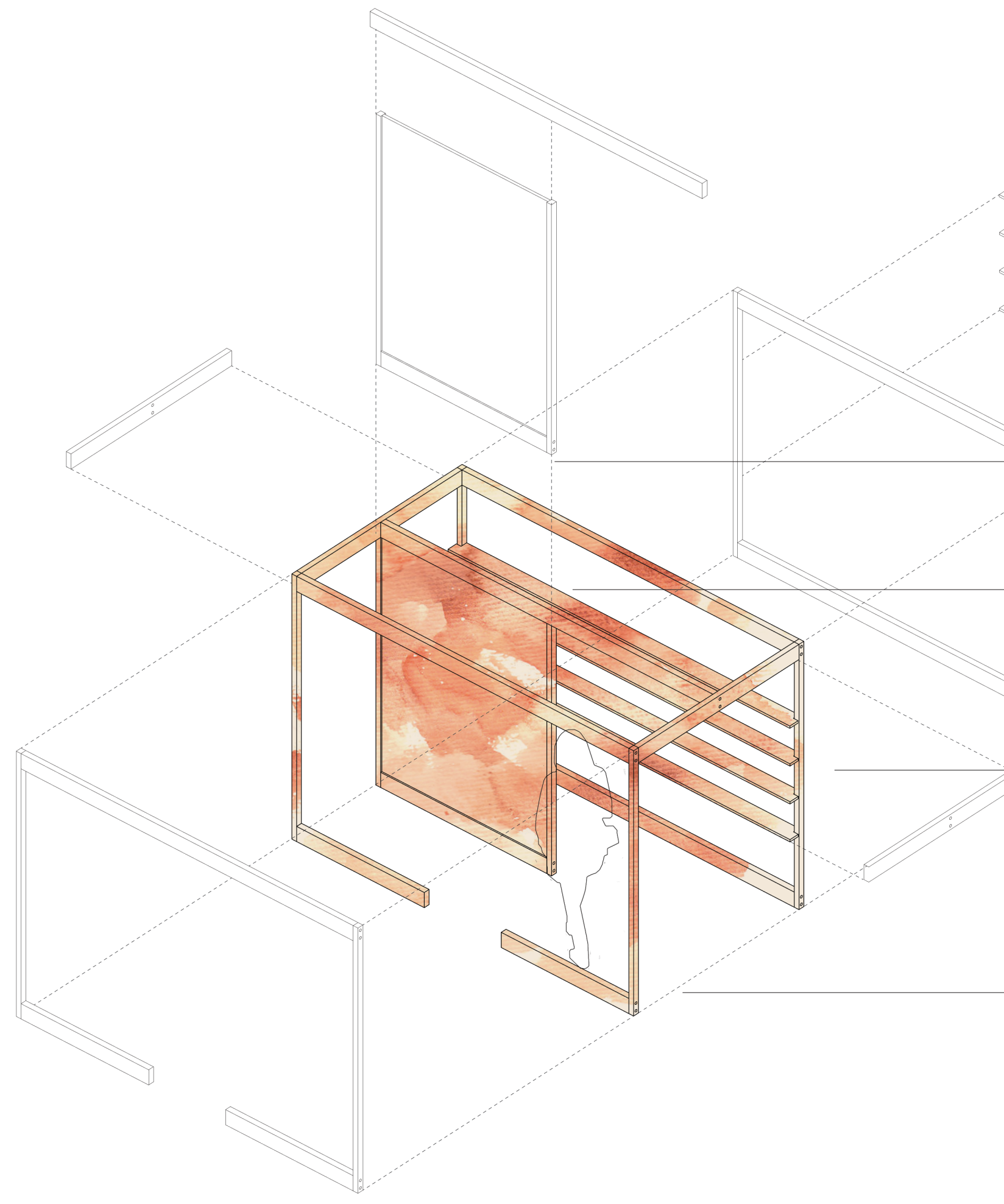


Modular shelves allow for prefabrication and alteration by users to suit the changing needs of the retail spaces.

Privacy Panel, increasing threshold into store various elements can be used to change the make-up of the space depending on product or service offered.

110/ Model of adjusted building.

Timber referenced the identified provincial aesthetic and links it to the modernist era residential built in furniture in a contemporary way. while allowing visual openness.

111/ Exploded store frame, shows light weight construction. Scale 1:50 


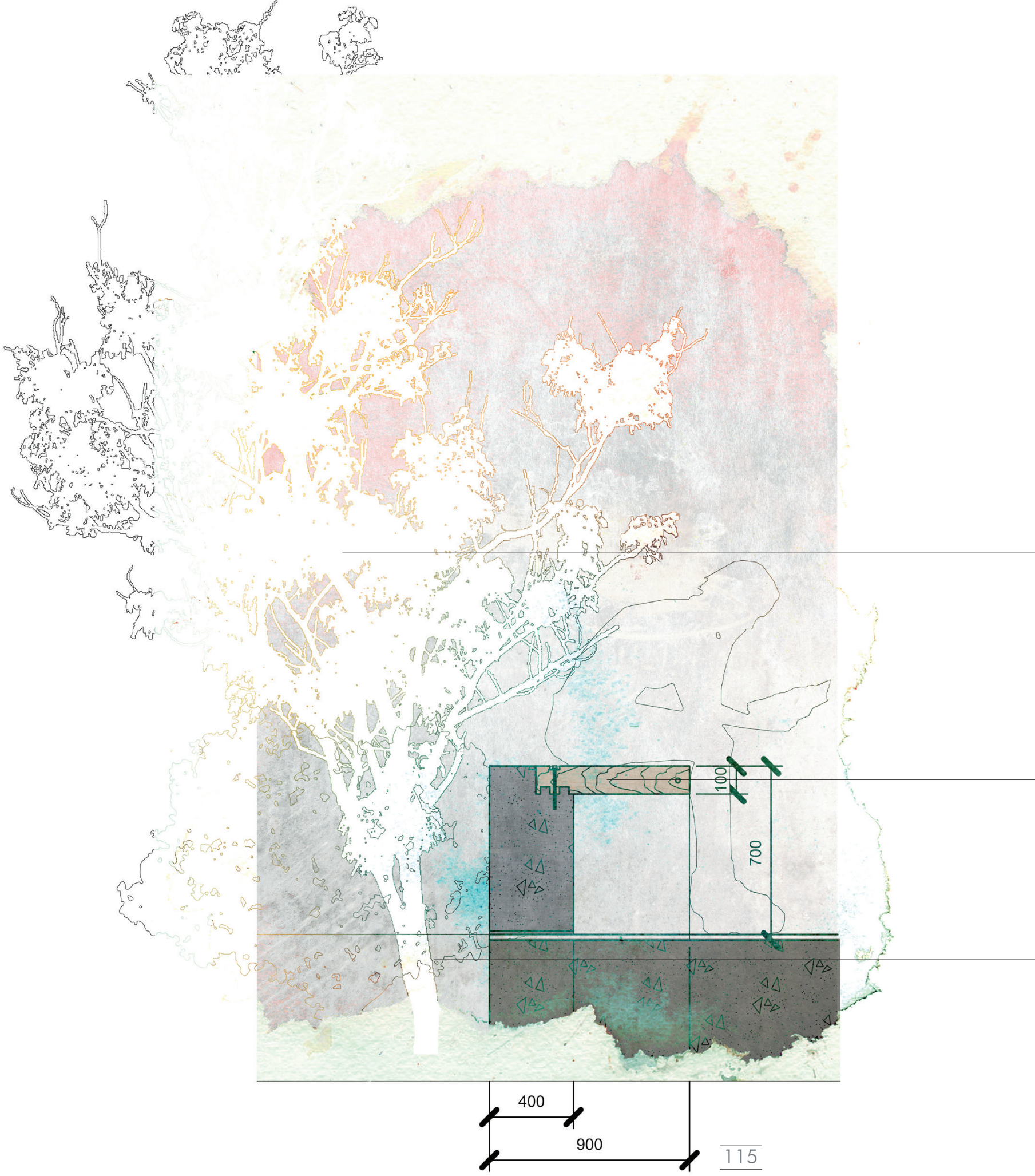

With seating placed on the edge of the garden, the users are immersed within nature. The planting allows for a softened edge.

The materiality of the timber seating softens the concrete, it connects the materials not only to nature but to provincial New Zealand.

Recessed flooring digs into the roots of the existing building, replacing them with trees, mimicking the artificial canopy 
Retail stores, positioned within the grid. Each shop is framed by a window opening.

ETFE roof creates an open sun filled courtyard.

Open roof element takes grid from existing building.

Intervention fits within the envelope of the host building.

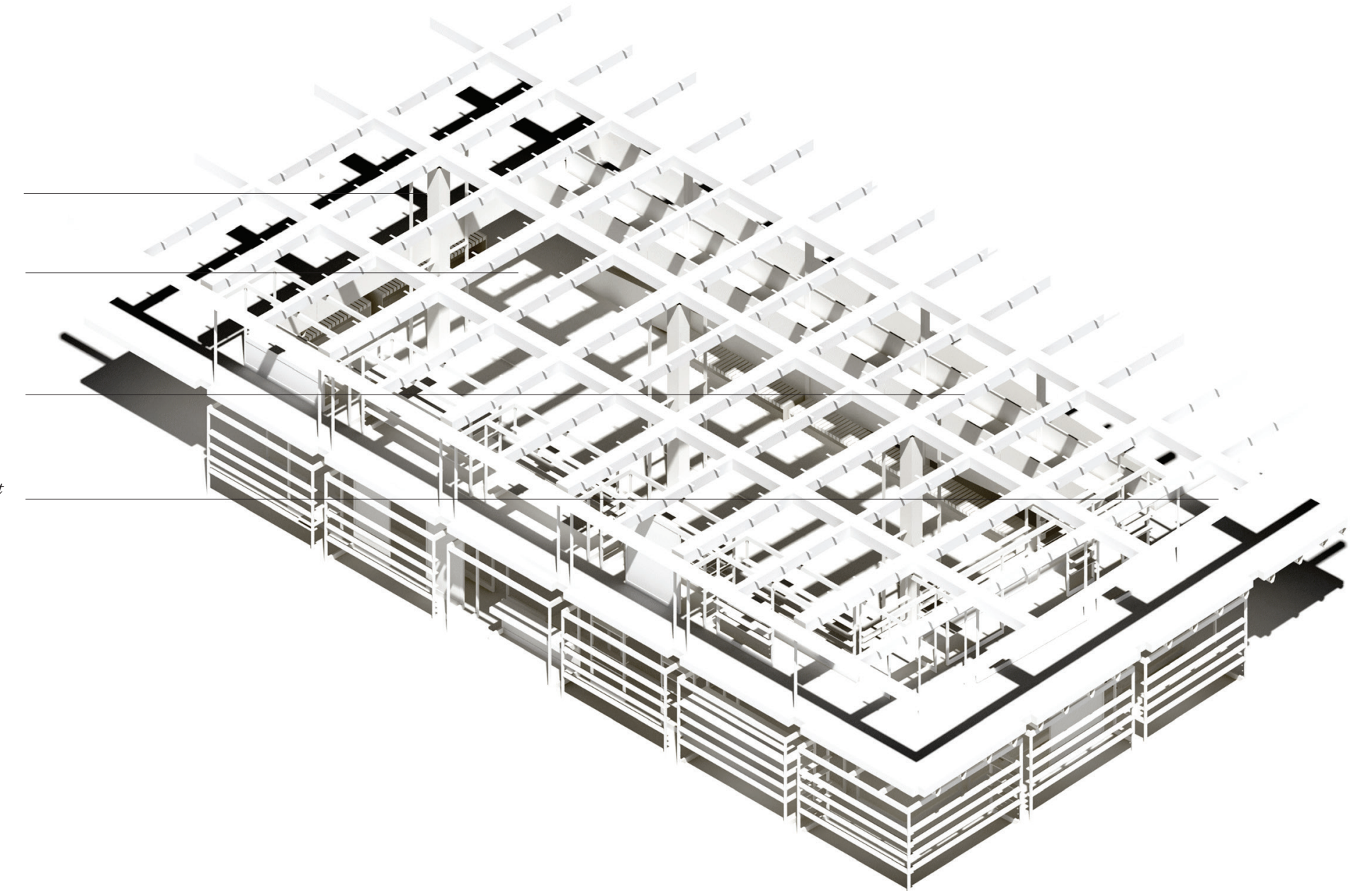

114/ Axonometric Intervention. The intervention

highlights how the design mimics geometric

symmetry present in the existing building. 



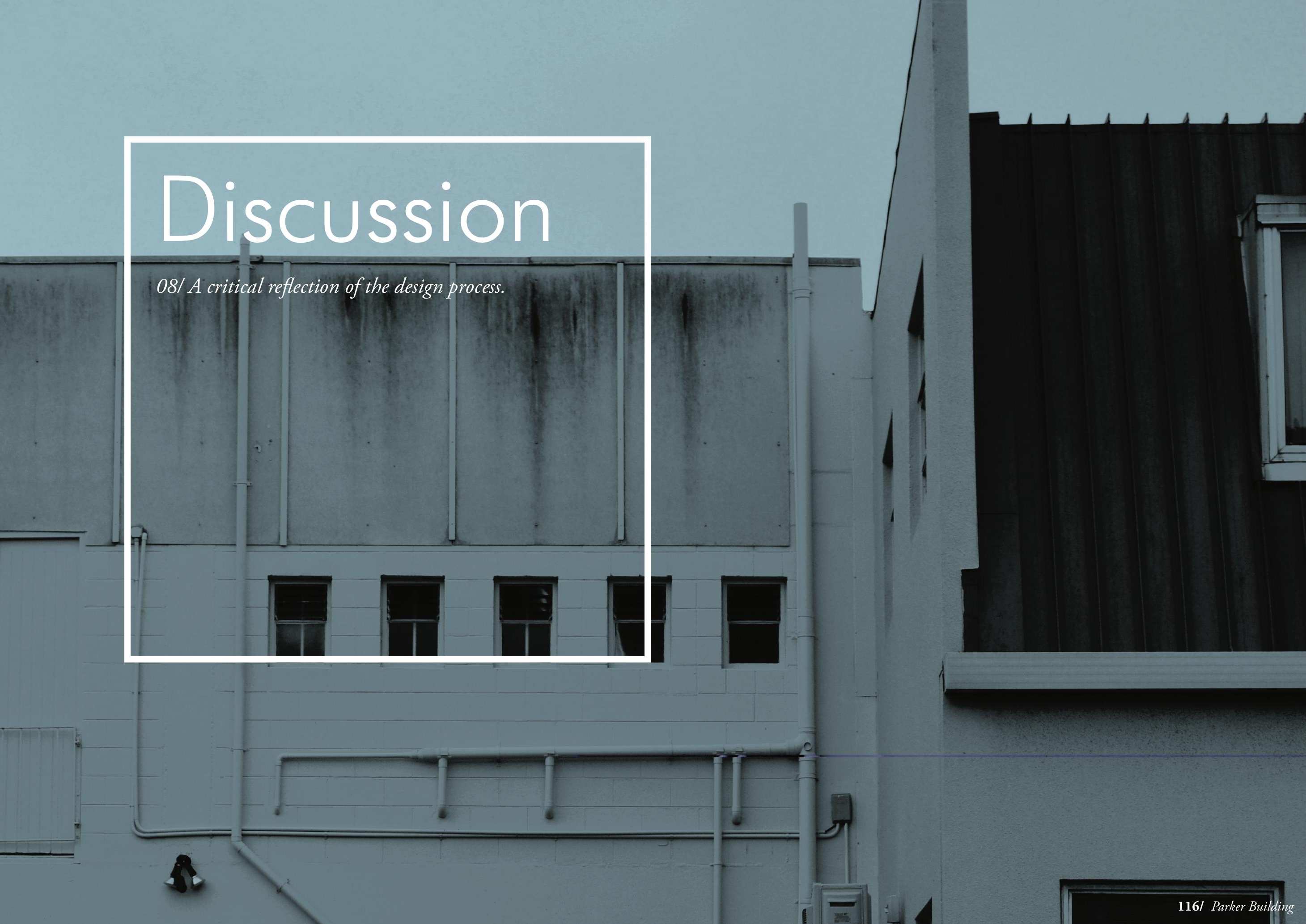




\section{Preservation; more than merely saving material existence}

The primary driver for most preservation projects is "the shell of a Modernist Building. This preservation keeps protection of buildings from our recent past" (Prudon, the facade at its current state, rather than the 1970s 2008) and "[safeguarding] them for generations" version. This, informed by research into ruins (pg. 70), (ICOMOS, 1965). There is a focus on materiality and shows how the entire history of a building is important. their long history. However, Modernist buildings create By removing parts of the interior, it allows for a new fit an additional challenge due to age, decay of temporary out responding to temporary yet specific social functions. materials and times of social change. Theory indicates to Traditional Repairing and Restoring, does not respond three key topics and the preservation of them:

- Repairing and Restoring

to the current community, wider setting of Waikanae and provincial New Zealand. The design allows for contemporary function, within an aging building.

- Adding to, and

- Enhancing Aesthetics

\section{Adding to}

As opposed previous theorists, who promoted the restoration of a building, Fedorchenko, De Smedt and Repairing and Restoring

Henriksson discuss the selection and protection of The core principle and practice, traditionally, is "better aspects of built history, amplifying the past while adding preserve than repair, better repair than restore, better to, fitting within new requirements - in the case of this restore than reconstruct" (Prudon, 2008). This statement design research project, the growing presence of Big Box is the common thread between the Venice Charter and retail in provincial centres and the implications on how Docomomo ('Docomomo', n.d.; ICOMOS, 1965). Modernist Buildings are programmed. The role of the The theorists set guidelines focussing on restoration and architect becomes one of fitting new architecture within conservation. The key aspect of this method is to reinstate the existing- adding to (De Smedt, 2015; Fedorchenko, the building to its original state.

2015; Henriksson, 2015). By adding to the Parker Building's existing shell in a unique and careful way, while

Contrasting this restoration process, the thesis research also selecting parts of history to preserve, transitions has led to the preservation of the internal structure and between old and new are formed. Using the "weight 
of history as a spring board" (Henriksson, 2015), the for the natural weathering of the buildings shell, the addition of light timber market structures adds a flexible shell becomes like a ruin with the new function naturally new programme, while allowing the structure to remain growing and changing within. Otero-Pailos, similar to as the backdrop for the activity within. Adding to allows Matta-Clark (fig 72) and Whiteread (fig 73), shows how the 'working interior' to change and transform to the the aesthetics or part of the aesthetics can be preserved needs of the tenants and community over time, further in the form of art or installation. This preservation adding to the ruins.

technique has a focus on acknowledging the buildings whole history.

Enhancing Aesthetics

Enhancing aesthetics sits somewhere between restoration The research has shown that there are many ways of and addition, acknowledging the past and natural approaching the task of preservation. Case studies progression of time, allowing the building's story to be and theory indicates three key approaches- Repairing told (fig 70). Otero-Pailos (2015), takes casts of dust, and Restoring, Adding to, and Enhancing Aesthetics. highlighting weathering of the building, showing an However, for each preservation case there are other factors imprint of a point in time rather than restoring to the to consider- site, type of building, present and proposed original design (Prudon, 2008). The project has allowed function, budget and aesthetics. The design research for

$117 /$ Enhancing Aesthetics

\section{BIG CHANGES}

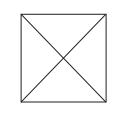

Repairing and Restoring
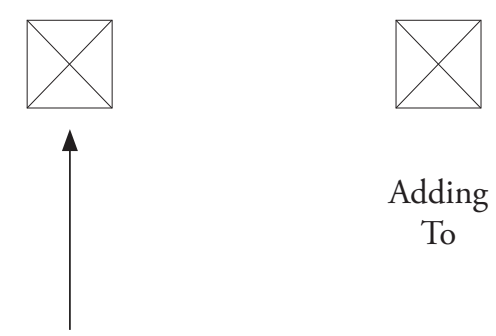

SMALL CHANGES

Adding

To 
the Parker Building highlighted how for a particular building, a combination of key approaches was most appropriate. It allowed for respectfulness of the building, while transforming it into a modern day functional space. The preservation is still about maintaining the building for the future, "[sustaining] it for future generations" (Prudon, 2008), but as a useable, reactivated space.

The aim for the reactivation was always to show how modernist buildings in provincial New Zealand can be used in a contemporary way. The buildings are part of our history, so should be respected. The contrast to this is demolition. The research leads to a cost effective alternative to traditional restoration. It doesn't make sense, financially or socially, to knock them down, instead we should alter them to work for today's generation. Timber structures, flexible programme and open spaces allow for the building to alter again with changing needs. 


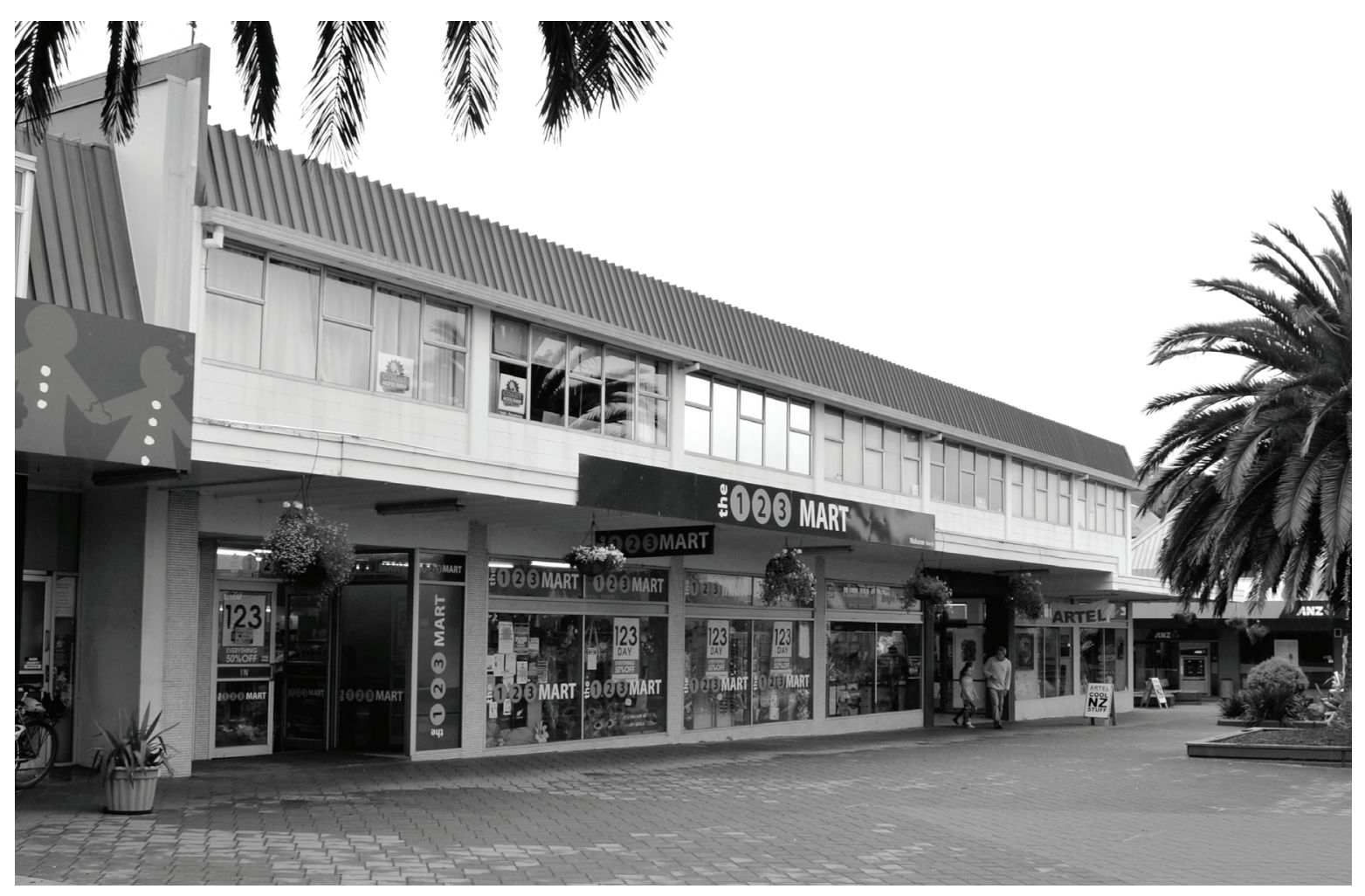

118/ Parker Building 


\section{Provincial Modernism in New Zealand; interiors within a broad context.}

Interior architecture can be designed in isolation from and placement within the context of the Parker Building, context, responding to the host building and programme, Mahara Place, Waikanae, Kapiti Coast, Provincial ignoring what is outside the building envelope. Provincial New Zealand, New Zealand as a whole and Modernist New Zealand and Mahara Place question what makes Buildings.

design purely provincial.

The interior space responds to these contexts, An initial hunch design was a mixed use community within mimicking dense retail experiences. The context and a dense market street. Hypothesising the densification of scale of provincial New Zealand reshapes the needs and Waikanae, supported by a new community at Mahara requirements of retail by shrinking the urban scale into Place, involved 'inserting' additional programmes a building. This acknowledges population parameters of into existing buildings. McWilliams (2015) explores small towns. Small box retail shows an alternative for a how specific, dense cultures translate to an urban site, provincial setting. Hall (2015) shows how mixed retail focusing on a consumer lead society with "cafes and niche works with mixed demographics.

shops" (Cumming, 2015). Mahara Place is not currently

urban, however the design experimented with scale. By Small Box Retail (pg. 89) discusses how this programme translating the dense East London urban fabric into a is best suited to the edge of the building, an appropriate single building, it provides a framework for the growth of solution to the wider context. With the edge activated, market stall holders and independent business, appealing an interior garden was developed for the remainder of the to the consumers and producers alike. This application building. This programme, seen in Atocha Train Station, appears fitting for provincial New Zealand, a creative and by Rafael Moneo and Cross Rail by Foster+Partners, technology driven area, with less materialistic generations, brings nature into the interior. By breaking the trend of limited space and demand (McWilliams, 2015). Many of concrete public spaces, the project creates inhabitable these derive from a limited budget, hence the context of spaces which allow for circulation, socialisation and provincial New Zealand.

tranquillity. The connection to nature is important in

Provincial townships; bringing people and the external

This concept from reactivation allowed for responsiveness environment into the space. 
The wider context informed experiments of materiality, programme, atmosphere and preservation. Research of how the building could be reactivated by integrating these experiments into the site, context and contemporary nature helped to answer what is purely provincial.

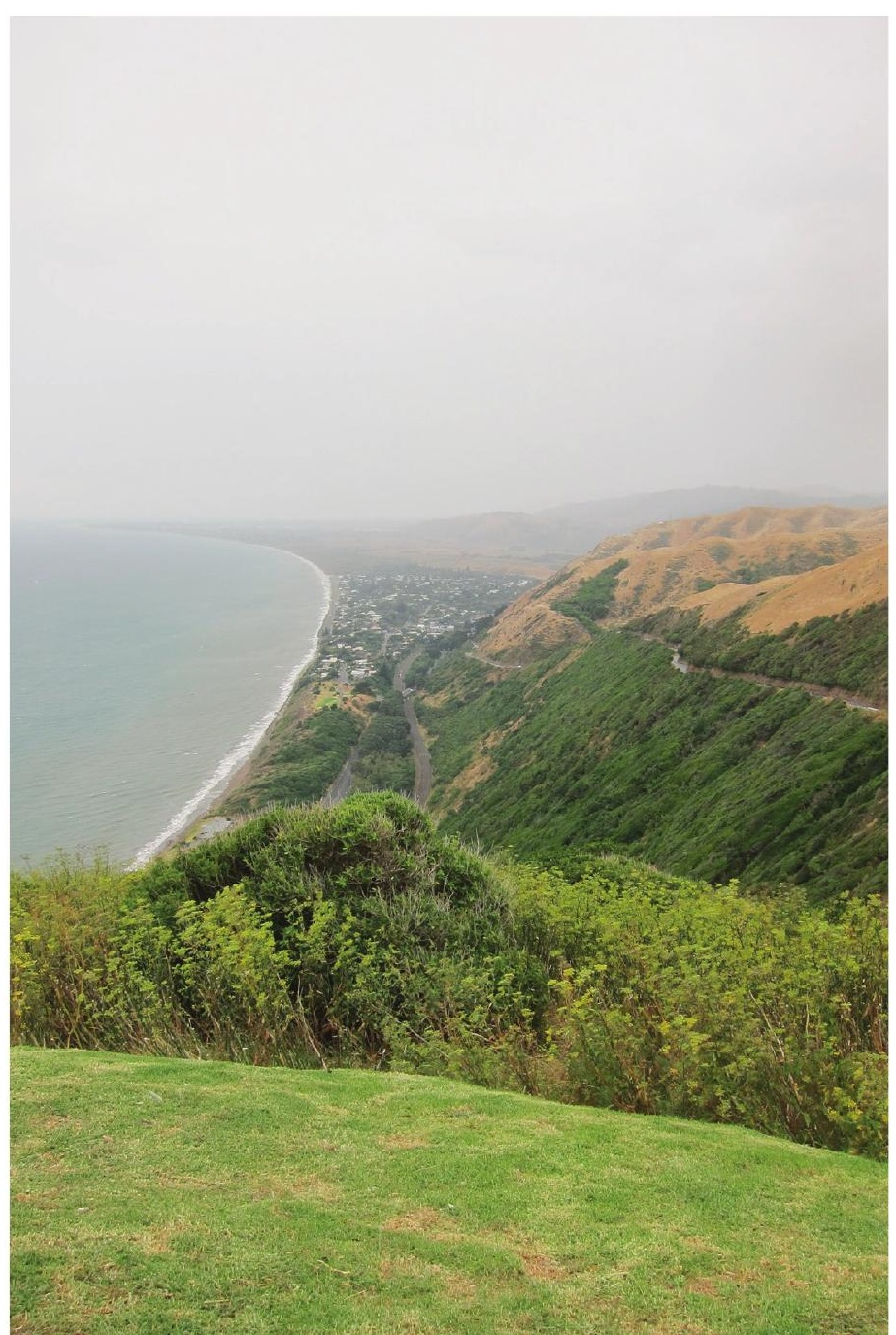




\section{Programme; or anti-programme}

Form follows function (Sullivan, 1896), however the itself (Gatley \& Lima, 2008). Working as an alternative thesis has struggled with solutions to programme. In to a community hall, the space could transform into an order for functional preservation, the correct programme art gallery, musical and theatrical performance space, was necessary to assist with design decisions. The building farmers market, community vegetable garden or meeting has had a high turnover of tenants, similar to many space.

other provincial buildings. The contemporary solution

allows function to be foremost, letting programme and Functions of the garden became an important tool to aesthetics to organically develop as needs change.

reflect on aims of the research, including that of the wider site. Refocusing on this revealed the need for buildings to As discussed above, with big and small box retail, the support and reflect Mahara Place as a whole. Like a market, building needs a flexible programme. Retail is ideal for the stores would be draw people into the building with its town centres. The research showed that the size and niche and personalised products, helping to reactivate it. organisation of current retail in Mahara place was an The central garden becomes a flexible community space; issue.

it may remove reactivation possibilities for the rest of the street. Community activities, such as farmer's market,

The interior garden became an anti-programme move could easily occur in the large street spaces.

for the interior of the building, enclosed by the façade

of retail and the existing walls. A garden has the ability Allowing the centre of the building to be purely a tranquil to work for the community, becoming a flexible space, garden there is opportunity for the space to be changed adaptable and open planned like the modernist building in the future. Light timber frames and relaxing seating in 
the garden, means that if requirements for the buildings were more specific in the future, the building could be easily changed- enhancing the adaptability.

Retail is important to the site, however without a programme there were risks and challenges that could be explored without the identification of traditional retail programme issues. A final programme was introduced late in the design process, when the formal language was already developed. This language developed by examining how different parts of the building work together, like an ecology. A variety of 'elements' were designed to change spatial understanding which when combined, formed a design scheme along with a fitting anti-programme.

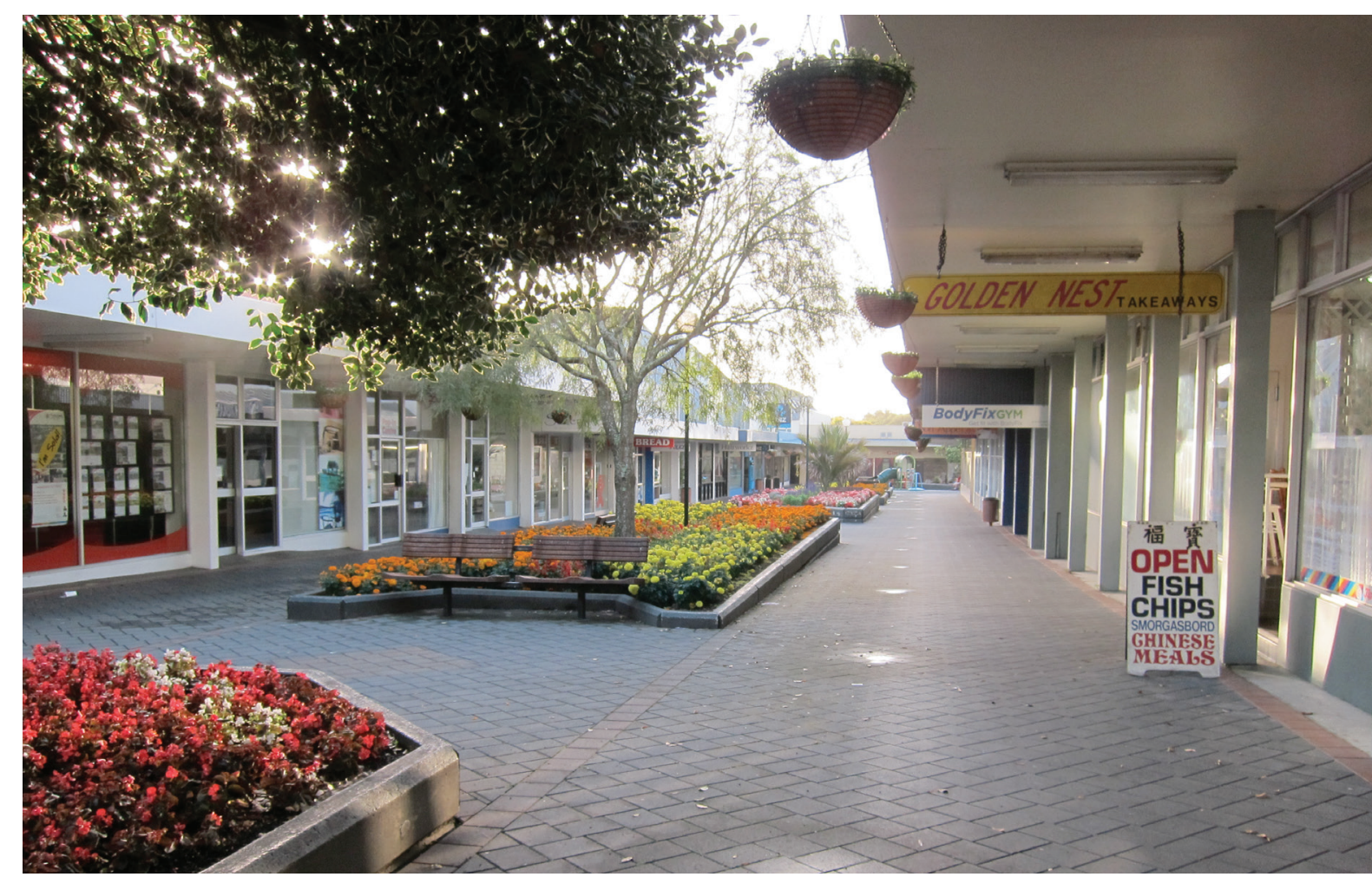

120/ Mahara Place 


.



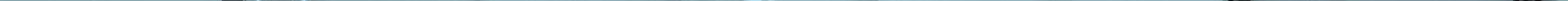
The pursuit of reactivation has led to the development of an interior design that reflects the social, economic and site constraints of provincial New Zealand. The design, an interior garden with small retail on the perimeter, acts as a solution not only to preserve a modernist building but also revitalise the shopping prescient.

The research, set in Waikanae, Kapiti Coast, fits into a wider body of research - Settling Regional Landscapes: Kapiti Horowhenua. Similar issues of resilience, development and urban systems can be explored at the scale of interiors. The design solution is strongly influenced by its setting within the landscape of a provincial town and its demographics, issues, trends and lifestyles.

The provincial township, in 2016, is one of decline; empty stores, lack of community space and a sense comradeship. These towns have the ability to be reactivated, responding to modern-day needs. Mahara Place, Waikanae, should be an energetic town centre, however it is a place of tiredness. The buildings could be used more practically

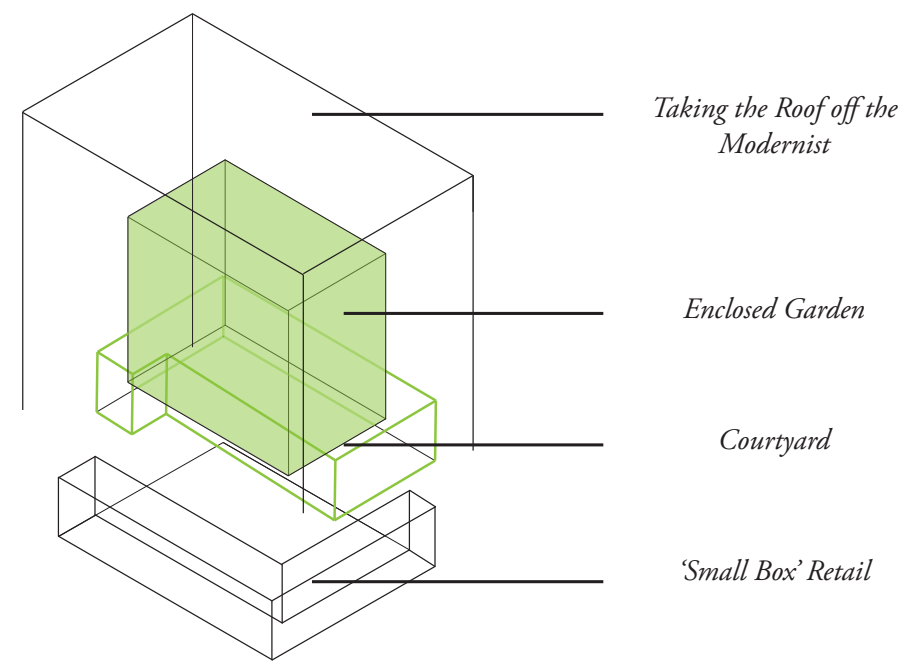
to assist current needs.

The design research became a search for reactivation, something that could mobilise a suitable alternative. It 
was influenced by the site and constraints, such as the beyond the original scope, producing an alternative suitability for provincial New Zealand e.g. budget and output.

source of material, becoming a balance of issues such as preservation and programme. The modernist case study The research leads onto further investigation:

raised issues of appropriate responses to preservation; is it one of protection, reinstatement, demolishment or alteration? The process became a range of iterative concepts, exploring hunches and theoretical ideas for the site.

The research explored the constraints and commonalities of the interior architecture discipline, alongside critiquing architecture preservation. Much of this was influenced by the context, where a contemporary multi-million dollar solution would not be appropriate. The design looked at how an interior can and should be influenced by more than what is happening within the walls.

Formed by retail densities, decline and degradation of disused buildings, courtyards and gardens, and developing preservation standards, the research forms a solution of a tranquil interior garden surrounded by an active series of retail stores.

The solution only tackles a single type, location and problem, however this design process could be used

- How can a similar process be used to reactivate other under used buildings in Mahara Place?

- Is this an appropriate solution for other modernist buildings?

- How could other provincial towns be designed in a similar way to this case study?

- How will the interior adapt to future programmatic needs?

Overall, this research is one solution that begins to reactivate Mahara Place and the larger Waikanae Township. Resilience in the provinces can and should involve using current buildings, adapting these to contemporary needs. Preservation should work with a similar ethos, using what is available, while allowing it to work for today but change again in the future. 


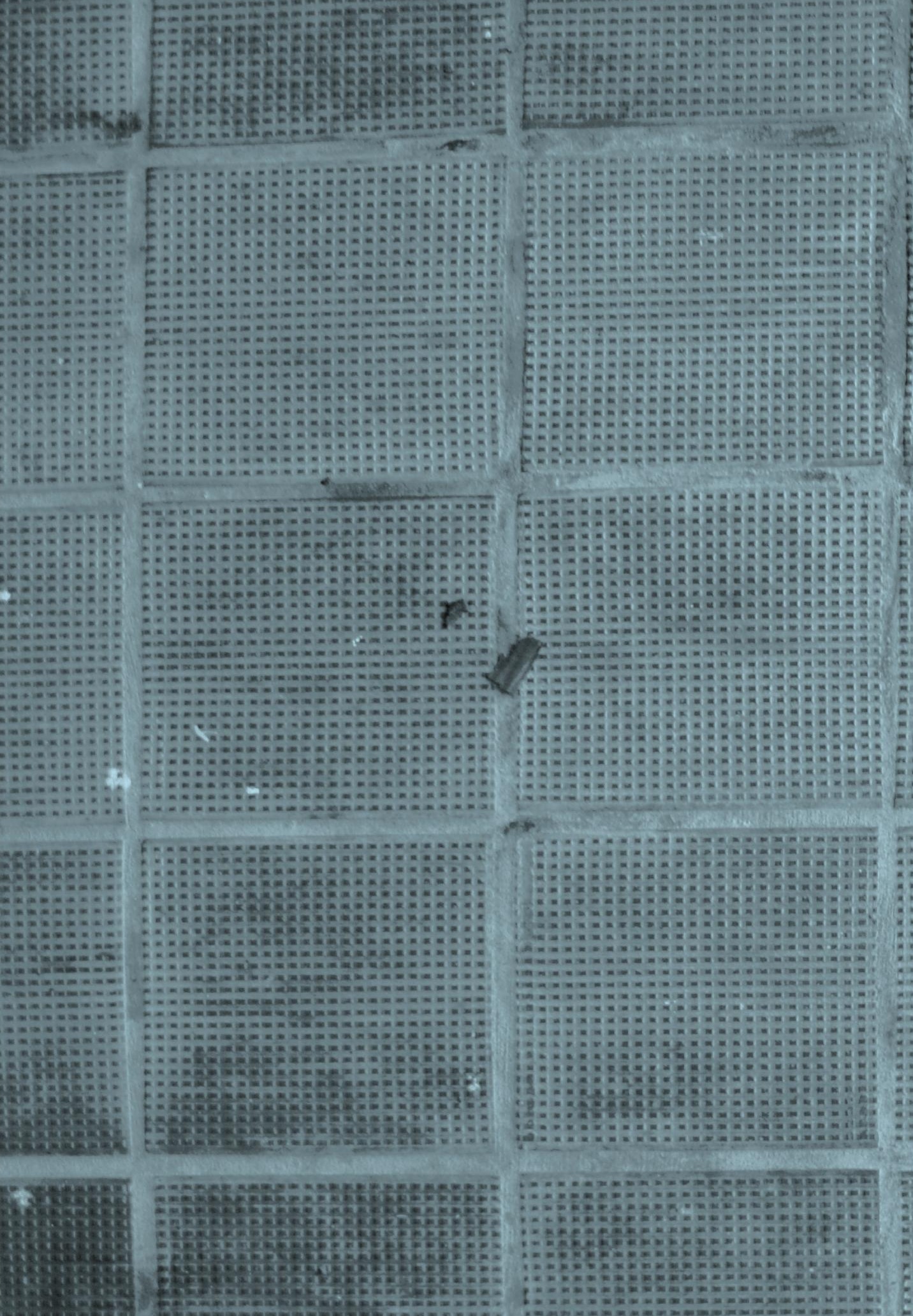




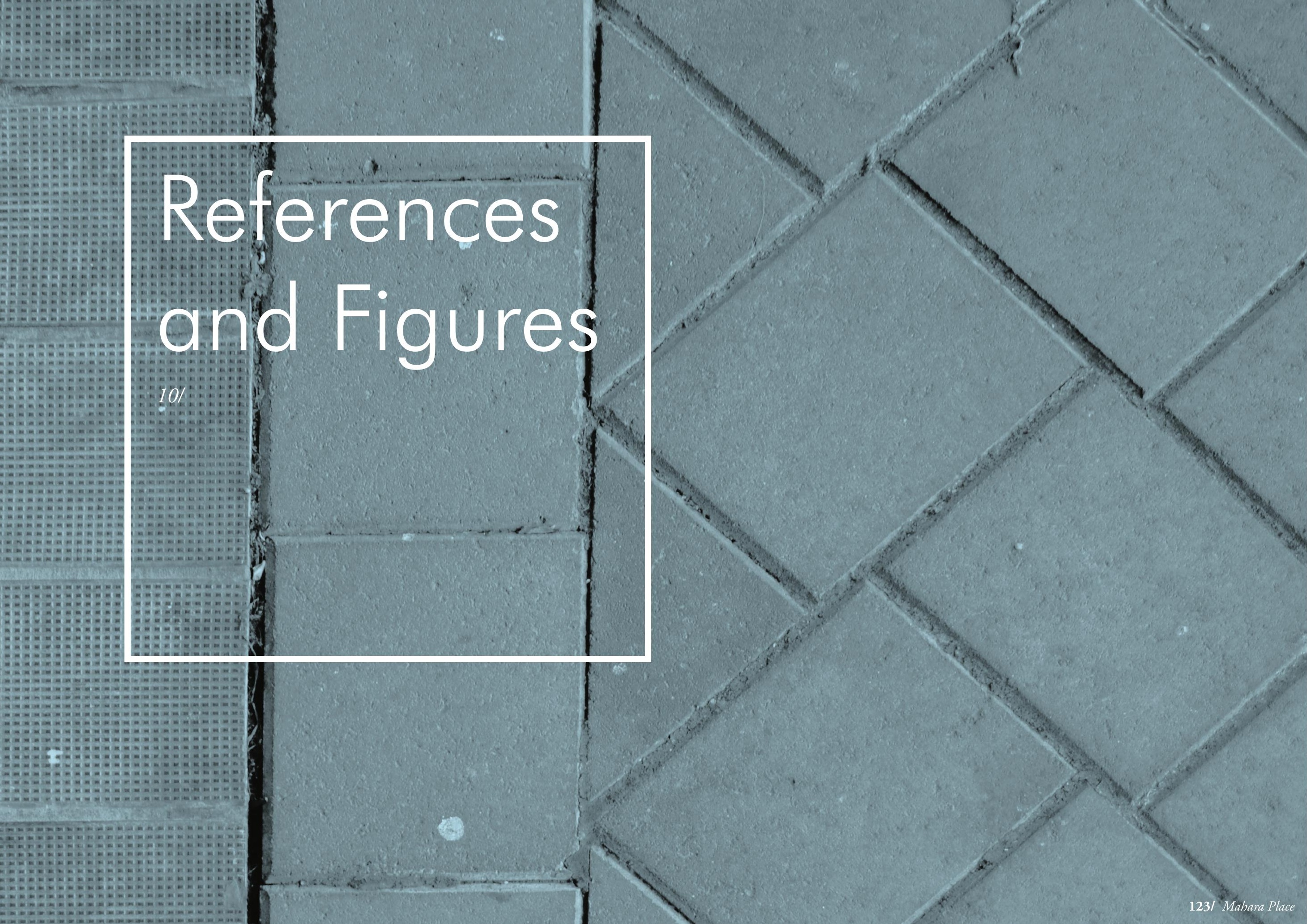




\section{References}

Aben, R. (1999). The enclosed garden: history and development of the hortus conclusus and its reintroduction into the present-day urban landscape. Rotterdam: 010 Publishers.

Allan, A. (2009). Issues Paper: Big Box Retailing in New Zealand. Opus.

Blundell, K. (2013, May 2). Businesses lock horns over Kapiti retail. The Dominion Post. Wellington. Retrieved from http://www.stuff.co.nz/business/ industries/8621569/Businesses-lock-horns-over-Kapitiretail

Canary Wharf Crossrail | Foster + Partners. (2015). Retrieved 7 December 2015, from http://www. fosterandpartners.com/projects/canary-wharf-crossrail/

Clark, J. (2000). Looking for the local: architecture and the New Zealand modern. Wellington: Victoria University Press.
Cumming, E. (2015, March 8). Can hipsters save the world? Retrieved 29 April 2015, from http://www. theguardian.com/uk-news/2015/mar/08/can-hipsterssave-the-world

Curran, D. (2002). Challenging the Sprawl of Big Box Retail: The Smart Growth Approach to 'Zone it and They Will Come' Development (SSRN Scholarly Paper No. ID 2279667). Rochester, NY: Social Science Research Network. Retrieved from http://papers.ssrn. com/abstract $=2279667$

De Smedt, J. (2015). Julien De Smedt 120TALKS 2015. Retrieved from https://vimeo.com/122301256

Docomomo. (n.d.). Retrieved from http://www. docomomo.org.nz/

Downton, P. (2003). Design Research. Melbourne, Australia: RMIT University Press. 
Ernst. Neufert. (1980). Architects' data(2d (international) Hall, S. (2012). City, street and citizen : the measure of English ed..). StAlbans, Eng: Granada Pub; New York. the ordinary. London: Routledge.

Fedorchenko, M. (2015). Maria Fedorchenko 120TALKS Hall， S. M. (2015). Super-diverse street: a 'trans2015. Retrieved from https://vimeo.com/120960691 ethnography' across migrant localities. Ethnic And Racial Studies, 38(1), 22-37. http://doi.org/10.1080/0141987 0.2013 .858175

Findeli, A. (1999). Introduction Design Issues. MIT Hansen, J. (2013). Modern: New Zealand Homes From Press, 15, 1-3. the 1938 To 1977. Auckland, New Zealand: Godwit.

Gatley, J., \& Lima, D. A. e. (2008). Long live the modern: Harbison, R. (1991). The built, the unbuilt, and the New Zealand's new architecture, 1904-1984. Auckland, unbuildable : in pursuit of architectural meaning (1st N.Z: Auckland University Press. MIT Press ed..). Cambridge, Mass: MIT Press.

Gehl, J. (2013). How to study public life. Washington, Heath, T. (2011, October). Kapiti Employment Areas DC: Island Press. Study. Kapiti District Council Property Economics. Retrieved from http://www.kapiticoast.govt.nz/conten tassets/0c65798ed06a43f5b7d826dfcec06e18/kapitiemployment-areas-study.pdf 
Henriksson, J. V. (2015). Jesper Victor Henriksson MacClean, C. (2015, June 29). 15. - Wellington places 120TALKS 2015 2. Retrieved from https://vimeo. - Te Ara Encyclopedia of New Zealand [Web page]. com/121001553 Retrieved 7 December 2015, from http://www.teara. govt.nz/en/wellington-places/page-15

ICOMOS. (1965). International Charter for the McWilliams, D. (2015). The Flat White Economy. UK: Conservation and Restoration of Monuments and Sites Gerald Duckworth \& Co Ltd (12 Mar. 2015).

(The Venice Charter 1964). Retrieved from www.icomos.

org/charters/venice_e.pdf

JMD Design. (2009). Paddington Reservoir. Retrieved Otero-Pailos, J. (2015). Jorge Otero-Pailos 120TALKS 20 January 2016, from http://www.jmddesign.com.au/ 2015. Retrieved from https://vimeo.com/121549825 paddington-reservoir/

Kapiti Coast District Council. (2015). Mahara Place-2,3 Prudon, T. H. M. (2008). Preservation of Modern ,5,6,7,8,9,10,12,13,14,15,16,18 Main Road- 50. Kapiti Architecture. Hoboken, NJ: Wiley.

District Council.

Krag, M. M. S. (2014). Transformation of Abandonment, Stockwell, D. (2009). The impact of big box retailing a New Critical Practice. In Creative Practice Conference on the future of rural SME retail businesses: a case 27-29 August Papers (pp. 55-62). ADAPT-r. study of the South Taranaki district (Thesis). Auckland University of Technology. Retrieved from http://aut. researchgateway.ac.nz/handle/10292/763 
Sullivan, L. H. (1896). The tall office building artistically considered. Retrieved from https://archive.org/details/ tallofficebuildi00sull

Vesci, J. (2005). Preserving modernist architecture. ProQuest Dissertations Publishing.

Zoio, N. (2015, July 24). Is Whanganui city centre in decline? Retrieved from https://insideretail. co.nz/2015/07/24/is-whanganui-city-centre-in-decline/ 


\section{Figures}

Note. All figures not attributed are author's own.

Figure 15

Figure 16

Figure 17

Figure 32

Figure 33

Figure 34

Figure 38

Figure 39
Waikanae Satellite Imagery. Google Earth, sourced from Kapiti Coast District Council 2007

Waikanae Satellite Imagery. Google Earth, sourced from Kapiti Coast District Council 2007

Waikanae Satellite Imagery. Google Earth, sourced from Kapiti Coast District Council 2007

Parker Building Archive Drawings, 1998. Kapiti Coast District Council. (2015). Mahara Place- 2,3,5,6,7,8,9,10,12,13,14,15,16,18 Main Road- 50. Kapiti District Council. CD.

Parker Building Archive Drawings, 1979. Kapiti Coast District Council. (2015). Mahara Place- 2,3,5,6,7,8,9,10,12,13,14,15,16,18 Main Road- 50. Kapiti District Council. CD.

Parker Building Archive Drawings, 1979. Kapiti Coast District Council. (2015). Mahara Place- 2,3,5,6,7,8,9,10,12,13,14,15,16,18 Main Road- 50. Kapiti District Council. CD.

Scott, John. Maori Battalion Memorial Hall, 1964. Palmerston North. Long Live the Modern. Gately, Julia. Auckland: Auckland University Press, 2008: 134. Print.

Ministry of Works. Government Precinct, 1973-1974. Nelson. Long Live the Modern. Gately, Julia. Auckland: Auckland University Press, 2008: 154. Print. 
Minson, Stewart. Timaru Telephone Exchange, 1957. Timaru. Long Live the Modern. Gately, Julia. Auckland: Auckland University Press, 2008: 82. Print.

Figure 41 Daniell \& Wevers. West Kindergarten, 1954-1955. Masterton. Long Live the Modern. Gately, Julia. Auckland: Auckland University Press, 2008: 71. Print.

Figure 42

Simpson, Lew. Georgetown Baptist Church (now Grace Presbyterian Church), 1967. Invercargill. Long Live the Modern. Gately, Julia. Auckland: Auckland University Press, 2008: 160. Print.

Figure 43 McNaught, Peter. Whangarei Harbour Board Administration Building (now Northport Ltd Building), 1962-1963. Northland. Long Live the Modern. Gately, Julia. Auckland: Auckland University Press, 2008: 133. Print.

Figure $44 \quad$ Firth, Cedric. McKenzie House, 1958. Wellington. Modern New Zealand Homes from 1937 to 1977. Hansen, Jeremy. Auckland: Random House New Zealand, 2013: 36. Print.

Figure 45

Donner, Tibor. Donner House, 1947. Auckland. Modern New Zealand Homes from 1937 to 1977. Hansen, Jeremy. Auckland: Random House New Zealand, 2013: 29. Print.

Figure 46 Archstudio. Rong Bao Zhai Coffee Bookstore, 2015. Beijing, China. 20 July 2015. Web. $<$ http://www.archdaily.com/771740/rong-bao-zhai-coffee-bookstore-archstudio?ad_ content=771740\&ad_medium=widget\&ad_name=featured_loop_main>

Figure 56

CUT Architectures. Community Centre CLEC, 2014. Montreuil, France. 14 July 2015. Web. <http://www.archdaily.com/589817/community-centre-clec-montreuil-cutarchitectures> 
Figure 60

Figure 70

Figure 72

Figure 73

Figure 74

Figure 89

Figure 90

Figure 93
Rh+ Architecture. New University Library, 2013. Cayenne, French Guiana. 30 June 2015. Web. <http://www.archdaily.com/475800/new-university-library-in-cayenne-rharchitecture>

Krag, Mo Michelsen Stochholm. Action D3: Controlled Ruin, 2014. Denmark. Creative Practice Conference Papers. Ed. Verveke, Johan; Biesen, Hanne Van Den; Berghe, Jo Van Den: Artoos NV, 2014. 59. Print.

Matta-Clark, Gordon. Conical Intersect, 1975. Paris, France. 12 January 2016. Web. < http://www.artinamericamagazine.com/news-features/previews/the-agenda-this-week-inlos-angeles-2/

Whiteread, Rachel. Ghost, 1990. London, England. 12 January 2016. Web <https:// simonharutyunyan.wordpress.com/2015/03/18/thomas-demand/>

The Theatre of Marcellus, 13BC. Rome, Italy. 10 August 2015. Web. <http:// umnistanbulstudyabroad.com/2014/02/05/ghetto-fabulous/>

Rye Lane, 2013. Peckham, England. 22 October 2015. Web. <http://

highwaymeninpeckham.co.uk/chapter-two/>

LSE Cities. Rye Lane, 2012. Peckham, England. 2 November 2015. Web. <https:// lsecities.net/objects/research-projects/ordinary-streets>

Beumer, Guus Beumer and Heuvel, Drik van den. Open: A Bakema Celebration, 2014. Venice, France. 16 November 2015. Web. < http://www.archdaily.com/525042/ inside-open-a-bakema-celebration-the-dutch-pavilion-at-the-2014-venice-biennale> 
Figure 101

Figure 103

Figure 104

Figure 105

Figure 106
Patio de la Acequia, 13th Century. Andalusia, Spain. The Enclosed Garden. Aben, Rob and Saskia de Wit. Rotterdam: The Authors and 010 Publishers: 64. Print.

Advantages of ETFE Film. 16 October 2015. Web. <http://www.makmax.com/business/ etfe_advantages.html>

Foster + Partners. Crossrail Station, 2007. London, England. 14 October 2015. Web. <http://www.skyscrapercity.com/showthread.php?t=871486\&page=107>

Moneo, Rafael. Atocha Station, 1992. Madrid, Spain. 3 November 2015. Web. <http:// inhabitat.com/madrids-atocha-station-doubles-as-an-indoor-botanical-garden-and-turtlesanctuary/>

JMD Design. Paddington Reservior, 2009. New South Wales, Australia. 20 January 2016 Web. <http://serenityinthegarden.blogspot.co.nz/2010/10/paddington-reservoir-gardens. html> 


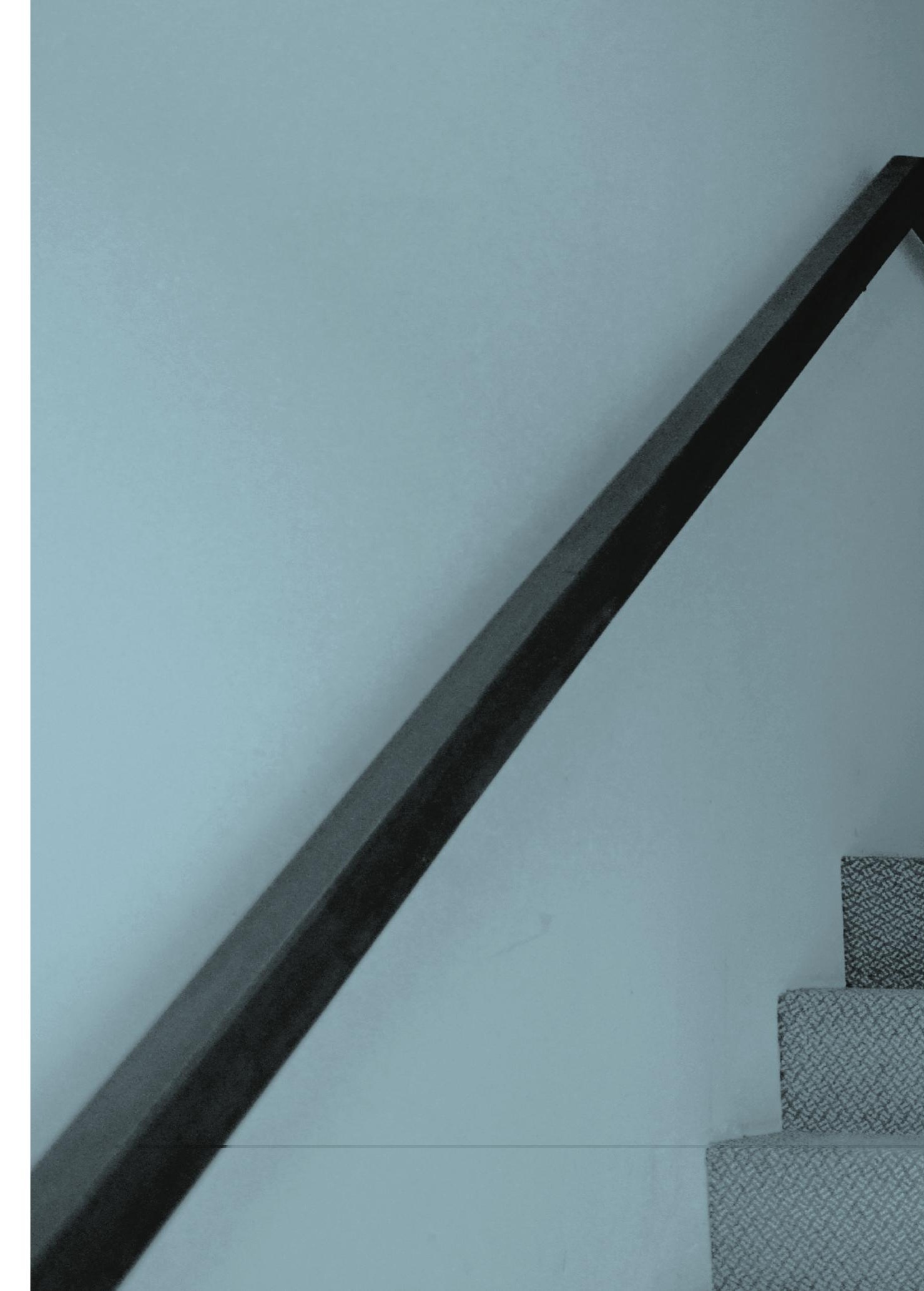



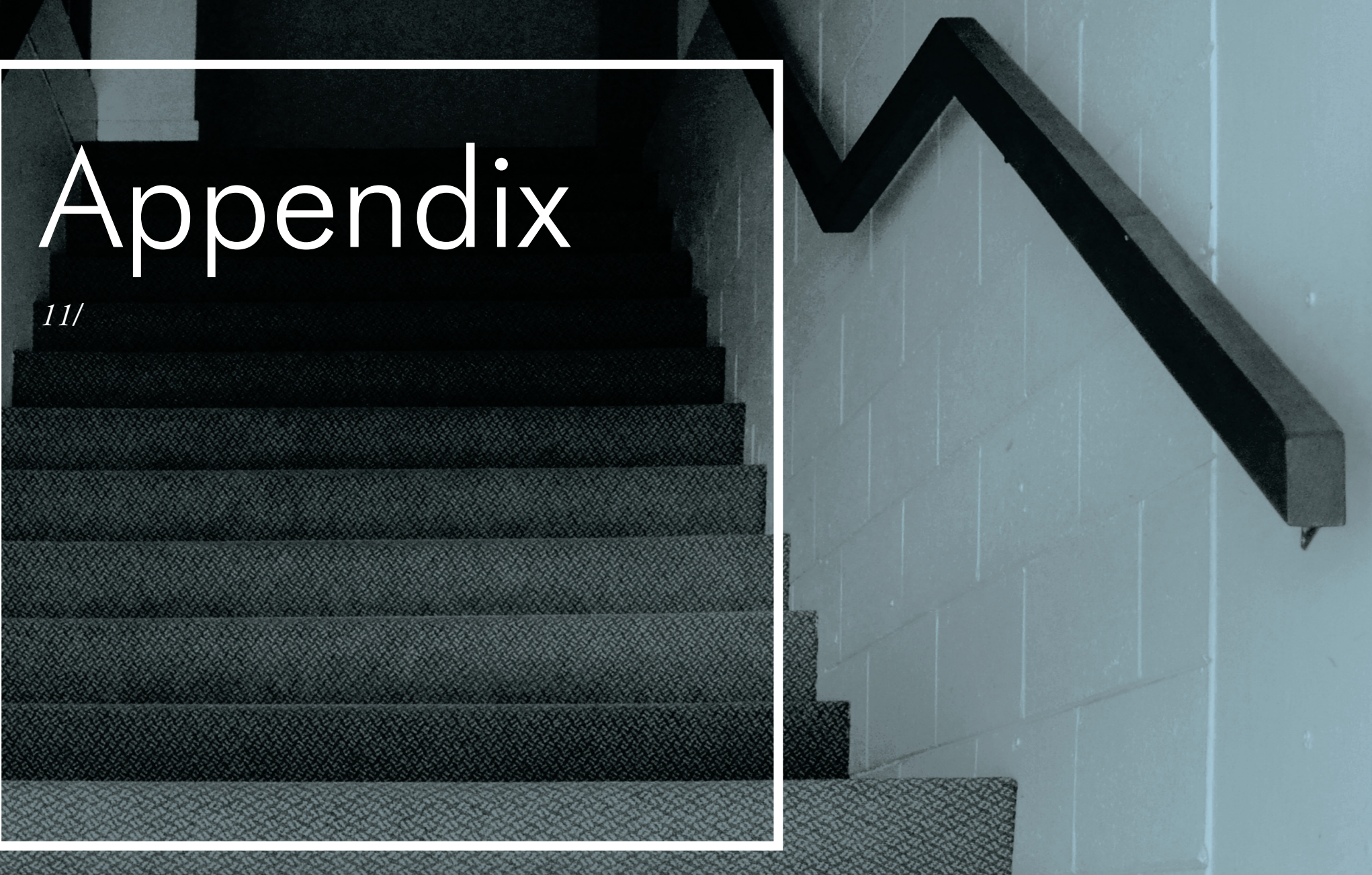


\section{Appendix A}

01- Service spaces and bathroom facilities located at rear of building to allow open facade to street.

02-Accessible lift added in 1998.

03-Existing 90degree stair, replaced with straight staircase in 1979.

04- Handrails inserted on both sides of staircase for accessshows increased awareness for safety in accessibility.

05- No intermediate space between interior and exterior. Same as other entry point.

06- Open floor plan with three structural columns. Allows for re configuration. Supports open planned programme. Function becomes the most important element.

08-Partition walls create privately zones retail spaces, each with a separate entrance.

09- 78degree corner. Aligns with Mahara Place.

10- New entry, designed in 1998. Includes ramp. Creates private entry points for ground floor tenants. Breaks intended facade.

11- Visual link to Mahara Place. North West.

12- No intermediate space between interior and exterior. Same as other entry point. 


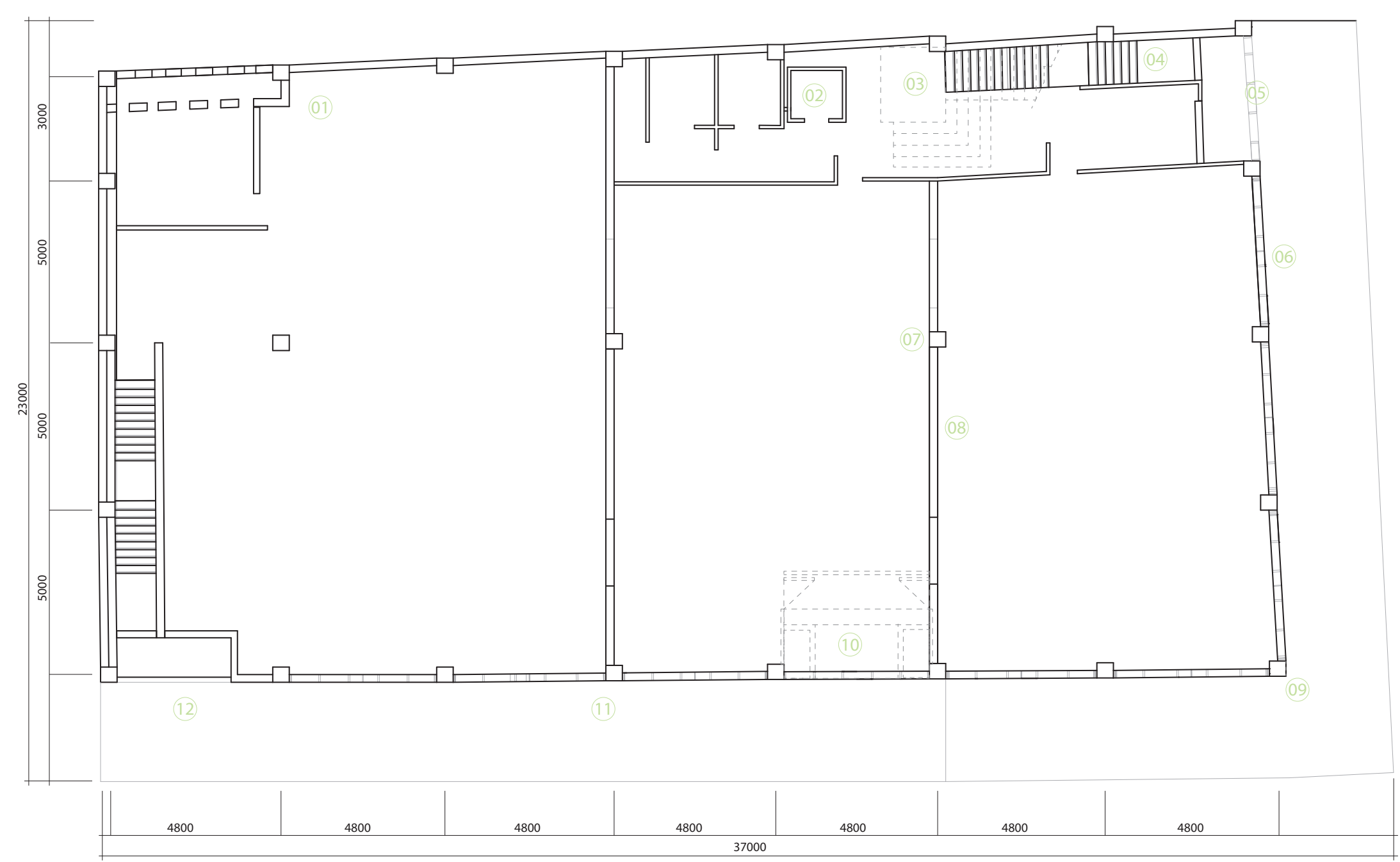

125/ Ground Floor 1:200. Assessment of existing

building. 9 Mahara Place. 


\section{Appendix B}

01- Bathroom facilities located at rear of building to allow open facade to Mahara Place. Similar facilities located on ground floor.

02- Foyer space at top of stairs.

03-Corridor. Circulation at rear of building.

04- Views to Mahara Place. South West facing.

05-Precast concrete floor slab.

06- Partitions mimic ground floor plan.

07- Overhand between ground and first floor. Creates sun shading for ground floor from north facing facade. Does not create any shading for upstairs offices.

08- Windows. Views out to Mahara Place. North West facing. Views are towards coast. 


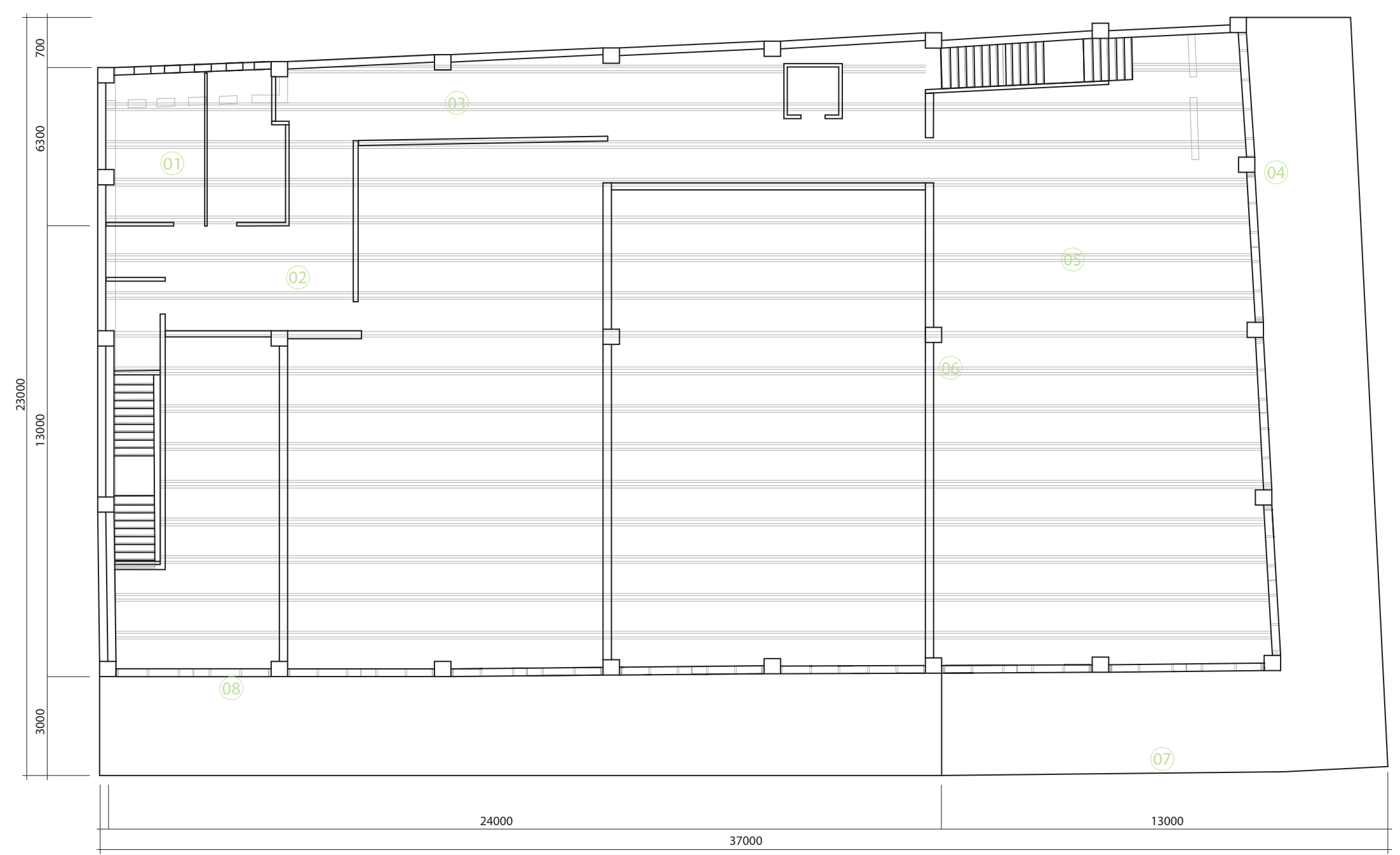

126/ First Floor 1:200. Assessment of existing

building. 9 Mahara Place. 


\section{Appendix C}

01- Flat roof with extended pitch. Relates back to modernist design.

02- Repeated windows.

03- Overhang between ground and first floor.

04- New entry, designed in 1989.

05- Tiled facade around windows and on columns on ground floor. Details that do not necessarily fir with rejection of ornamentation of modernist architecture.

06- Entry points at ends of building.

07- Neighboring building.

08-Entry points at ends of building. 


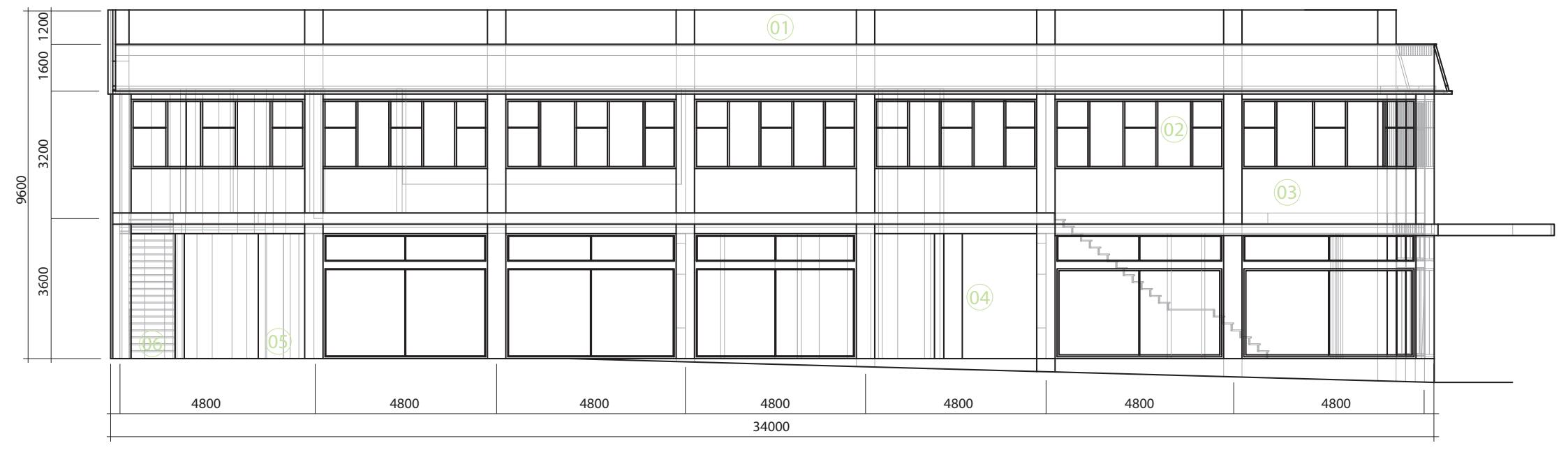

127I West Elevation 1:200. Assessment of existing building. 9 Mahara Place.

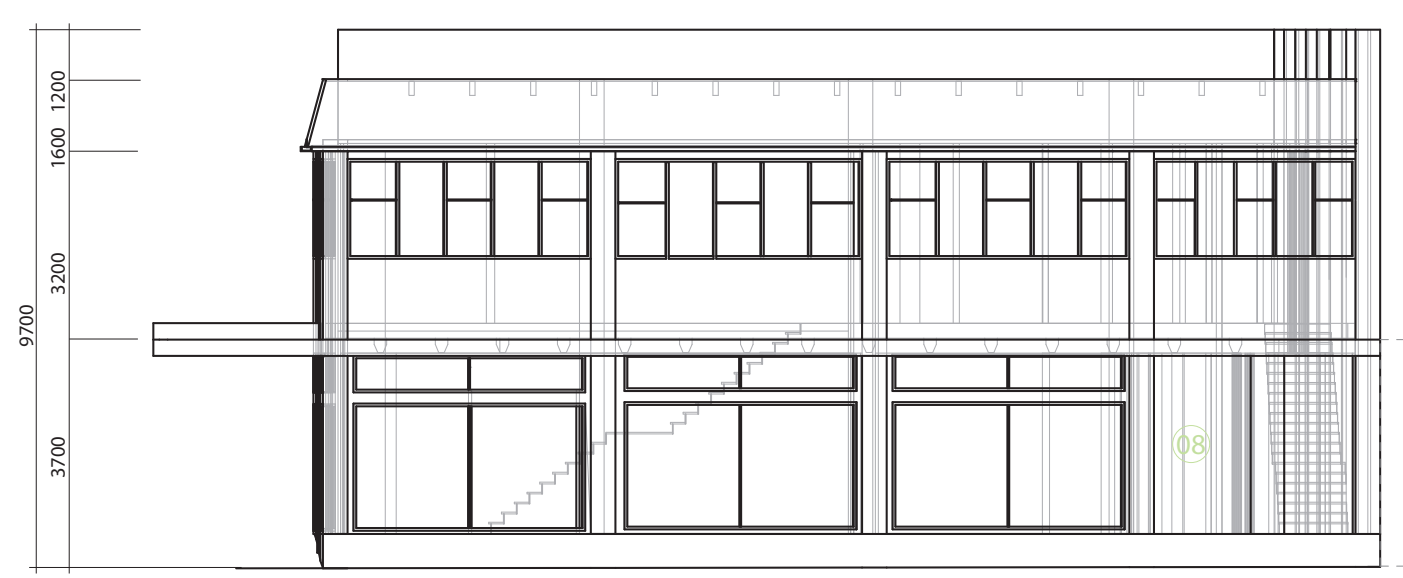




\section{Taking the Roof off a}

Modern Building

Helen Alice Brunskill 


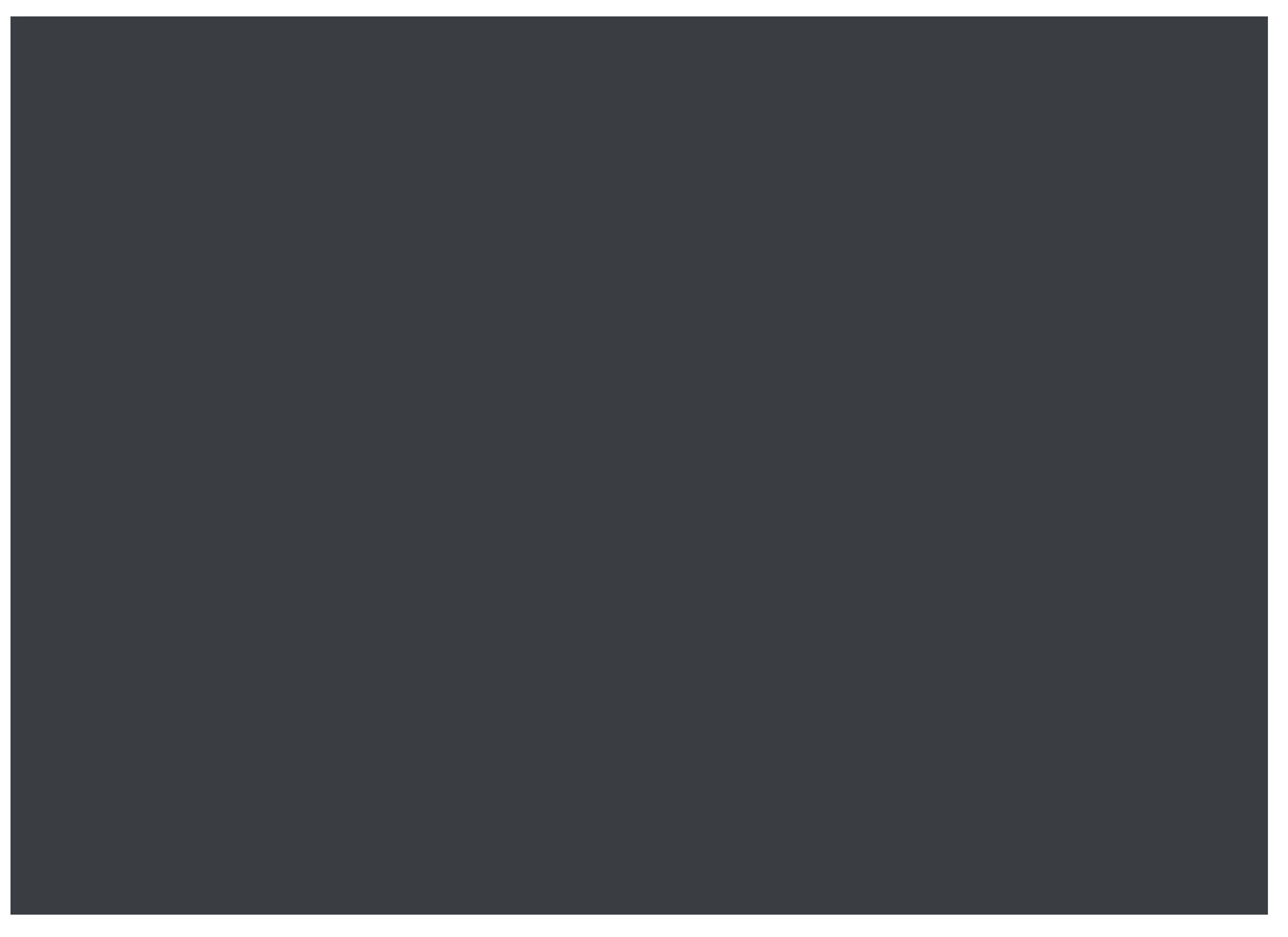




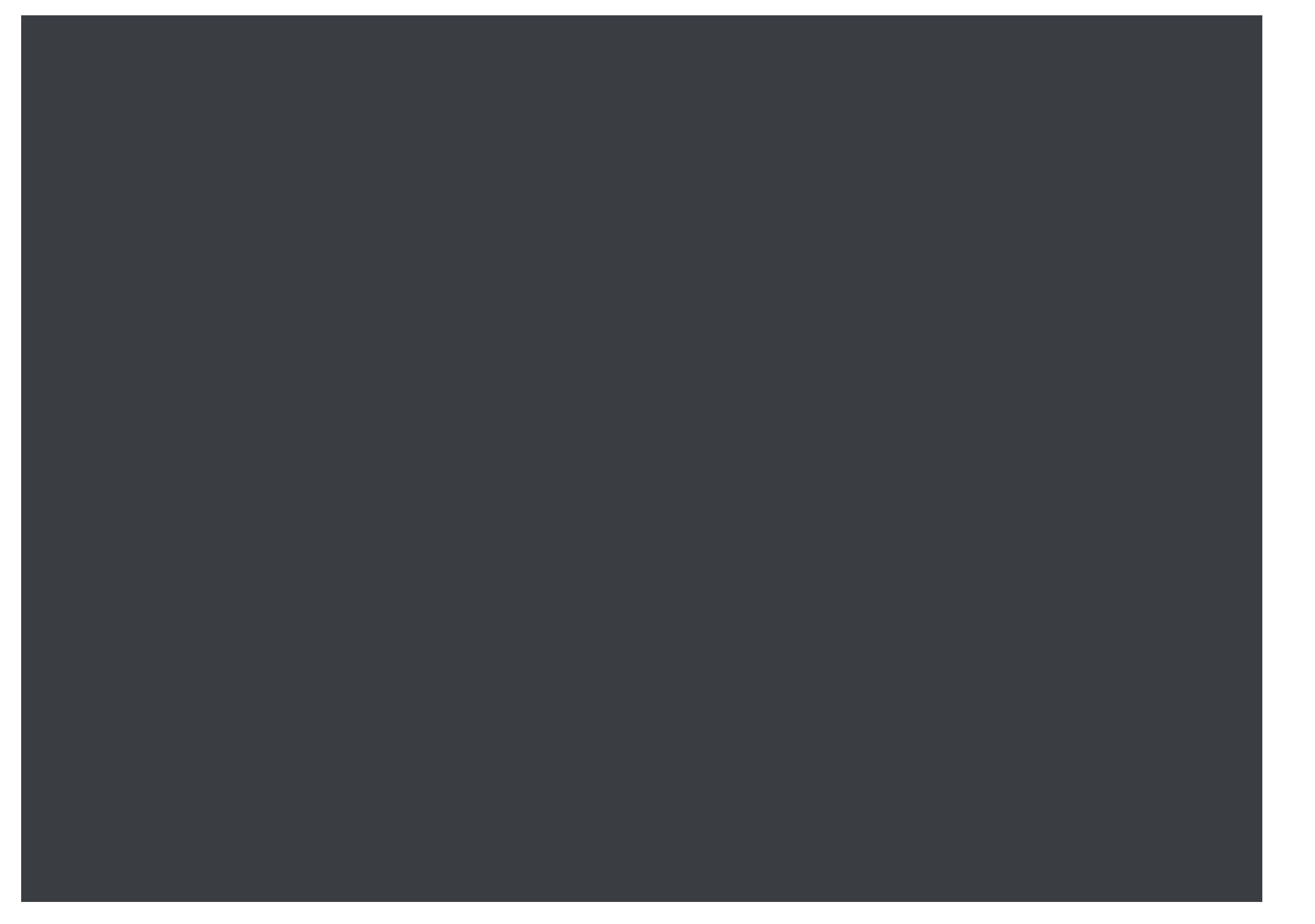

